\title{
Assessment of inflammatory activity in sarcoidosis
}

Citation for published version (APA):

Mostard, R. L. M. (2012). Assessment of inflammatory activity in sarcoidosis. [Doctoral Thesis, Maastricht University]. Maastricht University. https://doi.org/10.26481/dis.20121012rm

Document status and date:

Published: 01/01/2012

DOI:

10.26481/dis.20121012rm

Document Version:

Publisher's PDF, also known as Version of record

\section{Please check the document version of this publication:}

- A submitted manuscript is the version of the article upon submission and before peer-review. There can be important differences between the submitted version and the official published version of record.

People interested in the research are advised to contact the author for the final version of the publication, or visit the DOI to the publisher's website.

- The final author version and the galley proof are versions of the publication after peer review.

- The final published version features the final layout of the paper including the volume, issue and page numbers.

Link to publication

\footnotetext{
General rights rights.

- You may freely distribute the URL identifying the publication in the public portal. please follow below link for the End User Agreement:

www.umlib.nl/taverne-license

Take down policy

If you believe that this document breaches copyright please contact us at:

repository@maastrichtuniversity.nl

providing details and we will investigate your claim.
}

Copyright and moral rights for the publications made accessible in the public portal are retained by the authors and/or other copyright owners and it is a condition of accessing publications that users recognise and abide by the legal requirements associated with these

- Users may download and print one copy of any publication from the public portal for the purpose of private study or research.

- You may not further distribute the material or use it for any profit-making activity or commercial gain

If the publication is distributed under the terms of Article $25 \mathrm{fa}$ of the Dutch Copyright Act, indicated by the "Taverne" license above, 
Assessment of inflammatory activity in

\author{
sarcoidosis
}


(C) Rémy Mostard, Eupen (B) 2012

Layout: Tiny Wouters

Cover design: Nadine Stegers-Kengen

Production: Datawyse, Universitaire Pers Maastricht

ISBN: 978-90-78076-00-1

The printing of this thesis was financially supported by Abbott B.V., Boehringer Ingelheim B.V., Chiesi Pharmaceuticals B.V., Forest Laboratories Nederland, GlaxoSmithKline, ild care foundation, InterMune Benelux B.V., MSD, Mundipharma Pharmaceuticals B.V., Novartis Pharma B.V., Nycomed B.V., Roche Nederland B.V. 


\title{
Assessment of inflammatory activity in
}

\author{
sarcoidosis
}

\author{
PROEFSCHRIFT
}

Ter verkrijging van de graad van doctor

aan de Universiteit Maastricht, op gezag van de Rector Magnificus,

Prof. dr. L.L.G. Soete,

volgens het besluit van het College van Decanen,

in het openbaar te verdedigen

op vrijdag 12 oktober 2012 om 14.00 uur

door

Rémy Louis Marie Mostard 
Promotor

Prof. dr. M. Drent

Copromotor

Dr. M.J.P.G. van Kroonenburgh

Beoordelingscommissie

Prof. dr. M.P. van Dieijen-Visser (voorzitter)

Prof. dr. U. Costabel (Ruhrlandklinik, Essen, Duitsland)

Prof. dr. J.C. Grutters (St. Antonius Ziekenhuis Nieuwegein, UMC Utrecht)

Prof. dr. F.M. Mottaghy

Prof. dr. F.J. van Schooten 
Experience has shown, and a true philosophy will always show, that a vast, perhaps the larger portion of the truth arises from the seemingly irrelevant.

Edgar Allan Poe

Der Worte sind genug gewechselt, Lasst mich auch endlich Taten sehn!

Johann Wolfgang von Goethe 



\section{Contents}

$\begin{array}{ll}\text { Abbreviations } & 9\end{array}$

$\begin{array}{lll}\text { Chapter } 1 & \text { Introduction } & 11\end{array}$

Chapter 2 Metaiodobenzylguanidine scintigraphy in pulmonary and 35 cardiac disease

Chapter 3 Inflammatory activity assessment by ${ }^{18}$ F-FDG PET/CT in 45 persistent symptomatic sarcoidosis

Chapter $4 \quad{ }^{18}$ F-FDG PET/CT for detecting bone and bone marrow involvement in sarcoidosis patients

Chapter 5 Severity of pulmonary involvement and ${ }^{18}$ F-FDG PET activity in sarcoidosis

Chapter 6 A predictive tool for an effective use of ${ }^{18}$ F-FDG PET in assessing activity of sarcoidosis

Chapter 7 Adalimumab successful in sarcoidosis patients with refractory chronic non-infectious uveitis

Chapter 8 Summary, general discussion and directions for future research

Samenvatting

Dankwoord

Curriculum vitae 



\section{Abbreviations}

ACCESS A Case Control Etiologic Study of Sarcoidosis

ACE angiotensin-converting enzyme

$\mathrm{Ag} \quad$ antigen

ATS American Thoracic Society

AUC area under the curve

BAL bronchoalveolar lavage

BMI body mass index

BTNL2 butyrophilin-like 2

$\mathrm{Cl} \quad$ confidence interval

COPD chronic obstructive pulmonary disease

COMT catechol $O$-methyl transferase

CPAP continuous positive airway pressure

CRP C-reactive protein

CT computed tomography

CVID common variable immunodeficiency

CXR chest radiography

DLCO diffusion capacity for carbon monoxide

ECG electrocardiogram

ERS European Respiratory Society

FA fluorescein angiography

FAS fatigue assessment scale

FEV1 forced expiratory volume in one second

${ }^{18}$ F-FDG fluorine18-fluorodeoxyglucose

FVC forced vital capacity

HIV human immunodeficiency virus

$\mathrm{H}-\mathrm{L} \quad$ Hosmer and Lemeshow

HLA human leukocyte antigen

HRCT high-resolution computed tomography

IL interleukin

ild interstitial lung diseases

INF interferon

IPF idiopathic pulmonary fibrosis

IV intravenous

IWOS international workshop on ocular sarcoidosis

MIBG metaiodobenzylguanidine scintigraphy

MRC medical research council

MRI magnetic resonance imaging

MTX methotrexate

6MWD six-min walk distance

n number 


\begin{tabular}{ll} 
NF-KB & nuclear regulatory factor-kappa B \\
NS & not significant \\
NSAIDs & non-steroidal anti-inflammatory drugs \\
OCT & optical coherence tomography \\
OD & right eye \\
OS & left eye \\
OSAS & obstructive sleep apnea syndrome \\
PET & positron emission tomography \\
PPV & positive predictive value \\
ROC & receiver operating characteristic \\
SD & standard deviation \\
SFN & small fiber neuropathy \\
SFNSL & small fiber neuropathy screenings list \\
SIL-2R & soluble interleukin-2 receptor \\
SPECT & single photon emission computed tomography \\
SRS & somatostatin receptor scintigraphy \\
SUN & standardization of uveitis nomenclature \\
SUVmax & maximum standardized uptake value \\
TCR & T-cell receptor \\
TGF- $\beta$ & transforming growth factor beta \\
Th cell & helper T-cell \\
TNF & tumor necrosis factor \\
TOF & time-of-flight \\
QoL & quality of life \\
WASOG & World Association of Sarcoidosis and Other Granulomatous Diseases \\
& \\
\hline
\end{tabular}




\section{Chapter 1}

General introduction

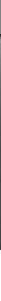


12 Chapter 1 


\section{Demographical and prognostic characteristics in sarcoidosis}

Sarcoidosis is a multisystemic disease characterized by cellular immunity activity with formation of noncaseating granuloma in various organ systems. ${ }^{1}$ The disease affects people of all ages, but most commonly those in the third to fourth decade of their lives. ${ }^{2}$ Sarcoidosis is prevalent throughout the world, but the incidence and phenotype differs according to specific regions and race. The highest annual incidence of sarcoidosis has been observed in northern European countries (5 to 40 cases per 100,000 people). ${ }^{3}$ In a study that was performed in the USA, African Americans had about a threefold higher age-adjusted annual incidence $(35.5$ per 100,000$)$ compared with Caucasians (10.9 per 100,000). ${ }^{4}$

Löfgren's syndrome is the most frequent type of presentation in the Scandinavian countries and is defined by the presence of acute onset symptoms with fever, arthralgias, erythema nodosum, and bilateral hilar lymphadenopathy (see Figure 1.1 and 1.4b). In Japan, cardiac involvement and uveitis are more common. ${ }^{5}$

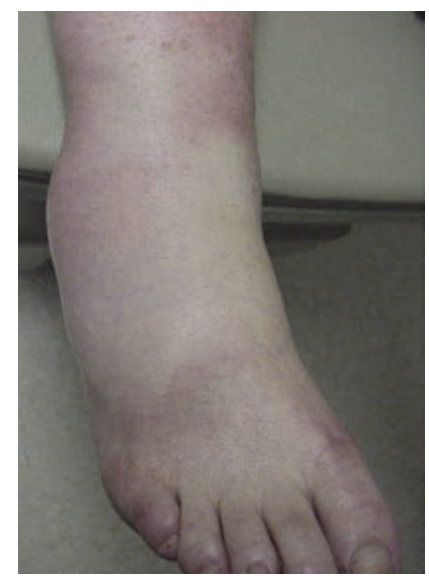

Figure 1.1 Ankle arthritis and erythema nodosum in a patient with Löfgren's syndrome.

In general, sarcoidosis has a beneficial prognosis. Remission occurs within 3 years of the diagnosis for more than half of the patients, and within a decade for two-thirds with few or no consequences. ${ }^{5}$ The remaining one-third of the patients suffers from persistent disease, leading to significant organ impairment. Less than $5 \%$ of patients die of sarcoidosis, death is usually the result of cardiac or neurological involvement, or of respiratory failure due to pulmonary fibrosis. ${ }^{2,6}$ Löfgren's syndrome usually carries a good prognosis, being self-limiting within six months after initial presentation in the majority of the patients. Patients characteristics like black race, lupus pernio, bone involvement, advanced pulmonary disease are associated with a chronic course of the 
disease (Table 1.1)..$^{7-10}$ The differences in incidence and phenotype complicate comparing and executing studies concerning prognosis and treatment effect, since patient populations are heterogeneous. Several scoring systems have been used to assess the level of disease and clinical outcome. In order to standardize the clinical outcome description of patients with sarcoidosis, a novel clinical outcome score was recently developed by a task force of the World Association of Sarcoidosis and Other Granulomatous Diseases (WASOG). ${ }^{11}$

Table 1.1 Characteristics associated with worse prognosis. ${ }^{12}$

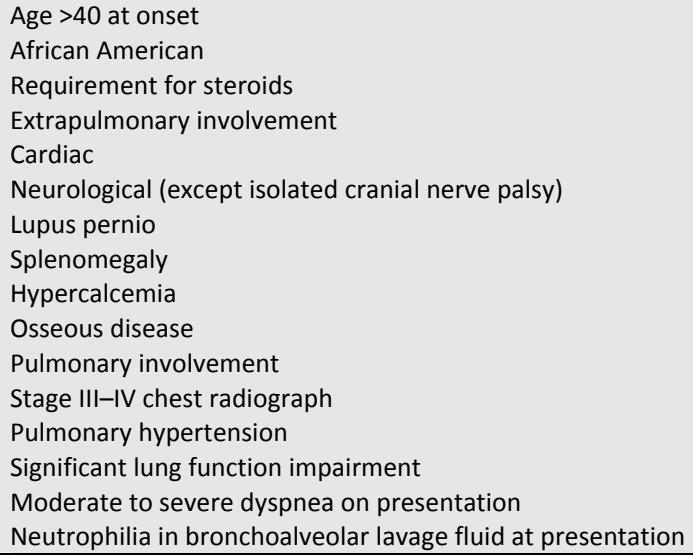

\section{Clinical presentation}

The clinical presentation is highly variable. The disease primarily affects the lungs and the lymphatic system, but virtually every organ system can be involved (Table 1.2). ${ }^{1}$ The most common symptoms include fatigue, respiratory symptoms like coughing or dyspnea, and symptoms related to extrapulmonary involvement. ${ }^{5}$

\section{Pulmonary involvement}

Involvement of the pulmonary parenchyma and mediastinal lymphadenopathy is present in approximately $90 \%$ of the sarcoidosis patients; hence the pulmonologist is often the prominent physician in the management of the disease. However, since any organ may be affected, a multidisciplinary approach is needed in a substantial part of the patients. ${ }^{1,13}$ The various diagnostic tools are discussed below. 
Table 1.2 Historical estimate of the prevalence of organ involvement in sarcoidosis. ${ }^{1}$

\begin{tabular}{lc}
\hline Organ involvement & \% of the patients \\
\hline Mediastinal lymphadenopathy & $95-98$ \\
Lung & $>90$ \\
Liver & $50-80$ \\
Spleen & $40-80$ \\
Eye & $20-80$ \\
Extrathoracic lymphadenopathy & $20-30$ \\
Skin & $25-30$ \\
Central nervous system & $10-15$ \\
Small fiber neuropathy & $25-70$ \\
Muscle & $10-75$ \\
Heart (symptomatic) & $5-15$ \\
Bone (symptomatic) & $1-10$ \\
Kidney & $2-5$ \\
\hline
\end{tabular}

\section{Fatigue}

Despite the fact that fatigue is a common problem (with a reported prevalence of 30$90 \%$ ) and a clear hallmark in sarcoidosis patients that affects quality of life, it still remains underestimated and poorly inderstood..$^{14}$ De Vries et al. found no relationship between fatigue in sarcoidosis patients and a number of clinical variables, including lung function, metabolic variables, laboratory parameters of inflammation and T-cell activation and granuloma formation. ${ }^{14} \mathrm{~A}$ recent study showed that, although exercise intolerance and muscle weakness are frequent problems in sarcoidosis, fatigue was not predicted by the presence of these and other clinical characteristics. ${ }^{15}$ The fatigue assessment scale (FAS) has been shown to be an easy, reliable and valid scale for assessing fatigue in sarcoidosis patients. ${ }^{16}$ When evaluating sarcoidosis patients suffering from fatigue, it is important to exclude disorders that may interact with fatigue in sarcoidosis, i.e. obstructive sleep apnea syndrome, hypothyroidism and depression. ${ }^{17-19}$

\section{Exercise capacity}

A substantial number of patients with symptomatic sarcoidosis display exercise intolerance (45\%), as well as muscle weakness (prevalence rates of $12-27 \%)$. Patients with impaired peripheral muscle strength are more fatigued and demonstrate impaired lung function test results, six-min walk distance (6MWD), and quality of life (QoL) compared with patients without reduced peripheral muscle strength. ${ }^{15}$ Another cause of exercise intolerance can be the presence of pulmonary hypertension, which occurs in $6-23 \%$ of patients at rest and in more than $40 \%$ of patients during exercise. ${ }^{20}$ Pulmonary hypertension complicates pulmonary sarcoidosis more frequently in advanced parenchymal disease and significantly worsens prognosis. ${ }^{5}$ 


\section{Neurosarcoidosis}

The prevalence of clinical involvement of the central nervous system is estimated to be about $5-15 \%$ in patients with sarcoidosis. ${ }^{21}$ It is a serious and commonly devastating complication of sarcoidosis and can present in many different ways, like cranial neuropathy, cerebral sarcoid lesions, papilledema, psychiatric symptoms, aseptic meningitis, hydrocephalus, seizures, spinal sarcoidosis, peripheral neuropathy, and small fiber neuropathy. ${ }^{21-23}$ Furthermore, patients may present with evidence of pituitary or hypothalamic dysfunction. ${ }^{24}$ In patients with confirmed active systemic sarcoidosis, neuroimaging studies, especially magnetic resonance imaging (MRI), and electrophysiological studies can support the diagnosis of neurosarcoidosis. Tissue confirmation remains the gold standard for unconfirmed cases or for patients with a history of sarcoidosis but with no evidence of disease activity. ${ }^{21}$

\section{Uveitis}

Ocular involvement is present in $30-60 \%$ of patients with sarcoidosis and can be a source of considerable morbidity if not properly diagnosed and treated. ${ }^{25}$ This eye disease may occur in the absence of apparent systemic involvement or may be the main site of disease without significant clinical disease elsewhere. ${ }^{26}$ Therefore, routine slit-lamp and funduscopic examination is necessary. Patients who present with only ocular findings pose a unique challenge, as establishing a definitive diagnosis with intraocular biopsy can be associated with significant morbidity. ${ }^{25}$ International criteria for the diagnosis of ocular sarcoidosis were reported by the committee of the first international workshop on ocular sarcoidosis (IWOS). ${ }^{26}$ Inflammatory patterns can be classified as anterior (iris and/or ciliary body), intermediate (vitreous) or posterior (retina, choroid) uveitis. Anterior uveitis is the most common manifestation, occurring in $65 \%$ of patients with ophthalmologic involvement. Acute anterior conjunctivitis can occur in Löfgren's syndrome and generally has a favorable prognosis. In contrast, chronic anterior uveitis is more notable for causing ocular morbidity. ${ }^{27}$ Posterior segment involvement is reported to occur in nearly $30 \%$ of the patients with ocular sarcoidosis. ${ }^{2}$ This type of uveitis should be considered vision-threatening and can be accompanied by central nervous system involvement. ${ }^{2,27}$ Inflammation of all three ocular compartments (anterior, intermediate, and posterior) or panuveitis is a poor prognostic risk factor. ${ }^{28}$

\section{Cardiac involvement}

Cardiac sarcoidosis is a rare but potentially fatal manifestation of sarcoidosis. Clinically apparent cardiac involvement is present in approximately $5 \%$ of the patients, but much higher frequencies of myocardial granulomas have been reported in autopsy studies. ${ }^{2,29}$ Cardiac sarcoidosis is manifested clinically as a cardiomyopathy with loss of muscle function or tachyarrhythmias and bradyarrhythmias (palpitations, syncope, 
and death). In every patient with sarcoidosis, an electrocardiogram (ECG) should be perfomed. ${ }^{1}$ If symptoms like palpitations or conduction abnormalities on the ECG are present, further evaluation, including cardiac MRI or fasting cardiac fluorine-18 fluorodeoxyglucose positron emission tomography $\left({ }^{18} \mathrm{~F}\right.$-FDG PET), is warranted. ${ }^{2,30,31}$ Active sarcoid lesions and their response to steroid treatment may be better detected by ${ }^{18}$ F-FDG PET, whereas fibrotic lesions might be shown more clearly by MRI or other nuclear myocardial perfusion imaging. ${ }^{32}$ The value of metaiodobenzylguanidine scintigraphy (MIBG) will be discussed in chapter 2 .

\section{Cutaneous involvement}

Cutaneous involvement is common (occurring in $25-35 \%$ of patients with sarcoidosis) and often overlooked or misinterpreted, given the variability of the lesions. ${ }^{2}$ Special attention should be given to scars and tattoos, since these are preferential sites of granulomatous inflammation. Lupus pernio is more common in women and is associated with chronic disease and extrapulmonary involvement. ${ }^{33}$ In contrast, erythema nodosum is mainly present in patients with Löfgren's syndrome. Detection of changes in cutaneous lesions can be of great value for the clinical assessment of inflammatory activity, since these sites are easily accessible without the need for technical investigations (Figure 1.2).

a

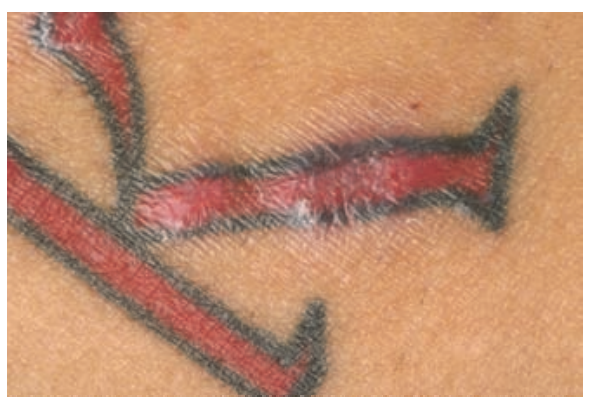

b

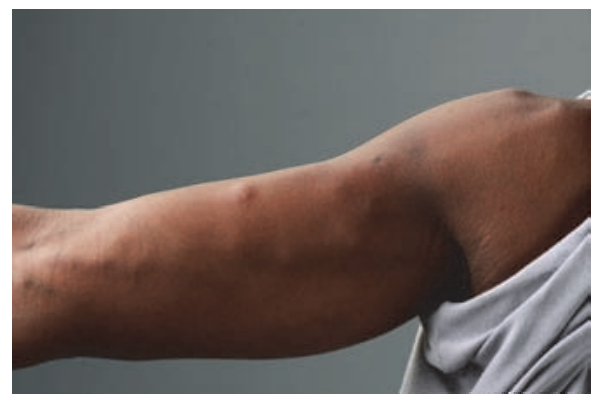

Figure 1.2 a. Sarcoid cutaneous involvement in a tattoo, b. Multiple subcutaneous nodules located on the upper extremity of a patient with sarcoidosis. 


\section{Pathogenesis}

Although advances in understanding the immunopathogenesis of sarcoidosis have been made, the cause of sarcoidosis remains unclear. The development of sarcoidosis is probably the end result of immune responses to various ubiquitous environmental triggers in genetically susceptible individuals. ${ }^{2}$

Granulomas, the hallmark of sarcoidosis, are compact, centrally organized collections of macrophages and epithelioid cells encircled by lymphocytes. The presence of granuloma is not specific for sarcoidosis, but can also occur in other interstitial lung diseases, e.g. hypersensitivity pneumonitis, berylliosis and pulmonary Langerhans cell histiocytosis. Granuloma formation and maintenance is initiated by the presence of CD4+ T-cells that interact with the major histocompatibility complex class II molecules on antigen presenting cells. ${ }^{34}$ These activated CD4+ T-cells differentiate into type 1 helper T (Th1)-like cells and secrete predominantly interleukin-2 (IL-2) and interferon$\gamma($ IFN- $\gamma$ ), augment macrophage tumor necrosis factor-alpha (TNF- $\alpha$ ) production, and amplify the local cellular immune response. ${ }^{2}$ IL-2 acts as a local growth factor for T-lymphocytes, whereas INF- $\gamma$ enhances the accessory and cytotoxic function of T-cells and regulates the secretion of other lymphokines. ${ }^{5}$ TNF, IL-12 and IL-18 induce IFN- $\gamma$ production and enhance T-cell cytotoxicity. ${ }^{35}$ Due to this immunological response the cells organize into granuloma. Granulomatous inflammation can spontaneously resolve or persist with the development of chronic disease. If ongoing antigen presentation is present, an increased production of macrophage-generated cytokines, e.g. transforming growth factor- $\beta$, favor the development of fibrosis. ${ }^{5}$ However, the exact mechanisms are still largely unknown. Recently, Sweiss et al. identified several significant associations between disease sub-phenotypes and serum levels of TNF- $\alpha$ and type I IFN, which were distinct in different ancestral backgrounds. ${ }^{36}$ These results suggest that different cytokines may be more important in a particular group of patients with sarcoidosis. Figure 1.3 shows a schematic presentation of granuloma formation in sarcoidosis.

The ACCESS (A Case Control Etiologic Study of Sarcoidosis) study identified several environmental exposures modestly associated with sarcoidosis risk, including insecticides, agricultural employment, and microbial bioaerosols. ${ }^{17}$ Occupational studies have shown positive associations with service in the U.S. Navy, metalworking, firefighting, the handling of building supplies and man-made mineral fibres. ${ }^{2,37}$ Furthermore, Mycobacteria and Propionibacteria have been identified as possible causative agents. $^{38}$ 


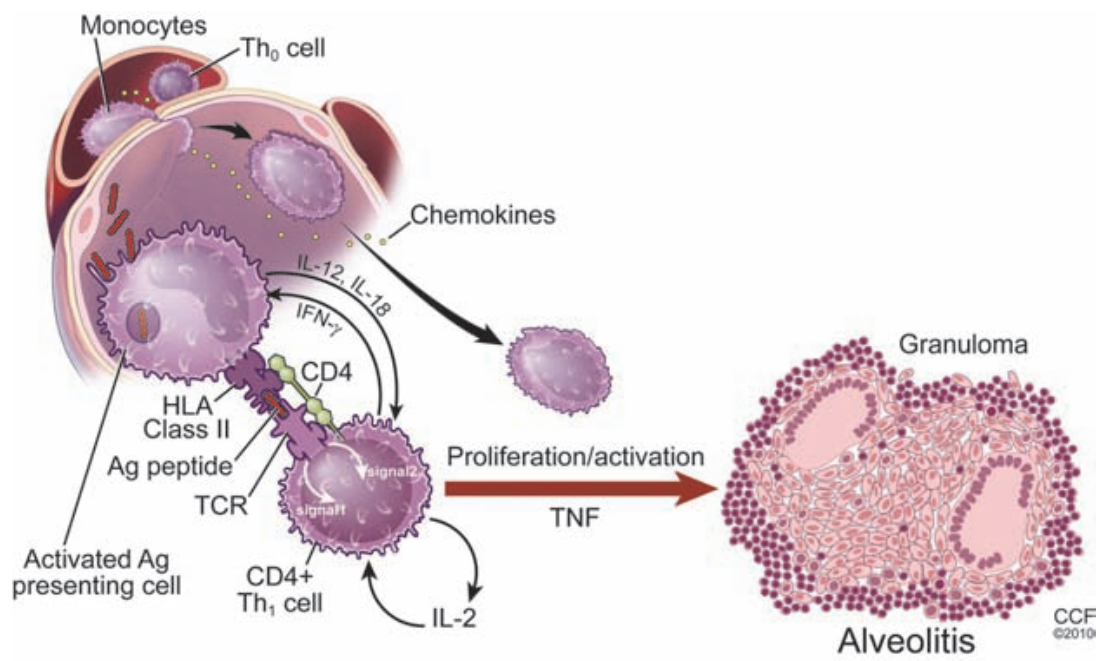

Figure 1.3 A schematic presentation of granuloma formation in sarcoidosis.

$\mathrm{Th}=\mathrm{T}$-helper; $\mathrm{Ag}=$ antigen; $\mathrm{HLA}$ : human leukocyte antigen; IFN- $\nu=$ interferon-gamma; IL= interleukin; TCR: T-cell receptor; TNF= tumor necrosis factor (adapted from Baughman ${ }^{48}$ ). Hypothetical model of the pathogenesis of sarcoidosis. An antigen induced antigen-specific, Th1-mediated granulomatous inflammation with production of Th1 cytokines (IFN- $\gamma$, IL-2). The efficiency of antigen processing, antigen presentation and cytokine release is probably under genetic control; evidence strongly supports a role for macrophage HLA and butyrophilin-like 2 (BTNL2) alleles in sarcoidosis susceptibility and phenotype. Granuloma formation is set in motion by activated macrophages and T-cells along with other effector cells (e.g. fibroblasts) under the regulatory influence of local cytokine production. Removal of the antigen allows transforming growth factor-beta (TGF- $\beta$ ) to downregulate the immune response. Alveolar macrophages activated in the context of a predominant Th2 response appear to stimulate fibroblast proliferation and collagen production, leading to progressive fibrosis. ${ }^{2}$

Familial clustering of sarcoidosis has been demonstrated. ${ }^{39}$ Patients stated that they had siblings or parents with sarcoidosis five times more often as control subjects. ${ }^{17}$ Human leukocyte antigens (HLA) are cell surface proteins that are essential for immune recognition and function. Reports suggest that specific HLA genotypes confer a predisposition to the disease phenotype rather than to susceptibility. ${ }^{2,40,41}$ For example, HLA-DQB1*0201 and HLA-DRB1*0301 are strongly associated with acute disease and a good prognosis, whereas the haplotype HLA-DRB1*1501/HLADQB1*0602 was found to be associated with a chronic course and severe pulmonary sarcoidosis. $^{41-44}$ The presence of butyrophilin-like 2 (BTNL2) variant alleles is associated with an increased risk of progressing to persistent pulmonary sarcoidosis, ${ }^{45}$ besides an increased risk to develop sarcoidosis ${ }^{45,46}$, although the independence of the BTNL2 association with sarcoidosis was questioned in another study. ${ }^{47}$ 


\section{Diagnosis}

The diagnosis of sarcoidosis is supported by a compatible clinical and radiographic presentation together with histological evidence of noncaseating granulomas on biopsy. In Löfgren's syndrome, a feasible diagnosis of sarcoidosis can be made on the clinical picture, without the need for a biopsy. ${ }^{1}$

\section{Treatment}

Most patients require no treatment, but several pharmacologic options exist for those patients with an indication for therapy. Nevertheless, none of these drugs are curative. Non-steroidal anti-inflammatory drugs (NSAIDs) can be efficient for symptom relief in patients with arthralgia/arthritis. Topical treatment can be very effective in cutaneous involvement. Decisions on whether to start systemic immunosuppressive treatment or not are based on clinical features, like organ dysfunction or, in selected cases, symptoms that affect quality of life, i.e. severe cutaneous involvement that does not respond to topical treatment. The drug of first choice is prednisone, limited evidence is available for the use of other immunosuppressive drugs like methotrexate, azathioprine, leflunomide or hydroxychloroquine and, more recently, TNF- $\alpha$ inhibitors. ${ }^{2,49-58}$

\section{Assessment of inflammatory activity}

In general, assessment of inflammatory activity is vital in the management of sarcoidosis, and is especially necessary to monitor the course of sarcoidosis and guide therapeutic strategies. ${ }^{57,59,60}$ The presence of inflammatory activity means that the disease has not yet come to a rest, that there is still ongoing T-cell and macrophage inflammation and granuloma formation, with the potential that the disease may progress, whereas the absence of inflammatory activity means that the disease has come to a rest and will likely not progress. ${ }^{59}$ However, in sarcoidosis, activity should be distinguished from severity. Activity in sarcoidosis does not necessarily indicate a progressive course, a fatal prognosis, or the need for medical treatment. ${ }^{61}$ The presence of inflammatory activity can be regarded as certain in case chest radiography (CXR) findings or lung function test results provide evidence of disease progression and in patients with acute, symptomatic sarcoidosis. ${ }^{62,63}$ Nevertheless, assessment of inflammatory activity in sarcoidosis patients with unexplained persistent disabling symptoms remains a challenge for clinicians.

The assessment of inflammatory activity by clinical and radiographic features can be complicated as organ involvement beyond the scope of the used diagnostic tools, 
might be missed. Symptoms like arthralgia or fatigue can be nonspecific and difficult to objectify. ${ }^{12,14,15}$ Furthermore, symptoms like coughing and dyspnea might be related to ongoing inflammatory activity as well as to end-stage disease, i.e. pulmonary fibrosis. It is important to be informed about the presence or absence of inflammatory activity in those patients as fibrosis itself is irreversible. In general, patients with fibrosis without ongoing inflammatory activity are thus supposed not to benefit from immunosuppressive treatment. ${ }^{12} \mathrm{~A}$ technique, able to evaluate the presence of inflammatory activity per organ system, is therefore desirable.

\section{Laboratory parameters}

Inflammatory activity is characterized by ongoing T-cell and macrophage activity and granuloma formation, reflected by an increase in serological markers of inflammatory activity, i.e. angiotensin-converting enzyme (ACE), soluble interleukin-2 receptor (sIL$2 \mathrm{R}$ ) and neopterin, or abnormal glucose metabolism. ${ }^{53,59,63-69}$

\section{ACE}

In sarcoidosis, ACE is mainly produced by activated granuloma cells (epithelioid cells). ${ }^{2}$ The reported sensitivity and specificity of ACE for diagnosing sarcoidosis is moderate, even if corrected for genotype (insertion/deletion polymorphism). ${ }^{70,71}$ In general, serum ACE levels are higher in clinically active compared with inactive disease, and correlate with disease extent to a certain degree. However, low ACE serum levels do not exclude activity of sarcoidosis, especially in chronic disease or when immunosuppressive therapy is used. ${ }^{59,72}$ Furthermore, there is insufficient evidence that ACE levels can predict disease outcome. It should be noted that measurement of ACE levels is not useful in patients taking ACE-inhibitors.

\section{SIL-2R and neopterin}

IL-2 plays an important role in controlling T-cell proliferation. ${ }^{73}$ After binding to the IL-2 receptor on T-cells, it forms the IL-2 receptor complex. ${ }^{74}$ IL-2R immunoassays can measure a soluble part of the IL-2R (sIL-2R). sIL-2R is elevated in patients with active sarcoidosis. $^{62,65,67}$ It has been shown to correlate with the number of CD4+ T-lymphocytes in bronchoalveolar lavage (BAL) fluid, extrapulmonary disease and respiratory functional impairment. ${ }^{64,67}$ It may have prognostic value in sarcoidosis. ${ }^{62,65,66}$ Neopterin represents activation of the monocyte/macrophage system, and is found to be increased in active and progressive disease as well. ${ }^{66}$

\section{C-reactive protein}

C-reactive protein (CRP) is an acute-phase protein. Measurement of plasma or serum CRP levels can be useful to differentiate inflammatory from non-inflammatory conditions. ${ }^{75}$ In sarcoidosis, CRP levels appeared to be elevated, especially in acute 
disease, but the mean CRP concentrations of patients with stable or progressing disease (indicating severe disease) did not differ significantly from those in healthy controls, in contrast to sIL-2R. ${ }^{62}$ In another study, the predictive value of CRP for the presence of respiratory functional impairment was much lower than that of sIL-2R. ${ }^{64}$

These serological inflammatory markers are not specific for sarcoidosis. CRP levels can be elevated by a wide range of inflammatory processes. ${ }^{75}$ Elevated ACE levels can be found in other granulomatous diseases like tuberculosis and silicosis, and also in hyperthyroidism. $^{76}$ sIL-2R levels can be increased in patients with malignant lymphomas, tuberculosis, HIV, rheumatoid arthritis, and lupus erythematosus. ${ }^{77-81}$ However, specificity is of less importance as these markers are not used for establishing the diagnosis of sarcoidosis, but only for the assessment of inflammatory activity.

Higher levels of other serological inflammatory markers like chitotriosidase, lysozyme, nuclear regulatory factor-kappaB (NF-KB), and the glycoprotein KL-6 have been observed in patients with active sarcoidosis, but these markers require further validation before they can be used in clinical practice. ${ }^{82-84}$

Elevated calcium levels can be found in both serum and independently in the urine as a result of increased production of 1,25-dihydroxyvitamin D3 in the granuloma and thus can be considered as a marker of granuloma activity, but with a low sensitivity. ${ }^{2,59}$ If hypercalcemia is present, other causes of this feature like hyperparathyroidism should be considered. Liver-test abnormalities are present in $10-25 \%$ of all sarcoidosis patients, but liver involvement is usually clinically silent. ${ }^{2,85}$ Moderate and severe liver-test abnormalities seemed to be associated with more advanced histopathological disease. ${ }^{85}$

\section{Lung function tests}

Deterioration of lung function is regarded as an indicator of disease activity in sarcoidosis. $^{59}$ A wide spectrum of lung function abnormalities can be present, including an obstructive pattern, restriction, a mixed obstructive and restrictive ventilatory effect, and a decreased diffusion capacity of the lungs for carbon monoxide (DLCO). ${ }^{86}$ Airway hyperreactivity occurs in $5-83 \%$ of patients. ${ }^{87}$ Abnormal lung function tests, especially forced expiratory volume in one second (FEV1), forced vital capacity (FVC), and DLCO are traditionally used as an indication for treatment. ${ }^{59}$ Baseline lung function tests are not related to the probability of disease progression and cannot distinguish between reversible granulomatous lesions and irreversible fibrotic changes. ${ }^{59}$ In $80 \%$ of sarcoidosis patients presenting with abnormal spirometric findings, values return normal within 2 years. ${ }^{88}$ No obvious correlation between lung function test results and CXR findings exists, although prominent lung restriction occurs especially in patients with CXR stages III-IV (this staging system is described below). ${ }^{59,86}$ Due to the wide-ranging variety of possible lung function 
abnormalities in sarcoidosis, depicting a single lung function test as primary measure of change is difficult. In an individual patient, repeated performance of complete lung function testing, including spirometric and plethysmographic volumes as well as DLCO measurement, seems most appropriate for longitudinal assessment. ${ }^{86}$ This shows that defining a single lung functional primary endpoint in pharmacological studies is problematic. Furthermore, assessment of disease activity through lung function tests requires evidence of progression between two measurements and so does not reflect that actual state.

\section{Bronchoalveolar lavage}

Disease presentation or activity at the time the BAL is performed as well as the smoking status is crucial for interpretation of individual BAL fluid analysis results. ${ }^{89}$ In sarcoidosis, the majority of patients have an increased number of lymphocytes and a normal amount of eosinophils and neutrophils. ${ }^{89,90}$ The relative proportion of lymphocytes can be somewhat higher in clinically active disease (range 20-80\%, mean around $40 \%$ ) versus clinically inactive sarcoidosis (mean lymphocytes $30 \%$ ). There is considerable overlap in lymphocytes between active and inactive disease, and BAL may be normal in $10-15 \%$ of patients. ${ }^{91,92}$ Lymphocytosis in BAL fluid has not shown to be predictive of more progressive pulmonary disease. To date, an increase in the number of neutrophils in BAL fluid was found to be associated with an unfavorable outcome. $^{62,93}$ The analysis of other inflammatory mediators like cytokines and chemokines in BAL fluid may have potential clinical application in the future. ${ }^{94-96} \mathrm{BAL}$ has no role in the detection of responsiveness to therapy. ${ }^{86}$

\section{Chest radiography}

Between 85 and $95 \%$ of sarcoidosis patients have abnormalities on chest radiographs. According to the Scadding radiographic staging system, five stages of radiographic abnormality can be recognised: stage 0 (normal CXR), stage I (bilateral hilar lymphadenopathy $(\mathrm{BHL})$ ), stage II (BHL and parenchymal abnormalities), stage III (parenchymal abnormalities without $\mathrm{BHL}$ ) and stage IV (advanced lung fibrosis with evidence of honeycombing, hilar retraction, bullae, cysts and/or emphysema) (Figure 1.4). ${ }^{1,97}$ Patients initially present with CXR stage 0 in $5-15 \%$, stage I in $45-65 \%$, stage II in $30-40 \%$, stage III in $10-15 \%$ and stage IV in $15-25 \%$, respectively. As mentioned before, there is no strong relationship between CXR stages and lung function test results. However, in general, patients with a lower radiographic stage are more likely to experience resolution of symptoms and CXR abnormalities. ${ }^{86} \mathrm{~A}$ recent study showed that survival is significantly decreased in CXR stage IV patients and that $75 \%$ of the fatalities are directly attributable to respiratory causes. ${ }^{98}$ 


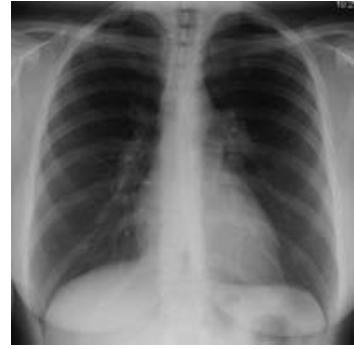

b

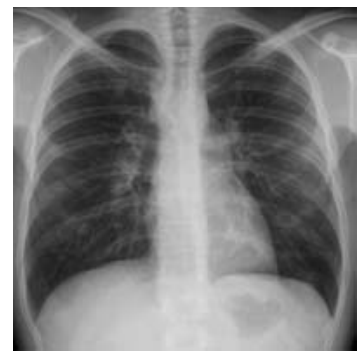

c

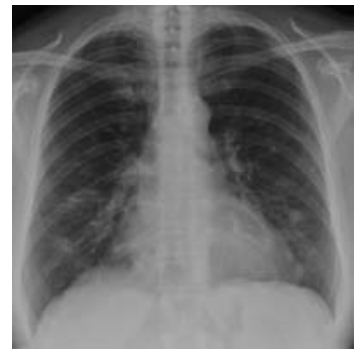

d

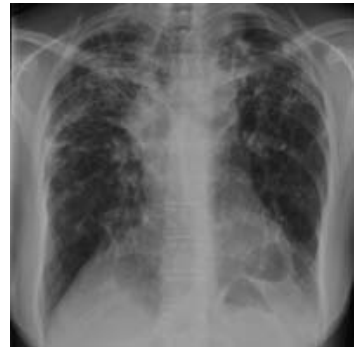

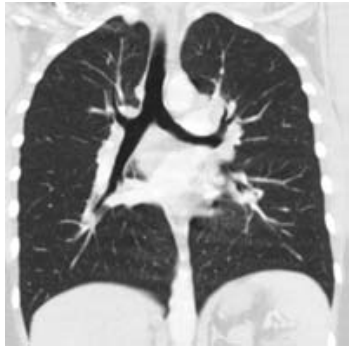
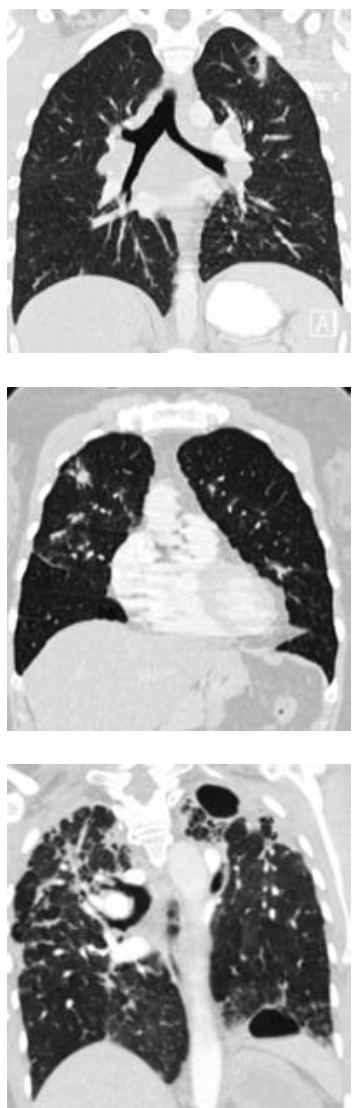

Figure 1.4 Chest radiographic staging system in sarcoidosis.

a. Stage I : CXR (left) and coronal high-resolution computed tomography scan (HRCT; right) showing bilateral hilar lymphadenopathy, without parenchymal abnormalities.

b. Stage II: CXR (left) and coronal HRCT image (right) showing both lymphadenopathy and parenchymal abnormalities (nodular and reticulonodular opacities).

c. Stage III: CXR (left) and coronal HRCT image (right) showing parenchymal abnormalities without hilar lymphadenopathy.

d. Stage IV: CXR (left) and coronal HRCT image (right) showing signs of lung fibrosis with hilar retraction and architectural distortion of the pulmonary parenchyma. 
a

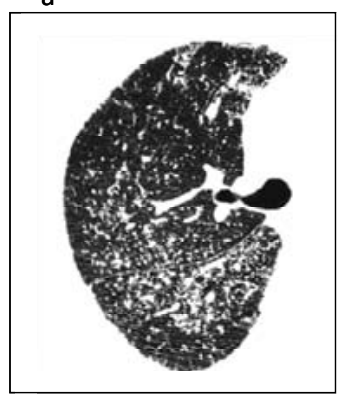

C

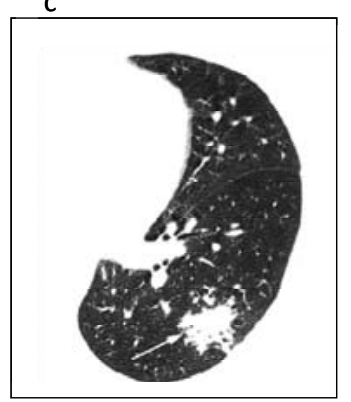

b

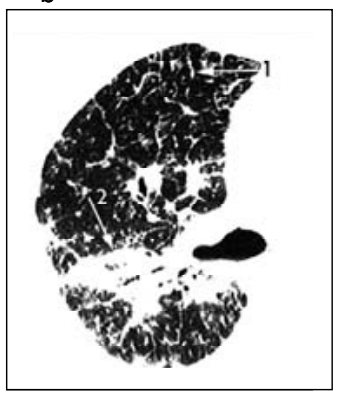

d

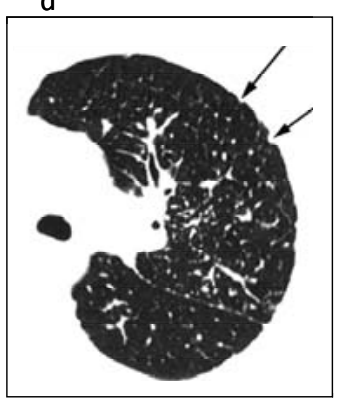

Figure 1.5 HRCT images of a sarcoidosis patient to illustrate the use of the semiquantitative HRCT scoring system that has been described by Oberstein et al. ${ }^{112}$ Adapted from Drent et al. ${ }^{107}$

a. Intra-parenchymal nodules. b. Septal and nonseptal lines $(1 \rightarrow)$; Thickening or irregularity of the bronchovascular bundle $(2 \rightarrow)$. c. Parenchymal consolidation (including ground-glass opacifications). d. Focal pleural thickening (arrows).

\section{High-resolution CT}

The high-resolution computed tomography (HRCT) uses short scanning times and thin collimation, making it possible to view lung parenchyma in detail and detect abnormal changes of the lung parenchyma at an early stage. ${ }^{99-104}$ HRCT appearances in sarcoidosis are characterized by peribronchovascular thickening and perilymphatic nodular distribution. Other common patterns are: enlargement of the mediastinal and hilar lymph nodes, ground-glass opacification, parenchymal consolidations, and signs of fibrosis (architectural distortion as shown by distortion of the airways and blood vessels, irregular distortion of the septal and intralobular lines, retraction of the hila and fissures, cystic formation and traction bronchiectasis). ${ }^{99,103,105}$ Follow-up CT scan studies in patients with pulmonary sarcoidosis showed that nodular opacities represent potentially reversible findings. ${ }^{105,106}$ In contrast, differentiation between fibrotic and granulomatous components in parenchymal consolidations cannot be made based on HRCT findings. The above-mentioned follow-up CT scan studies also 
showed that cystic air spaces and architectural distortion are irreversible findings, irrespective of treatment. ${ }^{105,106}$ Due to pre-existing major abnormalities, radiological features are frequently of limited value for assessment of inflammatory activity in sarcoidosis patients with fibrotic disease.

The presence and extent of parenchymal abnormalities on HRCT appeared to correlate with functional impairment in sarcoidosis. ${ }^{107-111}$ To achieve a reliable comparison of results, a standardized (semi-)quantitative estimation of abnormal findings on HRCT is mandatory. In clinical practice, it is important that the chosen HRCT score is complete, valid, reproducible, easy to learn, and rapid. ${ }^{107}$ Intra- and inter-reader reliability of a semiquantitative HRCT scoring system that was adapted from one previously described by Oberstein et al. ${ }^{112}$ (Figure 1.5; see also Chapter 5 and 6) demonstrated good agreement. ${ }^{107}$ This total HRCT score, but not the radiographic stage, appeared to predict the presence of respiratory functional impairment in the same study. Furthermore, this scoring system was related to various biochemical biomarkers of disease activity and the number of neutrophils in the BAL fluid. ${ }^{93,112}$

\section{${ }^{18}$ F-FDG PET}

${ }^{18}$ F-FDG PET is used to detect high glucose metabolism in malignancies or infectious foci and to explain fever of unknown origin. ${ }^{68,69,113}$ The glycolysis of inflammatory cells is enhanced when these cells are stimulated. This is mainly attributable to the high number of glucose transporters present in these cells and also to the enhanced affinity of these transporters for glucose. ${ }^{69}$ The uptake of ${ }^{18}$ F-FDG follows the same pathway as glucose, but once it has entered the cell, it is phosphorylated by hexokinase enzyme to ${ }^{18} \mathrm{~F}-2^{\prime}$-FDG-6 phosphate. This cannot be further degraded via the glycolysis pathway nor can it easily undergo dephosphorylation by glucose-6phosphatase. ${ }^{114}$ It is proposed that inflammatory cells such as activated macrophages and lymphocytes at the site of inflammation are responsible for the accumulation of FDG. ${ }^{114-116}$

PET has been shown to be a very sensitive technique for the assessment of inflammatory activity in sarcoidosis by detecting and quantifying the degree of inflammatory and granulomatous reactions that occur in the lungs and elsewhere in the body. ${ }^{63,117-119}$ In patients with proven sarcoidosis, the extent of involvement and quantification of inflammatory activity can be more accurately assessed by ${ }^{18}$ F-FDG PET than with ${ }^{67}$ Gallium scintigraphy. ${ }^{118-120}$ Apart from its value for assessment of inflammatory activity, ${ }^{18}$ F-FDG PET is therefore also useful to identify occult and reversible granulomas in patients with sarcoidosis (Figure 1.6). ${ }^{117}$ In addition, PET has several practical advantages over ${ }^{67}$ Gallium scintigraphy as it is less time-consuming, the inter observer agreement is higher and the radiation exposure lower. ${ }^{119}$

Somatostatin receptor scintigraphy (SRS), most frequently performed with Indium-111, has also been shown to reveal sarcoidosis sites. ${ }^{121}$ A study by Lebtahi et 
al. ${ }^{122}$ suggested that, compared with gallium scintigraphy, SRS appeared to be accurate and contributed to a better evaluation of organ involvement in sarcoidosis patients, especially those treated with corticosteroids. However, it missed $40 \%$ of the known extrathoracic sites. To our knowledge, the literature includes no data on potential advantages of SRS over PET-scanning in the detection of granulomatous sites in patients with proven sarcoidosis.

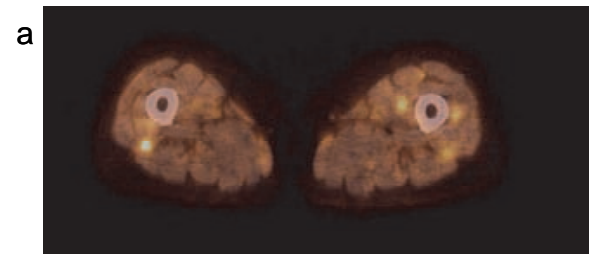

b

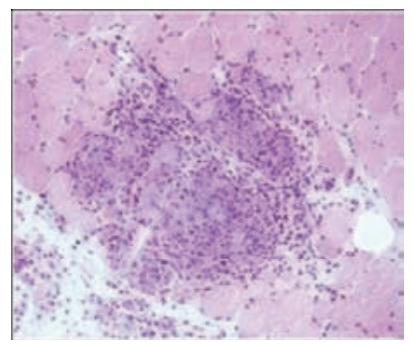

Figure 1.6 a. PET/CT image of a sarcoidosis patient showing multiple foci with increased FDG-uptake in the muscles of the lower extremities. b. Noncaseating granuloma present in a biopsy obtained from the left quadriceps muscle of the patient with sarcoidosis. 


\section{Scope and aims of the study}

In current clinical practice, serological parameters, i.e. ACE, CRP, sIL-2R, and neopterin, in combination with clinical indices like lung function parameters and radiological findings are most commonly used to assess inflammatory activity and disease severity in sarcoidosis. Sometimes however, patients suffer from disease related persistent disabling symptoms, and no signs of inflammatory activity could be detected with these routine investigations. Inflammatory activity assessment in these cases remains a challenge for clinicians, as absence of evidence does not mean evidence of absence. The management of patients with unexplained persistent disabling symptoms, therefore, requires reliable and clinically useful markers of inflammatory activity. The aims of the studies presented in this thesis were to evaluate the relationship between the currently available markers of inflammatory activity, and the relationship between these markers and parameters of disease severity in sarcoidosis patients. The studies included patients with sarcoidosis who had had unexplained persistent disease-related disabling symptoms for at least one year and were referred to a tertiary care center in the Netherlands. In addition, we assessed the response of inflammatory signs and clinical characteristics to treatment with adalimumab in sarcoidosis patients with refractory chronic uveitis.

Chapter $\mathbf{2}$ provides an overview of the knowledge about and limitations of the use of metaiodobenzylguanidine (MIBG) scintigraphy in cardiac and pulmonary diseases. Chapter 3 reports on the assessment of the presence of inflammatory activity using fluorine18-fluorodeoxyglucose positron emission tomography (PET) in 89 sarcoidosis patients with unexplained persistent disabling symptoms, and evaluates the association between PET findings and serological inflammatory markers. Chapter 4 describes the prevalence and distribution pattern of bone and bone marrow involvement as detected by PET/CT in 94 sarcoidosis patients with a positive PET. Chapter 5 evaluates the association between the severity of the pulmonary involvement and PET activity in 95 persistently symptomatic sarcoidosis patients. Chapter 6 makes an attempt to develop a prediction rule that can be used to identify persistently symptomatic sarcoidosis patients for whom there is a high probability that PET will show the presence of inflammatory activity. Chapter 7 presents the results of a prospective case series that included 26 sarcoidosis patients with refractory uveitis. The study evaluated the effect of adalimumab on intraocular inflammatory signs and other relevant clinical manifestations (lung function, serological inflammatory parameters, and fatigue) of sarcoidosis. Chapter $\mathbf{8}$ provides a summary of the findings presented in this thesis and argues their implications. Finally, directions for future research are discussed. 


\section{References}

1. Statement on sarcoidosis. Joint Statement of the American Thoracic Society (ATS), the European Respiratory Society (ERS) and the World Association of Sarcoidosis and Other Granulomatous Disorders (WASOG) adopted by the ATS Board of Directors and by the ERS Executive Committee, February 1999. Am J Respir Crit Care Med 1999;160:736-55.

2. Iannuzzi MC, Rybicki BA, Teirstein AS. Sarcoidosis. N Engl J Med 2007;357:2153-65.

3. Pietinalho $A$, Hiraga $Y$, Hosoda $Y$, Lofroos $A B$, Yamaguchi $M$, Selroos $O$. The frequency of sarcoidosis in Finland and Hokkaido, Japan. A comparative epidemiological study. Sarcoidosis 1995;12:61-7.

4. Rybicki BA, Major M, Popovich J Jr, Maliarik MJ, lannuzzi MC. Racial differences in sarcoidosis incidence: a 5-year study in a health maintenance organization. Am J Epidemiol 1997;145:234-41.

5. Iannuzzi MC, Fontana JR. Sarcoidosis: clinical presentation, immunopathogenesis, and therapeutics. JAMA 2011;305:391-9.

6. Baughman RP, Lower EE. Who dies from sarcoidosis and why? Am J Respir Crit Care Med 2011;183: 1446-7.

7. Baughman RP, Teirstein AS, Judson MA, Rossman MD, Yeager H Jr, Bresnitz EA, DePalo L, Hunninghake G, lannuzzi MC, Johns CJ, McLennan G, Moller DR, Newman LS, Rabin DL, Rose C, Rybicki B, Weinberger SE, Terrin ML, Knatterud GL, Cherniak R; Case Control Etiologic Study of Sarcoidosis (ACCESS) research group. Clinical characteristics of patients in a case control study of sarcoidosis. Am J Respir Crit Care Med 2001;164:1885-9.

8. Neville E, Carstairs LS, James DG. Sarcoidosis of bone. Q J Med 1977;46:215-27.

9. Zisman DA, Shorr AF, Lynch JP, 3rd. Sarcoidosis involving the musculoskeletal system. Semin Respir Crit Care Med 2002;23:555-70.

10. Mana J, Salazar A, Manresa F. Clinical factors predicting persistence of activity in sarcoidosis: a multivariate analysis of 193 cases. Respiration 1994;61:219-25.

11. Baughman RP, Nagai S, Balter M, Costabel U, Drent M, du Bois R, Grutters JC, Judson MA, Lambiri I, Lower EE, Muller-Quernheim J, Prasse A, Rizzato G, Rottoli P, Spagnolo P, Teirstein A. Defining the clinical outcome status (COS) in sarcoidosis: results of WASOG Task Force. Sarcoidosis Vasc Diffuse Lung Dis 2011;28:56-64.

12. Lazar CA, Culver DA. Treatment of sarcoidosis. Semin Respir Crit Care Med 2010;31:501-18.

13. Drent M. Sarcoidosis: benefits of a multidisciplinary approach. Eur J Intern Med 2003;14:217-20.

14. De Vries J, Rothkrantz-Kos S, van Dieijen-Visser MP, Drent M. The relationship between fatigue and clinical parameters in pulmonary sarcoidosis. Sarcoidosis Vasc Diffuse Lung Dis 2004;21:127-36.

15. Marcellis RG, Lenssen AF, Elfferich MD, De Vries J, Kassim S, Foerster K, Drent M. Exercise capacity, muscle strength and fatigue in sarcoidosis. Eur Respir J 2011;38:628-34.

16. De Vries J, Michielsen H, Van Heck GL, Drent M. Measuring fatigue in sarcoidosis: the Fatigue Assessment Scale (FAS). Br J Health Psychol 2004;9:279-91.

17. Newman LS, Rose CS, Bresnitz EA, Rossman MD, Barnard J, Frederick M, Terrin ML, Weinberger SE, Moller DR, McLennan G, Hunninghake G, DePalo L, Baughman RP, lannuzzi MC, Judson MA, Knatterud GL, Thompson BW, Teirstein AS, Yeager H Jr, Johns CJ, Rabin DL, Rybicki BA, Cherniack R; ACCESS Research Group. A case control etiologic study of sarcoidosis: environmental and occupational risk factors. Am J Respir Crit Care Med 2004;170: 1324-30.

18. Antonelli A, Fazzi P, Fallahi P, Ferrari SM, Ferrannini E. Prevalence of hypothyroidism and Graves disease in sarcoidosis. Chest 2006;130:526-32.

19. Verbraecken J, Hoitsma E, van der Grinten CP, Cobben NA, Wouters EF, Drent M. Sleep disturbances associated with periodic leg movements in chronic sarcoidosis. Sarcoidosis Vasc Diffuse Lung Dis 2004;21:137-46.

20. Fisher KA, Serlin DM, Wilson KC, Walter RE, Berman JS, Farber HW. Sarcoidosis-associated pulmonary hypertension: outcome with long-term epoprostenol treatment. Chest 2006;130:1481-8.

21. Hoitsma E, Faber C, Drent M, Sharma OP. Neurosarcoidosis: a clinical dilemma. Lancet Neurol 2004;3:397-407.

22. Sharma OP. Neurosarcoidosis. Chest 1991;100:301-2.

23. Scott TF. Neurosarcoidosis: progress and clinical aspects. Neurology 1993;43:8-12.

24. Murialdo G, Tamagno G. Endocrine aspects of neurosarcoidosis. J Endocrinol Invest 2002;25:650-62. 
25. Birnbaum AD, Oh FS, Chakrabarti A, Tessler HH, Goldstein DA. Clinical features and diagnostic evaluation of biopsy-proven ocular sarcoidosis. Arch Ophthalmol 2011;129:409-13.

26. Herbort CP, Rao NA, Mochizuki M. International criteria for the diagnosis of ocular sarcoidosis: results of the first International Workshop On Ocular Sarcoidosis (IWOS). Ocul Immunol Inflamm 2009;17:160-9.

27. Rose AS, Tielker MA, Knox KS. Hepatic, ocular, and cutaneous sarcoidosis. Clin Chest Med 2008;29:509-24, ix.

28. Rothova A, Suttorp-van Schulten MS, Frits Treffers W, Kijlstra A. Causes and frequency of blindness in patients with intraocular inflammatory disease. Br J Ophthalmol 1996;80:332-6.

29. Silverman KJ, Hutchins GM, Bulkley BH. Cardiac sarcoid: a clinicopathologic study of 84 unselected patients with systemic sarcoidosis. Circulation 1978;58:1204-11.

30. Hiraga $\mathrm{H}$, Hiroe $\mathrm{M}, \mathrm{K}$ I. Guideline for the diagnosis of cardiac sarcoidosis: study report on diffuse pulmonary diseases. Tokyo, The Japanese Ministry of Health and Welfare 1993:23-4.

31. Youssef G, Leung E, Mylonas I, Nery P, Williams K, Wisenberg G, Gulenchyn KY, Dekemp RA, Dasilva J, Birnie D, Wells GA, Beanlands RS. The Use of 18F-FDG PET in the Diagnosis of Cardiac Sarcoidosis: A Systematic Review and Metaanalysis Including the Ontario Experience. J Nucl Med 2012:Epub ahead of print.

32. Ohira H, Tsujino I, Yoshinaga K. (18)F-Fluoro-2-deoxyglucose positron emission tomography in cardiac sarcoidosis. Eur J Nucl Med Mol Imaging 2011;38:1773-83.

33. Yanardag H, Pamuk ON, Pamuk GE. Lupus pernio in sarcoidosis: clinical features and treatment outcomes of 14 patients. J Clin Rheumatol 2003;9:72-6.

34. Chen ES, Moller DR. Etiology of sarcoidosis. Clin Chest Med 2008;29:365-77, vii.

35. Shigehara K, Shijubo N, Ohmichi M, Takahashi R, Kon S, Okamura H, Kurimoto M, Hiraga Y, Tatsuno T, Abe S, Sato N. IL-12 and IL-18 are increased and stimulate IFN-gamma production in sarcoid lungs. $J$ Immunol 2001;166:642-9.

36. Sweiss NJ, Zhang W, Franek BS, Kariuki SN, Moller DR, Patterson KC, Bennett P, Girijala LR, Nair V, Baughman RP, Garcia JG, Niewold TB. Linkage of Type I Interferon Activity and TNF-Alpha Levels in Serum with Sarcoidosis Manifestations and Ancestry. PloS one 2011;6:e29126.

37. Drent M, Bomans PH, Van Suylen RJ, Lamers RJ, Bast A, Wouters EF. Association of man-made mineral fibre exposure and sarcoidlike granulomas. Respir Med 2000;94:815-20.

38. Gupta D, Agarwal R, Aggarwal AN, Jindal SK. Molecular evidence for the role of mycobacteria in sarcoidosis: a meta-analysis. Eur Respir J 2007;30:508-16.

39. Wirnsberger RM, de Vries J, Wouters EF, Drent M. Clinical presentation of sarcoidosis in The Netherlands an epidemiological study. Neth J Med 1998;53:53-60.

40. Iannuzzi MC, Maliarik MJ, Poisson LM, Rybicki BA. Sarcoidosis susceptibility and resistance HLA-DQB1 alleles in African Americans. Am J Respir Crit Care Med 2003;167:1225-31.

41. Sato H, Grutters JC, Pantelidis P, Mizzon AN, Ahmad T, Van Houte AJ, Lammers JW, Van Den Bosch JM, Welsh KI, Du Bois RM. HLA-DQB1*0201: a marker for good prognosis in British and Dutch patients with sarcoidosis. Am J Respir Cell Mol Biol 2002;27:406-12.

42. Berlin M, Fogdell-Hahn A, Olerup O, Eklund A, Grunewald J. HLA-DR predicts the prognosis in Scandinavian patients with pulmonary sarcoidosis. Am J Respir Crit Care Med 1997;156:1601-5.

43. Voorter CE, Drent $M$, van den Berg-Loonen EM. Severe pulmonary sarcoidosis is strongly associated with the haplotype HLA-DQB1*0602-DRB1*150101. Hum Immunol 2005;66:826-35.

44. Wijnen PA, Nelemans PJ, Verschakelen JA, Bekers O, Voorter CE, Drent M. The role of tumor necrosis factor alpha G-308A polymorphisms in the course of pulmonary sarcoidosis. Tissue Antigens 2010;75:262-8.

45. Wijnen PA, Voorter CE, Nelemans PJ, Verschakelen JA, Bekers O, Drent M. Butyrophilin-like 2 in pulmonary sarcoidosis: a factor for susceptibility and progression? Hum Immunol 2011;72:342-7.

46. Valentonyte R, Hampe J, Huse K, Rosenstiel P, Albrecht M, Stenzel A, Nagy M, Gaede KI, Franke A, Haesler R, Koch A, Lengauer T, Seegert D, Reiling N, Ehlers S, Schwinger E, Platzer M, Krawczak M, Müller-Quernheim J, Schürmann M, Schreiber S. Sarcoidosis is associated with a truncating splice site mutation in BTNL2. Nat Genet 2005;37:357-64.

47. Spagnolo P, Sato H, Grutters JC, Renzoni EA, Marshall SE, Ruven HJ, Wells AU, Tzouvelekis A, van Moorsel $\mathrm{CH}$, van den Bosch JM, du Bois RM, Welsh KI. Analysis of BTNL2 genetic polymorphisms in British and Dutch patients with sarcoidosis. Tissue Antigens 2007;70:219-27. 
48. Baughman RP, Culver DA, Judson MA. A concise review of pulmonary sarcoidosis. Am J Respir Crit Care Med 2011;183:573-81.

49. Sahoo DH, Bandyopadhyay D, Xu M, Pearson K, Parambil JG, Lazar CA, Chapman JT, Culver DA.. Effectiveness and safety of leflunomide for pulmonary and extrapulmonary sarcoidosis. Eur Respir $J$ 2011;38:1145-50.

50. Gibson GJ, Prescott RJ, Muers MF, Middleton WG, Mitchell DN, Connolly CK, Harrison BD. British Thoracic Society Sarcoidosis study: effects of long term corticosteroid treatment. Thorax 1996;51:238-47.

51. Baughman RP, Lower EE. A clinical approach to the use of methotrexate for sarcoidosis. Thorax 1999;54:742-6.

52. Baughman RP, Winget DB, Lower EE. Methotrexate is steroid sparing in acute sarcoidosis: results of a double blind, randomized trial. Sarcoidosis Vasc Diffuse Lung Dis 2000;17:60-6.

53. Morgenthau AS, lannuzzi MC. Recent advances in sarcoidosis. Chest 2011;139:174-82.

54. Baughman RP, Drent M, Kavuru M, Judson MA, Costabel U, du Bois R, Albera C, Brutsche M, Davis G, Donohue JF, Müller-Quernheim J, Schlenker-Herceg R, Flavin S, Lo KH, Oemar B, Barnathan ES; Sarcoidosis Investigators. Infliximab therapy in patients with chronic sarcoidosis and pulmonary involvement. Am J Respir Crit Care Med 2006;174:795-802.

55. Judson MA, Baughman RP, Costabel U, Flavin S, Lo KH, Kavuru MS, Drent M; Centocor T48 Sarcoidosis Investigators. Efficacy of infliximab in extrapulmonary sarcoidosis: results from a randomised trial. Eur Respir J 2008;31:1189-96.

56. Rossman MD, Newman LS, Baughman RP, Teirstein A, Weinberger SE, Miller W Jr, Sands BE. A doubleblinded, randomized, placebo-controlled trial of infliximab in subjects with active pulmonary sarcoidosis. Sarcoidosis Vasc Diffuse Lung Dis 2006;23:201-8.

57. Baughman RP, Lower EE, Drent M. Inhibitors of tumor necrosis factor (TNF) in sarcoidosis: who, what, and how to use them. Sarcoidosis Vasc Diffuse Lung Dis 2008;25:76-89.

58. Baughman RP, Nunes H. Therapy for sarcoidosis: evidence-based recommendations. Expert Rev Clin Immunol 2012;8:95-103.

59. Consensus conference: activity of sarcoidosis. Third WASOG meeting, Los Angeles, USA, September 811, 1993. Eur Respir J 1994;7:624-7.

60. Keijsers RG, Verzijlbergen JF, van Diepen DM, van den Bosch JM, Grutters JC. 18F-FDG PET in sarcoidosis: an observational study in 12 patients treated with infliximab. Sarcoidosis Vasc Diffuse Lung Dis 2008;25:143-9.

61. Sharma OP, Alam S. Diagnosis, pathogenesis, and treatment of sarcoidosis. Curr Opin Pulm Med 1995;1:392-400.

62. Ziegenhagen MW, Rothe ME, Schlaak M, Muller-Quernheim J. Bronchoalveolar and serological parameters reflecting the severity of sarcoidosis. Eur Respir J 2003;21:407-13.

63. Keijsers RG, Verzijlbergen FJ, Oyen WJ, van den Bosch JM, Ruven HJ, van Velzen-Blad H, Grutters JC. 18F-FDG PET, genotype-corrected ACE and sIL-2R in newly diagnosed sarcoidosis. Eur J Nucl Med Mol Imaging 2009;36:1131-7.

64. Rothkrantz-Kos S, van Dieijen-Visser MP, Mulder PG, Drent M. Potential usefulness of inflammatory markers to monitor respiratory functional impairment in sarcoidosis. Clin Chem 2003;49:1510-7.

65. Ziegenhagen MW, Benner UK, Zissel G, Zabel P, Schlaak M, Muller-Quernheim J. Sarcoidosis: TNFalpha release from alveolar macrophages and serum level of sIL-2R are prognostic markers. Am J Respir Crit Care Med 1997;156:1586-92.

66. Prasse A, Katic C, Germann M, Buchwald A, Zissel G, Muller-Quernheim J. Phenotyping sarcoidosis from a pulmonary perspective. Am J Respir Crit Care Med 2008;177:330-6.

67. Grutters JC, Fellrath JM, Mulder L, Janssen R, van den Bosch JM, van Velzen-Blad H. Serum soluble interleukin-2 receptor measurement in patients with sarcoidosis: a clinical evaluation. Chest 2003;124:186-95.

68. Love C, Tomas MB, Tronco GG, Palestro CJ. FDG PET of infection and inflammation. Radiographics 2005;25:1357-68.

69. El-Haddad G, Zhuang H, Gupta N, Alavi A. Evolving role of positron emission tomography in the management of patients with inflammatory and other benign disorders. Semin Nucl Med 2004;34: 313-29. 
70. Biller H, Zissel G, Ruprecht B, Nauck M, Busse Grawitz A, Muller-Quernheim J. Genotype-corrected reference values for serum angiotensin-converting enzyme. Eur Respir J 2006;28:1085-90.

71. Tomita H, Ina Y, Sugiura Y, Sato S, Kawaguchi H, Morishita M, Yamamoto M, Ueda R. Polymorphism in the angiotensin-converting enzyme (ACE) gene and sarcoidosis. Am J Respir Crit Care Med 1997;156: 255-9.

72. Klech $\mathrm{H}$, Kohn $\mathrm{H}$, Kummer F, Mostbeck A. Assessment of activity in Sarcoidosis. Sensitivity and specificity of 67Gallium scintigraphy, serum ACE levels, chest roentgenography, and blood lymphocyte subpopulations. Chest 1982;82:732-8.

73. Li XC, Demirci G, Ferrari-Lacraz S, Groves C, Coyle A, Malek TR, Strom TB. IL-15 and IL-2: a matter of life and death for T cells in vivo. Nat Med 2001;7:114-8.

74. Smith KA. Interleukin-2: inception, impact, and implications. Science 1988;240:1169-76.

75. Gabay C, Kushner I. Acute-phase proteins and other systemic responses to inflammation. $N$ Engl J Med 1999;340:448-54.

76. Yotsumoto H, Imai Y, Kuzuya N, Uchimura H, Matsuzaki F. Increased levels of serum angiotensinconverting enzyme activity in hyperthyroidism. Ann Intern Med 1982;96:326-8.

77. Costabel U, Teschler H. Biochemical changes in sarcoidosis. Clinics in chest medicine 1997;18:827-42.

78. Pizzolo G, Chilosi M, Vinante F, Dazzi F, Lestani M, Perona G, Benedetti F, Todeschini G, Vincenzi C, Trentin L, et al. Soluble interleukin-2 receptors in the serum of patients with Hodgkin's disease. $\mathrm{Br} J$ Cancer 1987;55:427-8.

79. Takahashi S, Setoguchi Y, Nukiwa T, Kira S. Soluble interleukin-2 receptor in sera of patients with pulmonary tuberculosis. Chest 1991;99:310-4.

80. Semenzato G, Bambara LM, Biasi D, Frigo A, Vinante F, Zuppini B, Trentin L, Feruglio C, Chilosi M, Pizzolo G. Increased serum levels of soluble interleukin-2 receptor in patients with systemic lupus erythematosus and rheumatoid arthritis. J Clin Immunol 1988;8:447-52.

81. Prince HE, Kleinman S, Williams AE. Soluble IL-2 receptor levels in serum from blood donors seropositive for HIV. J Immunol 1988;140:1139-41.

82. Bargagli E, Bianchi N, Margollicci M, Olivieri C, Luddi A, Coviello G, Grosso S, Rottoli P. Chitotriosidase and soluble IL-2 receptor: comparison of two markers of sarcoidosis severity. Scand J Clin Lab Invest 2008;68:479-83.

83. Miyoshi S, Hamada H, Kadowaki T, Hamaguchi N, Ito R, Irifune K, Higaki J. Comparative evaluation of serum markers in pulmonary sarcoidosis. Chest 2010;137:1391-7.

84. Drent M, van den Berg R, Haenen GR, van den Berg H, Wouters EF, Bast A. NF-kappaB activation in sarcoidosis. Sarcoidosis Vasc Diffuse Lung Dis 2001;18:50-6.

85. Cremers J, Drent M, Driessen A, Nieman F, Wijnen P, Baughman R, Koek G. Liver-test abnormalities in sarcoidosis. Eur J Gastroenterol Hepatol 2012;24:17-24.

86. Keir G, Wells AU. Assessing pulmonary disease and response to therapy: which test? Semin Respir Crit Care Med 2010;31:409-18.

87. Shorr AF, Torrington KG, Hnatiuk OW. Endobronchial involvement and airway hyperreactivity in patients with sarcoidosis. Chest 2001;120:881-6.

88. Judson MA, Baughman RP, Thompson BW, Teirstein AS, Terrin ML, Rossman MD, Yeager H Jr, McLennan G, Bresnitz EA, DePalo L, Hunninghake G, lannuzzi MC, Johns CJ, Moller DR, Newman LS, Rabin DL, Rose C, Rybicki BA, Weinberger SE, Knatterud GL, Cherniak R; ACCESS Research Group. Two year prognosis of sarcoidosis: the ACCESS experience. Sarcoidosis Vasc Diffuse Lung Dis 2003;20: 204-11.

89. Drent M, Mansour K, Linssen C. Bronchoalveolar lavage in sarcoidosis. Semin Respir Crit Care Med 2007;28:486-95.

90. Meyer KC, Raghu G, Baughman RP, Brown KK, Costabel U, du Bois RM, Drent M, Haslam PL, Kim DS, Nagai S, Rottoli P, Saltini C, Selman M, Strange C, Wood B; American Thoracic Society Committee on BAL in Interstitial Lung Disease. An official American Thoracic Society clinical practice guideline: the clinical utility of bronchoalveolar lavage cellular analysis in interstitial lung disease. Am J Respir Crit Care Med 2012;185:1004-14.

91. Drent M, van Velzen-Blad H, Diamant M, Hoogsteden HC, van den Bosch JM. Relationship between presentation of sarcoidosis and T lymphocyte profile. A study in bronchoalveolar lavage fluid. Chest 1993;104:795-800. 
92. Costabel U, Guzman J. Bronchoalveolar lavage in interstitial lung disease. Curr Opin Pulm Med 2001;7:255-61.

93. Drent M, Jacobs JA, de Vries J, Lamers RJ, Liem IH, Wouters EF. Does the cellular bronchoalveolar lavage fluid profile reflect the severity of sarcoidosis? Eur Respir J 1999;13:1338-44.

94. Bargagli E, Mazzi A, Rottoli P. Markers of inflammation in sarcoidosis: blood, urine, BAL, sputum, and exhaled gas. Clin Chest Med 2008;29:445-58, viii.

95. Bargagli E, Margollicci M, Perrone A, Luddi A, Perari MG, Bianchi N, Refini RM, Grosso S, Volterrani L, Rottoli P. Chitotriosidase analysis in bronchoalveolar lavage of patients with sarcoidosis. Sarcoidosis Vasc Diffuse Lung Dis 2007;24:59-64.

96. Ten Berge B, Paats MS, Bergen IM, van den Blink B, Hoogsteden HC, Lambrecht BN, Hendriks RW, Kleinjan A. Increased IL-17A expression in granulomas and in circulating memory T cells in sarcoidosis. Rheumatology (Oxford) 2012;51:37-46.

97. Costabel U, Hunninghake GW. ATS/ERS/WASOG statement on sarcoidosis. Sarcoidosis Statement Committee. American Thoracic Society. European Respiratory Society. World Association for Sarcoidosis and Other Granulomatous Disorders. Eur Respir J 1999;14:735-7.

98. Nardi A, Brillet PY, Letoumelin P, Girard F, Brauner M, Uzunhan Y, Naccache JM, Valeyre D, Nunes H. Stage IV sarcoidosis comparison of survival with the general population and causes of death. Eur Respir J 2011;38:1368-73.

99. Verschakelen JA. The role of high-resolution computed tomography in the work-up of interstitial lung disease. Curr Opin Pulm Med 2011;16:503-10.

100. Hansell DM, Milne DG, Wilsher ML, Wells AU. Pulmonary sarcoidosis: morphologic associations of airflow obstruction at thin-section CT. Radiology 1998;209:697-704.

101. Murata K, Khan A, Herman PG. Pulmonary parenchymal disease: evaluation with high-resolution CT. Radiology 1989;170:629-35.

102. Orens JB, Kazerooni EA, Martinez FJ, Curtis JL, Gross BH, Flint A, Lynch JP 3rd. The sensitivity of highresolution $\mathrm{CT}$ in detecting idiopathic pulmonary fibrosis proved by open lung biopsy. $A$ prospective study. Chest 1995;108:109-15.

103. Wells A. High resolution computed tomography in sarcoidosis: a clinical perspective. Sarcoidosis Vasc Diffuse Lung Dis 1998;15:140-6.

104. Ellis SM, Hansell DM. Idiopathic interstitial pneumonias: imaging-pathology correlation. Eur Radiol 2002;12:610-26.

105. Brauner MW, Lenoir S, Grenier P, Cluzel P, Battesti JP, Valeyre D. Pulmonary sarcoidosis: CT assessment of lesion reversibility. Radiology 1992;182:349-54.

106. Murdoch J, Muller NL. Pulmonary sarcoidosis: changes on follow-up CT examination. AJR Am J Roentgenol 1992;159:473-7.

107. Drent M, De Vries J, Lenters M, Lamers RJ, Rothkranz-Kos S, Wouters EF, van Dieijen-Visser MP, Verschakelen JA. Sarcoidosis: assessment of disease severity using HRCT. Eur Radiol 2003;13:2462-71.

108. Remy-Jardin M, Giraud F, Remy J, Wattinne L, Wallaert B, Duhamel A. Pulmonary sarcoidosis: role of $\mathrm{CT}$ in the evaluation of disease activity and functional impairment and in prognosis assessment. Radiology 1994;191:675-80.

109. Bergin CJ, Bell DY, Coblentz CL, Chiles C, Gamsu G, Maclntyre NR, Coleman RE, Putman CE. Sarcoidosis: correlation of pulmonary parenchymal pattern at $\mathrm{CT}$ with results of pulmonary function tests. Radiology 1989;171:619-24.

110. Leung AN, Brauner MW, Caillat-Vigneron N, Valeyre D, Grenier P. Sarcoidosis activity: correlation of HRCT findings with those of $67 \mathrm{Ga}$ scanning, bronchoalveolar lavage, and serum angiotensinconverting enzyme assay. J Comput Assist Tomogr 1998;22:229-34.

111. Abehsera M, Valeyre D, Grenier P, Jaillet H, Battesti JP, Brauner MW. Sarcoidosis with pulmonary fibrosis: CT patterns and correlation with pulmonary function. AJR Am J Roentgenol 2000;174:1751-7.

112. Oberstein A, von Zitzewitz $H$, Schweden $F$, Muller-Quernheim J. Non invasive evaluation of the inflammatory activity in sarcoidosis with high-resolution computed tomography. Sarcoidosis Vasc Diffuse Lung Dis 1997;14:65-72.

113. Bomanji J, Almuhaideb A, Zumla A. Combined PET and X-ray computed tomography imaging in pulmonary infections and inflammation. Curr Opin Pulm Med 2011;17:197-205.

114. Abouzied MM, Crawford ES, Nabi HA. 18F-FDG imaging: pitfalls and artifacts. J Nucl Med Technol 2005;33:145-55. 
115. Basu S, Saboury B, Werner T, Alavi A. Clinical Utility of FDG-PET and PET/CT in Non-malignant Thoracic Disorders. Mol Imaging Biol 2011;13:1051-60.

116. Ishimori T, Saga T, Mamede M, Kobayashi H, Higashi T, Nakamoto $Y$, Sato N, Konishi J. Increased (18)F-FDG uptake in a model of inflammation: concanavalin A-mediated lymphocyte activation. J Nucl Med 2002;43:658-63.

117. Teirstein AS, Machac J, Almeida O, Lu P, Padilla ML, lannuzzi MC. Results of 188 whole-body fluorodeoxyglucose positron emission tomography scans in 137 patients with sarcoidosis. Chest 2007;132:1949-53.

118. Braun JJ, Kessler R, Constantinesco A, Imperiale A. 18F-FDG PET/CT in sarcoidosis management: review and report of 20 cases. Eur J Nucl Med Mol Imaging 2008;35:1537-43.

119. Keijsers RG, Grutters JC, Thomeer M, Du Bois RM, Van Buul MM, Lavalaye J, Van Den Bosch JM, Verzijlbergen FJ. Imaging the inflammatory activity of sarcoidosis: sensitivity and inter observer agreement of (67)Ga imaging and (18)F-FDG PET. Q J Nucl Med Mol Imaging 2011;55:66-71.

120. Nishiyama $Y$, Yamamoto $Y$, Fukunaga K, Takinami H, Iwado Y, Satoh K, Ohkawa M. Comparative evaluation of 18F-FDG PET and 67Ga scintigraphy in patients with sarcoidosis. $J \mathrm{Nucl}$ Med 2006;47:1571-6.

121. Dalm VA, van Hagen PM, Krenning EP. The role of octreotide scintigraphy in rheumatoid arthritis and sarcoidosis. Q J Nucl Med 2003;47:270-8.

122. Lebtahi R, Crestani B, Belmatoug N, Daou D, Genin R, Dombret MC, Palazzo E, Faraggi M, Aubier M, Le Guludec D. Somatostatin receptor scintigraphy and gallium scintigraphy in patients with sarcoidosis. $J$ Nucl Med 2001;42:21-6. 


\section{Chapter 2}

Metaiodobenzylguanidine

scintigraphy in pulmonary

and cardiac disease
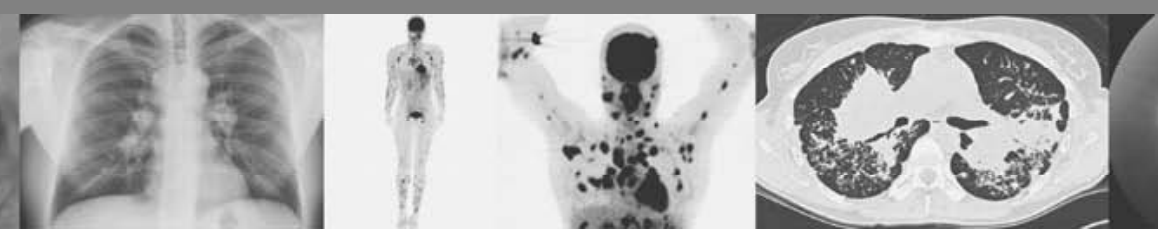

MJPG van Kroonenburgh, RLM Mostard, S Vöö

Curr Opin Pulm Med 2010;16:511-515 


\section{Abstract}

\section{Purpose of review}

Nuclear medicine techniques have the capacity to investigate neuronal dysfunction at the synapse level. For instance, metaiodobenzylguanidine (MIBG) shows a similar uptake, storage and release as norepinephrine. Intravenously injected radiolabeled MIBG is able to reflect neuronal damage induced by inflammation and tumors. The purpose of this review is to evaluate the results and limitations of these neuronal imaging techniques in patients with pulmonary and cardiac diseases and to give an opinion about the clinical value of these new diagnostic tools.

\section{Recent findings}

MIBG neuronal images of the lungs and heart can show heterogeneous distribution patterns with either diminished or increased MIBG uptake and/or wash-out. These changes reflect changes in endothelial integrity, neuronal innervations and clearance of norepinephrine. Interest in the role of neurotransmitter involvement and the relation between endothelial cell integrity and vascularization is growing and of utmost importance to understand the effect on pathophysiology of diseases.

\section{Summary}

At this moment, there is no added clinical value to routinely use MIBG scanning of the lungs and the heart. This is partly due to the many unresolved questions such as what actually happens and which factors influence MIBG uptake and washout under normal physiological circumstances. But the technique, if standardized and when dynamic time acquisition is performed with the latest equipment, such as positron emission tomography (PET) and single photon emission computed tomography-computed tomography (SPECT-CT), has a tremendously great potential. It can unravel till now unknown relationships between innervation, vascularization and endothelial integrity. Other diagnostic tools like magnetic resonance imaging (MRI) and CT do not have this capacity, so the future looks bright for these new neuronal imaging techniques. 


\section{Introduction}

In nuclear medicine, radiolabeled neurotransmitters are used as a diagnostic aid in clinical diagnosis. The visualization of neuroblastoma and pheochromocytoma by radiolabeled ${ }^{123}$ I-metaiodobenzylguanidine scintigraphy (MIBG) is of great clinical value. ${ }^{123}$ I-radiolabeled MIBG reflects adrenergic neuron integrity. MIBG and norepinephrine enter adrenergic cells through the same uptake mechanism and both are stored in the vesicles at the sympathetic nerve ending. In addition to this active uptake mechanism, MIBG, in contrast with norepinephrine, is also taken up by a diffusion type of pathway, which facilitates a substantial proportion of MIBG uptake into the adrenergic nerves. The uptake of MIBG is diminished by injury to adrenergic neurons, for instance induced by inflammation, and an increased sympathetic activity is associated with a more rapid rate of loss of MIBG. ${ }^{1}$ Therefore radiolabeled MIBG is able to reflect neuronal dysfunction in different organs. The myocardium, lungs, adrenal glands, parotids, submandibular glands, uterus and intestines are all richly supplied with sympathetic nerves. A study from Nakayo et al. ${ }^{2}$ suggested that serial measurements of time activity of radioiodinated MIBG in certain organs may be useful in the assessment of adrenergic neuropathy.

The lungs are able to extract circulating norepinephrine from the circulation, a process that is mediated by the pulmonary vascular endothelial cells. The extent to which the lungs are participating in the removal of these biogenic amines has been measured and it appears that approximately $25 \%$ of the circulating norepinephrine is extracted through the passage through the lungs in resting humans. ${ }^{3}$ The focus on sympathetic innervations and/or removal of biogenic amines has led to questions as follows: is there an association between certain pulmonary diseases and adrenergic dysfunction? What is exactly the role of these innervations and why do the lungs play a role in the excretion of the biologically active amines? Is there any relation between chronic obstructive pulmonary disease (COPD) or pulmonary hypertension and neurogenic dysfunction and what is the effect of infectious disease? There are more questions than answers and the literature is scarce, but recently growing in numbers, indicating an awakening in interest in this area of science. Numerous sympathetic nerves innervate vessels in the lung. ${ }^{4}$ Neurotransmitters released from sympathetic neurons can potentially affect endothelial cells and it has been hypothesized that the interaction between neuronal and endothelial cells may regulate vascular tone., There remains a compelling need for investigating these kinds of innervations mechanism in the lungs and much is already learned from the innervations studies which have been done with radiolabeled MIBG in the heart. 


\section{Review}

It is now well established that the lungs of many species actively take up circulating biogenic amines such as serotonin and norepinephrine. ${ }^{7}$ Animal models showed that injured endothelial cells have a decreased ability to extract norepinephrine. ${ }^{8}$ In 1999, Sakami et al. ${ }^{9}$ compared MIBG imaging and plasma norepinephrine concentration between patients with COPD and normals. They showed that plasma norepinephrine in COPD was higher than in the controls and that patients with COPD have significant sympathetic nervous impairment of the left ventricle myocardium as a result of generalized sympathetic overactivity. It has been demonstrated that increased sympathetic activity can contribute significantly to myocardial infarction, arrhythmia and heart failure and that adrenergic blockade can be used as a therapy. ${ }^{10}$

\section{Scintigraphy}

Scintigraphic assessment showed evidence of diminished uptake of ${ }^{123}$ I-MIBG in the lungs of patients suffering from COPD $^{9,11}$, but also in patients with pulmonary fibrosis $^{12}$, vasculitis ${ }^{13}$, high altitude pulmonary edema ${ }^{14,15}$, chronic hypoxia ${ }^{16}$ and after radiotherapy. ${ }^{17}$ In other diseases, increased or prolonged retention of MIBG have been shown. This was observed in patients with diabetes ${ }^{18,19}$, in Behçet's disease ${ }^{20}$, and in patients with chronic heart failure. ${ }^{21}$ Furthermore the decreased lung washout rate of MIBG was related to the severity of pulmonary hypertension. ${ }^{21}$ Increased or decreased uptake in the lungs, either homogeneous or not, is easily detected on a scintigram (Figure 2.1) and can be quantitated. It has been reported that plasma norepinephrine kinetics in sympathetic nerve terminals may change with age. ${ }^{22,23}$
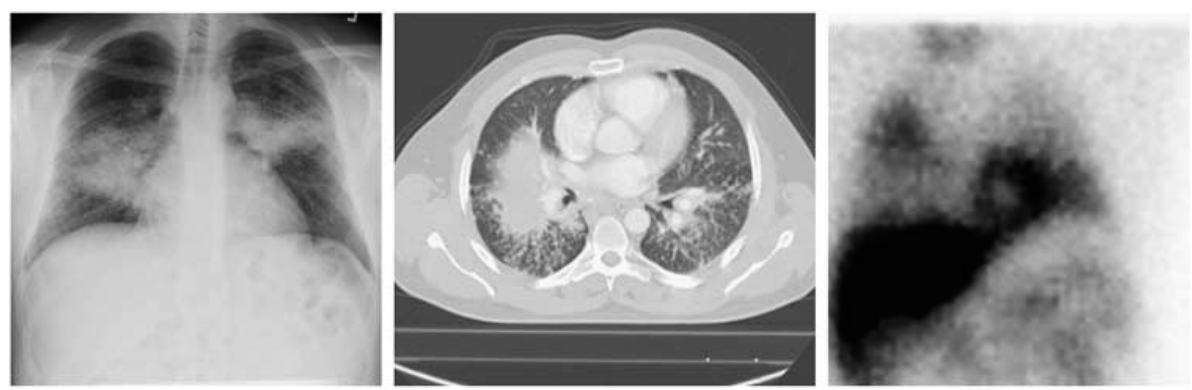

Figure 2.1 Metaiodobenzylguanidine and sarcoidosis.

Anterior chest radiograph, transaxial CT slice and planar anterior image of the thorax made of a patient with active sarcoidosis disease $4 \mathrm{~h}$ after intravenous injection of $185 \mathrm{Mbq}$ ${ }^{123}$ I-metaiodobenzylguanidine (MIBG). Note the remarkable irregular distribution of MIBG in the lungs. 
Lung uptake of MIBG involves a sodium-dependent energy-requiring active transporter located in the endothelial cell membrane and changes in uptake can be due to changes in lung endothelial cell integrity of pre and postcapillary vessels and pulmonary veins. ${ }^{24}$ Uptake by nerve endings is negligible. ${ }^{25}$ After uptake in the endothelial cells, norepinephrine is rapidly degraded by monoamine oxidase and catechol $O$-methyl transferase (COMT). ${ }^{24}$ In this way, the lungs are capable to regulate the amount of circulating norepinephrine. A decrease of around $20 \%$ in the uptake of MIBG in the lungs was observed both in a rat model after bleomycine ${ }^{6}$ and in a rabbit model after amiodarone-induced pulmonary toxicity. ${ }^{26}$ Because the lung endothelium has no vesicles and cannot store norepinephrine, the clearance of ${ }^{123}$ I-MIBG from the lung is relatively rapid compared to that of the heart. ${ }^{27}$ Of great interest in this respect is the study from Lee et al. ${ }^{28}$ who investigated the characteristics and regulation of ${ }^{123}$ I-MIBG transport in cultured pulmonary endothelial cells. A $50 \%$ percent wash-out was observed after $2 \mathrm{~h}$. This time dependency is of importance and very few studies pay attention to this effect. As seen in Figure 2.2, uptake of MIBG in the lungs, 5 minutes after intravenous injection, has already shown different distribution patterns in patients with sarcoidosis. Lung uptake and washout of MIBG in sarcoidosis is diminished as described by Jonker et al. ${ }^{29}$

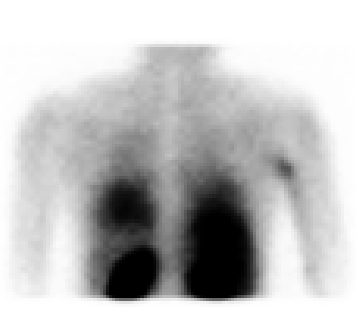

1

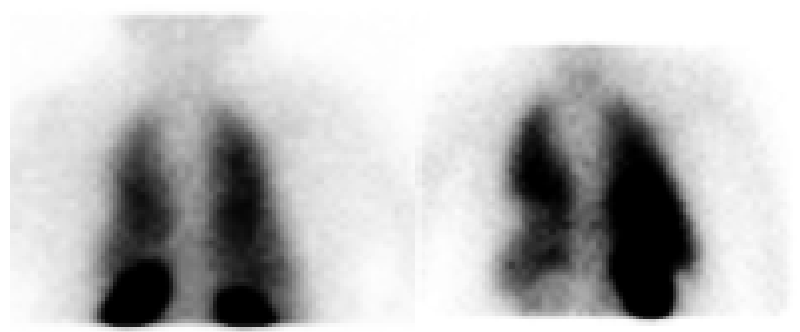

2
3

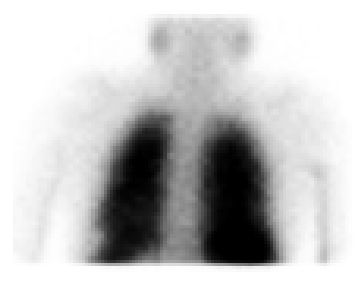

4

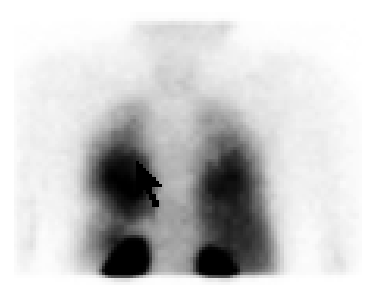

5

Figure 2.2 Dynamic metaiodobenzylguanidine scintigraphy.

Posterior images of the thorax made in five patients with sarcoidosis, directly (5 minutes) after intravenous injection of $185 \mathrm{Mbq}^{123} \mathrm{I}$-metaiodobenzylguanidine (MIBG). Arrows point to the heart uptake of MIBG. Note the different uptake patterns of MIBG in the lungs, reflecting different MIBG uptake in the endothelial cells of the lungs. 
In sarcoidosis and other autoimmune diseases in which cardiac autonomic dysfunction is involved, a change in MIBG uptake can appear. Cardiac sympathetic nerves take up ${ }^{123}$ I-MIBG. This permits visualization of the presynaptic sympathetic innervation of the heart. Defects on MIBG scans in sarcoidosis have been reported ${ }^{30-33}$, but, to date, the underlying mechanism has remained unclear. One possible explanation postulated is that local ischemia or myocardial inflammation may play an important role. Recently, it was found that small fibre neuropathy (SFN) occurs frequently in sarcoidosis. ${ }^{34}$ Moreover, an imbalance in sympathetic tone is considered to increase the propensity for developing ventricular arrhythmias in various cardiac diseases and conditions. ${ }^{35}$ Autonomic dysregulation might contribute to fatal arrhythmias and unexplained sudden death in sarcoidosis. It is known from patients with neuropathy that the involvement of small autonomic nerve fibres is a predictor of cardiovascular mortality. ${ }^{36,37}$ Sudden death is a rare, but dramatic complication. ${ }^{38}$ In the case of sarcoidosis, it is thought to be due mainly to cardiac involvement. Active granulomatous infiltration and resulting myocardial fibrosis are considered to be the substrate. Cardiac sympathetic dysfunction, assessed by use of myocardial ${ }^{123}$ I-MIBG scanning, appears to be heterogeneous in sarcoidosis patients and dependent on the presence or absence of SFN. ${ }^{39}$ In 18 out of $47(38 \%)$ of these cases, mild-to-moderate heterogeneity of ${ }^{123}$ I-MIBG uptake in the myocardium was demonstrated. Cardiac sympathetic nervous system abnormalities detected by ${ }^{123}$ I-MIBG have a predictive power in ventricular tachyarrhythmia, assessing prognosis in patients with chronic heart failure and assessing the risk of sudden death as shown in very recent studies. $^{40-42}$

For correct interpretation of the results of MIBG scintigraphy, one should be aware of drug interference. Many drugs such as opioids, tricyclic antidepressants, sympathomimetics, antihypertensives and some anti-psychotics are known to interfere with the uptake and/or vesicular storage of ${ }^{123}$ I-MIBG and those drugs should be discontinued for an adequate time prior to imaging. ${ }^{43}$

\section{Conclusion}

MIBG uptake and washout is a dynamic process and, therefore, implies appropriate timing for imaging and quantifying the neuronal accumulation. Imaging with MIBG in pulmonary diseases showed different patterns, probably related to disturbances in vascular endothelial function, but probably also related to the used imaging procedures and the vascularization status of the lungs and heart. Focusing on the lungs, we can say that changes in MIBG uptake and excretion can not be reliably differentiated on only one MIBG image, but serial or dynamic images are needed. Till now the imaging procedure has not been standardized, which makes interpretation and judging the clinical value difficult, if not impossible. Standardized, full dynamic acquisition with three-dimensional visualization of the MIBG uptake in the lung area 
has never been performed. With single photon emission computed tomographycomputed tomography (SPECT-CT) or positron emission tomography-computed tomography (PET-CT) with ${ }^{124}$ I-MIBG, we have the tools to perform these studies of dynamic MIBG uptake in the lungs and heart in more detail. Lung perfusion and additional MIBG studies in humans has never been published. However, perfusion and MIBG studies from the heart often show mismatch of images, with normal perfusion of the heart and with clear innervation abnormalities observed by MIBG uptake. In our opinion, MIBG scanning of the lungs and heart is just started. However, the possibilities and instrumentation are available to investigate the relation between neuropathy and pulmonary and cardiac diseases in much more detail. 


\section{References}

1. Sisson JC, Wieland DM, Sherman P, Mangner TJ, Tobes MC, Jacques Jr. S. Metaiodobenzylguanidine as an index of the adrenergic nervous system integrity and function. J Nucl Med 1987;28:1620-4.

2. Nakayo M, Shimabukuro K, Miyaji N, Shimada J, Shirono K, Sakata H, Yoshimura H, Yonekura R, Shinohara S. Rapid clearance if iodine-131 MIBG from the heart and liver in patients with adrenergic dysfunction and pheochromocytoma. J Nucl Med 1985;26:357-65.

3. Sole MJ, Drobac M, Schwartz L, Hussain N, Vaughan-Neil EF. The extraction of circulating catecholamines by the lungs in normal man and in patients with pulmonary hypertension Circulation 1979;60:160-3.

4. Fillenz M. Innervation of pulmonary and bronchial blood vessels. J Anat 1970;106:449-61.

5. Lincoln J, Burnstock G. An introduction to current research. In The Endothelium, Warren J (ed), new York, Wiley-Liss, Inc. 1990:21-32.

6. Miller VM. Interactions between neural and endothelial mechanisms in control of vascular tone. NIPS 1991;6:60-3.

7. Junod AF. 5-hydroxytryptamine and other amines in the lungs. In handbook of physiology. The respiratory system 1. 1985:337-49.

8. Slosman DO, Polla BS and Donath A. ${ }^{123}$ I- MIBG pulmonary removal: a biochemical marker of minimal lung endothelial cell lesions. Eur J Nucl Med 1990;16:633-7.

9. Sakamaki F, Satoh T, Nagaya N, Kyotani S, Nakanishi N, Ishida Y. Abnormality of left ventricular sympathetic nervous function assessed by 1231 -Metaiodobenzylguanidine imaging in patients with COPD. Chest 1999;116:1575-80.

10. Mark AL. Sympathetic dysregulation in heart failure mechanisms and therapy. Clin Cardiology 1995;18:13-18.

11. Arao T, Takabatake N, Sata M, Abe S, Shibata Y, Honma T, Takahashi K, Okada A, Takeishi Y, Kubota I. In vivo evidence of endothelial injury in chronic obstructive pulmonary disease by lung scintigraphic assessment of ${ }^{\mathbf{1 2 3}}$ I-Metaiodobenzylguanidine. J Nucl Med 2003;44:1747-54.

12. Takabatake N, Arao T, Sata M, Abe S, Inoue S, Shibata Y, Takeishi Y, Kubota I. Involvement of pulmonary endothelial cell injury in the pathogenesis of pulmonary fibrosis: clinical assessment by ${ }^{123}$ I-MIBG lung scintigraphy. Eur J Nucl Med Mol Imaging 2005;32:221-8.

13. Yoshiike F, Koizumi T, Urushihata K, Hanaoka M,Kubo K. Reduced lung uptake of lodine-123 Metaiodobenzylguanidine in patients with myeloperoxidase antineutrophil cytoplasmic antibodiespositive vasculitis. Respiration 2006;73:191-6.

14. Kotzumi T, Kubo K, Hanaoka M, Yamamoto H, Yamaguchi S, Fujii T, Kobayashi T. Serial scintigraphic assessment of iodine-123 Metaiodobenzylguanidine lung uptake in a patient with high altitude pulmonary edema. Chest 1999;116:1129-31.

15. Urushihata K, Koizumi T, Hanaoka M, Fujimoto K, Kubo K, Kobayashi T, Fujii T. Reduced lung uptake of iodine-123 metaiodobenzylguanidine in high-altitude pulmonary oedema. Respirology 2008;13: 897-902.

16. Richalet $\mathrm{JP}$, Merlet $\mathrm{P}$, Bourguignon $\mathrm{M}$, Le-Trong $\mathrm{JL}$, Kéromès $\mathrm{A}$, Rathat $\mathrm{C}$, Jouve $\mathrm{B}$, Hot $\mathrm{MA}$, Castaigne A, Syrota A. MIBG scintigraphic assessment of cardiac adrenergic activity in response to altitude hypoxia. J Nucl Med 1990;31:34-7.

17. Suga K, Kume N, Shimizu K, Nishigauchi K, Hara A, Motoyama K, Matsunaga N. Potential of iodine-123 metaiodobenzylguanidine single-photon emission tomography to detect abnormal functional status of the pulmonary neuroadrenergic system in irradiated lung. Eur J Nucl Med 1999;26:647-54.

18. Ünlü M, İnanir S. Prolonged lung retention of lodine-123-MIBG in diabetic patients. J Nucl Med 1998; 39:116-8.

19. Murashima S, Takeda K, Matsumura K, Yamakado K, Sakuma H, Kitano T, Nakagawa T, Ichihara T, Yamakado T, Murata K. Increased lung uptake of lodine-123-MIBG in diabetics with sympathetic Nervous dysfunction. J Nucl Med 1998;39:334-8.

20. Ünlü $M$, Akincioğlu $C$, Yamaç $K$ and Önder M. Pulmonary involvement in Behçet's disease: evaluation of I123-MIBG retention. Nucl Med Comm 2001;22:1083-8. 
21. Mu X, Hasegawa S, Yoshioka J, Maruyama A, Maruyama K, Paul AK, Yamaguchi H, Morozumi T, Hashimoto K, Kusuoka H, Nishimura T. Clinical value of lung uptake of iodine-123 metaiodobenzylguanidine (MIBG), a myocardial sympathetic nerve imaging agent, in patients with chronic failure. Ann nucl Med 2001;15:411-6.

22. Veith RC, Featherstone JA, Linares OA, Halter JR. Age differences in plasma norepinephrine kinetics in humans. J Gerontol 1986;41:319-24.

23. Kanzaki N, Soda R, Takahashi K, Sato K, Hayabara T, Kibata M, Takeda Y, Hiraki Y. Influence of age and gender on iodine-123 MIBG kinetics in normal lung. Ann Nucl Med 1998;12:225-9.

24. Nicholas TE, Strum JM. Angelo LS, Junod AF. Site and mechanism of uptake of 3H-1-norepinephrine by isolated perfused rat lungs. Circ Res 1974;35:670.

25. Sole MJ, Hussain MN. A simple specific radioenzymatic assay for the simultaneously measurement of pictogram quantities of norepinephrine, epinephrine and dopamine in plasma and tissues. Biochem Med 1977;18:301.

26. Durmuş-Altun G, Altun A, Aktas RG, Salihoglu YS, Yigitbasi NO. Use of iodine-123 metaiodobenzylguanidine scintigraphy for the detection of amiodarone induced pulmonary toxicity in a rabbit model: a comparative study with technetium-99m diethyltriaminepenta acetic acid radioaerosol scintigraphy. Ann Nucl Med 2005;19:217-24.

27. Morozumi T, Kusuoka H, Fukuchi K, Tani A, Uehara T, Matsuda S, Tsujimura E, Ito Y, Hori M, Kamada T, Nishimura T. Myocardial lodine-123-metaiodobenzylguanidine images and autonomic nerve activity in normal subjects. J Nucl Med 1997;38:49-52.

28. Lee KH, Ko BH, Paik JY, Jung KH, Bae JS, Choi JY, Choe YS, Kim BT. Characteristics and regulation of 123I-MIBG transport in cultured pulmonary endothelial cells. J Nucl Med 2006;47:437-42.

29. Jonker GJ, Smulders NM, van Kroonenburgh MJ, Halders S, de Vries J, Faber CG, Drent M. Lung-uptake and -washout of MIBG in sarcoidosis. Respir Med 2008;102:64-70.

30. Smulders NM, Bast A, van Kroonenburgh MJ, Drent M. Improvement of cardiac sympathetic nerve function in sarcoidosis. Sarcoidosis Vasc Diffuse Lung Dis 2008;25:140-2.

31. Imai E, Kaminaga T, Takada K, Kutomi K, Furui S. Radioactive defect on I-123 MIBG myocardial SPECT imaging in a patient with cardiac sarcoidosis. Clin Nucl Med 2002;27:729-30.

32. Matsuo S, Nakamura $Y$, Matsui T, Matsumoto T, Kinoshita M. Detection of denervated but viable myocardium in cardiac sarcoidosis with I-123 MIBG and TI-201 SPECT imaging. Ann Nucl Med 2001; 15:373-5.

33. Misumi I, Kimura Y, Hokamura Y, Honda Y, Yasunaga T, Nakashima K, Takemura N, Asoshina M, Uranaka N, Takenaka S, Shima K. Scintigraphic detection of regional disruption of the adrenergic nervous system in sarcoid heart disease. Jpn Circ J 1996;60:774-8.

34. Hoitsma E, Marziniak M, Faber CG, Reulen JP, Sommer C, De Baets M, Drent M. Small fibre neuropathy in sarcoidosis. Lancet 2002;359:2085-6.

35. Wichter T, Matheja P, Eckardt L, Kies P, Schäfers K, Schulze-Bahr E, Haverkamp W, Borggrefe M, Schober O, Breithardt G, Schäfers M. Cardiac autonomic dysfunction in Brugada syndrome. Circulation 2002;105:702-6.

36. Tuck RR, McLeod JG. Autonomic dysfunction in Guillain-Barre syndrome. J Neurol Neurosurg Psychiatry 1981;44:983-90.

37. Ewing DJ, Campbell IW, Clarke BF. Assessment of cardiovascular effects in diabetic autonomic neuropathy and prognostic implications. Ann Intern Med 1980;92:308-11.

38. Ewing DJ, Boland O, Neilson JM, Cho CG, Clarke BF. Autonomic neuropathy, QT interval lengthening, and unexpected deaths in male diabetic patients. Diabetologia 1991;34:182-5.

39. Hoitsma E, Faber CG, van Kroonenburgh MJ, Gorgels AP, Halders SG, Heidendal GA, Kessels AG, Reulen JP, Drent M. Association of small fiber neuropathy with cardiac sympathetic dysfunction in sarcoidosis. Sarcoidosis Vasc Diffuse Lung Dis 2005;22:43-50.

40. Akutsu Y, Kaneko K, Kodamo Y, Li HL, Kawamura M, Asano T, Tanno K, Shinozuka A, Gokan T, Kobashi $Y$. The significance of cardiac sympathetic nervous system abnormality in the long-term prognosis of patients with a history of ventricular tachyarrhytmia. J Nucl Med 2009;50:61-7.

41. Jacobson AF, Lombard J, Banerjee G, Camici PG. ${ }^{123}$ I- MIBG Scintigraphy to predict risk for adverse cardiac outcomes in heart failure patients: Design of two prospective multicenter international trials. J Nucl Cardiol 2009;16:113-21. 
42. Tamaki S, Yamada T, Okuyama Y, Morita T, Sanada S, Tsukamoto Y, Masuda M, Okuda K, Iwasaki Y, Yasui T, Hori M, Fukunami M. Cardiac lodine-123 metaiodobenzylguanidine imaging predicts sudden cardiac death independently of left venrticular ejection fraction in patients with chronic heart failure and left ventricular systolic dysfunction. J Am Coll Cardiol 2009;53:426-35.

43. Bombardieri E, Aktolun C, Baum RP, Bishof-Delaloye A, Buscombe J, Chatal JF, Maffioli L, Moncayo R, Mortelmans L, Reske SN. ${ }^{131} \mathrm{I} /{ }^{123} \mathrm{I}-$ Metaiodobenzylguanidine (MIBG) scintigraphy procedure guidelines for tumour imaging. Eur J Nucl Med Mol Imaging 2003;30:132-9. 


\section{Chapter 3}

Inflammatory activity

assessment by ${ }^{18} \mathrm{~F}$-FDG

$\mathrm{PET} / \mathrm{CT}$ in persistent

symptomatic sarcoidosis
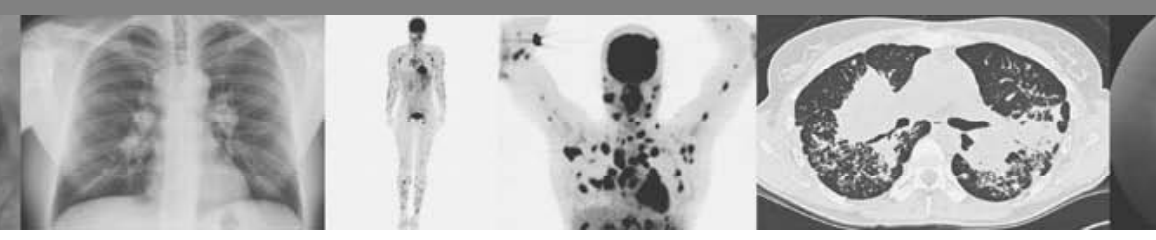

RLM Mostard, S Vöö, MJPG van Kroonenburgh, JA Verschakelen, PAHM Wijnen, PJ Nelemans, RJ Erckens, M Drent

Respir Med 2011;105:1917-1924 


\section{Abstract}

\section{Background}

Establishing inflammatory activity in sarcoidosis patients with persistent disabling symptoms is important. Whole body ${ }^{18}$ F-FDG PET/CT (PET) appeared to be a sensitive method to detect inflammatory activity in newly diagnosed symptomatic sarcoidosis. The aim was to assess the presence of inflammatory activity using PET in sarcoidosis patients with unexplained persistent disabling symptoms and the association between PET findings and serological inflammatory markers.

\section{Methods}

Sarcoidosis patients who underwent a PET between June 2005 and June $2010(n=89)$, were retrospectively included. All PET scans were examined and positive findings were classified as thoracic and/or extrathoracic. As serological markers of inflammatory activity angiotensinconverting enzyme (ACE), soluble interleukin-2 receptor (sIL-2R), and neopterin were considered.

\section{Results}

In $65 / 89$ (73\%) of the studied patients PET was positive, 52 of them ( $80 \%$ ) had serological signs of inflammatory activity. PET was positive in $14 / 15$ patients with chest radiograph stage IV. In $80 \%$ of the PET-positive patients extrathoracic inflammatory activity was found. Sensitivity of combined serological inflammatory markers for the presence of inflammatory activity as detected by PET was $80 \%$, specificity $100 \%$, positive predictive value $100 \%$, negative predictive value $65 \%$.

\section{Conclusions}

The majority of sarcoidosis patients with persistent disabling symptoms, even those with radiological stage IV, had positive PET findings with remarkably $80 \%$ extrathoracic lesions. In $20 \%$ PET was positive without signs of serological inflammatory activity. PET appeared to offer added value in assessing inflammatory activity in patients with persistent symptoms in the absence of signs of serological inflammatory activity, as well as in detecting extrathoracic lesions. 


\section{Introduction}

Sarcoidosis is a multisystemic disease characterized by activity of cellular immunity with formation of noncaseating granuloma in various organ systems. ${ }^{1}$ Establishing the presence of inflammatory activity is helpful in monitoring the course of sarcoidosis and in the follow-up of the effect of treatment. ${ }^{2-4}$ In contrast to acute sarcoidosis, ${ }^{5,6}$ assessment of inflammatory activity in sarcoidosis patients with persistent disabling symptoms remains a challenge for the clinician.

The assessment of inflammatory activity by clinical and radiographic features can be complicated by the fact that other organs than evaluated might be involved. Symptoms like fatigue can be nonspecific and difficult to objectify. ${ }^{7-9}$ Furthermore, symptoms like coughing and dyspnea might be related to ongoing inflammatory activity as well as to end-stage disease, i.e. pulmonary fibrosis. It is important to be informed about the presence or absence of inflammatory activity as fibrosis itself is irreversible. In general, patients with fibrosis without ongoing inflammatory activity are supposed not to benefit from immunosuppressive treatment. ${ }^{7}$ A technique, able to evaluate the presence of inflammatory activity per organ system, is therefore desirable.

Inflammatory activity is characterized by ongoing T-cell and macrophage activity and granuloma formation, reflected by an increase of serological markers of inflammatory activity, i.e. angiotensin-converting enzyme (ACE), soluble interleukin-2 receptor (sIL-2R) and neopterin, or abnormality in glucose metabolism., ${ }^{6,10,11}$ The reported sensitivity and specificity of ACE, produced in granuloma is moderate, even if corrected for genotype (ACE polymorphism). ${ }^{12,13}$ sIL-2R, mainly secreted by activated T-cells, is elevated in patients with active sarcoidosis. ${ }^{5,14,15}$ Neopterin represents activation of the monocyte/macrophage system, and is found to be increased in active disease as well. ${ }^{5,14,15}$ Although the value of these separate markers for assessing disease activity has been studied, the value of combining these serological markers is unknown. ${ }^{5,14-18}$

${ }^{18}$ F-FDG PET/CT (PET) is used for detecting high glucose metabolism in malignancies, infectious diseases and fever of unknown origin. ${ }^{10,11,19}$ High uptake of ${ }^{18} \mathrm{~F}$-FDG has also been reported in patients with sarcoidosis., ${ }^{60-22}$ Presumably inflammatory cells including activated macrophages, lymphocytes and neutrophils are responsible for the accumulation of FDG. ${ }^{19,23-25}$ To date, an increase of the number of neutrophils in bronchoalveolar lavage (BAL) fluid was found to be associated with an unfavorable outcome. ${ }^{5,26}$ According to these findings it is tempting to speculate that increased FDG uptake in the pulmonary parenchyma is associated not only with inflammatory activity but also with disease severity.

Recently, the value of PET in assessing inflammatory activity in newly diagnosed, symptomatic sarcoidosis patients was shown with a high (94\%) sensitivity. ${ }^{6}$ However, the potential of PET to depict inflammatory activity in patients with persistent disabling symptoms has to be established. The aim of this retrospective study was to 
assess the presence of inflammatory activity using PET in sarcoidosis patients with unexplained persistent disabling symptoms for at least one year and the association between PET findings and serological inflammatory markers.

\section{Materials and methods}

\section{Study population}

Between June 2005 and June 2010 a PET was performed in 122/512 sarcoidosis patients referred to the interstitial lung disease service (ild care team) of the department of Respiratory Medicine at the Maastricht University Medical Centre (Maastricht, The Netherlands), a tertiary referral center. The indication for the PET was the presence of unexplained disease related disabling symptoms that persisted for at least one year. Persistent disabling symptoms were defined as the presence of more than one symptom that had substantial influence on quality of life, and that could not be explained with the results of routine investigations including the absence of lung functional or chest radiographic deterioration. These symptoms included fatigue (Fatigue Assessment Scale (FAS) $\geq 22$ ) $^{27}$, symptoms compatible with small fiber neuropathy (SFN; SFN Screenings List (SFNSL) score $\geq 11)^{28}$, arthralgia and/or muscle pain, dyspnea (MRC dyspnea scale $\geq 3$ ), exercise intolerance or coughing. Laboratory testing, lung function testing and a chest radiography (CXR) were performed within an interval of less than two weeks of the PET scanning. Blood samples were simultaneously obtained. In the routine workup all patients completed the FAS ${ }^{27}$ and the SFNSL. ${ }^{28}$ Sarcoidosis was proven by the presence of noncaseating granulomas on biopsy according with a compatible clinical picture. Moreover, other causes of granulomatous disease were excluded, according with the consensus statement on sarcoidosis of the American Thoracic Society (ATS)/European Respiratory Society (ERS)/World Association of Sarcoidosis and Other Granulomatous Disorders (WASOG). ${ }^{1}$ Exclusion criteria were the coexistence of other diseases that are able to cause PET-positive findings. Therefore, five patients with common variable immunodeficiency (CVID), five patients with malignancy and one patient with both rheumatoid arthritis and amyloidosis were excluded. After exclusion for these criteria, 111 patients were selected. Due to an inappropriate interval between PET scanning and obtaining blood samples another 22 patients were excluded. Finally, 89 patients were included. Inflammatory activity was considered to be present in case the PET demonstrated positive findings. Relevant clinical data were gathered retrospectively. All patients signed an informed consent. 


\section{Laboratory tests}

Serum ACE was measured by colorimetric method (cat. no. FU 116; Fujirebio Inc.). The imprecision of the ACE assay was $<5.6 \%$ and the reference interval 9-25 $\mathrm{U} / \mathrm{I}$.

Serum levels of sIL-2R were analyzed in commercially available Diaclone ELISA kits (Sanquin, Amsterdam, The Netherlands). Normal values were assessed in 40 healthy controls mean \pm 2 SD: $240-3154 \mathrm{pg} / \mathrm{ml}$. Serum levels of neopterin were evaluated by the principle of a competitive ELISA, using a kit produced by IBL (Hamburg, Germany). Serum levels were considered elevated if $>2.5 \mathrm{ng} / \mathrm{ml}$.

Results for combined serological inflammatory marker testing (ACE, sIL-2R and neopterin) were considered positive if at least one of the serological markers was elevated.

CRP was measured using a turbidimetric method performed using the Beckman synchron CX-7 system (kit 465231; Mijdrecht, The Netherlands. The detection limit for CRP was $2 \mu \mathrm{g} / \mathrm{ml}$, with a normal range of $2-9 \mu \mathrm{g} / \mathrm{ml}$.

\section{Radiology}

According to the Scadding radiographic staging system, five stages of radiographic abnormality were recognized: stage 0 (normal CXR), stage I (bilateral hilar lymphadenopathy $(\mathrm{BHL})$ ), stage II (BHL and parenchymal abnormalities), stage III (parenchymal abnormalities without BHL) and stage IV (end stage lung fibrosis). ${ }^{1}$

\section{Lung function tests}

Forced vital capacity (FVC) was measured with a pneumotachograph (Masterlab, Jaeger, Würzburg, Germany). The diffusing capacity for carbon monoxide (DLCO) was measured by the single-breath method (Masterlab, Jaeger, Würzburg, Germany). Values were expressed as a percentage of predicted values. ${ }^{29}$

\section{${ }^{18}$ F-FDG PET/CT}

A fluorine18-fluorodeoxyglucose positron emission tomography/computed tomography $\left({ }^{18}\right.$ F-FDG PET/CT) scan was performed. Patients were scanned using a Gemini PET/CT (Philips Medical Systems) scanner with time-of-flight (TOF) capability, together with a 64-slice Brilliance CT scanner. This scanner has a transverse and axial Field of View (FOV) of, respectively 57.6 and $18 \mathrm{~cm}$. The spatial resolution is around $5 \mathrm{~mm}$.

Patients were fasting for at least 6 hours before the examination. In all patients blood glucose was measured to ensure that the blood glucose was below $10 \mathrm{mmol} / \mathrm{l}$. ${ }^{18}$ F-FDG (GE Health, Eindhoven, The Netherlands) was injected intravenously and followed by physiologic saline $(10 \mathrm{ml})$. The injected total activity of FDG depended on the weight of the patient. Mean injected dose was: $200 \mathrm{MBq}$. After a resting period of 45 minutes (time needed for uptake of FDG) PET and CT images were acquired from the head to the feet. A low dose CT scan was performed without intravenous contrast and was used for attenuation correction of the PET images. The PET images were 
acquired in 5-minute bed positions. The complete PET data set was reconstructed iteratively with a reconstruction increment of $5 \mathrm{~mm}$ to provide isotropic voxel.

All PET scans were examined independently and blindly by two experienced nuclear physicians (MvK and SV) to assess the inter-observer variability. Findings were scored as either positive or negative. PET findings were described as positive if increased FDG-uptake was seen in the mediastinum and/or lung parenchyma or on extrathoracic sites like lymph nodes, visceral organs (like parotid glands, liver, spleen), nasopharynx, skin, muscle, and bone. Positive findings were classified as thoracic and/or extrathoracic. Positive thoracic PET findings were subdivided as positive PET findings in the pulmonary parenchyma and/or mediastinal lymph nodes. The maximum standardized uptake value (SUVmax) was measured at the various PETpositive lesions.

\section{Statistical procedure}

Statistical analyses were performed using SPSS, version 15.0 for Windows. Differences between groups in demographic characteristics and clinical characteristics (such as duration of disease and pulmonary function tests) were tested for statistical significance using the Student's t-test for independent samples in case of continuous variables or chi-square test in case of categorical variables. A p-value of $<0.05$ (two sided) was considered to indicate statistical significance. ROC analysis was performed for assessing the association between PET-positive results and the results of the separate serological markers. As a measure of internal consistency and reliability to assess the inter-observer agreement, kappa statistics were used. A k-value less than 0.20 indicates poor, between 0.21 and 0.40 moderate, between 0.41 and 0.60 fair, between 0.61 and 0.80 good and between 0.81 and 1.00 excellent agreement, respectively.

\section{Results}

\section{General clinical characteristics}

Disabling symptoms of the 89 studied patients ( 81 Caucasians, 6 of African origin and 2 of Asian origin) included fatigue (80\%; FAS $\geq 22$ ), symptoms compatible with small fiber neuropathy (SFN; 70\%; SFNSL score $\geq 11$ ), arthralgia and/or muscle pain (59\%), dyspnea (45\%; MRC dyspnea scale $\geq 3$ ), exercise intolerance (38\%) or coughing (21\%). Treatment at admission (20 cases: $22.5 \%$ ) consisted of prednisone alone (median dose $15 \mathrm{mg}$ daily (range $10-40 \mathrm{mg}$ ) in nine patients (10\%), methotrexate (MTX) alone (median dose $10 \mathrm{mg}$ a week (range 7.5-12.5 mg)) in four patients (4\%), prednisone combined with MTX (all patients $10 \mathrm{mg}$ prednisone daily and median dose MTX $10 \mathrm{mg}$ a week (range 10-12.5 mg)) in seven patients (8\%). 


\section{PET scan results}

A summary of the demographic and clinical characteristics of the 89 studied sarcoidosis patients subdivided in PET-negative $(n=24: 27 \%)$ and PET-positive $(n=65$ : 73\%) cases is shown in Table 3.1. Ninety-two \% of these latter patients demonstrated thoracic positive PET findings, $80 \%$ one or more extrathoracic lesion(s), whereas $8 \%$ only extrathoracic lesions, respectively. The involved extrathoracic organs included peripheral lymph nodes $(n=48)$, bone $(n=14)$, spleen $(n=11)$, muscle $(n=10)$ liver $(n=6)$, skin $(n=2)$, and central nervous system $(n=2)$, respectively. No correlation between serologic inflammatory markers and the various involved extrathoracic organs was found. Analysis of the group with extrathoracic lesions compared with the group with exclusively positive thoracic PET findings showed no significant differences regarding serological markers or other patient characteristics.

Table 3.1 Summary of relevant clinical characteristics of the studied sarcoidosis patients divided according to the absence $(n=24)$ and presence $(n=65)$ of PET abnormalities and subdivided in a treatment and no treatment group.

\begin{tabular}{|c|c|c|c|c|c|c|}
\hline & \multicolumn{3}{|c|}{ PET-negative patients } & \multicolumn{3}{|c|}{ PET-positive patients } \\
\hline & $\begin{array}{l}\text { total PET - } \\
\text { population }\end{array}$ & treatment & no treatment & $\begin{array}{l}\text { total PET + } \\
\text { population }\end{array}$ & treatment & no treatment \\
\hline number & 24 & 6 & 18 & 65 & 14 & 51 \\
\hline age, yrs & $49(24-73)$ & $44(33-55)$ & $50(24-73)$ & $45(26-76)$ & $48(28-66)$ & $44(26-76)$ \\
\hline sex (male) & $15(63 \%)$ & $2(33 \%)$ & $13(72 \%)$ & $35(54 \%)$ & $9(64 \%)$ & $26(51 \%)$ \\
\hline time since diagnosis, yrs & $4(1-14)$ & $1(1-13)$ & $7(1-14)$ & $2(1-27)$ & $3(1-19)$ & $1(1-27)$ \\
\hline BMI & $27.7 \pm 4.9$ & $26.7 \pm 3.9$ & $28.0 \pm 5.2$ & $28.1 \pm 5.6$ & $28.0 \pm 3.8$ & $28.5 \pm 6.1$ \\
\hline Chest $\mathrm{X}$-ray stage $0 / \mathrm{I} / \mathrm{II} / \mathrm{III} / \mathrm{IV}$ & $16 / 2 / 3 / 2 / 1$ & $3 / 0 / 2 / 1 / 0$ & $13 / 2 / 1 / 1 / 1$ & $8 / 17 / 24 / 2 / 14$ & $1 / 3 / 3 / 0 / 7$ & $7 / 14 / 21 / 2 / 7$ \\
\hline Thoracic PET + & 0 & 0 & 0 & $60(92 \%)$ & $14(100 \%)$ & $46(90 \%)$ \\
\hline Mediastinal lymph nodes & 0 & 0 & 0 & $54(83 \%)$ & $12(86 \%)$ & $42(82 \%)$ \\
\hline \multicolumn{7}{|l|}{$\mathrm{PET}+$} \\
\hline Pulmonary parenchyma & 0 & 0 & 0 & $43(66 \%)$ & $10(71 \%)$ & $33(65 \%)$ \\
\hline \multicolumn{7}{|l|}{ PET + } \\
\hline extrathoracic PET+ & 0 & 0 & 0 & $52 / 65(80.0 \%)$ & $10(71 \%)$ & $42(82 \%)$ \\
\hline FVC (\% pred) & $101 \pm 19$ & $90 \pm 21$ & $105 \pm 18$ & $91 \pm 26$ & $74 \pm 20$ & $96 \pm 25$ \\
\hline DLCO (\% pred) & $80 \pm 15$ & $75 \pm 8$ & $82 \pm 16$ & $71 \pm 19$ & $58 \pm 19$ & $76 \pm 17$ \\
\hline ACE (9-25 U/I) & $17 \pm 4$ & $13 \pm 3.0$ & $18 \pm 4$ & $21 \pm 6$ & $21 \pm 5$ & $21 \pm 7$ \\
\hline sIL-2R (240- $3154 \mathrm{pg} / \mathrm{ml})$ & $1599 \pm 671$ & $1275 \pm 633$ & $1706 \pm 666$ & $4526 \pm 2577^{*}$ & $4340 \pm 2438^{*}$ & $4577 \pm 2634^{*}$ \\
\hline $\begin{array}{l}\text { Neopterin } \\
(<2.5 \mathrm{ng} / \mathrm{ml} ; \mathrm{n}=62)\end{array}$ & $1.7 \pm 0.4$ & $1.5 \pm 0.7$ & $1.7 \pm 0.3$ & $3.2 \pm 1.6^{*}$ & $2.8 \pm 1.0^{*}$ & $3.3 \pm 1.7^{*}$ \\
\hline $\operatorname{CRP}(2-9 \mu \mathrm{g} / \mathrm{ml} ; \mathrm{n}=85)$ & $4.3 \pm 4.2$ & $4.7 \pm 4.6$ & $4.1 \pm 4.2$ & $11.9 \pm 16.1^{* *}$ & $9.6 \pm 11.2$ & $12.5 \pm 17.3$ \\
\hline
\end{tabular}

Data are presented as median with range in parentheses; mean $\pm \mathrm{SD}$; absolute numbers or percentages if appropriate. PET: positron emission tomography; -: negative; +: positive; yrs: years; BMI: Body Mass Index; FVC: forced vital capacity; \% pred: percentage of predicted values; DLCO: diffusion capacity for carbon monoxide; ACE: serum angiotensin-converting enzyme; sIL-2R: soluble interleukin-2 Receptor; CRP: C-reactive protein. ${ }^{*} p<0.001$ PET+ versus PET-; ** $p<0.05$ PET+ versus PET-.

Eight of the patients with CXR stage 0 (33\%) demonstrated positive PET findings. Only four of them had exclusively extrathoracic lesions and only three had serological signs of inflammation. 
Only one of the included patients with CXR stage IV $(n=15)$ was PET-negative. Thirteen of the PET-positive patients with CXR stage IV were positive in the pulmonary parenchyma and 10 demonstrated extrathoracic lesions. The majority (85\%) of the PET-positive patients with CXR stage IV had serological signs of inflammation. An example of a patient with CXR stage IV and signs of pulmonary inflammatory activity is shown in Figure 3.1.

The inter-observer agreement concerning the PET scores is shown in Table 3.2. Median SUV of the PET-positive lesions was 7.0 (2.5-33.3).

a

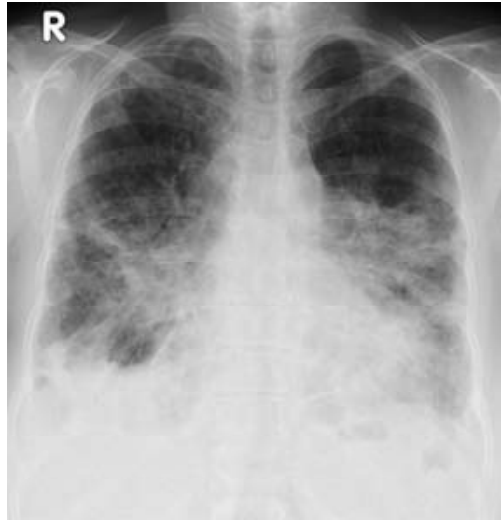

b

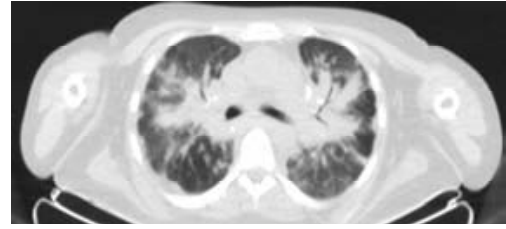

C

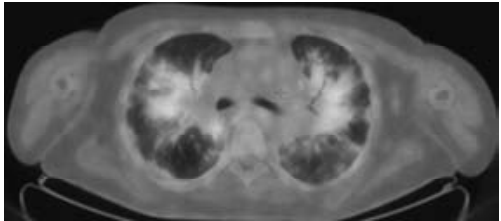

d

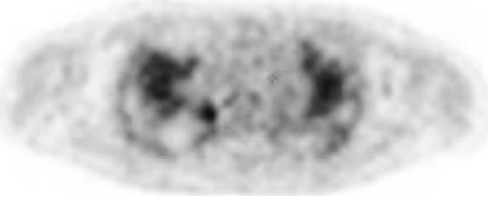

Figure 3.1 Example of a sarcoidosis patient with Chest X-ray stage IV and signs of inflammatory activity on PET/CT. a. Chest X-ray showing bilateral irregular opacities and some surrounding lung deformation. b. CT-scan image at thoracic level showing bilateral perihilar opacities, bilateral hilar and mediastinal lymphadenopathy with calcifications and deformation of the surrounding lung architecture. c. PET/CT fusion image at thoracic level showing diffuse increased FDG-uptake in the bilateral perihilar opacities. d. PET image at thoracic level showing diffuse bilateral increased FDG-uptake in the pulmonary parenchyma.

Table 3.2 Inter-observer agreement concerning PET scores.

\begin{tabular}{lc}
\hline & Weighted kappa \\
\hline PET-positivity & 1.000 \\
Thoracic PET-positivity & 0.975 \\
Mediastinal lymph nodes PET-positivity & 0.931 \\
Pulmonary parenchyma PET-positivity & 0.912 \\
Extrathoracic PET-positivity & 1.000 \\
\hline
\end{tabular}

PET: positron emission tomography. 


\section{Serological inflammatory markers and PET results}

Mean ACE levels were calculated after exclusion of ACE values $<9 \mathrm{U} / \mathrm{I}(n=9)$, because these values were under the lower limit of the reference value and due to the use of ACE-inhibitors. Neopterin values were only available in 62 patients (70\%). Levels of sIL-2R and neopterin differed significantly between the PET positive and PET negative group ( $p<0.001$; Table 3.1). None of the PET-negative patients had serological signs of inflammation, whereas $13(20 \%)$ of the PET-positive patients had no serological signs of inflammation (Table 3.3).

Table 3.3 The association between PET results and serological inflammatory activity markers.

\begin{tabular}{lcc}
\hline Marker & PET - & PET + \\
\hline Serum angiotensin-converting enzyme (ACE) & & 65 \\
$\quad$ number & 24 & $78 \%(n=51)$ \\
ACE $-(n=75)$ & $100 \%(n=24)$ & $22 \%(n=14)$ \\
ACE $+(n=14)$ & $0 \%(n=0)$ & 65 \\
Soluble interleukin-2 receptor (sIL-2R) & & $32 \%(n=21)$ \\
number & 24 & $68 \%(n=44)$ \\
sIL-2R $-(n=45)$ & $100 \%(n=24)$ & \\
sIL-2R $+(n=44)$ & $0 \%(n=0)$ & 42 \\
Neopterin & & $36 \%(n=15)$ \\
number & 20 & $64 \%(n=27)$ \\
Neopterin $-(n=35)$ & $100 \%(n=20)$ & 65 \\
Neopterin $+(n=27)$ & $0 \%(n=0)$ & $20 \%(n=13)$ \\
Combined serological inflammatory markers (CIM) & & $80 \%(n=52)$ \\
number & 24 & 62 \\
CIM $-(n=37)$ & $100 \%(n=24)$ & $68 \%(n=42)$ \\
CIM $+(n=52)$ & $0 \%(n=0)$ & $32 \%(n=20)$ \\
C-reactive protein (CRP) & & 23 \\
number & $83 \%(n=19)$ & \\
CRP $-(n=61)$ & $17 \%(n=4)$ & \\
CRP $+(n=24)$ & & \\
\hline
\end{tabular}

PET: positron emission tomography; -: negative; +: positive; n: number; Combined serological inflammatory markers: defined as positive if at least one serological marker (ACE, sIL-2R or neopterin) was elevated.

ROC analysis results for the association between PET-positive results and the results of the separate serological markers are presented in Figure 3.2. Overall, the area under the curve (AUC) of sIL-2R and neopterin is significantly different from the nullhypothesis, true area $=0.5$ (meaning no discrimination). Sensitivity and specificity of both the separate and the combined results of the serological inflammatory markers for detecting inflammatory activity as shown by PET is demonstrated in Table 3.3. The sensitivity of combined results of the serological markers was $80 \%$. Specificity was $100 \%$ for all serological markers. Positive predictive value (PPV) was $100 \%$ in all cases. Negative predictive value of combined results of the serological markers was $65 \%$. As shown in Table 3.3, adding CRP to the serological inflammatory classification would 
increase the sensitivity, but decrease the excellent specificity and PPV of the combined serological markers.

Analysis of the relation between levels of the studied serological markers and the CXR stages in the patients with positive PET findings in the pulmonary parenchyma showed no significant differences. In the group with positive PET findings in the pulmonary parenchyma, DLCO and FVC were significantly lower in the patients with CXR stage IV compared with the other CXR stages. Comparison of clinical or laboratory parameters between PET-positive CXR stage IV patients $(n=14)$ and PET-negative CXR stage IV patients $(n=1)$ was not possible due to the low number in the latter group.

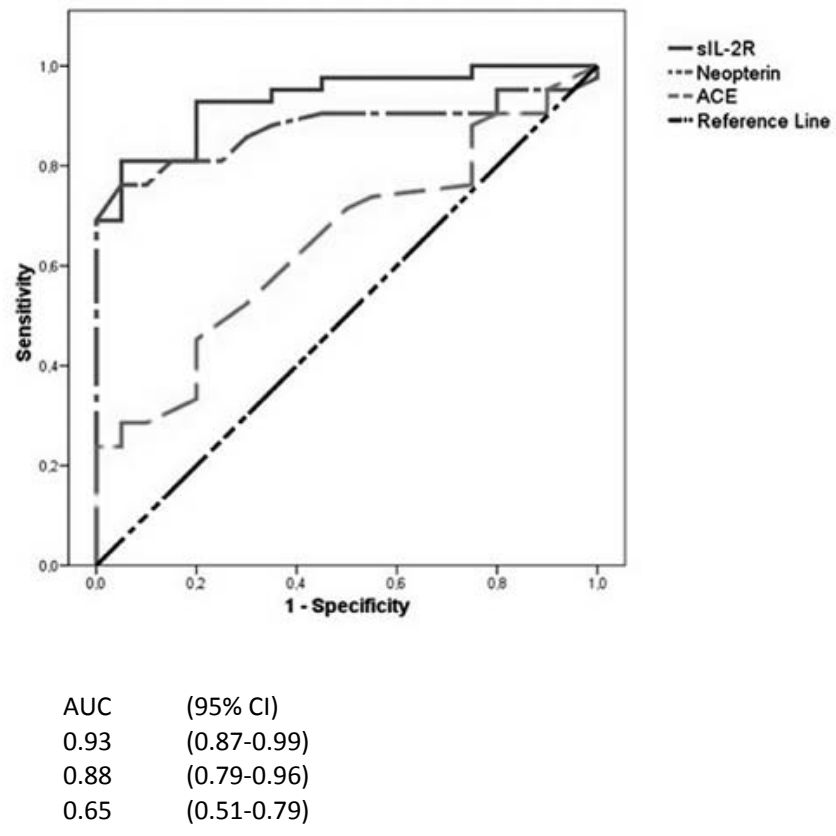

Figure 3.2 Receiver operating characteristic (ROC) curve of the association between PET-positive results and serological inflammatory activity marker separately. SIL-2R: soluble interleukin-2 Receptor; ACE: serum angiotensin-converting enzyme; AUC: area under the curve; $\mathrm{Cl}$ : confidence interval

\section{Discussion}

This study demonstrated that the majority of sarcoidosis patients with unexplained persistent disabling symptoms had signs of inflammatory activity detected by positive PET findings. Positive PET findings were associated with increased levels of serological inflammatory parameters in sarcoidosis, especially with sIL-2R and neopterin levels. 
Positive predictive value of serological inflammatory marker testing for the presence of inflammatory activity on PET was excellent (100\% in this study). However, negative predictive value of serological inflammatory marker testing, even if the results were combined, was moderate.

Assessing inflammatory activity in sarcoidosis patients without lung functional or radiological deterioration but with unexplained persistent disabling symptoms often is problematic. In this study, the value of PET for assessment of inflammatory activity in this difficult category of patients is demonstrated since almost $75 \%$ of the patients with persistent disease related symptoms had signs of inflammatory activity as detected by PET. Although the study design and population was not completely comparable this was in line with the results of Teirstein et al. ${ }^{20}$ It is important to stress that either normal CXR findings (stage 0) or CXR stage IV (and thus signs of fibrosis) do not exclude inflammatory activity in the pulmonary parenchyma. The latter still harbours significant inflammatory lesions that might be target, together with respiratory functional impairment, for appropriate treatment. Because of the radiation dose and expense of performing PET, measurement of serological inflammatory markers should be, after excluding lung functional or radiological deterioration, first performed for assessing inflammatory activity in sarcoidosis patients with unexplained persistent disabling symptoms. Using the strategy of combining serological marker testing provided enough information to determine the presence of inflammatory activity in $58 \%$ of the studied patients (52/89). However, since the negative predictive value of serological marker testing is moderate $(65 \%)$, negative serological test results do not exclude the presence of inflammatory activity and therefore PET offers added value in assessing inflammatory activity in sarcoidosis patients with persistent symptoms in the absence of serological signs of inflammatory activity.

In contrast with Grutters et al. $^{15}$, no association between sIL-2R levels and extrathoracic lesions was found in our population. A possible explanation would be that the prevalence of extrathoracic lesions in our study was higher, which could be due to a better sensitivity of PET for detecting extrathoracic lesions than the sensitivity of the used diagnostic techniques (no use of PET or Gallium scanning) in the latter study to detect extrathoracic lesions. The prevalence of extrathoracic lesions in the PET-positive patients in our study is comparable to the prevalence found in other studies using PET in active sarcoidosis. ${ }^{6,22}$ Although determination of the frequency of extrathoracic sarcoidosis lesions was not the aim of this study, the established high frequency of these findings shows that this is another merit of performing PET (assessing extent of the disease).

The disabling symptoms in the 24 PET-negative patients can be caused by multiple factors. ${ }^{9,30,31}$ Sleeping disorders may interact with fatigue in sarcoidosis. ${ }^{32}$ Twenty four of the included patients $(n=89)$ in the present study were evaluated for the presence or absence of an obstructive sleep apnea syndrome (OSAS). Five of these patients appeared to have an OSAS. However, these patients still suffered from disabling 
symptoms, including fatigue, despite adequate treatment for their OSAS. PET appeared to be positive in all these patients, showing that inflammatory activity was still present (data not shown).

In the Sarcoidosis Investigators study, results of the post hoc analysis suggested a greater benefit of infliximab therapy in patients with more severe disease. ${ }^{33}$ This indicates the importance of establishing inflammatory activity in patients with CXR stage IV disease since it may have therapeutic implications and thus this underlines the value of PET especially in this group of chronic sarcoidosis patients. However, the exact value of the presence of inflammatory activity for treatment decisions needs to be established in future studies. A study in a small cohort of sarcoidosis patients treated with infliximab showed that changes in PET-imaging correlated with clinical signs of improvement to a considerable extent. ${ }^{4}$ Apart from the value of PET-imaging in treatment decisions or follow-up, simply validating that there is an organic cause for the symptoms can be extremely reassuring to many patients. ${ }^{34}$

Since this was a retrospective study and BAL was infrequently performed close to the date of the PET, we only have gathered data on BAL fluid analysis of 20 PET-positive patients of whom 6 appeared to have stage IV disease on chest X-ray. All 20 cases showed signs of inflammation in the BAL fluid (increased number of lymphocytes as well as polymorphonuclear neutrophils, indicating disease severity). ${ }^{5,26}$ These signs were even more prominent in the 6 cases with chest X-ray stage IV (data not shown). This is in line with Keijsers et al. ${ }^{23}$ who found that increased FDG uptake in the pulmonary parenchyma correlated with the number of neutrophils in BAL fluid of sarcoidosis patients.

Several attempts to define disease activity in sarcoidosis have been undertaken. However, no single marker available can accurately predict the likelihood of activity or progression. ${ }^{3,16}$ Comparing PET results with pulmonary function and CXR only addresses pulmonary involvement and does not provide any information about the presence or absence of systemic inflammatory activity. Since PET can be considered as a useful additional tool in the evaluation of systemic sarcoidosis, comparison with the already existing markers of systemic inflammatory activity is needed. Although we are aware of the limitations of serological markers, these were in the present clinical study the most appropriate.

Our centre is a referral centre for sarcoidosis, and, therefore the refractory character may be more severe than in a general sarcoidosis population. Moreover, PET was not performed in every referred patient. This might cause a selection bias. However, a PET scan was really not necessary in every patient. The questions and reasons for referring the patients to our interstitial lung disease service were very divers. It varied from a therapeutic advice in refractory sarcoidosis like hypercalcemia, uveitis or severe respiratory impairment not responding to corticosteroids to questions about genetic issues or occupational exposures. In these patients a PET was not indicated to answer the questions appropriately. That does not mean the patients had less severe sarcoidosis, however. The subpopulation that did not have a PET scan did not differ 
from the population who underwent a PET regarding clinical data (data not shown). Although no other diseases that are able to cause positive PET findings were diagnosed during the follow-up, other causes of positive PET findings cannot be excluded completely.

In conclusion, PET appeared to offer added value in assessing inflammatory activity in sarcoidosis patients with unexplained persistent disabling symptoms in the absence of serological signs of inflammation. In almost $75 \%$ of these sarcoidosis patients PET was positive, with the presence of extrathoracic lesions in $80 \%$ of them. Remarkably, the majority of patients with radiological stage IV disease had positive PET findings. Combining results of serological inflammatory markers increased sensitivity for detecting inflammatory activity in sarcoidosis without false positive results. Future studies are needed to evaluate the added value of PET in the follow-up and management of the disease. 


\section{References}

1. Hunninghake GW, Costabel U, Ando M, Baughman R, Cordier JF, du Bois R, Eklund A, Kitaichi M, Lynch J, Rizzato G, Rose C, Selroos O, Semenzato G, Sharma OP. ATS/ERS/WASOG statement on sarcoidosis. American Thoracic Society/European Respiratory Society/World Association of Sarcoidosis and other Granulomatous Disorders. Sarcoidosis Vasc Diffuse Lung Dis 1999;16:149-73.

2. Baughman RP, Lower EE, Drent M. Inhibitors of tumor necrosis factor (TNF) in sarcoidosis: who, what, and how to use them. Sarcoidosis Vasc Diffuse Lung Dis 2008;25:76-89.

3. Consensus conference: activity of sarcoidosis. Third WASOG meeting, Los Angeles, USA, September 811, 1993. Eur Respir J 1994;7:624-7.

4. Keijsers RG, Verzijlbergen JF, van Diepen DM, van den Bosch JM, Grutters JC. 18F-FDG PET in sarcoidosis: an observational study in 12 patients treated with infliximab. Sarcoidosis Vasc Diffuse Lung Dis 2008;25:143-9.

5. Ziegenhagen MW, Rothe ME, Schlaak M, Muller-Quernheim J. Bronchoalveolar and serological parameters reflecting the severity of sarcoidosis. Eur Respir J 2003;21:407-13.

6. Keijsers RG, Verzijlbergen FJ, Oyen WJ, van den Bosch JM, Ruven HJ, van Velzen-Blad H, Grutters JC. 18F-FDG PET, genotype-corrected ACE and sIL-2R in newly diagnosed sarcoidosis. Eur J Nucl Med Mol Imaging 2009;36:1131-7.

7. Lazar CA, Culver DA. Treatment of sarcoidosis. Semin Respir Crit Care Med 2010;31:501-18.

8. De Vries J, Rothkrantz-Kos S, van Dieijen-Visser MP, Drent M. The relationship between fatigue and clinical parameters in pulmonary sarcoidosis. Sarcoidosis Vasc Diffuse Lung Dis 2004;21:127-36.

9. Marcellis RG, Lenssen AF, Elfferich MD, De Vries J, Kassim S, Foerster K, Drent M. Exercise capacity, muscle strength and fatigue in sarcoidosis. Eur Respir J 2011;38:628-34.

10. Love C, Tomas MB, Tronco GG, Palestro CJ. FDG PET of infection and inflammation. Radiographics 2005;25:1357-68.

11. El-Haddad G, Zhuang H, Gupta N, Alavi A. Evolving role of positron emission tomography in the management of patients with inflammatory and other benign disorders. Semin Nucl Med 2004;34:313-29.

12. Biller H, Zissel G, Ruprecht B, Nauck M, Busse Grawitz A, Müller-Quernheim J. Genotype-corrected reference values for serum angiotensin-converting enzyme. Eur Respir J 2006;28:1085-90.

13. Tomita $H$, Ina $Y$, Sugiura $Y$, Sato $S$, Kawaguchi $H$, Morishita $M$, Yamamoto $M$, Ueda R. Polymorphism in the angiotensin-converting enzyme (ACE) gene and sarcoidosis. Am J Respir Crit Care Med 1997;156:255-9.

14. Ziegenhagen MW, Benner UK, Zissel G, Zabel P, Schlaak M, Müller-Quernheim J. Sarcoidosis: TNFalpha release from alveolar macrophages and serum level of sIL-2R are prognostic markers. $\mathrm{Am} J$ Respir Crit Care Med 1997;156:1586-92.

15. Grutters JC, Fellrath JM, Mulder L, Janssen R, van den Bosch JM, van Velzen-Blad H. Serum soluble interleukin-2 receptor measurement in patients with sarcoidosis: a clinical evaluation. Chest 2003;124:186-95.

16. Prasse A, Katic C, Germann M, Buchwald A, Zissel G, Müller-Quernheim J. Phenotyping sarcoidosis from a pulmonary perspective. Am J Respir Crit Care Med 2008;177:330-6.

17. Muller-Quernheim J. Serum markers for the staging of disease activity of sarcoidosis and other interstitial lung diseases of unknown etiology. Sarcoidosis Vasc Diffuse Lung Dis 1998;15:22-37.

18. Rothkrantz-Kos S, van Dieijen-Visser MP, Mulder PG, Drent M. Potential usefulness of inflammatory markers to monitor respiratory functional impairment in sarcoidosis. Clin Chem 2003;49:1510-7.

19. Bomanji J, Almuhaideb A, Zumla A. Combined PET and X-ray computed tomography imaging in pulmonary infections and inflammation. Curr Opin Pulm Med 2011;17:197-205.

20. Teirstein AS, Machac J, Almeida O, Lu P, Padilla ML, lannuzzi MC. Results of 188 whole-body fluorodeoxyglucose positron emission tomography scans in 137 patients with sarcoidosis. Chest 2007;132:1949-53.

21. Braun JJ, Kessler R, Constantinesco A, Imperiale A. 18F-FDG PET/CT in sarcoidosis management: review and report of 20 cases. Eur J Nucl Med Mol Imaging 2008;35:1537-43. 
22. Nishiyama Y, Yamamoto Y, Fukunaga K, Takinami H, Iwado Y, Satoh K, Ohkawa M. Comparative evaluation of 18F-FDG PET and 67Ga scintigraphy in patients with sarcoidosis. J Nucl Med 2006;47: 1571-6.

23. Keijsers RG, Grutters JC, van Velzen-Blad H, van den Bosch JM, Oyen WJ, Verzijlbergen FJ. (18)F-FDG PET patterns and BAL cell profiles in pulmonary sarcoidosis. Eur J Nucl Med Mol Imaging 2010;37: 1181-8.

24. Basu S, Saboury B, Werner T, Alavi A. Clinical Utility of FDG-PET and PET/CT in Non-malignant Thoracic Disorders. Mol Imaging Biol 2010.

25. Ishimori T, Saga T, Mamede M, Kobayashi H, Higashi T, Nakamoto $Y$, Sato N, Konishi J. Increased (18)F-FDG uptake in a model of inflammation: concanavalin A-mediated lymphocyte activation. J Nucl Med 2002;43:658-63.

26. Drent M, Jacobs JA, de Vries J, Lamers RJ, Liem IH, Wouters EF. Does the cellular bronchoalveolar lavage fluid profile reflect the severity of sarcoidosis? Eur Respir J 1999;13:1338-44.

27. de Kleijn WP, Elfferich MD, De Vries J, Jonker GJ, Lower EE, Baughman RP, King TE Jr, Drent M. Fatigue in sarcoidosis: American versus Dutch patients. Sarcoidosis Vasc Diffuse Lung Dis 2009;26:92-7.

28. Hoitsma E, De Vries J, Drent M. The small fiber neuropathy screening list: Construction and crossvalidation in sarcoidosis. Respir Med 2011;105:95-100.

29. Quanjer PH, Tammeling GJ, Cotes JE, Pedersen OF, Peslin R, Yernault JC. Lung volumes and forced ventilatory flows. Report Working Party Standardization of Lung Function Tests, European Community for Steel and Coal. Official Statement of the European Respiratory Society. Eur Respir J Suppl 1993;16:5-40.

30. James DG: Complications of sarcoidosis. Chronic fatigue syndrome. Sarcoidosis 1993;10:1-3.

31. Korenromp IH, Heijnen CJ, Vogels OJ, van den Bosch JM, Grutters JC. Characterization of chronic fatigue in sarcoidosis in clinical remission. Chest 2011;140:441-7

32. Verbraecken J, Hoitsma E, van der Grinten CP, Cobben NA, Wouters EF, Drent M. Sleep disturbances associated with periodic leg movements in chronic sarcoidosis. Sarcoidosis Vasc Diffuse Lung Dis 2004;21:137-46.

33. Baughman RP, Drent M, Kavuru M, Judson MA, Costabel U, du Bois R, Albera C, Brutsche M, Davis G, Donohue JF, Müller-Quernheim J, Schlenker-Herceg R, Flavin S, Lo KH, Oemar B, Barnathan ES; Sarcoidosis Investigators. Infliximab therapy in patients with chronic sarcoidosis and pulmonary involvement. Am J Respir Crit Care Med 2006;174:795-802.

34. Hoitsma E, Faber CG, van Santen-Hoeufft M, De Vries J, Reulen JP, Drent M. Improvement of small fiber neuropathy in a sarcoidosis patient after treatment with infliximab. Sarcoidosis Vasc Diffuse Lung Dis 2006;23:73-7. 



\title{
Chapter 4
}

\author{
${ }^{18}$ F-FDG PET/CT for detecting bone \\ and bone marrow involvement in \\ sarcoidosis patients
}
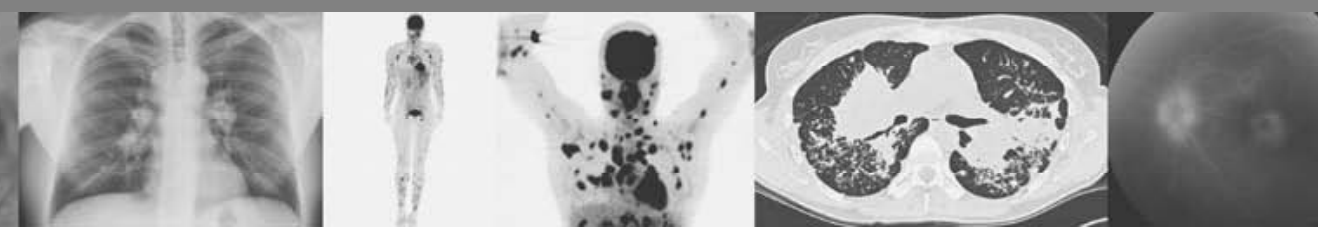

RLM Mostard, L Prompers, RE Weijers, MJPG van Kroonenburgh, PAHM Wijnen, PPMM Geusens, M Drent

Clin Nucl Med 2012;37:21-25 


\section{Abstract}

\section{Background}

The prevalence of bone involvement in sarcoidosis has been estimated to be $3-5 \%$, mostly affecting the phalanges. The aim of this study was to assess the prevalence and distribution pattern of bone and bone marrow involvement as detected by fluorine18-fluorodeoxyglucose positron emission tomography/ computed tomography (PET/CT) in sarcoidosis patients.

\section{Methods}

Between June 2006 and September 2010, 122 patients suffering from severe sarcoidosis that underwent a PET/CT and met the inclusion criteria were studied. In 94 (77\%) patients, the $\mathrm{PET} / \mathrm{CT}$ demonstrated positive findings associated with sarcoidosis. The $94 \mathrm{PET} / \mathrm{CT}$ s were screened to localize any bone/bone marrow lesions. Additionally, low-dose CT scans were screened for other causes of increased bone uptake. Relevant clinical data were gathered retrospectively.

\section{Results}

Evidence for bone/bone marrow involvement was found in $34 \%$ of the 94 patients with PET/CTpositive findings. Of these patients, $60 \%$ showed obvious focal bone lesions at various locations: axial skeleton (47\%), pelvis (40\%), extremities (34\%), and skull (2\%). In $40 \%$ diffuse increased uptake in both axial and peripheral bone marrow, without focal lesions, were found. Both diffuse and focal uptake was seen in $34 \%$, whereas in $25 \%$ only focal lesions. In all but two (6\%) patients no bone-abnormalities on low-dose CT were found.

\section{Conclusions}

More than one-third of PET/CT-positive sarcoidosis patients had osseous abnormalities on $\mathrm{PET} / \mathrm{CT}$. The majority of these lesions (94\%) could not be detected on low-dose CT. No single preferred location was found. These preliminary results stress the value of PET/CT imaging in the assessment of bone/bone marrow involvement in sarcoidosis patients. 


\section{Introduction}

Sarcoidosis is a multisystemic disease characterized by activity of cellular immunity with formation of noncaseating granuloma in various organ systems. ${ }^{1}$ The first case of sarcoidosis involving bone was described by Besnier in $1898 .^{2}$ After that case-report, more publications followed, and several retrospective series reported a prevalence of bone involvement in sarcoidosis patients of 3-5\%., ${ }^{3,4}$ However, the reported prevalence varies widely depending on the studied population and the used diagnostic techniques. In most studies, conventional radiography was performed for detection of bone involvement. A study on bone scintigraphy conducted in a population of 63 sarcoidosis patients showed bone abnormalities, defined as enlarged osteoclast activity, in $38.1 \%$ of the patients. ${ }^{5}$ Until today, the exact prevalence of bone involvement in sarcoidosis is unknown, due to these different results and because many lesions are asymptomatic.

Osseous sarcoidosis is more common in blacks and females and is associated with a chronic and severe course of the disease as well as multisystemic involvement. ${ }^{3,6} \mathrm{~A}$ frequent association between skeletal sarcoidosis and both lupus pernio and ocular involvement has been reported. ${ }^{3}$ Both are associated with a worse prognosis. In contrast, erythema nodosum is rare in patients with osseous sarcoidosis but often present in Löfgren's syndrome, which is an acute presentation of sarcoidosis with, in general, a favorable outcome. This implicates that assessment of bone involvement is relevant in the clinical management of sarcoidosis patients.

Bone and bone marrow involvement detected by fluorine18-fluorodeoxyglucose positron emission tomography/computed tomography $\left({ }^{18} \mathrm{~F}-\mathrm{FDG} \mathrm{PET}\right)$ in sarcoidosis patients has been reported by several groups. ${ }^{7-12}$ However, these reports mainly concerned case-reports and a case series of three sarcoidosis patients. Until now, the usefulness of ${ }^{18}$ F-FDG PET/CT (PET/CT) in detection of osseous involvement has not been evaluated in a large patient population. The aim of this study was to determine the prevalence and distribution pattern of bone and bone marrow involvement as detected by PET/CT in 122 sarcoidosis patients.

\section{Materials and methods}

\section{Study population}

Between June 2005 and September 2010 a PET/CT scan was performed in 134 sarcoidosis patients referred to the interstitial lung disease service (ild care team) of the department of Respiratory Medicine at the Maastricht University Medical Centre (Maastricht, The Netherlands), a tertiary referral center. The indication for performing $\mathrm{PET} / \mathrm{CT}$ was the presence of unexplained disease related disabling symptoms that persisted for at least one year. Persistent disabling symptoms were defined as the 
presence of more than one symptom that had substantial influence on quality of life, and that could not be explained with the results of routine investigations including lung function tests or chest X-rays (CXR).

Laboratory testing, lung function testing and a CXR were performed within an interval of less than two weeks of the PET/CT scanning. Blood samples were simultaneously obtained. Sarcoidosis was proven by the presence of noncaseating granulomas on biopsy according with a compatible clinical picture. Moreover, other causes of granulomatous disease were excluded, in accordance with the consensus statement on sarcoidosis of the American Thoracic Society/European Respiratory Society/World Association of Sarcoidosis and Other Granulomatous Disorders. ${ }^{1}$ Patients with other conditions associated with PET-positive findings were excluded. Therefore, five patients with common variable immunodeficiency, six patients with malignancy and one patient with both rheumatoid arthritis and amyloidosis were excluded. After exclusion for these criteria, 122 patients (median age 46 years; range 24-76; 72 males) were selected. The median time since diagnosis was two years (range 1-53 years). In all, 112 patients were Caucasian, seven of African origin and three of Asian origin. The most frequently recalled symptoms were fatigue (91\%), symptoms compatible with small fiber neuropathy (70\%), arthralgia and/or muscle/skeletal pain (45\%), dyspnea $(45 \%)$, and coughing (21\%). At the time of performance of the PET, a total of 27 patients $(22 \%)$ were treated for their sarcoidosis. This treatment consisted of prednisone alone (median dose $10 \mathrm{mg}$ daily [range $7.5-40 \mathrm{mg}$ ] in 15 patients (12\%), methotrexate (MTX) alone (median dose $10 \mathrm{mg}$ a week [range 5-12.5 mg]) in three patients (2\%), prednisone combined with MTX (all patients $10 \mathrm{mg}$ prednisone daily and median dose MTX $11.25 \mathrm{mg}$ a week [range 10-12.5 mg]) in seven patients (6\%), infliximab alone (400 mg intravenous [IV] every four weeks) in one patient (1\%) and infliximab (400 mg IV every four weeks) combined with MTX (both patients $7.5 \mathrm{mg}$ a week) in one patient (1\%).

A summary of the demographic and clinical characteristics of the patients is shown in Table 4.1, organized first by PET/CT-negative and -positive patients ( $n=94)$, and accordingly, the PET/CT-positive patients were divided in those patients without PET/CT bone lesions and those with PET/CT-positive bone lesions ( $n=32$ ).

Relevant clinical data were gathered retrospectively. All patients signed an informed consent to allow using their data for study purposes.

\section{Laboratory tests}

Laboratory tests were performed on the Synchron LX20 Pro Clinical System (Beckman Coulter B.V., Woerden, The Netherlands) according to the manufacturers' instructions.

Serum angiotensin-converting enzyme (ACE) was measured by colorimetric method (cat. no. FU 116; Fujirebio Inc.), serum levels of soluble interleukin-2 receptor (sIL-2R) were analyzed in commercially available Diaclone ELISA kits (Sanquin, Amsterdam, 
The Netherlands) and serum levels of neopterin were evaluated by the principle of a competitive ELISA, using a kit produced by IBL (Hamburg, Germany).

Table 4.1 Summary of relevant clinical characteristics of the studied sarcoidosis patients $(n=122)$ organised first by PET/CT-negative and -positive patients $(n=94)$, respectively.

\begin{tabular}{|c|c|c|c|c|c|c|}
\hline & $\begin{array}{c}\text { PET - patients } \\
(n=28)\end{array}$ & $\begin{array}{c}\text { PET + patients } \\
(n=94)\end{array}$ & $p$-value ${ }^{a}$ & $\begin{array}{c}\text { PET +/bone - } \\
\text { patients } \\
(n=62)\end{array}$ & $\begin{array}{c}\text { PET }+ \text { /bone }+ \\
\text { patients } \\
(n=32)\end{array}$ & $p$-value ${ }^{b}$ \\
\hline Age (y) & $49(24-73)$ & $46(24-76)$ & NS & $49(24-76)$ & $42(26-65)$ & 0.01 \\
\hline Sex (male) & $18(64 \%)$ & $54(57 \%)$ & NS & $43(69 \%)$ & $11(34 \%)$ & 0.001 \\
\hline Time since diagnosis (yrs) & $2(1-27)$ & $2(1-27)$ & NS & $2(1-26)$ & $2(1-27)$ & NS \\
\hline Caucasian/Black/Asian & $26 / 1 / 1$ & $86 / 6 / 2$ & NS & $56 / 4 / 2$ & $30 / 2 / 0$ & NS \\
\hline $\begin{array}{l}\text { Chest X-ray stage } \\
0 / \mathrm{I} / \mathrm{II} / \mathrm{III} / \mathrm{IV}\end{array}$ & $20 / 3 / 3 / 2 / 0$ & $16 / 23 / 19 / 9 / 27$ & $<0.001$ & $10 / 14 / 14 / 8 / 16$ & $6 / 9 / 5 / 1 / 11$ & NS \\
\hline Therapy total/1/2/3/4 & $5 / 2 / 0 / 3 / 0$ & $22 / 13 / 3 / 4 / 2$ & NS & $16 / 9 / 3 / 2 / 2$ & $6 / 4 / 0 / 2 / 0$ & NS \\
\hline FVC (\% pred) & $101 \pm 19$ & $91 \pm 26$ & NS & $90 \pm 27$ & $92 \pm 24$ & NS \\
\hline DLCO (\% pred) & $81 \pm 18$ & $73 \pm 20$ & 0.046 & $71 \pm 22$ & $76 \pm 14$ & NS \\
\hline $\begin{array}{l}\text { Calcium } \\
(2.10-2.60 \mathrm{mmol} / \mathrm{l})\end{array}$ & $2.31 \pm 0.11$ & $2.33 \pm 0.09$ & NS & $2.31 \pm 0.07$ & $2.31 \pm 0.07$ & NS \\
\hline $\begin{array}{l}\text { Alkaline phosphatase } \\
(45-140 \mathrm{U} / \mathrm{I})\end{array}$ & $79 \pm 24$ & $97 \pm 45$ & NS & $97 \pm 51$ & $95 \pm 27$ & NS \\
\hline $\begin{array}{l}\text { Lactate dehydrogenase } \\
(0-480 \mathrm{U} / \mathrm{I})\end{array}$ & $382 \pm 195$ & $353 \pm 107$ & NS & $347 \pm 112$ & $383 \pm 95$ & NS \\
\hline $\begin{array}{l}\text { Hemoglobin } \\
(8.2-11.0 \mathrm{mmol} / \mathrm{l})\end{array}$ & $9.3(7.3-10.6)$ & $8.9(6.8-10.7)$ & NS & $9.2(8.1-10.7)$ & $8.7(6.8-10.2)$ & NS \\
\hline $\begin{array}{l}\text { Leucocytes } \\
\left(3.5-11.010^{9} / I\right)\end{array}$ & $7.9(4.0-14.1)$ & $8.1(3.2-17)$ & NS & $7.3(4.0-17.0)$ & $7.2(3.2-15.7)$ & NS \\
\hline $\begin{array}{l}\text { Trombocytes } \\
\left(130-35010^{9} / 1\right)\end{array}$ & $234(129-369)$ & $302(144-1033)$ & NS & $266(144-1033)$ & $282(173-448)$ & NS \\
\hline ACE (9-25 U/I) & $17 \pm 15$ & $21 \pm 18$ & NS & $25 \pm 22$ & $18 \pm 6$ & NS \\
\hline slL-2R (240-3154 pg/ml) & $1656 \pm 751$ & $4459 \pm 2783$ & $<0.001$ & $3481 \pm 2722$ & $4813 \pm 2922$ & NS \\
\hline Neopterin $(<2.5 \mathrm{ng} / \mathrm{ml})$ & $1.8 \pm 0.4$ & $3.9 \pm 3.6$ & 0.009 & $3.9 \pm 4.0$ & $3.9 \pm 2.1$ & NS \\
\hline $\operatorname{CRP}(2-9 \mu \mathrm{g} / \mathrm{ml})$ & $5 \pm 5$ & $12 \pm 17$ & NS & $12 \pm 17$ & $12 \pm 17$ & NS \\
\hline
\end{tabular}

Accordingly, the PET/CT positive patients were divided in those patients without PET/CT bone lesions and those with PET/CT positive bone lesions $(n=32)$. Data are presented as median with range in parentheses; mean $\pm S D$; absolute numbers or percentages if appropriate. ${ }^{a}: p$-value for PET-negative versus PET-positive patients. ${ }^{b}$ : $p$-value for bone-negative versus bone-positive patients. $p<0.05$ was considered to be significant. PET indicates positron emission tomography; -: negative; +: positive; n:number; yrs: years; NS: not significant; therapy total: total number of patients treated at time of PET scanning; 1 : prednisone monotherapy; 2: methotrexate (MTX) monotherapy; 3: prednisone and MTX combination therapy; 4: MTX and infliximab combination therapy; FVC: forced vital capacity; \% pred: percentage of predicted values; DLCO: diffusion capacity for carbon monoxide; ACE: serum angiotensin-converting enzyme; sIL-2R: soluble interleukin-2 Receptor; CRP: C-reactive protein.

\section{Chest X-ray}

According to the Scadding radiographic staging system, five stages of radiographic abnormality were recognized: stage 0 (normal CXR), stage I (bilateral hilar lymphadenopathy [BHL]), stage II (BHL and parenchymal abnormalities), stage III (parenchymal abnormalities without $\mathrm{BHL}$ ) and stage IV (end-stage lung fibrosis). 


\section{Lung function test}

Forced vital capacity (FVC) was measured with a pneumotachograph (Masterlab, Jaeger, Würzburg, Germany). The diffusing capacity for carbon monoxide (DLCO) was measured by the single-breath method (Masterlab, Jaeger). Values were expressed as a percentage of predicted values. ${ }^{13}$

\section{${ }^{18}$ F-FDG PET/CT}

A ${ }^{18}$ F-FDG PET/CT scan was performed. Patients were scanned using a Gemini PET-CT (Philips Medical Systems) scanner with time-of-flight (TOF) capability and a 64-slice Brilliance CT scanner. The PET scanner has a transverse and axial field of view of 57.6 and $18 \mathrm{~cm}$, respectively. The transverse spatial resolution is around $5 \mathrm{~mm}$.

Patients were fasting for at least six hours before the examination. In all patients, blood glucose was measured to ensure that the blood glucose was $<10 \mathrm{mmol} / \mathrm{l}$. ${ }^{18}$ F-FDG (GE Health, Eindhoven, The Netherlands) was injected intravenously and flushed with physiologic saline $(10 \mathrm{ml})$. The injected total activity of FDG depended on the weight of the patient. Mean injected dose was $200 \mathrm{MBq}$. After a resting period of 45 minutes (time needed for uptake of FDG), PET and CT images were acquired from the head to the feet. A low-dose CT-scan was used for attenuation correction of the PET images, with $5 \mathrm{~mm}$ slice thickness without intravenous contrast. Typical values were $120 \mathrm{kVp}$; $30 \mathrm{mAs}$; volume computed dose index, $1.8 \mathrm{mGy}$ and dose-length product $143 \mathrm{mGy}$. The PET images were acquired in 5-minute bed positions. The complete PET data set was reconstructed iteratively, with a reconstruction increment of $5 \mathrm{~mm}$ to provide isotropic voxel.

All PET/CT were interpreted by two experienced nuclear medicine physicians (M.v.K., L.P.). If bone lesions were present, all low-dose CT scans were again examined by an experienced musculoskeletal radiologist (R.W.) to exclude other causes of increased bone uptake. PET/CT findings regarding bone or bone marrow involvement were scored as either positive or negative. PET/CT findings were described as positive if increased FDG-uptake was seen in the skeleton. PET/CT-positive findings in the skeleton were subdivided by locations in the skull, upper extremity, lower extremity, axial skeleton, pelvis and the bone part of the rib. Diffuse and focal uptakes were scored separately. The available follow-up PET/CT scans were evaluated as well.

\section{Statistical procedure}

Statistical analyses were performed using SPSS, version 15.0 for Windows. Differences between groups in demographic and clinical characteristics (such as, duration of disease and pulmonary function tests) were tested for statistical significance using the Student t-test for independent samples in case of continuous variables or chi-square test in case of categorical variables. $p<0.05$ (two sided) was considered to indicate statistical significance. 


\section{Results}

Of the 122 included patients, 94 (77\%) patients had PET/CT-positive findings associated with sarcoidosis. In 32 (34\%) of these 94 patients, PET/CT-positive bone or bone marrow lesions were present. Sixty percent (19/32) of the patients with bone/bone marrow lesions on PET/CT, showed obvious focal bone lesions at various locations: axial skeleton (47\%), pelvis (40\%), extremities (34\%), bone part of the rib (18\%) and skull (2\%). In $41 \%$ of the patients $(n=13 / 32)$, diffuse enlarged uptake in both the axial and peripheral bone marrow, without focal lesions, was found. Both diffuse and focal uptake was seen in $34 \%(11 / 32)$, whereas only focal lesions were seen in $25 \%(8 / 32)$. A rather interesting finding is that corresponding CT lesions were identified in only $2(6 \%)$ of the patients with PET-detected bone abnormalities.

In the total population, PET/CT-positive patients had significantly lower DLCO, sIL-2R and neopterin levels and higher CXR stages when compared with the PET/CT-negative patients. In the PET/CT-positive population, female sex and younger age were significantly more common in patients with bone/bone marrow involvement (Table 4.1). Mean ACE levels were calculated after exclusion of ACE values $<9 \quad U / I \quad(n=10)$, because these values were under the lower limit of the reference value and due to the use of ACE-inhibitors.

Signs of decreased hematopoiesis were present in only one patient of the total population. This female patient had a slight anemia (hemoglobin, $6.8 \mathrm{mmol} / \mathrm{l}$; lower reference value for the female population $7.3 \mathrm{mmol} / \mathrm{l}$ ) and a minor leucopenia

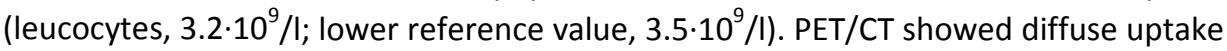
in the pelvis and proximal femora, consistent with bone marrow activity in this patient.

Histological evidence of osseous sarcoidosis was available in two patients. PET/CT was repeated after a change in therapy in three patients with bone involvement. The reason for therapy change was not the bone involvement itself, but was based on the general presentation (e.g. pulmonary function decline, hypercalciuria). This therapy change consisted of starting prednisone in one patient and adding MTX to prednisone therapy in two patients. Follow-up PET/CT after a median time interval of 7 months (range 3-20 months) showed a decrease in the mean total number of bone lesions from $13.7 \pm 14.8$ to $3.3 \pm 5.8$ and the maximum standardized uptake value (SUVmax) decreased from $9.8 \pm 3.5$ to $3.1 \pm 4.3$. Testing for statistical significance on these results was not considered to be relevant due to the low number of involved patients.

An example of a patient with diffuse bone lesions and other sarcoidosis-related lesions visible on the pretreatment PET/CT and with obvious improvement after therapy is shown in Figure 4.1. 

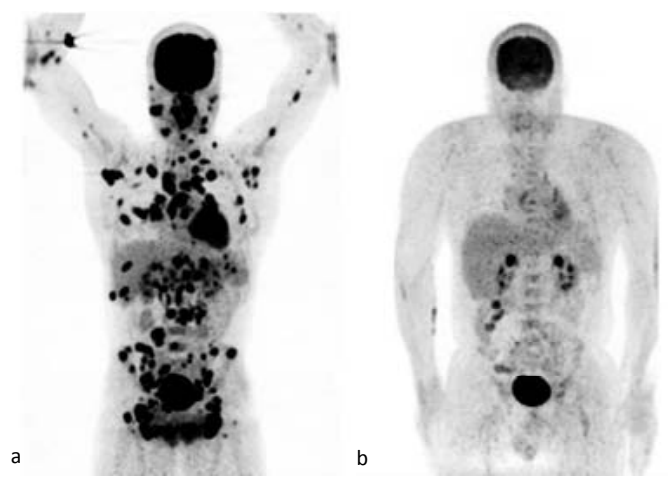

C
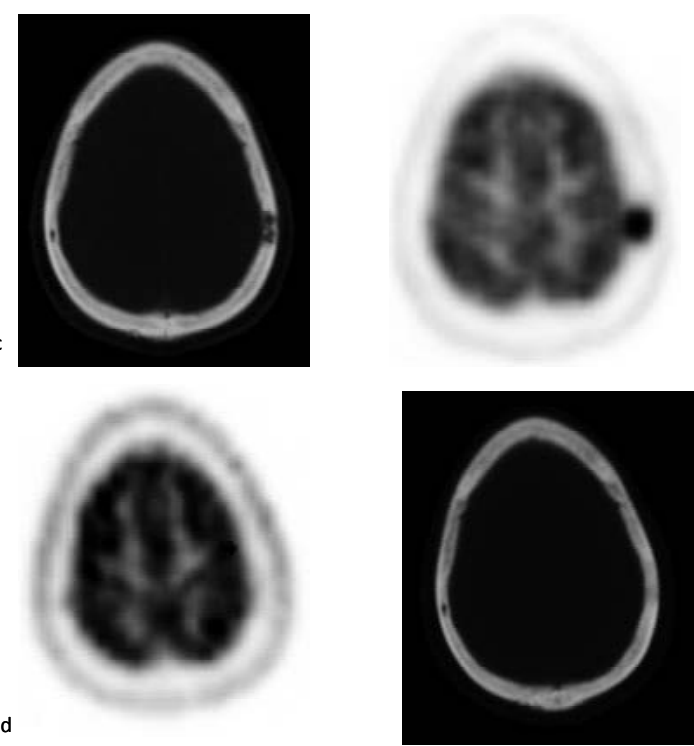

Figure 4.1 Example of a 40-year-old PET-positive sarcoidosis patient with focal PET-positive lesions at multiple locations. a. Overview projection of the pretreatment ${ }^{18} \mathrm{~F}$-FDG PET scan showing diffusely increased focal ${ }^{18}$ F-FDG uptake in multiple bone locations and multiple locations in mediastinal and peripheral lymph nodes, muscles, spleen and parotid glands. b. Overview projection of the ${ }^{18}$ F-FDG PET scan after 18 months of treatment with prednisone and methotrexate showing obvious decrease of the ${ }^{18} \mathrm{~F}-\mathrm{FDG}$ uptake with only mild residual uptake in mediastinal, hilar and inguinal lymph nodes. c. Corresponding transversal CT and PET images at a cranial level showing a focal lytic bone lesion and increased ${ }^{18}$ F-FDG uptake pretreatment in the left parietal bone. The right parietal bone shows a lucency in the diploe as part of the normal venous structures. d. Corresponding transversal CT and PET images at the same level as in c. after 18 months of treatment with prednisone and methotrexate. The lesion in the left parietal bone resolved as indicated by the normalization of the bone mineralization on the CT image and of the ${ }^{18} \mathrm{~F}$-FDG uptake on the PET image. 


\section{Discussion}

To the best of our knowledge, this was the first study investigating the prevalence of bone/bone marrow involvement assessed by PET/CT in a large population of sarcoidosis patients with persistent symptoms. In more than one-third (32/94) of the patients PET/CT-positive findings compatible with bone/bone marrow involvement were present. This was much higher than expected according to most previously published studies. Moreover, it showed that PET/CT may be an excellent modality to detect bone/bone marrow involvement compared with more conventional modalities. 3 .4

Previous studies suggest that sarcoidosis most commonly affects the phalanges. ${ }^{3,14}$ No single preferred location was found in our study. Both the axial and peripheral skeleton was affected. However, it should be noted that evaluation of the phalanges was not possible in all patients since the hands and most of the arm and lower extremities were outside the field of view. Of great interest is the low rate of abnormalities on low-dose CT. Clear bone lesions on CT were identified in only two of the 32 patients with PET detected bone abnormalities. This finding suggests that physiological changes precede morphological changes, which is a concept known from $\mathrm{PET} / \mathrm{CT}$ in oncology. ${ }^{15}$ One of the limitations of our study is that only low-dose CT was available for evaluation of anatomical abnormalities. Although high-dose CT could have improved detection of abnormalities on $\mathrm{CT}$, we observed a clear difference between the rate of physiological abnormalities and morphological abnormalities. This finding is in line with the report of Milman et al. ${ }^{5}$, showing a similar low rate of anatomical abnormalities when comparing bone scintigraphy to conventional radiography. However, it should be realized that bone scintigraphy is not able to visualize bone marrow activity directly. Concerning PET/CT, differentiation between increased FDG uptake in bone and bone marrow is difficult, but we assumed diffuse uptake in the femora and/or pelvis without focal lesions to be more likely bone marrow involvement.

Magnetic resonance imaging (MRI) could also be an interesting tool for evaluation of bone or bone marrow involvement in sarcoidosis, but only case reports and one series of 13 patients have been published so far. ${ }^{14,16-18}$

In our population, bone/bone marrow involvement was more common in female patients, which is in accordance with data from previous studies. ${ }^{3,6}$

Bone marrow involvement in sarcoidosis may cause a decreased hematopoiesis (anemia, leucopenia or thrombocytopenia). ${ }^{8,19}$ Thrombocytopenia in sarcoidosis patients could, apart from bone marrow involvement, also be due to autoimmune thrombocytopenic purpura, a shortened lifespan of the platelets or hypersplenism. ${ }^{20,21}$ Signs of decreased hematopoiesis were present in only one patient of our study population. This patient had a slight anemia and leucopenia. In this patient, the anemia could be due to inflammatory bone marrow activity associated with sarcoidosis. However, it could not be excluded that the bone marrow activity was 
associated with anemia, secondary to another cause than sarcoidosis. To date, no other cause of anemia was established.

No patients had trombocytopenia or splenomegaly at the time of PET/CT scanning (data concerning splenomegaly is not shown).

Two of the patients with bone/bone marrow lesions on PET/CT used MTX, a drug that might affect the bone marrow metabolism. In only one of these patients, diffuse enlarged uptake in both the axial and peripheral bone marrow was demonstrated. The dose of MTX was 7.5mg once a week in this patient, which is rather low. None of the studied patients used other drugs that might affect the bone marrow metabolism.

No data exist on the prognostic significance of PET/CT-positive osseous findings in sarcoidosis patients or on whether there is an increased risk of fracture at these sites. However, sarcoidal bone involvement has been associated with a chronic course of the disease and therefore, establishing its presence is valuable in the clinical assessment of sarcoidosis patients. ${ }^{6}$ Because follow-up PET/CT after therapy showed improvement of the osseous involvement, $\mathrm{PET} / \mathrm{CT}$ may play a role in monitoring osseous involvement in sarcoidosis. Another limitation to our study is that histological evidence of osseous sarcoidosis was only available in few patients. Nevertheless, the diagnosis of sarcoidosis was already confirmed in all the studied cases, and other causes of bone lesions were excluded as far as possible by examining all lesions on the concurrent low-dose CT scans. During the follow-up period, no other pathology was found. Moreover, our centre is a referral centre for sarcoidosis, and therefore, the refractory character may be more severe than in a general sarcoidosis population. Besides, PET/CT was not performed in every referred patient.

In conclusion, PET/CT findings consistent with bone or bone marrow involvement were present in more than one-third of the patients with positive PET scans. This is far more than in most studies described previously. The rate of anatomical abnormalities on low-dose CT was low compared to the physiological abnormalities detected by PET. This may suggest that physiological changes may precede anatomical abnormalities and stresses the strength of functional PET imaging as a potentially sensitive tool to investigate bone involvement in sarcoidosis. The detection of sarcoidal bone or bone marrow involvement can change the clinical assessment of severity of disease and, therefore, may influence the management and follow-up. Further studies are needed to evaluate the exact clinical relevance and prognostic value of these bone lesions. 


\section{References}

1. Costabel U, Hunninghake GW. ATS/ERS/WASOG statement on sarcoidosis. Sarcoidosis Statement Committee. American Thoracic Society. European Respiratory Society. World Association for Sarcoidosis and Other Granulomatous Disorders. Eur Respir J 1999;14:735-7.

2. Besnier E. Lupus pernio de la face. Ann Dermatol Syph (Paris) 1898; 10: 333.

3. Neville E, Carstairs LS, James DG. Sarcoidosis of bone. Q J Med 1977;46:215-27.

4. James DG, Neville E, Siltzbach LE. A worldwide review of sarcoidosis. Ann N Y Acad Sci 1976;278: 321-34.

5. Milman N, Lund JO, Graudal N, Enevoldsen H, Evald T, Nørgård P. Diagnostic value of routine radioisotope bone scanning in a series of 63 patients with pulmonary sarcoidosis. Sarcoidosis Vasc Diffuse Lung Dis 2000;17:67-70.

6. Zisman DA, Shorr AF, Lynch JP, 3rd. Sarcoidosis involving the musculoskeletal system. Semin Respir Crit Care Med 2002;23:555-70.

7. Baldini S, Pupi A, Di Lollo S, Marchionni N, Shraim R, Bosi A. PET positivity with bone marrow biopsy revealing sarcoidosis in a patient in whom bone marrow metastases had been suspected. $\mathrm{Br} J$ Haematol 2008;143:306.

8. de Prost N KK, Sibony M, Talbot J-N, Wislez M, Cadranel J. Fluorine-18 Fluorodeoxyglucose with Positron Emission Tomography Revealed Bone Marrow Involvement in Sarcoidosis Patients with Anaemia. Respiration 2010;79:25-31.

9. Aberg C, Ponzo F, Raphael B, Amorosi E, Moran V, Kramer E. FDG positron emission tomography of bone involvement in sarcoidosis. AJR Am J Roentgenol 2004;182:975-7.

10. Clarençon F, Silbermann-Hoffman O, Lebreton C, Fernandez P, Kerrou K, Marchand-Adam S, Hourseau $M$, Schouman-Claeys E, Feydy A. Diffuse spine involvement in sarcoidosis with sternal lytic lesions: two case reports. Spine (Phila Pa 1976) 2007;32:E594-7.

11. Kaira K, Oriuchi N, Otani Y, Yanagitani N, Sunaga N, Hisada T, Ishizuka T, Endo K, Mori M. Diagnostic usefulness of fluorine-18-alpha-methyltyrosine positron emission tomography in combination with 18F-fluorodeoxyglucose in sarcoidosis patients. Chest 2007;131:1019-27.

12. Ludwig V, Fordice S, Lamar R, Martin WH, Delbeke D. Unsuspected skeletal sarcoidosis mimicking metastatic disease on FDG positron emission tomography and bone scintigraphy. Clin Nucl Med 2003; 28:176-9.

13. Quanjer PH, Tammeling GJ, Cotes JE, Pedersen OF, Peslin R, Yernault JC. Lung volumes and forced ventilatory flows. Report Working Party Standardization of Lung Function Tests, European Community for Steel and Coal. Official Statement of the European Respiratory Society. Eur Respir J Supp/ 1993;16: 5-40.

14. Moore SL, Teirstein AE. Musculoskeletal sarcoidosis: spectrum of appearances at MR imaging. Radiographics 2003;23:1389-99.

15. Tutt AN, Plunkett TA, Barrington SF, Leslie MD. The role of positron emission tomography in the management of colorectal cancer. Colorectal Dis 2004;6:2-9.

16. Valencia MP, Deaver PM, Mammarappallil MC. Sarcoidosis of the thoracic and lumbar vertebrae, mimicking metastasis or multifocal osteomyelitis by MRI: case report. Clin Imaging 2009;33:478-81.

17. Fisher AJ, Gilula LA, Kyriakos M, Holzaepfel CD. MR imaging changes of lumbar vertebral sarcoidosis. AJR Am J Roentgenol 1999;173:354-6.

18. Poyanli A, Poyanli O, Sencer S, Akan K, Sayrak H, Acunaş B. Vertebral sarcoidosis: imaging findings. Eur Radiol 2000;10:92-4.

19. Lower EE, Smith JT, Martelo OJ, Baughman RP. The anemia of sarcoidosis. Sarcoidosis 1988;5:51-5.

20. Mahevas M, Le Page L, Salle V, et al. Thrombocytopenia in sarcoidosis. Sarcoidosis Vasc Diffuse Lung Dis 2006;23:229-35.

21. Dickerman JD, Holbrook PR, Zinkham WH. Etiology and therapy of thrombocytopenia associated with sarcoidosis. J Pediatr 1972;81:758-64. 



\section{Chapter 5}

\section{Severity of pulmonary involvement and ${ }^{18}$ F-FDG PET activity in sarcoidosis}
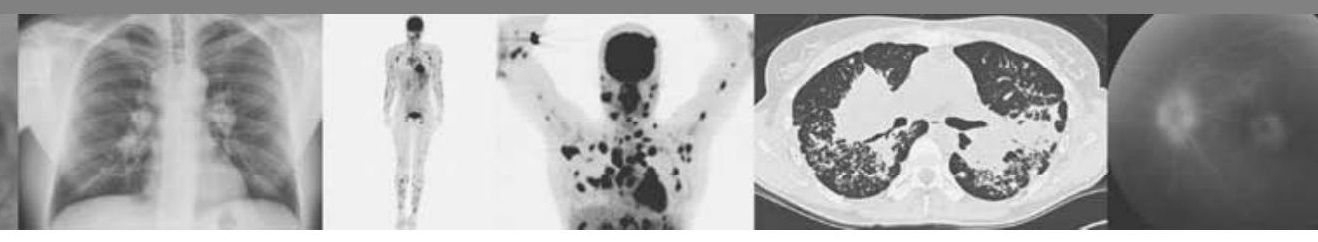

RLM Mostard, JA Verschakelen, MJPG van Kroonenburgh, PJ Nelemans, PAHM Wijnen, S Vöö, M Drent

\section{Submitted}




\section{Abstract}

\section{Background}

Assessing inflammatory activity is useful in the management of persistent symptomatic sarcoidosis patients. ${ }^{18}$ F-FDG PET (PET) appeared to be a sensitive technique to assess inflammatory activity in sarcoidosis. The aim of this study was to evaluate whether the severity of the pulmonary involvement is associated with PET activity in persistent symptomatic sarcoidosis patients.

\section{Methods}

Over a 5-year period, relevant clinical data including laboratory and lung function test results were gathered from the medical records of 95 sarcoidosis patients with persistent disabling symptoms who underwent both a PET and a high-resolution computed tomography (HRCT). HRCT scans were classified using a semi-quantitative scoring system and PET findings as positive or negative, respectively.

\section{Results}

PET was positive in 77/95 patients, of whom 56 demonstrated pulmonary PET-positivity. HRCT scores were high (7.1 \pm 3.6 ) in patients with positive pulmonary PET findings $(n=56)$ compared to patients with negative pulmonary PET findings $(n=39 ; 3.0 \pm 2.9 ; p<0.001)$. The diffusion capacity for carbon monoxide (DLCO) $(65 \pm 20 \%$ predicted) and the forced vital capacity (FVC) $(85 \pm 24 \%$ predicted) were low in patients with pulmonary PET-positivity versus those with negative pulmonary PET findings $(79 \pm 16 \%$ predicted; $p=0.001$ and $96 \pm 22 \%$ predicted; $p=0.044$, respectively). Interestingly, out of the 26 patients with fibrotic changes, $22(85 \%)$ had positive pulmonary PET findings, of whom 18/22 (82\%) showed extrathoracic PET-positive lesions and $16 / 22(73 \%)$ showed signs of serological inflammation.

\section{Conclusions}

The severity of the pulmonary involvement, assessed by HRCT features and lung function parameters, appeared to be associated with increased PET activity in sarcoidosis. The majority of patients with fibrotic changes demonstrated inflammatory activity, next to pulmonary also at extrathoracic sites. 


\section{Introduction}

Sarcoidosis is a multisystemic disease characterized by activity of cellular immunity with formation of noncaseating granuloma in various organ systems. ${ }^{1}$ The majority of deaths from sarcoidosis results from respiratory failure and no universal definition exists for what constitutes 'active' pulmonary disease. It is therefore important to accurately assess pulmonary involvement. The reliable detection of changes in pulmonary disease severity in sarcoidosis by using chest radiography and lung function testing has proved problematic. ${ }^{2}$ Forced vital capacity (FVC) and the diffusing capacity for carbon monoxide (DLCO) have been regarded as the most accurate pulmonary function measures of pulmonary involvement in sarcoidosis and deterioration is regarded as an indicator of disease activity in sarcoidosis. ${ }^{2,3}$ However, assessment of disease activity through lung function tests requires evidence of progression between two measurements and so does not reflect the current status. Moreover, lung function testing cannot distinguish between reversible granulomatous lesions and irreversible fibrotic changes, and correlates only modestly with the level of dyspnea reported by patients. ${ }^{3,4}$ Although chest radiography (CXR) is most often the first diagnostic imaging study for assessment of pulmonary involvement in sarcoidosis, the radiographic score (stages 0 -IV) possesses limited value in predicting inflammatory activity. $^{1,5-7}$

The high-resolution CT (HRCT) uses short scanning times and thin collimation, making it possible to demonstrate lung parenchyma in detail and detect abnormal changes of the lung parenchyma at an early stage. ${ }^{8}$ The presence and extent of parenchymal abnormalities on HRCT has been found to correlate with respiratory functional impairment in sarcoidosis. ${ }^{6,9-13}$. However, HRCT is a morphological imaging technique that provides only indirect information on the underlying metabolic changes. Due to pre-existing major abnormalities, HRCT features are therefore frequently of limited value for the assessment of inflammatory activity in sarcoidosis patients with pulmonary fibrosis, since it is not possible to differentiate between fibrotic and residual granulomatous components in the parenchymal consolidations.

${ }^{18}$ F-FDG PET/CT (PET) is used to detect high glucose metabolism and has been shown to be useful for the assessment of inflammatory activity in sarcoidosis. ${ }^{14-18}$ Recently, elevated serological inflammatory markers were found to be associated with PETpositivity. ${ }^{19}$ To date, only limited information is available about the relationship between morphological- and functional pulmonary abnormalities, and metabolic changes as measured by PET findings in sarcoidosis patients.

The aim of the present study was to evaluate whether the severity of pulmonary involvement as assessed by HRCT features and lung function parameters is associated with PET activity in sarcoidosis. 


\section{Materials and methods}

We reviewed the medical records of all sarcoidosis patients referred to the interstitial lung disease service (ild care team) of the department of Respiratory Medicine at the Maastricht University Medical Centre (Maastricht, The Netherlands), a tertiary referral center, between June 2005 and September 2010. All sarcoidosis patients who underwent both a PET and a HRCT $(n=106)$ were included. The indication for performing the PET was the presence of unexplained disease related disabling symptoms that persisted for at least one year. Persistent disabling symptoms were defined as the presence of more than one symptom that had substantial influence on quality of life, and that could not be explained with the results of routine investigations, including the absence of lung functional or chest radiographic deterioration. These symptoms included fatigue (Fatigue Assessment Scale [FAS] $\geq 22$ ), ${ }^{20}$ symptoms compatible with small fiber neuropathy (SFN; SFN Screenings List [SFNSL] score $\geq 11$ ), ${ }^{21}$ arthralgia and/or muscle pain, dyspnea (MRC dyspnea scale $\geq 3$ ), exercise intolerance or coughing. Laboratory and lung-function testing were performed within a 2-week interval before or after the HRCT. PET scans were made within a 3-months interval before or after the HRCT, without changing the therapy during this period. In all cases, patients had a clinical presentation compatible with sarcoidosis. The diagnosis was based on consistent clinical features and bronchoalveolar lavage (BAL) fluid analysis results, according to the international guidelines. ${ }^{1}$ The diagnosis was confirmed histological, demonstrating noncaseating epitheloid cell granulomas, in most cases (75\%). Patients with known co-morbid conditions associated with PET positive findings were excluded. Therefore, five patients with common variable immunodeficiency (CVID), five patients with malignancy and one patient with both rheumatoid arthritis and amyloidosis were excluded. After exclusion for these criteria, 95 patients were selected. The study protocol was approved by the Medical Research Ethics Committee of our institution.

\section{Laboratory tests}

Serum angiotensin-converting enzyme (ACE) was measured by colorimetric method (cat. no. FU 116; Fujirebio Inc.), the reference interval was 9-25 U/I. Serum levels of soluble interleukin-2 receptor (sIL-2R) were analyzed in commercially available Diaclone ELISA kits (Sanquin, Amsterdam, The Netherlands) and considered elevated if $>3154 \mathrm{pg} / \mathrm{l}$. Serum levels of neopterin were evaluated by a competitive ELISA (IBL; Hamburg, Germany). Serum levels were considered elevated if $>2.5 \mathrm{ng} / \mathrm{l}$.

Results for combined serological inflammatory marker testing (ACE, sIL-2R and neopterin) were considered positive if at least one of the serological inflammatory markers was elevated. 
C-reactive protein (CRP) was measured using a turbidimetric method performed using the Beckman synchron CX-7 system (kit 465231; Mijdrecht, The Netherlands). The detection limit for CRP was $2 \mu \mathrm{g} / \mathrm{ml}$, with a normal range of $2-9 \mu \mathrm{g} / \mathrm{ml}$.

\section{Chest radiography}

According to the Scadding radiographic staging system, five stages of radiographic abnormality (0-IV) were recognized. ${ }^{1}$

\section{Lung function tests}

FVC was measured with a pneumotachograph (Masterlab, Jaeger, Würzburg, Germany). DLCO was measured by the single-breath method (Masterlab, Jaeger, Würzburg, Germany). Values were expressed as a percentage of predicted values. ${ }^{22}$

\section{Imaging}

Thin-section scans with 1-mm collimation were obtained at $10-\mathrm{mm}$ intervals through the chest (Somaton Plus, Siemens, Erlangen, Germany). The scanning parameters included $137 \mathrm{kVP}, 255 \mathrm{~mA}$, and 1-s scanning time. Both mediastinal (width $400 \mathrm{HU}$, level $40 \mathrm{HU}$ ) and lung (width $1600 \mathrm{HU}$, level $-800 \mathrm{HU}$ ) window images were obtained. Scans were reconstructed with a high-frequency reconstruction algorithm.

A whole body ${ }^{18}$ F-FDG PET/CT scan was performed using a Gemini PET-CT (Philips Medical Systems) scanner with time-of-flight (TOF) capability, together with a 64-slice Brilliance CT scanner. Patients were fasting for at least six hours before the examination. In all patients blood glucose was measured to ensure that the blood glucose was below $10 \mathrm{mmol} / \mathrm{ml} .{ }^{18} \mathrm{~F}-\mathrm{FDG}$ (GE Health, Eindhoven, The Netherlands) was injected intravenously and followed by physiologic saline $(10 \mathrm{ml})$. The injected total activity of FDG depended on the weight of the patient. Mean injected dose was: 200 $\mathrm{MBq}$. After a resting period of 45 minutes (time needed for uptake of FDG) PET and CT images were acquired from the head to the feet. A low dose CT-scan was performed without intravenous contrast and was used for attenuation correction of the PET images. The PET images were acquired in 5-minute bed positions. The complete PET data set was reconstructed iteratively with a reconstruction increment of $5 \mathrm{~mm}$ to provide isotropic voxel.

\section{Image analysis}

An experienced thoracic radiologist (JV), blinded to the patient's clinical history and to the PET findings, classified the scans of both lungs using a semiquantitative HRCT scoring system that has been described by Oberstein et al. ${ }^{13}$ and that has been used in previous studies of our group. ${ }^{6}$ This scoring system is explained in detail in Table 5.1. 
Table 5.1 Definition of abnormal high-resolution computed tomography (HRCT) findings in sarcoidosis, adapted from Oberstein et al. ${ }^{13}$, visual score.

\begin{tabular}{|c|c|c|c|c|}
\hline & $\begin{array}{c}\text { Lung volume affected }^{\mathrm{a}} \\
\text { No lesions: } 0\end{array}$ & $<33 \%: 1$ & $<66 \%: 2$ & $>66 \%: 3$ \\
\hline \multicolumn{5}{|c|}{$\begin{array}{l}\text { Typical patterns of } \\
\text { parenchymal involvement }\end{array}$} \\
\hline \multicolumn{5}{|c|}{ BVB } \\
\hline \multicolumn{5}{|l|}{ PC } \\
\hline \multicolumn{5}{|c|}{ ND } \\
\hline \multicolumn{5}{|l|}{ LS } \\
\hline & Pathological findings ${ }^{b}$ & & & \\
\hline & None: 0 & Minor:1 & Moderate: 2 & Pronounced:3 \\
\hline \multicolumn{5}{|l|}{$\mathrm{PL}$} \\
\hline LN & & & & \\
\hline
\end{tabular}

BVB: thickening or irregularity of the bronchovascular bundle; PC: parenchymal consolidation (including ground-glass opacifications); ND: intraparenchymal nodules; LS: septal and nonseptal lines; PL: focal pleural thickening; LN: enlargement of the mediastinal lymph nodes

The total score is obtained by adding up the individual scores (BVB, ND, LS, PC, LN, and PL)

${ }^{a}$ The lung volume affected is quantified by a visual score: $0=$ no lesions found; $1=$ up to $33 \%$; $2=$ up to $66 \%$; and $3=$ more than $66 \%$ of the volume affected

${ }^{\mathrm{b}}$ The PL and the enlargement of the $\mathrm{LN}$ (with a short axis of $1 \mathrm{~cm}$ or more considered enlarged) were quantified: $0=$ no pathological findings; $1=$ minor; $2=$ moderate; and $3=$ pronounced changes

Separately, the presence of signs of fibrosis (architectural distortion as shown by distortion of the airways and blood vessels, irregular distortion of the septal and intralobular lines, retraction of the hila and fissures, cystic formation and traction bronchiectasis) ${ }^{23,24}$ was evaluated.

All PET were interpreted by an experienced nuclear medicine physician (MvK), blinded to the patient's clinical history and to the HRCT findings. PET findings in the lungs, lymph nodes, or other soft tissues or bones were scored as either positive or negative. A positive PET-scan interpretation was performed visually, with a threshold standardized uptake value (SUVmax) $\geq 2.5 .{ }^{18} \mathrm{~F}$-FDG uptake was quantified by drawing a region of interest around the area of pathology of the co-registered transaxial slice. SUVmax was calculated as the maximal pixel activity within the region of interest. The degree of increased metabolic activity in the pulmonary parenchyma needed to be higher than the mediastinal background.

In a next step in a consensus meeting between radiologist and nuclear medicine physician, in the patients with pulmonary PET-positivity, the area of most intensive thoracic ${ }^{18}$ F-FDG uptake was identified and the HRCT pattern in this region was assessed. This predominant HRCT substrate of thoracic ${ }^{18} \mathrm{~F}$-FDG uptake was classified as one of the items included in the HRCT score. Inter-reader reliability of the total HRCT score and of the simple PET classification system we used proved to be very good, as reported in previous studies with the same observers (weighted kappa 0.99 and 1.00 , respectively). ${ }^{6,19}$ Accordingly, in the present study, observation by a single radiologist and a single nuclear physician was regarded to be sufficient. 


\section{Statistical procedure}

Statistical analyses were performed using SPSS, version 15.0 for Windows. Differences were tested for statistical significance using the Student's t-test for independent samples in case of continuous variables or chi-square test in case of categorical variables. A p-value of $<0.05$ (two sided) was considered to indicate statistical significance.

Receiver operating characteristic (ROC) curves were constructed to evaluate the ability of the total HRCT score and the HRCT subscores to predict the presence of PETpositive results. Area under the curve (AUC) values with $95 \%$ confidence intervals (CI) were used to quantify and visualise the strength of the association.

\section{Results}

In Table 5.2, relevant demographic and clinical characteristics of the studied sarcoidosis patients (87 Caucasians, five of African origin and three of Asian origin) categorized by absence ( $n=39: 41 \%)$ or presence $(n=56: 59 \%)$ of positive PET findings in the pulmonary parenchyma are summarized. The median SUVmax in the PETpositive patients was $7.0(2.5-24.2)$.

Forty patients (71\%) in the pulmonary PET-positive group demonstrated one or more extrathoracic lesions. In the pulmonary PET-negative group, 21 patients had extrathoracic positive PET findings. Extrathoracic positive PET findings in the sarcoidosis patients categorized by absence or presence of positive PET findings in the pulmonary parenchyma are shown in Table 5.3.

\section{Relation between morphological and metabolic changes}

\section{Association between HRCT (sub)scores and pulmonary PET-positivity}

The total HRCT score as well as the subscores of the 56 patients with pulmonary PETpositivity was high compared with the 39 patients with pulmonary PET-negativity (see Table 5.4).

ROC curve results for the association between the total HRCT score and pulmonary PET-positive results are presented in Figure 5.1. The AUC was 0.81 ( $95 \% \mathrm{Cl}$ : 0.73-0.90). The AUCs of the various HRCT patterns as included in the HRCT score are presented in Table 5.5. All patients with a total HRCT score $>9(n=17)$ had positive PET findings and all patients with a total HRCT score $>10(n=16)$ had pulmonary positive PET findings. None of the patients with a total HRCT score of 0 points $(n=11)$ had pulmonary PETpositive findings, nevertheless five of them had extrathoracic positive PET findings and two of them showed increased serological inflammatory markers. 
Table 5.2 Demographic and clinical characteristics of the sarcoidosis patients categorized by absence or presence of positive PET findings in the pulmonary parenchyma.

\begin{tabular}{lccc}
\hline & $\begin{array}{c}\text { Pulmonary parenchyma } \\
\text { PET - patients }(n=39)\end{array}$ & $\begin{array}{c}\text { Pulmonary parenchyma } \\
\text { PET + patients }(n=56)\end{array}$ & p-value \\
\hline Age (yrs) & $44(22-72)$ & $48(24-76)$ & NS \\
Sex (male) & $22(56 \%)$ & $33(59 \%)$ & NS \\
Time since diagnosis (yrs) & $2(1-20)$ & $2(1-21)$ & NS \\
Therapy total number (\%) & $9(23 \%)$ & $17(30 \%)$ & NS \\
$1 / 2 / 3 / 4$ & $4 / 1 / 4 / 0$ & $9 / 6 / 1 / 1$ & 0.030 \\
ACE $(9-25$ U/I) & $15(1-35)$ & $19(3-60)$ & 0.004 \\
sIL-2R (240- 3154 pg/ml) & $2028(518-9662)$ & $3451(1191-15000)$ & 0.004 \\
Neopterin (<2.5 ng/ml) & $1.7(0.8-2.8)$ & $3.0(0.7-18.2)$ & NS \\
CRP (2-9 $\mu$ g/ml) & $4(1-80)$ & $6(1-70)$ & 0.016 \\
CXR stage 0/I & $22 / 7$ & $8 / 9$ & NS \\
CXR stage II/III/IV & $2 / 5 / 3$ & $11 / 5 / 23$ & 0.044 \\
FVC total (\% pred) & $96 \pm 22$ & $85 \pm 24$ & NS \\
CXR 0-I & $98 \pm 22$ & $105 \pm 11$ & NS \\
CXR II-IV & $91 \pm 24$ & $80 \pm 20$ & 0.001 \\
DLCO total (\% pred) & $79 \pm 16$ & $65 \pm 20$ & NS \\
CXR 0-I & $81 \pm 16$ & $76 \pm 19$ & NS \\
CXR II-IV & $71 \pm 16$ & $60 \pm 19$ & 0.008 \\
RFI total & $21 / 39(54 \%)$ & $45 / 56(81 \%)$ & NS \\
CXR 0-I & $14 / 29(48 \%)$ & $11 / 17(65 \%)$ & NS \\
CXR II-IV & $7 / 10(70 \%)$ & $34 / 39(87 \%)$ & \\
\hline
\end{tabular}

Data are presented as median with range in parentheses; mean $\pm \mathrm{SD}$; absolute numbers or percentages if appropriate. PET: positron emission tomography; -: negative; +: positive; n:number; yrs: years; NS: not significant; therapy total: total number of patients treated at time of PET scanning; 1: prednisone monotherapy; 2: methotrexate monotherapy; 3: prednisone and methotrexate combination therapy; 4: methotrexate and infliximab combination therapy; ACE: serum angiotensin-converting enzyme; sIL-2R: soluble interleukin-2 Receptor; CRP: C-reactive protein; CXR: chest X-ray; FVC: forced vital capacity; \% pred: percentage of predicted values; DLCO: diffusion capacity for carbon monoxide; RFI: respiratory functional impairment, defined as present if DLCO was $<80 \%$, FEV1 was $<80 \%$, or FVC was $<80 \%$ of the predicted value. $\mathrm{p}<0.05$ was considered to indicate significance.

Table 5.3 Extrathoracic and mediastinal positive PET findings in the sarcoidosis patients categorized by absence or presence of positive PET findings in the pulmonary parenchyma.

\begin{tabular}{lcc}
\hline $\begin{array}{l}\text { Extrathoracic and mediastinal } \\
\text { positive PET findings }\end{array}$ & $\begin{array}{c}\text { Pulmonary parenchyma } \\
\text { PET - patients } \\
(n=39 ; \text { CXR 0-I/II-IV: 29/10) }\end{array}$ & $\begin{array}{c}\text { Pulmonary parenchyma } \\
\text { PET + patients } \\
(n=56 ; \text { CXR 0-I/II-IV: 17/39) }\end{array}$ \\
\hline Mediastinal lymph nodes & $15(39 \%)$ & $43(77 \%)$ \\
Peripheral lymph nodes & $18(46 \%)$ & $38(68 \%)$ \\
Liver & 0 & $9(16 \%)$ \\
Spleen & $2(5 \%)$ & $14(25 \%)$ \\
Parotid glands & $4(10 \%)$ & $13(23 \%)$ \\
Skin & $1(3 \%)$ & $1(2 \%)$ \\
Bone & $7(18 \%)$ & $16(29 \%)$ \\
Central nervous system & 0 & $1(2 \%)$ \\
\hline
\end{tabular}

Data are presented as absolute numbers with percentages in parentheses; PET: positron emission tomography; $\mathrm{n}=$ number; $\mathrm{CXR}$ : chest $\mathrm{X}$-ray 
Table 5.4 HRCT features of the sarcoidosis patients categorized by absence or presence of positive PET findings in the pulmonary parenchyma.

\begin{tabular}{lccr}
\hline & $\begin{array}{c}\text { Pulmonary parenchyma } \\
\text { PET - patients }(n=39)\end{array}$ & $\begin{array}{c}\text { Pulmonary parenchyma } \\
\text { PET + patients }(n=56)\end{array}$ & $p$-value \\
\hline Total HRCT score & $3.0 \pm 2.9$ & $7.1 \pm 3.6$ & $<0.001$ \\
BVB score & $0.4 \pm 0.7$ & $1.3 \pm 1.1$ & $<0.001$ \\
ND score & $0.6 \pm 0.7$ & $1.3 \pm 0.9$ & $<0.001$ \\
LS score & $0.3 \pm 0.5$ & $0.8 \pm 0.8$ & 0.001 \\
PC score & $0.4 \pm 0.6$ & $1.0 \pm 0.8$ & 0.001 \\
PL score & $0.5 \pm 0.8$ & $1.3 \pm 1.0$ & $<0.001$ \\
LN score & $0.8 \pm 1.1$ & $1.5 \pm 0.9$ & 0.002 \\
Fibrosis on HRCT & $4(10 \%)$ & $22(39 \%)$ & 0.002 \\
\hline
\end{tabular}

Data are presented as mean $\pm \mathrm{SD}$; absolute numbers or percentages if appropriate. PET: positron emission tomography; -: negative; +: positive; $\mathrm{n}$ : number; HRCT: high-resolution computed tomography; BVB: thickening or irregularity of the bronchovascular bundle; PC: parenchymal consolidation (including groundglass opacifications); ND: intraparenchymal nodules; LS: septal and nonseptal lines; PL: focal pleural thickening; LN: enlargement of the mediastinal lymph nodes. $p<0.05$ was considered to indicate significance.

Table 5.5 Area under the curve (AUC) values for the association between positive pulmonary parenchymal results and the different HRCT patterns as included in the HRCT score.

\begin{tabular}{lcc}
\hline & AUC & Confidence interval \\
\hline BVB & 0.75 & $0.65-0.85$ \\
ND & 0.72 & $0.61-0.82$ \\
LS & 0.68 & $0.58-0.79$ \\
PC & 0.75 & $0.58-0.80$ \\
PL & 0.68 & $0.65-0.85$ \\
LN & 0.81 & $0.57-0.80$ \\
\hline
\end{tabular}

AUC: area under the curve; HRCT: high-resolution computed tomography; BVB: thickening or irregularity of the bronchovascular bundle; PC: parenchymal consolidation (including ground-glass opacifications); ND: intraparenchymal nodules; LS: septal and nonseptal lines; PL: focal pleural thickening; LN: enlargement of the mediastinal lymph nodes

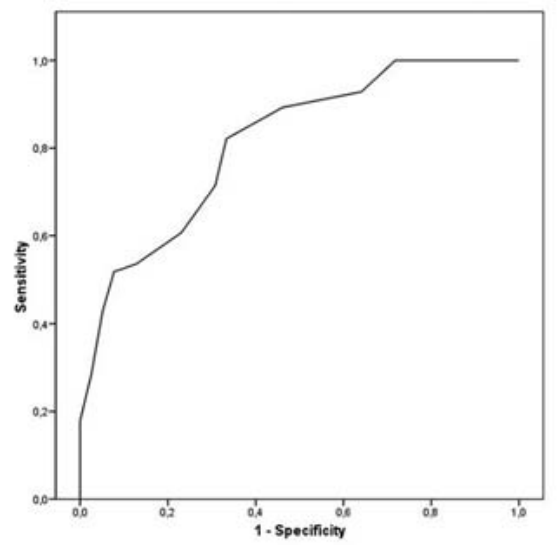

Figure 5.1 Reciever operating characteristic (ROC) curve of the association between the total HRCT score and positive PET results. AUC 0.81; $\mathrm{Cl} 0.73-0.90$ 


\section{Predominant HRCT pattern on area of most intensive thoracic ${ }^{18}$ F-FDG uptake}

The predominant HRCT pattern on the area of most intensive thoracic ${ }^{18}$ F-FDG uptake were parenchymal consolidations in $48 \%$, lymph nodes in $25 \%$, intraparenchymal nodules in $21 \%$, septal and non-septal lines in $4 \%$ and pleural thickening in $2 \%$ of the patients, respectively.

\section{Presence of fibrosis on HRCT}

Signs of fibrosis on HRCT were present in 26 patients. The majority (22/26; 85\%) of these patients showed positive pulmonary PET findings. Median SUVmax in these patients was 7.1 (3.1-16.2). Extrathoracic PET-positive findings were present in 18 (82\%) and positive combined serological inflammatory marker testing in 16 (73\%), respectively. An example of pulmonary PET-positivity in a sarcoidosis patient with fibrotic changes on HRCT is shown in Figure 5.2.
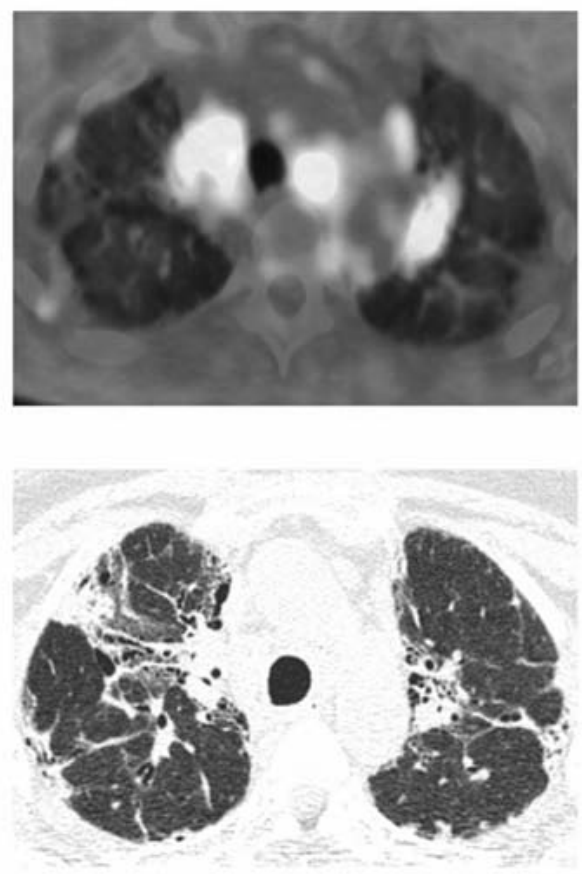

Figure 5.2 Example of pulmonary PET-positivity in a 45-year-old female sarcoidosis patient with fibrotic changes on HRCT.

The transversal PET/CT fusion image at thoracic level (upper image) shows areas of FDG accumulation bilateral in the hilar regions and in several mediastinal lymph nodes. The HRCT image (lower image) at the same level shows architectural parenchymal distortion with parenchymal opacities, thickening and irregularity of the bronchovascular bundle, irregular pleural thickening and in the left lung a limited area of honeycombing. 


\section{Relation between functional tests and metabolic changes}

\section{Association between lung function and pulmonary PET-positivity}

In the PET-positive patient group, DLCO was lower in patients with pulmonary PETpositivity $(65 \pm 20 \%$ predicted) versus the patients with exclusively extrapulmonary PET-positivity (79 $\pm 16 \%$ predicted; $p=0.001$ ). The predictive value for PET-positivity of a model based on lung function parameters expressed by the AUC was for FVC and DLCO $0.62(\mathrm{Cl} 0.49-0.74)$ and $0.73(\mathrm{Cl} 0.60-0.83)$, respectively. All patients with DLCO $<45 \%(n=8)$ or FVC $<50 \%(n=3)$ showed positive pulmonary PET findings.

\section{Discussion}

In this study, we demonstrated that the severity of pulmonary involvement as assessed by HRCT features and lung function parameters is associated with pulmonary PET activity in sarcoidosis. Remarkably, inflammatory activity appeared to be present in the majority of patients with signs of fibrosis on HRCT.

\section{HRCT features and PET findings}

All HRCT features included in the used HRCT scoring system were associated with pulmonary PET positivity. Previous follow-up CT studies in patients with pulmonary sarcoidosis have shown that nodular opacities represent potentially reversible findings, and thus the presence of inflammatory activity in these nodules could be expected. ${ }^{24,25}$ However, the use of HRCT findings to identify the presence of residual active, reversible lesions in a background of fibrosis is much more difficult. The previously mentioned follow-up CT scan studies showed that cystic air spaces and architectural distortion are irreversible findings, with or without treatment. ${ }^{24,25}$ Based on the results of the present study, these latter findings do not exclude the presence of associated potentially reversible pulmonary parenchymal lesions, though. The used HRCT scoring system was criticized in the past because of the lack of an included fibrosis score. ${ }^{6}$ Therefore, in the present study the presence of signs of fibrosis on HRCT was scored separately. The majority of patients with signs of fibrosis on HRCT and CXR had positive pulmonary PET findings. Increased FDG uptake has also been observed in patients with idiopathic pulmonary fibrosis (IPF). ${ }^{26-29}$ All of the models proposed for the pathogenesis of pulmonary fibrosis involve a central role for fibroblasts, which are known to express glucose transporter-1. ${ }^{27,30}$ It is tempting to speculate that the elevated FDG uptake in patients with fibrotic changes, including honeycombing, might be a reflection of increased fibroblast metabolism and not due to inflammatory activity sensu strictu. In contrast to IPF patients, the majority of the pulmonary PET-positive sarcoidosis patients with fibrosis on HRCT in our population showed extrathoracic PET-positive findings (82\%) and increased serological 
inflammatory markers (73\%). Furthermore, mean SUVmax $(7.1 \pm 3.6)$ in these patients was higher than reported by two studies with IPF patients ${ }^{26,27}(0.99 \pm 0.29$ and $2.9 \pm 1.1$, respectively). These findings strongly suggest that PET-positive findings in sarcoidosis patients with CXR stage IV are indeed related to inflammatory activity.

Deciding which sarcoidosis patients with pulmonary fibrosis may benefit from pharmacological treatment remains a challenge to clinicians, as it is not always clear whether respiratory symptoms in these patients are a result of organ damage or due to ongoing inflammation or both. Careful consideration also needs to be given to the likely benefits of any therapy, set against the risk of adverse events, since adding the burden of medication like corticosteroids to these disabled patients might harm them even further. To date, there is no medication with the capability of reversing fibrosis, but there is hope that treatment can arrest fibrosis of reversible granulomas that persist among the fibrotic elements. ${ }^{31}$ This is in line with the results of the post-hoc analysis in the Sarcoidosis Investigators study, which suggested a greater benefit of infliximab therapy in patients with more severe disease, including radiographic stage $I V^{32}$ Techniques that are purported to differentiate fibrotic tissue from granulomatous tissue with inflammatory activity are therefore of importance. There is little evidence to support corticosteroid or immunosuppressive treatment of fibrotic lung disease unless the presence of inflammatory activity can be demonstrated. ${ }^{31}$

Several reports have demonstrated a significant reduction of FDG uptake after the initiation or modification of treatment in sarcoidosis patients. ${ }^{16,18,33-35}$ Keijsers et al. ${ }^{33}$ demonstrated that changes in PET-imaging in a small cohort of sarcoidosis patients treated with infliximab considerably correlated with clinical signs of improvement. Another study showed that diffuse pulmonary parenchymal activity in sarcoidosis patients, as imaged by ${ }^{18}$ F-FDG PET, predicted a future deterioration of DLCO when medical treatment was withheld, while treatment with corticosteroids or immunosuppressive drugs significantly improved lung function. ${ }^{36}$ Teirstein et al. ${ }^{18}$ described that the improvement of symptoms, conventional imaging findings, and physiological data paralleled the therapy-related decrease in SUVmax as seen on the PET scans in most patients, including three patients with radiographic stage IV. Although the exact importance of the presence of inflammatory activity for treatment decisions obviously needs to be established in future prospective, longitudinal studies, the above-mentioned findings support the clinical and therapeutic relevance of positive PET findings in sarcoidosis. Moreover, the detection of PET-positive extrathoracic lesions can be helpful to differentiate between sarcoidosis and other ild like IPF in patients presenting with pulmonary fibrosis.

HRCT appeared to be superior to CXR for presuming positive pulmonary PET findings because pulmonary PET-positivity was assessed or excluded with specific values of the total HRCT score (in case of respectively $>10$ and 0 points). A positive relation was found between pulmonary positive PET findings and higher CXR stages, however, CXR stage 0 did not exclude positive pulmonary PET findings ( $27 \%$ had positive pulmonary PET findings) and a minority of patients (12\%) with CXR stage IV had negative 
pulmonary PET findings. It should be noted that although all patients with a total HRCT score of 0 points $(n=11)$ had negative pulmonary PET findings, five of them demonstrated extrathoracic positive PET findings. This warrants the use of other diagnostic tools like PET for assessment of inflammatory activity in patients with persistent disabling symptoms in the absence of lung functional deterioration or serological signs of inflammatory activity and with no or limited (total HRCT score<10) radiologic abnormalities.

\section{Lung function and PET findings}

The relationship between respiratory functional impairment and morphological abnormalities on HRCT is well established in sarcoidosis patients. ${ }^{6,12,23,37}$ The present study demonstrated a relationship between decreased lung function and pulmonary PET-positivity. This is in accordance with the above-mentioned study of Keijsers et al. ${ }^{36}$ and with a study in a population of patients with mixed interstitial lung disease. ${ }^{27}$ In the present study, PET-positivity was demonstrated in all patients with a DLCO $<45 \%$ or $\mathrm{FVC}<50 \%$. Further studies are required to prove whereas these values can be adopted as threshold for clinical use.

This study has several limitations. First, the study population was gathered in a referral centre for sarcoidosis, so the refractory character of the disease may have been more severe than in a general sarcoidosis population. Follow-up of the patients was generally performed by their own physicians and therefore no standardized follow-up data were available for analysis. Second, HRCT and PET were not performed in every referred patient, since only part of the patients was referred because of unexplained persistent disease related symptoms. This might cause a selection bias. The questions asked by the referring physicians and the reasons for referring the patients to our centre were very diverse and these investigations were not necessary in all patients to answer the questions appropriately. However, this does not mean that these patients had less severe sarcoidosis.

In conclusion, the severity of pulmonary involvement as assessed by HRCT features and lung function parameters was associated with increased PET activity in sarcoidosis. Interestingly, inflammatory activity was demonstrated by positive PET findings, next to pulmonary also extrathoracic (82\%), as well as by serological signs of inflammatory activity $(73 \%)$ in the majority $(85 \%)$ of patients with radiological fibrotic changes. 


\section{References}

1. Costabel U, Hunninghake GW. ATS/ERS/WASOG statement on sarcoidosis. Sarcoidosis Statement Committee. American Thoracic Society. European Respiratory Society. World Association for Sarcoidosis and Other Granulomatous Disorders. Eur Respir J 1999;14:735-7.

2. Keir G, Wells AU. Assessing pulmonary disease and response to therapy: which test? Semin Respir Crit Care Med 2011;31:409-18.

3. Consensus conference: activity of sarcoidosis. Third WASOG meeting, Los Angeles, USA, September 811, 1993. Eur Respir J 1994;7:624-7.

4. Baughman RP, Culver DA, Judson MA. A concise review of pulmonary sarcoidosis. Am J Respir Crit Care Med 2011;183:573-81.

5. DeRemee RA. The roentgenographic staging of sarcoidosis. Historic and contemporary perspectives. Chest 1983;83:128-33.

6. Drent M, De Vries J, Lenters M, Lamers RJ, Rothkranz-Kos S, Wouters EF, van Dieijen-Visser MP, Verschakelen JA. Sarcoidosis: assessment of disease severity using HRCT. Eur Radiol 2003;13: 2462-71.

7. Baughman RP, Shipley R, Desai S, Drent M, Judson MA, Costabel U, du Bois RM, Kavuru M, SchlenkerHerceg R, Flavin S, Lo KH, Barnathan ES. Changes in chest roentgenogram of sarcoidosis patients during a clinical trial of infliximab therapy: comparison of different methods of evaluation. Chest 2009;136:526-35.

8. Verschakelen JA. The role of high-resolution computed tomography in the work-up of interstitial lung disease. Curr Opin Pulm Med 2010;16:503-10.

9. Remy-Jardin M, Giraud F, Remy J, Wattinne L, Wallaert B, Duhamel A. Pulmonary sarcoidosis: role of $\mathrm{CT}$ in the evaluation of disease activity and functional impairment and in prognosis assessment. Radiology 1994;191:675-80.

10. Bergin CJ, Bell DY, Coblentz CL, Chiles C, Gamsu G, Maclntyre NR, Coleman RE, Putman CE. Sarcoidosis: correlation of pulmonary parenchymal pattern at CT with results of pulmonary function tests. Radiology 1989;171:619-24.

11. Leung AN, Brauner MW, Caillat-Vigneron N, Valeyre D, Grenier P. Sarcoidosis activity: correlation of HRCT findings with those of 67Ga scanning, bronchoalveolar lavage, and serum angiotensinconverting enzyme assay. J Comput Assist Tomogr 1998;22:229-34.

12. Abehsera M, Valeyre D, Grenier P, Jaillet H, Battesti JP, Brauner MW. Sarcoidosis with pulmonary fibrosis: CT patterns and correlation with pulmonary function. AJR Am J Roentgenol 2000;174: 1751-7.

13. Oberstein A, von Zitzewitz $H$, Schweden F, Muller-Quernheim J. Non invasive evaluation of the inflammatory activity in sarcoidosis with high-resolution computed tomography. Sarcoidosis Vasc Diffuse Lung Dis 1997;14:65-72.

14. Keijsers RG, Grutters JC, Thomeer M, Du Bois RM, Van Buul MM, Lavalaye J, Van Den Bosch JM, Verzijlbergen FJ. Imaging the inflammatory activity of sarcoidosis: sensitivity and inter observer agreement of (67)Ga imaging and (18)F-FDG PET. Q J Nucl Med Mol Imaging 2011;55:66-71.

15. Nishiyama Y, Yamamoto Y, Fukunaga K, Takinami H, Iwado Y, Satoh K, Ohkawa M. Comparative evaluation of 18F-FDG PET and 67Ga scintigraphy in patients with sarcoidosis. J Nucl Med 2006;47: 1571-6.

16. Braun JJ, Kessler R, Constantinesco A, Imperiale A. 18F-FDG PET/CT in sarcoidosis management: review and report of 20 cases. Eur J Nucl Med Mol Imaging 2008;35:1537-43.

17. Keijsers RG, Verzijlbergen FJ, Oyen WJ, van den Bosch JM, Ruven HJ, van Velzen-Blad H, Grutters JC. 18F-FDG PET, genotype-corrected ACE and SIL-2R in newly diagnosed sarcoidosis. Eur J Nucl Med Mol Imaging 2009;36:1131-7.

18. Teirstein AS, Machac J, Almeida O, Lu P, Padilla ML, lannuzzi MC. Results of 188 whole-body fluorodeoxyglucose positron emission tomography scans in 137 patients with sarcoidosis. Chest 2007;132:1949-53.

19. Mostard RLM, Voo S, van Kroonenburgh MJPG, Verschakelen JA, Wijnen PAHM, Nelemans PJ, Erckens RJ, Drent M. Inflammatory activity assessment by F18 FDG-PET/CT in persistent symptomatic sarcoidosis Respir Med 2011;105:1917-24. 
20. de Kleijn WP, Elfferich MD, De Vries J, Jonker GJ, Lower EE, Baughman RP, King TE Jr, Drent M. Fatigue in sarcoidosis: American versus Dutch patients. Sarcoidosis Vasc Diffuse Lung Dis 2009;26: 92-7.

21. Hoitsma E, De Vries J, Drent M. The small fiber neuropathy screening list: Construction and crossvalidation in sarcoidosis. Respir Med 2011;105:95-100.

22. Quanjer PH, Tammeling GJ, Cotes JE, Pedersen OF, Peslin R, Yernault JC. Lung volumes and forced ventilatory flows. Report Working Party Standardization of Lung Function Tests, European Community for Steel and Coal. Official Statement of the European Respiratory Society. Eur Respir J Suppl 1993;16:5-40.

23. Akira M, Kozuka $T$, Inoue $Y$, Sakatani $M$. Long-term follow-up CT scan evaluation in patients with pulmonary sarcoidosis. Chest 2005;127:185-91.

24. Brauner MW, Lenoir S, Grenier P, Cluzel P, Battesti JP, Valeyre D. Pulmonary sarcoidosis: CT assessment of lesion reversibility. Radiology 1992;182:349-54.

25. Murdoch J, Muller NL. Pulmonary sarcoidosis: changes on follow-up CT examination. AJR Am J Roentgenol 1992;159:473-7.

26. Umeda Y, Demura Y, Ishizaki T, Ameshima S, Miyamori I, Saito Y, Tsuchida T, Fujibayashi Y, Okazawa $\mathrm{H}$. Dual-time-point 18F-FDG PET imaging for diagnosis of disease type and disease activity in patients with idiopathic interstitial pneumonia. Eur J Nucl Med Mol Imaging 2009;36:1121-30.

27. Groves AM, Win T, Screaton NJ, Berovic M, Endozo R, Booth H, Kayani I, Menezes LJ, Dickson JC, Ell PJ. Idiopathic pulmonary fibrosis and diffuse parenchymal lung disease: implications from initial experience with 18F-FDG PET/CT. J Nucl Med 2009;50:538-45.

28. Meissner HH, Soo Hoo GW, Khonsary SA, Mandelkern M, Brown CV, Santiago SM. Idiopathic pulmonary fibrosis: evaluation with positron emission tomography. Respiration 2006;73:197-202.

29. Nusair S, Rubinstein R, Freedman NM, Amir G, Bogot NR, Izhar U, Breuer R. Positron emission tomography in interstitial lung disease. Respirology 2007;12:843-7.

30. Ortiz PA, Haspel HC. Differential control of the functional cell surface expression and content of hexose transporter GLUT-1 by glucose and glucose metabolism in murine fibroblasts. Biochem $J$ 1993;295 ( Pt 1):67-72.

31. Teirstein AT, Morgenthau AS. "End-stage" pulmonary fibrosis in sarcoidosis. Mt Sinai J Med 2009;76:30-6.

32. Baughman RP, Drent M, Kavuru M, Judson MA, Costabel U, du Bois R, Albera C, Brutsche M, Davis G, Donohue JF, Muller-Quernheim J, Schlenker-Herceg R, Flavin S, Lo KH, Oemar B, Barnathan ES. Infliximab therapy in patients with chronic sarcoidosis and pulmonary involvement. Am J Respir Crit Care Med 2006;174:795-802.

33. Keijsers RG, Verzijlbergen JF, van Diepen DM, van den Bosch JM, Grutters JC. 18F-FDG PET in sarcoidosis: an observational study in 12 patients treated with infliximab. Sarcoidosis Vasc Diffuse Lung Dis 2008;25:143-9.

34. Mostard RL, Prompers L, Weijers RE, van Kroonenburgh MJ, Wijnen PA, Geusens PP, Drent M. F-18 FDG PET/CT for Detecting Bone and Bone Marrow Involvement in Sarcoidosis Patients. Clin Nucl Med 2012;37:21-5.

35. Milman N, Graudal N, Loft A, Mortensen J, Larsen J, Baslund B. Effect of the TNFalpha inhibitor adalimumab in patients with recalcitrant sarcoidosis: a prospective observational study using FDGPET. Clin Respir J 2011 Nov 30 Epub ahead of print.

36. Keijsers RG, Verzijlbergen FJ, van den Bosch JM, Zanen P, van de Garde EM, Oyen WJ, Grutters JC. 18F-FDG PET as a predictor of pulmonary function in sarcoidosis Sarcoidosis Vasc Diffuse Lung Dis 2011;28:123-9.

37. Hansell DM, Milne DG, Wilsher ML, Wells AU. Pulmonary sarcoidosis: morphologic associations of airflow obstruction at thin-section CT. Radiology 1998;209:697-704. 



\section{Chapter 6}

\section{A predictive tool for an effective use of ${ }^{18}$ F-FDG PET in assessing activity of sarcoidosis}
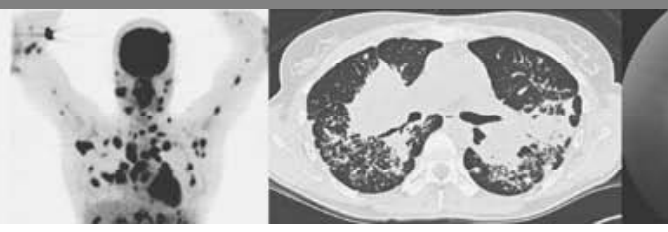

RLM Mostard, SMJ Van Kuijk, JA Verschakelen, MJPG van Kroonenburgh, PJ Nelemans, PAHM Wijnen, M Drent

BMC Pulm Med 2012; in press 


\section{Abstract}

\section{Background}

${ }^{18}$ F-FDG PET/CT (PET) is useful in assessing inflammatory activity in sarcoidosis. However, no appropriate indications are available. The aim of this study was to develop a prediction rule that can be used to identify symptomatic sarcoidosis patients who have a high probability of PETpositivity.

\section{Methods}

We retrospectively analyzed a cohort of sarcoidosis patients with persistent disabling symptoms $(n=95)$. Results of soluble interleukin-2 receptor (sIL-2R) assessment and high-resolution computed tomography (HRCT) were included in the predefined model. HRCT scans were classified using a semi-quantitative scoring system and PET findings as positive or negative, respectively. A prediction model was derived based on logistic regression analysis. We quantified the model's performance using measures of discrimination and calibration. Finally, we constructed a prediction rule that should be easily applicable in clinical practice.

\section{Results}

The prediction rule showed good calibration and good overall performance (goodness-of-fit test, $p=0.78$, Brier score $20.1 \%$ ) and discriminated between patients with positive and negative PET findings (area under the receiver-operating characteristic curve, 0.83 ). If a positive predictive value for the presence of inflammatory activity of $\geq 90 \%$ is considered acceptable for clinical decision-making without referral to PET, PET would be indicated in only $29.5 \%$ of the patients. Using a positive predictive value of $98 \%$, about half of the patients (46.3\%) would require referral to $\mathrm{PET}$.

\section{Conclusions}

The derived and internally validated clinical prediction rule, based on SIL-2R levels and HRCT scoring results, appeared to be useful to identify sarcoidosis patients with a high probability of inflammatory activity. Using this rule may enable a more effective use of PET scan for assessment of inflammatory activity in sarcoidosis. 


\section{Introduction}

Sarcoidosis is a multisystemic disease characterized by cellular immunity activity with formation of noncaseating granuloma in various organ systems. ${ }^{1,2}$ Assessing the presence of inflammatory activity is important for the management of sarcoidosis and for the follow-up of treatment effect. ${ }^{3-5}$ Unlike acute sarcoidosis ${ }^{6,7}$, assessment of inflammatory activity in sarcoidosis patients with persistent disabling symptoms that cannot be explained from the results of routine investigations, including the absence of lung functional or chest radiographic deterioration, remains a challenge to clinicians. $^{8-10}$ In these patients, it is often complicated to differentiate between reversible and irreversible disease. Symptoms like fatigue can be nonspecific and difficult to objectify. ${ }^{11-14}$ Furthermore, symptoms like coughing and dyspnea might be related to ongoing inflammatory activity as well as to end-stage disease, i.e. pulmonary fibrosis. In this respect, it is important to know about the presence or absence of inflammatory activity, as fibrosis itself is irreversible. In general, immunosuppressive treatment does not seems beneficial to patients with fibrosis without ongoing inflammatory activity. ${ }^{11}$

Inflammatory activity is characterized by ongoing T-cell and macrophage activity and granuloma formation, reflected by an increase in serological markers of inflammatory activity, i.e. angiotensin-converting enzyme (ACE), soluble interleukin-2 receptor (sIL-2R) and neopterin, or abnormalities of glucose metabolism. ${ }^{7,15,16}{ }^{18} \mathrm{~F}$-FDG PET/CT (PET) is used to detect high glucose metabolism and has been shown to be useful for the assessment of inflammatory activity in sarcoidosis., ${ }^{77-22}$ Previous studies found that elevated serological inflammatory markers, abnormalities on high-resolution computed tomography (HRCT) and impaired lung function were associated with PETpositivity. $7,8,23,24$ In addition, diffusely increased metabolic activity in the lung parenchyma was found to predict a future deterioration of diffusion capacity for carbon monoxide (DLCO) when untreated. ${ }^{24}$

It is important to gain knowledge and understanding about the appropriate use of this new technique for assessment of inflammatory activity in clinical practice. ${ }^{21,22}$ This means that, in view of the radiation dose and costs, defining appropriate indications for PET-scanning is vital. Therefore, the aim of this study was to develop a prediction rule that can be used in clinical practice to identify symptomatic sarcoidosis patients for whom there is a high probability that PET will show the presence of inflammatory activity.

\section{Materials and methods}

We reviewed the medical records of all sarcoidosis patients referred to the interstitial lung disease service (ild care team) of the department of Respiratory Medicine at the Maastricht University Medical Centre (Maastricht, The Netherlands), a tertiary referral 
center, between June 2005 and September 2010. The study included all patients who underwent laboratory and lung function testing, HRCT, as well as a PET scan $(n=106)$. The indication for performing PET was the presence of unexplained, non organ specific, disease-related disabling symptoms persisting for at least one year. Persistent disabling symptoms were defined as the presence of more than one symptom that had substantial influence on quality of life, and that could not be explained from the results of routine investigations, including the absence of lung functional or chest radiographic deterioration. These symptoms had to be present for at least one year and included fatigue (Fatigue Assessment Scale [FAS] $\geq 22)^{25}$, symptoms compatible with small fiber neuropathy (SFN; SFN Screenings List [SFNSL] score $\geq 11$ ) $^{26}$, arthralgia and/or muscle pain, dyspnea (MRC dyspnea scale $\geq 3$ ), exercise intolerance or coughing. Laboratory and lung function testing were performed within a 2-week interval before or after the HRCT. PET scans were made within a 3-months interval before or after the HRCT, without changing the therapy during this period. The diagnosis was based on consistent clinical features and bronchoalveolar lavage (BAL) fluid analysis results, according to the international guidelines. The diagnosis was confirmed histological, demonstrating noncaseating epitheloid cell granulomas, in most cases (75\%). ${ }^{1}$ Patients with known co-morbid conditions associated with positive PET findings were excluded. This meant that five patients with common variable immunodeficiency (CVID), five patients with malignancies and one patient with both rheumatoid arthritis and amyloidosis were excluded. After exclusion based on these criteria, 95 patients were selected. The study protocol was approved by the Medical Research Ethics Committee of the Maastricht University Medical Centre (MEC number 04.145.11).

\section{Laboratory and lung-function tests}

Serum levels of sIL-2R were analyzed using commercially available Diaclone ELISA kits (Sanquin, Amsterdam, The Netherlands) and considered elevated if $>3154 \mathrm{pg} / \mathrm{ml}$. Other laboratory analysis and lung function tests were performed as described previously (Chapter 3$)^{8}$

\section{Imaging}

Thin-section scans with 1-mm collimation were obtained at $10-\mathrm{mm}$ intervals through the chest (Somaton Plus, Siemens, Erlangen, Germany). The scanning parameters included $137 \mathrm{kVP}, 255 \mathrm{~mA}$, and 1-s scanning time. Both mediastinal (width $400 \mathrm{HU}$, level $40 \mathrm{HU}$ ) and lung (width $1600 \mathrm{HU}$, level $-800 \mathrm{HU}$ ) window images were obtained. Scans were reconstructed with a high-frequency reconstruction algorithm.

A whole body ${ }^{18}$ F-FDG PET/CT scan was performed using a Gemini ${ }^{\circ}$ PET/CT (Philips Medical Systems) scanner with time-of-flight (TOF) capability and a 64-slice Brilliance CT scanner. Patients were fasting for at least six hours before the examination. In all patients blood glucose was measured to ensure that the blood glucose was below 
$10 \mathrm{mmol} / \mathrm{l} .{ }^{18}$ F-FDG (GE Health, Eindhoven, The Netherlands) was injected intravenously and followed by physiologic saline $(10 \mathrm{ml})$. The injected total activity of FDG depended on the weight of the patient. Mean injected dose was: $200 \mathrm{MBq}$. After a resting period of 45 minutes (time needed for uptake of FDG) PET and CT images were acquired from the head to the feet. A low-dose CT scan was performed without intravenous contrast and was used for attenuation correction of the PET images. The PET images were acquired in 5-minute bed positions. The complete PET data set was reconstructed iteratively with a reconstruction increment of $5 \mathrm{~mm}$ to provide isotropic voxel.

\section{Image analysis}

An experienced thoracic radiologist (JV), blinded to the patient's clinical history and to the PET findings, classified the scans of both lungs using a semi-quantitative HRCT scoring system that has been described by Oberstein et al. ${ }^{27}$ and that has been used in previous studies by our group (a detailed description of this scoring system is shown in the appendix). ${ }^{28}$

All PET scans were interpreted by an experienced nuclear medicine physician (MvK), blinded to the patient's clinical history and to the HRCT findings. PET findings in the lungs, lymph nodes, or other soft tissues or bones were scored as either positive or negative. A positive PET scan interpretation was performed visually, with a threshold standardized uptake value (SUVmax) $\geq 2.5 .{ }^{18}$ F-FDG uptake was quantified by drawing a region of interest around the area of pathology of the co-registered transaxial slice. SUVmax was calculated as the maximal pixel activity within the region of interest. Inter-reader reliability of both the total HRCT score and the simple PET classification system had already demonstrated good agreement in the above-mentioned studies with the same observers (with weighted kappa values of 0.99 and 1.00, respectively). ${ }^{8,28}$ Accordingly, a single radiologist and a single nuclear physician were regarded as sufficient in the present study.

\section{Potential predictors}

Because of the limited number of patients with a negative PET scan (the least frequent outcome in this study) and the usual recommendation to include one predictor for at least ten events, we had to select the two predictors with the strongest associations with PET-positivity. ${ }^{29}$ Based on the results of recent studies, the following clinical characteristics were selected in view of their association with PETpositivity: elevated serological inflammatory markers (sIL-2R and neopterin), HRCT abnormalities as assessed by the HRCT scoring system, and lung function tests (forced vital capacity (FVC), DLCO). ${ }^{8,23}$ of the serological inflammatory parameters, positive SIL-2R had shown the strongest association with PET-positivity in the previous study. ${ }^{8}$ Neopterin was not added as predictor since neopterin values were missing in almost half of the studied patients. Moreover, from a practical point of view sIL-2R also is 
preferable considering that in clinical practice accessibility to neopterin measurement is less compared to sIL-2R. Lung function tests and HRCT scoring results were strongly associated with each other ${ }^{23}$ and we decided to include the total HRCT score. In the end, therefore, two potential predictor variables (sIL-2R and total HRCT scoring results) were included in the predefined model.

\section{Model development}

Missing values were imputed using regression imputation, since the omission of patients who have one or more predictor variables missing from the analysis can cause a considerable loss of precision and may bias results. ${ }^{30-32}$ Predefined predictors (sIL-2R and the total HRCT score) were entered into a multivariable logistic regression model with the PET result (positive versus negative) as the dependent variable. As recommended by prediction modeling guidelines, the preselected predictors remained in the model irrespective of statistical significance. ${ }^{29}$

To assess the performance of the final model, we quantified its performance with respect to discrimination and calibration. Discrimination is the model's ability to discriminate between PET-negative and PET-positive patients, quantified as the area under the receiver operating characteristic (ROC) curve. ${ }^{33}$ This can range from 0.5 (no discrimination) to 1.0 (perfect discrimination). Calibration is used to quantify the agreement between the predicted probability and the actual, or observed, frequencies. To this end, we computed the Hosmer and Lemeshow $(\mathrm{H}-\mathrm{L})$ goodness-offit statistic. A high $\mathrm{H}$-L statistic will yield a low $\mathrm{p}$-value and provides evidence of lack of fit. As a measure of overall performance, we computed the Brier score, which was scaled from 0 to $100 \%$, so it could be interpreted as an r-squared statistic of explained variance. $^{34}$ Statistical analyses were performed using $\mathrm{R}$ (version 2.12.2; http://www.r-project.org).

\section{Results}

Table 6.1 shows a summary of relevant demographic and clinical characteristics of the sarcoidosis patients ( $n=95: 87$ Caucasians, five of African origin and three of Asian origin) categorized by the absence $(n=18: 19 \%)$ or presence $(n=77: 81 \%)$ of positive PET findings. The PET-positive group demonstrated significantly higher sIL-2R levels ( $n=77 ; 18$ (18.9\%) missing values) and total HRCT scores, but lower DLCO values compared to the PET-negative group. The number of patients with a CXR stage $0 /$ I was higher in the PET-negative group. In the PET-positive group, 56/77 (73\%) patients showed pulmonary PET-positive findings and 61/77 (79\%) demonstrated extrathoracic PET-positive findings.

Signs of fibrosis on HRCT were present in 26 patients. Twenty-two (85\%) of these patients had positive pulmonary PET findings whereas only four $(15 \%)$ had negative pulmonary PET findings $(p=0.002)$. Median SUVmax in the former patients was 7.1 
(3.1-16.2). Extrathoracic PET-positive findings were present in 18 (82\%) and positive serological inflammatory marker testing in $16(73 \%)$, respectively, of those pulmonary PET-positive patients with signs of fibrosis on HRCT.

Table 6.1 Clinical and demographic characteristics of the sarcoidosis patients categorized by absence or presence of positive PET findings.

\begin{tabular}{|c|c|c|c|}
\hline & $\begin{array}{c}\text { PET - patients } \\
(n=18)\end{array}$ & $\begin{array}{c}\text { PET + patients } \\
(n=77)\end{array}$ & $p$-value \\
\hline age (yrs) & $46(22-72)$ & $45(24-76)$ & NS \\
\hline sex (male) & $11(61 \%)$ & $44(57 \%)$ & NS \\
\hline time since diagnosis (yrs) & $4(1-20)$ & $2(1-21)$ & NS \\
\hline Therapy total, number (\%) & $6(33 \%)$ & $20(26 \%)$ & NS \\
\hline $1 / 2 / 3 / 4$ & $3 / 0 / 3 / 0$ & $10 / 1 / 7 / 2$ & NS \\
\hline ACE (9-25 U/I) & $15(1-29)$ & $18(3-60)$ & NS \\
\hline slL-2R (240-3154 pg/ml) & 1784 (518-4614) & $3434(1191-15000)$ & 0.048 \\
\hline Neopterin $(<2.5 \mathrm{ng} / \mathrm{ml})$ & $1.7(0.8-2.6)$ & $2.8(0.7-18.2)$ & NS \\
\hline CRP $(2-9 \mu \mathrm{g} / \mathrm{ml})$ & $6(1-15)$ & $6(1-80)$ & NS \\
\hline CXR stage $0 / I$ & $12 / 1$ & $18 / 14$ & 0.005 \\
\hline CXR stage II/III/IV & $1 / 3 / 1$ & $12 / 8 / 25$ & NS \\
\hline Total HRCT score & $2.9 \pm 3.0$ & $6.0 \pm 3.9$ & 0.002 \\
\hline FVC total (\% pred) & $90 \pm 22$ & $91 \pm 22$ & NS \\
\hline CXR 0-I & $94 \pm 24$ & $103 \pm 15$ & NS \\
\hline CXR II-IV & $79 \pm 14$ & $83 \pm 22$ & NS \\
\hline DLCO total (\% pred) & $78 \pm 18$ & $69 \pm 20$ & 0.046 \\
\hline CXR 0-I & $79 \pm 17$ & $80 \pm 17$ & NS \\
\hline CXR II-IV & $71 \pm 19$ & $60 \pm 19$ & NS \\
\hline
\end{tabular}

Data are presented as median with range in parentheses; mean $\pm \mathrm{SD}$; absolute numbers or percentages if appropriate. PET: positron emission tomography; -: negative; +: positive; n:number; yrs: years; NS: not significant; therapy total: total number of patients treated at time of PET scanning; 1 : prednisone monotherapy; 2: methotrexate monotherapy; 3: prednisone and methotrexate combination therapy; 4 : methotrexate and infliximab combination therapy; ACE: serum angiotensin-converting enzyme; sIL-2R: soluble interleukin-2 Receptor; CRP: C-reactive protein; CXR: chest X-ray; HRCT: high-resolution computed tomography; FVC: forced vital capacity; \% pred: percentage of predicted values; DLCO: diffusion capacity for carbon monoxide. $\mathrm{p}<0.05$ was considered to indicate significance.

\section{Derivation of the scores in the prediction rule}

Table 6.2 shows the regression coefficients and odds ratios as derived from the original prediction model for the probability of a positive PET result, and a validated model after the bootstrap validation. The bootstrap validation yielded a shrinkage factor of 0.93, which was used to adjust the regression coefficients for overfitting. The formula in table 2 allows predicted probabilities to be calculated for future patients. Figure 6.1 shows the ROC curve of the internally validated model. The area under the curve was 0.83 (95\% confidence interval $(\mathrm{Cl})=0.74-0.93)$ indicating good discriminatory ability. Calibration as quantified using the $\mathrm{H}-\mathrm{L}$ goodness-of-fit test yielded a p-value of 0.78 , and the Brier score was $20.1 \%$, indicating both good calibration and good overall performance. 
To improve feasibility of the prediction rule in clinical practice, the rescaled regression coefficients for sIL-2R and the total HRCT score were multiplied by 4 in order to arrive at scores of 8 for a positive sIL-2R result and 1 per unit of the HRCT score, respectively. Hence, the prediction rule score is based on sIL-2R results ( 0 points for a negative result and 8 points for a positive result) and total HRCT score (0-18 points). For example, the prediction rule score for a patient with a positive sIL-2R result and a total HRCT score of 5 would be $13(8+5)$ points.

Table 6.2 Regression coefficients and odds ratios with 95\% confidence intervals as derived from the original model and the internally validated model.

\begin{tabular}{lccccc}
\hline & \multicolumn{3}{c}{ Original model } & \multicolumn{3}{c}{ Model after internal validation } \\
\cline { 2 - 6 } Variable & $\begin{array}{c}\text { Regression } \\
\text { Coefficient }\end{array}$ & $\begin{array}{c}\text { Odds ratio } \\
(95 \% \mathrm{Cl})\end{array}$ & $\begin{array}{c}\text { p-value } \\
\text { Coefficient* }\end{array}$ & $\begin{array}{c}\text { Odds ratio } \\
(95 \% \mathrm{Cl})\end{array}$ \\
\hline Intercept & -0.32 & - & - & -0.23 & - \\
Elevated sIL-2R levels & 1.98 & $7.27(1.86-28.40)$ & 0.004 & 1.85 & $6.33(1.73-28.17)$ \\
Total HRCT score & 0.24 & $1.27(1.06-1.52)$ & 0.011 & 0.22 & $1.25(1.04-1.50)$ \\
\hline To calculate the absolute risk of a positive PET result: & & & \\
$\mathrm{P}_{\text {(PET-positive) }}=(1 /(1+\exp (-(-0.23+1.85 *$ sIL-2R $+0.22 *$ HRCT score $)))) * 100 \%$ & \\
\hline
\end{tabular}

$\mathrm{Cl}$ : confidence interval; sIL-2R: soluble interleukin-2 Receptor; HRCT: high-resolution computed tomography; PET: positron emission tomography

* Regression coefficients after adjustment for overfitting by shrinkage (shrinkage factor $=0.93$ ); the intercept was re-estimated.

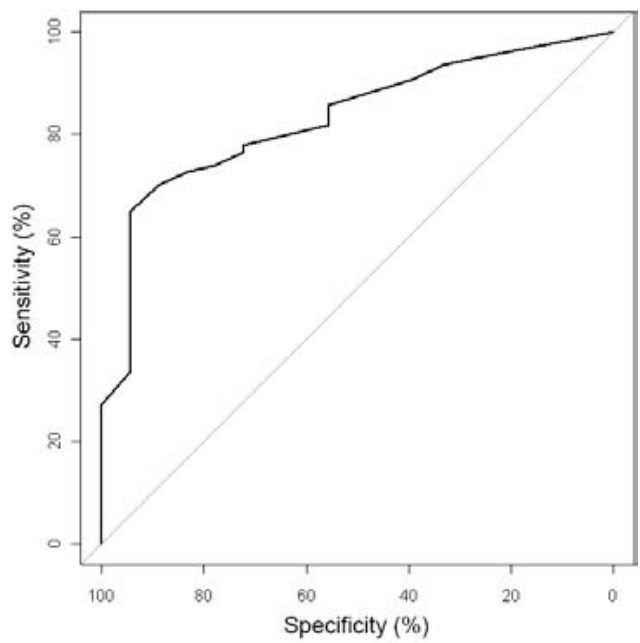

Figure 6.1 Receiver operating characteristic (ROC) curve of the model's ability to discriminate between PET-negative and PET-positive patients.

The implications of using the prediction rule in clinical practice are shown in Table 6.3. The right column displays the number and percentage of patients that would have an 
indication to be referred for PET using consecutive cut-off points for the prediction rule score. No data above a prediction rule score of 21 points are displayed, since this was the highest prediction score observed in the included patients. As this table shows, a prediction rule score of $\geq 6$ points (which can be attained with a positive sIL-2R result only) is associated with a positive predictive value of $\geq 91.0 \%$ for the presence of inflammatory activity, whereas the negative predictive value would be $42.9 \%$ in this case. If a positive predictive value of $\geq 90 \%$ is considered acceptable for clinical decision-making without referral to PET, only patients with a score $<6(29.5 \%$ (28/95)) would have to be referred for PET (Table 6.3, right column). Using a somewhat higher cut-off value of $\geq 10$ points yields a positive predictive value $\geq 98 \%$, and about half of the patients $(46.3 \%)$ would require referral to PET.

Table 6.3 Sensitivity, specificity, and positive and negative predictive values for PET-positivity at consecutive cut-off points of the prediction rule score.

\begin{tabular}{lccccc}
\hline $\begin{array}{l}\text { Prediction rule } \\
\text { cut-off point* }\end{array}$ & $\begin{array}{c}\text { Sensitivity } \\
(\%)^{* *}\end{array}$ & $\begin{array}{c}\text { Specificity } \\
(\%)^{* *}\end{array}$ & $\begin{array}{c}\text { Positive predictive } \\
\text { value }(\%)^{* *}\end{array}$ & $\begin{array}{c}\text { Negative predictive } \\
\text { value (\%)** }\end{array}$ & $\begin{array}{c}\text { Patients referred } \\
\text { for PET (\%)*** }\end{array}$ \\
\hline 0 & $100(77 / 77)$ & $0(0 / 18)$ & $81(77 / 95)$ & - & $0(/ 95)$ \\
1 & $94.8(73 / 77)$ & $27.8(5 / 18)$ & $84.8(73 / 86)$ & $55.5(5 / 9)$ & $9.5(9 / 95)$ \\
2 & $93.5(72 / 77)$ & $33.3(6 / 18)$ & $85.7(72 / 84)$ & $54.5(6 / 11)$ & $11.6(11 / 95)$ \\
3 & $90.9(70 / 77)$ & $38.9(7 / 18)$ & $86.4(70 / 81)$ & $50.0(7 / 14)$ & $14.7(14 / 95)$ \\
4 & $85.7(66 / 77)$ & $55.6(10 / 18)$ & $89.2(66 / 74)$ & $47.6(10 / 21)$ & $22.1(21 / 95)$ \\
5 & $81.8(63 / 77)$ & $55.6(10 / 18)$ & $88.7(63 / 71)$ & $41.7(10 / 24)$ & $25.3(24 / 95)$ \\
6 & $79.2(61 / 77)$ & $66.7(12 / 18)$ & $91.0(61 / 76)$ & $42.9(12 / 28)$ & $29.5(28 / 95)$ \\
7 & $77.9(60 / 77)$ & $72.2(13 / 18)$ & $92.3(60 / 65)$ & $43.3(13 / 30)$ & $31.6(30 / 95)$ \\
8 & $76.6(59 / 77)$ & $72.2(13 / 18)$ & $92.2(59 / 64)$ & $41.9(13 / 31)$ & $32.6(31 / 95)$ \\
9 & $72.7(56 / 77)$ & $83.3(15 / 18)$ & $94.9(56 / 59)$ & $41.7(15 / 36)$ & $37.9(36 / 95)$ \\
10 & $64.9(50 / 77)$ & $94.4(17 / 18)$ & $98.0(50 / 51)$ & $38.6(17 / 44)$ & $46.3(44 / 95)$ \\
11 & $53.2(41 / 77)$ & $94.4(17 / 18)$ & $97.6(41 / 42)$ & $32.0(17 / 53)$ & $55.8(53 / 95)$ \\
12 & $48.1(37 / 77)$ & $94.4(17 / 18)$ & $97.4(37 / 38)$ & $29.8(17 / 57)$ & $60.0(57 / 95)$ \\
13 & $41.6(32 / 77)$ & $94.4(17 / 18)$ & $97.0(32 / 33)$ & $27.4(17 / 62)$ & $65.3(62 / 95)$ \\
14 & $35.1(27 / 77)$ & $94.4(17 / 18)$ & $96.4(27 / 28)$ & $25.4(17 / 67)$ & $70.5(67 / 95)$ \\
15 & $27.3(21 / 77)$ & $100(18 / 18)$ & $100(21 / 21)$ & $24.3(18 / 74)$ & $77.9(74 / 95)$ \\
16 & $24.6(19 / 77)$ & $100(18 / 18)$ & $100(19 / 19)$ & $23.7(18 / 76)$ & $80.0(76 / 95)$ \\
17 & $20.8(16 / 77)$ & $100(18 / 18)$ & $100(16 / 16)$ & $22.8(18 / 79)$ & $83.2(79 / 95)$ \\
18 & $13.0(10 / 77)$ & $100(18 / 18)$ & $100(10 / 10)$ & $21.2(18 / 85)$ & $89.5(85 / 95)$ \\
19 & $7.8(6 / 77)$ & $100(18 / 18)$ & $100(6 / 6)$ & $20.2(18 / 89)$ & $93.7(89 / 95)$ \\
20 & $7.8(6 / 77)$ & $100(18 / 18)$ & $100(6 / 6)$ & $20.2(18 / 89)$ & $93.7(89 / 95)$ \\
21 & $3.9(3 / 77)$ & $100(18 / 18)$ & $100(3 / 3)$ & $19.6(18 / 92)$ & $96.8(92 / 95)$ \\
\hline & & & & &
\end{tabular}

*Patients were considered test-positive if the prediction rule score was at or above this level. **Data in parentheses represent proportions. ${ }^{* * *}$ Number of patients that would have been indicated for referral to PET if the prediction rule score was at or above the corresponding level.

Figure 6.2 provides a graphical representation of the predicted values and their $95 \%$ Cls. The probability can also be calculated using the formula given in Table 6.2. 


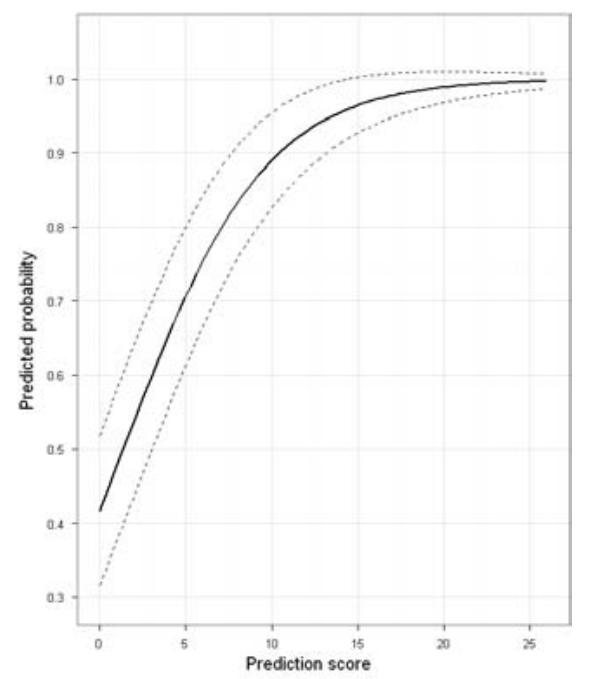

Figure 6.2 Predicted probability of inflammatory activity being detected by PET in sarcoidosis patients as a function of the prediction rule score.

\section{Discussion}

In the present study, we developed an internally validated clinical prediction rule that appeared to be useful to identify symptomatic sarcoidosis patients in whom the presence of inflammatory activity is highly likely. This clinical prediction rule is based on sIL-2R (positive/negative) and HRCT results. Inflammatory activity was regarded as present if PET findings were positive.

To the best of our knowledge, this is the first clinical prediction rule to predict inflammatory activity in sarcoidosis patients that has been constructed according to the methodological standards for clinical prediction rules.

In general, assessment of inflammatory activity is vital in the management of sarcoidosis, and is especially necessary to monitor the course of sarcoidosis and guide therapeutic strategies. ${ }^{3-5}$ The presence of inflammatory activity is considered to indicate persistent evolution of the disease and may therefore be a target for therapy. The presence of inflammatory activity can be regarded as certain in case CXR findings or lung function test results provide evidence of disease progression. ${ }^{4}$ However, the management of patients with unexplained, non organ specific, persistent disabling symptoms requires reliable and clinically useful markers of inflammatory activity. PET has been shown to be a very sensitive technique to assess inflammatory activity in sarcoidosis. ${ }^{7,17-20}$ Several reports demonstrated a significant reduction of FDG uptake after the initiation or modification of treatment in sarcoidosis patients. $5,17,18,35,36$ 
Keijsers et al. ${ }^{5}$ demonstrated that changes in PET imaging in a small cohort of sarcoidosis patients treated with infliximab correlated with clinical improvement. Another study showed that diffuse pulmonary parenchymal activity in sarcoidosis patients, as imaged by ${ }^{18}$ F-FDG PET, predicted a future deterioration of DLCO when medical treatment was withheld, while treatment significantly improved lung function. ${ }^{24}$

In the present study, a high frequency of both pulmonary- and extrathoracic PETpositivity as well as serological signs of inflammatory activity was established in the majority of patients. Even most sarcoidosis patients with signs of pulmonary fibrosis demonstrated positive pulmonary PET findings and extrathoracic PET-positive findings (82\%) and increased serological inflammatory markers (73\%). These findings strongly suggest that PET-positive findings in sarcoidosis patients with CXR stage IV are related to inflammatory activity.

This supports the value of PET, even in patients with signs of pulmonary fibrosis. ${ }^{8,23}$ Deciding which sarcoidosis patients with signs of pulmonary fibrosis may benefit from pharmacological treatment remains a challenge to clinicians, as it is not always clear whether respiratory symptoms in these patients are a result of organ damage or due to ongoing inflammation or both. To date, there is no medication with the capability of reversing fibrosis, but treatment might arrest fibrosis of reversible granulomas that persist among the fibrotic elements. ${ }^{37}$ Teirstein et al. ${ }^{17}$ reported a response to therapy in PET-positive patients, including patients with radiographic stage IV, with partial clearing of the parenchymal radiographic abnormalities, improvement in pulmonary function and decreased hypermetabolism by repeated PET. Furthermore, detecting extrathoracic inflammatory lesions may also provide an explanation for (mainly extrathoracic) symptoms. ${ }^{8}$

The question can be raised which patients might benefit from having a PET scan. ${ }^{21,22}$ Until now, there have been no guidelines for selecting those patients with unexplained persistent disabling symptoms for whom PET might offer added value in the assessment of inflammatory activity. The prediction rule developed in the present study proved to be able to distinguish between patients with positive and negative PET findings. Applying this simple prediction rule quantifies the probability that inflammatory activity will be established by PET. As presented in Table 6.3, PET would only be indicated in less than one third of the patients in our study if a positive predictive value for the presence of inflammatory activity (PET-positivity) of $\geq 90 \%$ is considered acceptable for clinical decision making without referral to PET. This predictive value was reached with a positive SIL-2R result alone ( 8 points; positive predictive value $92.2 \%)$. Among patients with a normal sIL-2R level, PET appeared only to be indicated in those with a total HRCT score of $<6$ points (positive predictive value $<90 \%$ ). If a positive predictive value of approximately $100 \%$ is considered desirable, a cut-off value of $<10$ points can be used (positive predictive value $<98 \%$ ) in deciding whether to refer patients to PET. In this case, referral to PET would be indicated in about half of the patients. 
Using this prediction rule to select patients for whom a PET might be indicated can help to reduce the number of PET scans. This may result in considerable cost reductions, as only a limited number of tests have to be used and these tests are far less expensive than PET. In addition, our prediction rule represents the first attempt to standardize the assessment of inflammatory activity in sarcoidosis.

It should be noted that this rule has been developed in a sample of sarcoidosis patients with unexplained persistent disabling symptoms. It was derived from and validated in patients from a single referral centre for sarcoidosis, which could limit the generalization of these results. Hence, validation of this prediction rule in other, and larger, sarcoidosis patient populations is warranted. We used bootstrap validation for the internal validation, and adjusted the regression coefficients using the shrinkage factor. Prospective evaluation of the prediction rule in the future should use the internally validated model as described in Table 6.2.

In conclusion, the derived and internally validated clinical prediction rule, based on sIL-2R levels and HRCT scoring results, appeared to be useful to identify sarcoidosis patients with a high probability of inflammatory activity. Hence, using this rule may be helpful to identify sarcoidosis patient in whom a PET might be of additional value to assess inflammatory activity. These results may affect patient care by providing supportive evidence for more effective use of PET scan in the assessment of inflammatory activity in sarcoidosis.

\section{Acknowledgements}

Financial support by InterMune for the article processing charge is gratefully acknowledged. 


\section{References}

1. Hunninghake GW, Costabel U, Ando M, Baughman R, Cordier JF, du Bois R, Eklund A, Kitaichi M, Lynch J, Rizzato G, Rose C, Selroos O, Semenzato G, Sharma OP. ATS/ERS/WASOG statement on sarcoidosis. American Thoracic Society/European Respiratory Society/World Association of Sarcoidosis and other Granulomatous Disorders. Sarcoidosis Vasc Diffuse Lung Dis 1999: 16: 149-73.

2. Iannuzzi MC, Fontana JR. Sarcoidosis: clinical presentation, immunopathogenesis, and therapeutics. JAMA 2011: 305: 391-9.

3. Baughman RP, Lower EE, Drent M. Inhibitors of tumor necrosis factor (TNF) in sarcoidosis: who, what, and how to use them. Sarcoidosis Vasc Diffuse Lung Dis 2008: 25: 76-89.

4. Consensus conference: activity of sarcoidosis. Third WASOG meeting, Los Angeles, USA, September 811, 1993. Eur Respir J 1994: 7: 624-7.

5. Keijsers RG, Verzijlbergen JF, van Diepen DM, van den Bosch JM, Grutters JC. 18F-FDG PET in sarcoidosis: an observational study in 12 patients treated with infliximab. Sarcoidosis Vasc Diffuse Lung Dis 2008: 25: 143-9.

6. Ziegenhagen MW, Rothe ME, Schlaak M, Muller-Quernheim J. Bronchoalveolar and serological parameters reflecting the severity of sarcoidosis. Eur Respir J 2003: 21: 407-13.

7. Keijsers RG, Verzijlbergen FJ, Oyen WJ, van den Bosch JM, Ruven HJ, van Velzen-Blad H, Grutters JC. 18F-FDG PET, genotype-corrected ACE and sIL-2R in newly diagnosed sarcoidosis. Eur J Nucl Med Mol Imaging 2009: 36: 1131-7.

8. Mostard RLM, Voo S, van Kroonenburgh MJPG, Verschakelen JA, Wijnen PAHM, Nelemans PJ, Erckens RJ, Drent M. Inflammatory activity assessment by F18 FDG-PET/CT in persistent symptomatic sarcoidosis. Respir Med 2011: 105: 1917-24.

9. Vardhanabhuti V, Venkatanarasimha N, Bhatnagar G, Maviki M, lyengar S, Adams WM, Suresh P. Extra-pulmonary manifestations of sarcoidosis. Clinical radiology 2012: 67: 263-76.

10. Baughman RP, Culver DA, Judson MA. A concise review of pulmonary sarcoidosis. Am J Respir Crit Care Med 2011: 183: 573-81.

11. Lazar CA, Culver DA. Treatment of sarcoidosis. Semin Respir Crit Care Med 2010: 31: 501-18.

12. De Vries J, Rothkrantz-Kos S, van Dieijen-Visser MP, Drent M. The relationship between fatigue and clinical parameters in pulmonary sarcoidosis. Sarcoidosis Vasc Diffuse Lung Dis 2004: 21: 127-36.

13. Marcellis RG, Lenssen AF, Elfferich MD, De Vries J, Kassim S, Foerster K, Drent M. Exercise capacity, muscle strength and fatigue in sarcoidosis. Eur Respir J 2011: 38: 628-34.

14. Baughman RP, Nunes H. Therapy for sarcoidosis: evidence-based recommendations. Expert Rev Clin Immunol 2012: 8: 95-103.

15. El-Haddad G, Zhuang H, Gupta N, Alavi A. Evolving role of positron emission tomography in the management of patients with inflammatory and other benign disorders. Semin Nucl Med 2004: 34: 313-29.

16. Basu S, Saboury B, Werner T, Alavi A. Clinical Utility of FDG-PET and PET/CT in Non-malignant Thoracic Disorders. Mol Imaging Biol 2011;13:1051-60.

17. Teirstein AS, Machac J, Almeida O, Lu P, Padilla ML, lannuzzi MC. Results of 188 whole-body fluorodeoxyglucose positron emission tomography scans in 137 patients with sarcoidosis. Chest 2007: 132: 1949-53.

18. Braun JJ, Kessler R, Constantinesco A, Imperiale A. 18F-FDG PET/CT in sarcoidosis management: review and report of 20 cases. Eur J Nucl Med Mol Imaging 2008: 35: 1537-43.

19. Nishiyama Y, Yamamoto Y, Fukunaga K, Takinami H, Iwado Y, Satoh K, Ohkawa M. Comparative evaluation of 18F-FDG PET and 67Ga scintigraphy in patients with sarcoidosis. J Nucl Med 2006: 47: 1571-6.

20. Keijsers RG, Grutters JC, Thomeer M, Du Bois RM, Van Buul MM, Lavalaye J, Van Den Bosch JM, Verzijlbergen FJ. Imaging the inflammatory activity of sarcoidosis: sensitivity and inter observer agreement of (67)Ga imaging and (18)F-FDG PET. Q J Nucl Med Mol Imaging 2011: 55: 66-71.

21. Treglia G, Taralli S, Giordano A. Emerging role of whole-body 18F-fluorodeoxyglucose positron emission tomography as a marker of disease activity in patients with sarcoidosis: a systematic review. Sarcoidosis Vasc Diffuse Lung Dis 2011: 28: 87-94. 
22. Youssef G, Leung E, Mylonas I, Nery P, Williams K, Wisenberg G, Gulenchyn KY, Dekemp RA, Dasilva J, Birnie D, Wells GA, Beanlands RS. The use of 18F-FDG PET in the diagnosis of cardiac sarcoidosis: a systematic review and metaanalysis including the Ontario experience. J Nucl Med 2012: 53: 241-8.

23. Mostard RL, Verschakelen JA, Kroonenburgh van MJPG, Voo S, Wijnen PAHM, M D. Association of HRCT findings with pulmonary PET activity in sarcoidosis. Sarcoidosis Vasc Diffuse Lung Dis 2011: 28(Suppl. 1): 13.

24. Keijsers R.G., Verzijlbergen F.J., van den Bosch J.M., Zanen P., van de Garde E.M., Oyen W.J., J.C. G. 18F-FDG PET as predictor of pulmonary function in sarcoidosis. Sarcoidosis Vasc Diffuse Lung Dis 2011: 28: 123-9.

25. de Kleijn WP, Elfferich MD, De Vries J, Jonker GJ, Lower EE, Baughman RP, King TE, Jr., Drent M. Fatigue in sarcoidosis: American versus Dutch patients. Sarcoidosis Vasc Diffuse Lung Dis 2009: 26: 92-7.

26. Hoitsma E, De Vries J, Drent M. The small fiber neuropathy screening list: Construction and crossvalidation in sarcoidosis. Respir Med 2011: 105: 95-100.

27. Oberstein A, von Zitzewitz H, Schweden F, Muller-Quernheim J. Non invasive evaluation of the inflammatory activity in sarcoidosis with high-resolution computed tomography. Sarcoidosis Vasc Diffuse Lung Dis 1997: 14: 65-72.

28. Drent M., De Vries J., Lenters M., Lamers RJ, Rothkranz-Kos S, Wouters EF, van Dieijen-Visser MP, Verschakelen JA. Sarcoidosis: assessment of disease severity using HRCT. Eur Radiol 2003: 13: 2462-71.

29. Frank E. Harrell J. Regression Modeling Strategies. Springer, New York, 2001.

30. Allison PD. Missing Data. Sage, lowa, 2001.

31. Steyerberg EW. Clinical Prediction Models. Springer, New York, 2009.

32. Rubin DB. Inference and missing data. Biometrika 1976: 63: 581-92.

33. Hanley JA, McNeil BJ. The meaning and use of the area under a receiver operating characteristic (ROC) curve. Radiology 1982: 143: 29-36.

34. Steyerberg EW, Vickers AJ, Cook NR, Gerds T, Gonen M, Obuchowski N, Pencina MJ, Kattan MW. Assessing the performance of prediction models: a framework for traditional and novel measures. Epidemiology 2010: 21: 128-38.

35. Mostard R, Prompers L, Weijers R, van Kroonenburgh M, Wijnen P, Geusens P, Drent M. F18 FDG$\mathrm{PET} / \mathrm{CT}$ for detecting bone and bone marrow involvement in sarcoidosis patients. Clin Nucl Med 2012: 37: 21-5.

36. Milman N, Graudal N, Loft A, Mortensen J, Larsen J, Baslund B. Effect of the TNFalpha inhibitor adalimumab in patients with recalcitrant sarcoidosis: a prospective observational study using FDGPET. Clin Respir J 2011: doi: 10.1111/j.1752-1699X.2011.00276.x. [Epub ahead of print].

37. Teirstein AT, Morgenthau AS. "End-stage" pulmonary fibrosis in sarcoidosis. Mt Sinai J Med 2009: 76: 30-6. 


\section{APPENDIX}

Definition of abnormal high-resolution computed tomography (HRCT) findings in sarcoidosis, adapted from Oberstein et al. ${ }^{27}$, visual score.

\begin{tabular}{|c|c|c|c|c|}
\hline & Lung volume affected & & & \\
\hline & No lesions: 0 & $<33 \%: 1$ & $<66 \%: 2$ & $>66 \%: 3$ \\
\hline Typ & & & & \\
\hline BVE & & & & \\
\hline PC & & & & \\
\hline ND & & & & \\
\hline LS & & & & \\
\hline & Pathological findings ${ }^{b}$ & & & \\
\hline & None: 0 & Minor:1 & Moderate: 2 & Pronounced:3 \\
\hline PL & & & & \\
\hline LN & & & & \\
\hline
\end{tabular}

BVB: thickening or irregularity of the bronchovascular bundle; PC: parenchymal consolidation (including ground-glass opacifications); ND: intraparenchymal nodules; LS: septal and nonseptal lines; PL: focal pleural thickening; LN: enlargement of the mediastinal lymph nodes

The total score is obtained by adding up the individual scores (BVB, ND, LS, PC, LN, and PL).

${ }^{a}$ The lung volume affected is quantified by a visual score: $0=$ no lesions found; $1=u p$ to $33 \%$; $2=u p$ to $66 \%$; and $3=$ more than $66 \%$ of the volume affected.

${ }^{b}$ The $\mathrm{PL}$ and the enlargement of the $\mathrm{LN}$ (with a short axis of $1 \mathrm{~cm}$ or more considered enlarged) is quantified: $0=$ no pathological findings; $1=$ minor; $2=$ moderate; and $3=$ pronounced changes. 



\title{
Chapter 7
}

\author{
Adalimumab successful in \\ sarcoidosis patients with \\ refractory chronic non- \\ infectious uveitis
}
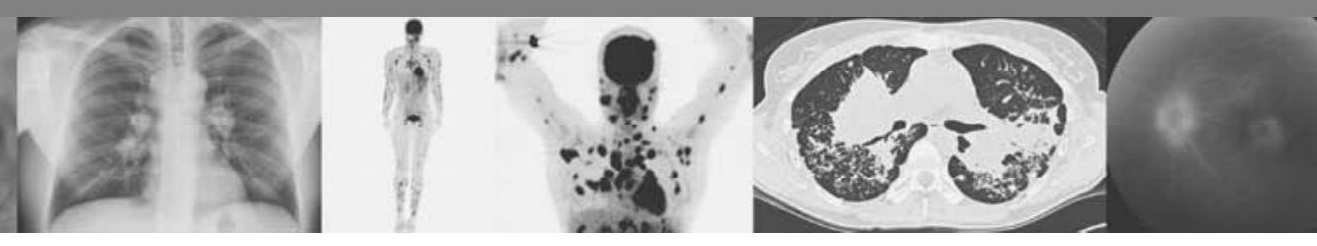

RLM Mostard, RJ Erckens, PAHM Wijnen, JS Schouten, M Drent

Graefes Arch Clin Exp Ophthalmol 2012;250:713-720 


\section{Abstract}

\section{Background}

Adalimumab, a humanized monoclonal antibody targeted against TNF- $\alpha$, has proved to be successful in the treatment of uveitis. Another anti-TNF- $\alpha$ agent, i.e. infliximab, has been reported of benefit in the treatment of refractory sarcoidosis. The aim of this prospective case series was to evaluate the effect of adalimumab on intraocular inflammatory signs and other relevant clinical manifestations (lung function, serological inflammatory parameters, and fatigue) of sarcoidosis.

\section{Methods}

Sarcoidosis patients with refractory posterior uveitis ( $n=26,17$ females, 41 eyes in total) were systematically followed for 12 months after initiation of adalimumab $40 \mathrm{mg}$ sc once a week. Inclusion criteria were non-responsiveness to prednisone and methotrexate (MTX), or intolerance to these drugs. Adjunctive therapy with prednisone and MTX was tapered during treatment with adalimumab. Location and improvement, stabilization or deterioration of intraocular inflammatory signs was scored. Pulmonary function- and laboratory testing were performed and Fatigue Assessment Scale was completed. Results at baseline, 6 months and 12 months were compared.

\section{Results}

Choroidal involvement resolved in 10/15 patients, five demonstrated partial improvement; vasculitis resolved in $1 / 1$ patient; papillitis resolved in $7 / 8$ patients, one showed partial response; macular edema resolved in $5 / 8$ patients, three demonstrated partial response; vitreous cleared completely in $5 / 5$ patients. Overall outcome regarding intraocular inflammatory signs showed improvement in 22 patients (85\%) and stabilization in four patients (15\%). At 12 months, no recurrences were reported in those successfully treated. Laboratory parameters of inflammatory activity (C-reactive protein; serum angiotensin-converting enzyme and soluble interleukin-2 Receptor) improved ( $p<0.01$ ). Moreover, fatigue improved in $14 / 21$ $(67 \%)$ of the patients suffering from fatigue and the diffusion capacity for carbon monoxide (DLCO) improved in $7 / 8(88 \%)$ of the patients with a decreased DLCO $(p<0.01)$. The dosage of both prednisone and MTX could be tapered down significantly $(p<0.01$ and $p<0.05$, respectively).

\section{Conclusion}

Adalimumab appeared successful in the treatment of sarcoidosis patients with refractory chronic non-infectious uveitis by showing improvement in intraocular inflammatory signs as well as in other relevant clinical indicators of disease activity. Future randomized studies are needed to determine the optimal dosage, dose interval, and duration of therapy in refractory multisystemic sarcoidosis. 


\section{Introduction}

Uveitis is a sight-threatening eye disease inflicted by auto-immune disorders or infectious agents. ${ }^{1}$ Sarcoidosis is a multisystemic granulomatous chronic disorder with unknown etiology. ${ }^{2,3}$ In the eye, this can cause uveitis with anterior chamber cells and flare, corneal deposits, synechiae formation, macular edema, vasculitis, retinitis, papillitis and/or a vitritis. ${ }^{4}$ Ocular manifestations of systemic sarcoidosis have significant impact on visual prognosis. ${ }^{5,6}$ Sarcoidosis patients with chronic disease often require prolonged treatment. Moreover, since sarcoidosis is a systemic disease, the effect of treatment on the various affected organs is important in deciding which therapy is the most appropriate. Regarding eye involvement, intermediate uveitis, posterior uveitis and panuveitis all require aggressive treatment regimen with immunosuppressive drugs in order to preserve vision and function of the eye. ${ }^{6,7}$ Corticosteroids remain the mainstay of treatment. However, in case this treatment does not have a favourable outcome or if disabling side effects which accompany prolonged treatment occur, the use of other alternative, steroid-sparing agents is mandatory. Methotrexate (MTX) has been proven to be a good alternative. ${ }^{8}$ In case this therapy also fails, the use of biologic agents which block tumor necrosis factoralpha (TNF- $\alpha$ ) can provide effective treatment for the diverse manifestations of sarcoidosis. ${ }^{9-11}$ Among the TNF- $\alpha$ inhibitors, infliximab has been studied most extensively in sarcoidosis. ${ }^{9,11-13}$ Anti-TNF- $\alpha$ treatment has been efficacious for the treatment of refractory ocular inflammatory disease. ${ }^{7,14-18}$

Adalimumab, a humanized monoclonal antibody targeted against TNF- $\alpha$, has also been reported useful in treating uveitis, sarcoidosis and various other auto-immune disorders. $^{9,18-26}$ The aim of this prospective case series was to evaluate the effect of adalimumab on intraocular inflammatory signs and other relevant clinical manifestations (lung function, laboratory inflammatory parameters and fatigue) in sarcoidosis patients with refractory chronic non-infectious uveitis.

\section{Materials and methods}

All sarcoidosis patients referred to the sarcoidosis management team of the Maastricht University Medical Centre (MUMC), The Netherlands (a tertiary referral center), who started treatment with the anti-TNF- $\alpha$ drug adalimumab initiated by our ophthalmologist (RE) because of refractory posterior uveitis between March 2006 and December 2009 were followed systematically according to a clinical protocol for 12 months. Adalimumab was started based on the following clinical criteria: patients with refractory posterior uveitis who did not respond to the original therapy with immunosuppressive drugs (both prednisone and MTX; $n=20$ ) and patients who responded to previous therapy with these immunosuppressive drugs, but demonstrated severe adverse effects $(n=6)$. It has to be emphasized that in order to 
prescribe the drug in the Netherlands for the treatment of uveitis, the patient had to be treated with at least two different immunosuppressive drugs, previously. Therefore, it is not allowed to use this drug as first choice in treating severe uveitis. Adalimumab was administrated at a dose of $40 \mathrm{mg}$ subcutaneously once a week. Patients were instructed to inject themselves and to report side effects immediately. Only patients who were treated with adalimumab for at least six months and completed the follow-up period of 12 months were included in the analysis $(n=26)$.

The diagnosis sarcoidosis was based on consistent clinical features and bronchoalveolar lavage fluid analysis, in accordance with the WASOG guidelines with biopsy-proven noncaseating epithelioid cell granulomas confirming sarcoidosis in $21 / 26(77 \%)$ patients. ${ }^{27}$ None of these patients had a relevant medical history or comorbidity. At initial diagnosis, the presence of active tuberculosis was excluded. Just before initiating anti-TNF-alpha treatment a Quantiferon ${ }^{\circledR}$-TB Gold in combination with the tuberculin skin test was repeated to exclude latent tuberculosis infection (LTBI) as this is a contraindication for treatment with TNF- $\alpha$ inhibitor therapy and also recommended in the guidelines of our hospital. ${ }^{4,28}$ At both time points, these tests were negative in all included patients.

\section{Evaluation of clinical course}

The different outcome measures were scored at baseline, six months, and 12 months.

\section{Evaluation of uveitis}

All the patients were evaluated by the same ophthalmologist (RE). He screened the patients for the presence of uveitis on the following items. Using spit-lamp examination, the eye was scrutinized on the presence of noduli in the conjunctival tissue; corneal deposits; anterior chamber cells and flare; anterior and posterior synechiae formation. These findings are not included because in our cases the anterior segment had no active signs of inflammation. In fact, 21 patients had no signs at all of uveitis anterior, while five patients had uveitis anterior in the past that showed no activity at the initial examination. Using funduscopy, the presence of macular edema, snowballs or vitreous opacities; multiple chorioretinal peripheral lesions; nodular and/or segmental periphlebitis and/or macroaneurysms or optic disc nodules were recorded. The Standardization of Uveitis Nomenclature (SUN) for clinical data was used in conjunction with the results of the first international workshop on the International Criteria for the Diagnosis of Ocular Sarcoidosis (IWOS) to score the location and activity of the uveitis. ${ }^{4,29}$

Additionally fluorescein angiography (FA, Topcon, TRC-50 EX) or optical coherence tomography (OCT, Zeiss, Stratus model 3000) was performed in 20 patients to detect the presence of vasculitis, papillitis, or macular edema. In 16 cases, these findings were present bilateral. In total, three patients refused FA; in the remaining three cases FA was not considered to be of additional value. 
Outcome of the specific inflammatory signs was scored as resolved if complete clearance of the specific inflammatory activity was seen; partial response if the specific inflammatory activity had decreased; stabilization if the specific inflammatory activity remained unchanged and deterioration if the specific inflammatory activity had increased.

Overall outcome of intraocular inflammatory signs was scored as improvement if at least one of the scored inflammatory signs showed a complete clearance in the absence of deterioration of other inflammatory signs; partial improvement if at least one of the scored inflammatory signs improved in the absence of deterioration of other inflammatory signs; stabilization if all inflammatory signs remained unchanged; deterioration if at least one of the inflammatory signs increased.

\section{Pulmonary evaluation}

The chest X-rays (CXR) were graded by one single person, blinded to the clinical data and according to the standard radiographic staging for sarcoidosis. According to the Scadding radiographic staging system, five stages of radiographic abnormality (0-IV) were recognized. ${ }^{27}$ The CXR stages of the included patients at the start of treatment with adalimumab were, respectively: 16 patients (62\%) stage 0 , four patients (15\%) stage I, four patients (15\%) stage II, and two patients (8\%) stage III.

Lung function measurements, including forced vital capacity (FVC) were measured with a pneumotachograph (Masterlab, Jaeger, Würzburg, Germany). The diffusing capacity for carbon monoxide (DLCO) was measured by the single-breath method (Masterlab, Jaeger, Würzburg, Germany). Values were expressed as a percentage of predicted values. Lung function characteristics of the included patients are shown in Table 7.1.

Table 7.1 Summary of relevant clinical characteristics of the studied sarcoidosis patients and the effect on clinical manifestations after six and 12 months of treatment with adalimumab.

\begin{tabular}{|c|c|c|c|}
\hline & $\begin{array}{c}\text { Total population; } \\
n=26 ; \text { baseline }\end{array}$ & $\begin{array}{c}\text { After } 6 \text { months treatment } \\
\text { with adalimumab }\end{array}$ & $\begin{array}{c}\text { After } 1 \text { year treatment } \\
\text { with adalimumab }(n=25)\end{array}$ \\
\hline $\begin{array}{l}\text { DLCO }(\% \text { predicted } \pm \text { SD) } \\
\text { (normal }>80 \% \text { of predicted) }\end{array}$ & $88 \pm 18$ & $92 \pm 12$ & $90 \pm 15$ \\
\hline $\begin{array}{l}\text { FVC }(\% \text { predicted } \pm \text { SD) } \\
\text { (normal }>80 \% \text { of predicted) }\end{array}$ & $97 \pm 15$ & $94 \pm 22$ & $102 \pm 20$ \\
\hline $\begin{array}{l}\text { CRP }(\text { mean } \pm S D) \\
(2-9 \mu g / I)\end{array}$ & $4.8 \pm 5.3$ & $2.4 \pm 2.6^{*}$ & $3.6 \pm 4.4^{*}$ \\
\hline $\begin{array}{l}\text { ACE (mean } \pm S D) \\
(9-25 \mathrm{U} / \mathrm{I})\end{array}$ & $19 \pm 8$ & $14 \pm 9 *$ & $15 \pm 10$ \\
\hline $\begin{array}{l}\text { sIL-2R (mean } \pm S D) \\
(240-3154 \mathrm{pg} / \mathrm{I})\end{array}$ & $2803 \pm 2224$ & $1888 \pm 1537 *$ & $2188 \pm 1801 *$ \\
\hline $\begin{array}{l}\text { FAS (mean } \pm \text { SD) } \\
\text { (<22: no fatigue) }\end{array}$ & $31.1 \pm 11.1$ & $28.5 \pm 7.8^{*}$ & $28.9 \pm 10.0 *$ \\
\hline
\end{tabular}

$\mathrm{n}$ : number; SD: standard deviation; DLCO: diffusion capacity for carbon monoxide; FVC: forced vital capacity; CRP: C-reactive protein; ACE: serum angiotensin-converting enzyme; sIL-2R: soluble interleukin-2 Receptor; FAS: Fatigue Assessment Scale. ${ }^{*} \mathrm{p}<0.01$ compared with baseline 


\section{Laboratory assays}

The C-reactive protein (CRP) concentration and serum levels of angiotensin-converting enzyme (ACE) and soluble interleukin-2 Receptor (sIL-2R) were measured as described previously (Chapter 3$).^{30}$

\section{Fatigue questionnaire}

The Fatigue Assessment Scale (FAS) is a 10-item questionnaire to asses fatigue. Five questions reflecting physical fatigue and five questions assessing mental fatigue. ${ }^{31}$

The response scale is a five-point scale ( 1 never to 5 always); scores on the FAS can range from 10 to 50 . The cut-off score of the FAS was 22 . A score below 22 indicates no fatigue, whereas a score of 22 or higher indicates fatigue.

\section{Statistical procedure}

Differences between results at baseline, six months, and 12 months were tested for statistical significance using the paired t-test in case of continuous variables or Chisquare test in case of categorical variables. Statistical analyses were performed using SPSS, version 15.0 for Windows (SPSS Inc., Chicago, IL, USA). A p-value less than 0.05 was considered to indicate statistical significance.

\section{Results}

Relevant baseline clinical characteristics of the 26 included patients are shown in Table 7.1. The details on the uveitis manifestations at baseline are included in Table 7.2. Mean age was $51 \pm 15$ years, nine patients were female. Before adalimumab was initiated all patients were treated with oral corticosteroids (starting dose 20-60 mg daily), if this did not have a positive effect, MTX was added (12.5-15 mg once a week orally). In eight cases, no MTX was added due to earlier reported side effects. One patient (number 16 in Table 7.2) was previously treated with infliximab, however, she developed antibodies after two years of treatment. To reduce sideeffects of treatment, adjunctive therapy in the studied population $(n=26)$ was tapered during treatment with adalimumab: prednisone from $15.6 \pm 10.7 \mathrm{mg}$ to $3.6 \pm 5.0 \mathrm{mg}$ $(p<0.01)$ and MTX from $9.6 \pm 5.5 \mathrm{mg}$ to $5.6 \pm 4.1 \mathrm{mg}(p<0.05)$, respectively. The dosages of these drugs could be tapered gradually within the first six months of treatment with adalimumab. Thereafter, all patients remained on the same (lower) dosage. After tapering, adjunctive therapy consisted of only oral corticosteroids in four patients (5-10mg daily); corticosteroids together with MTX in six (mean dose MTX 8.6 \pm 4.4 ; range 5-15 mg daily), and MTX alone in 12 patients (mean dose 7.6 \pm 2.4 ; range 5-12.5 mg once a week orally). Four patients did not use adjunctive therapy. 


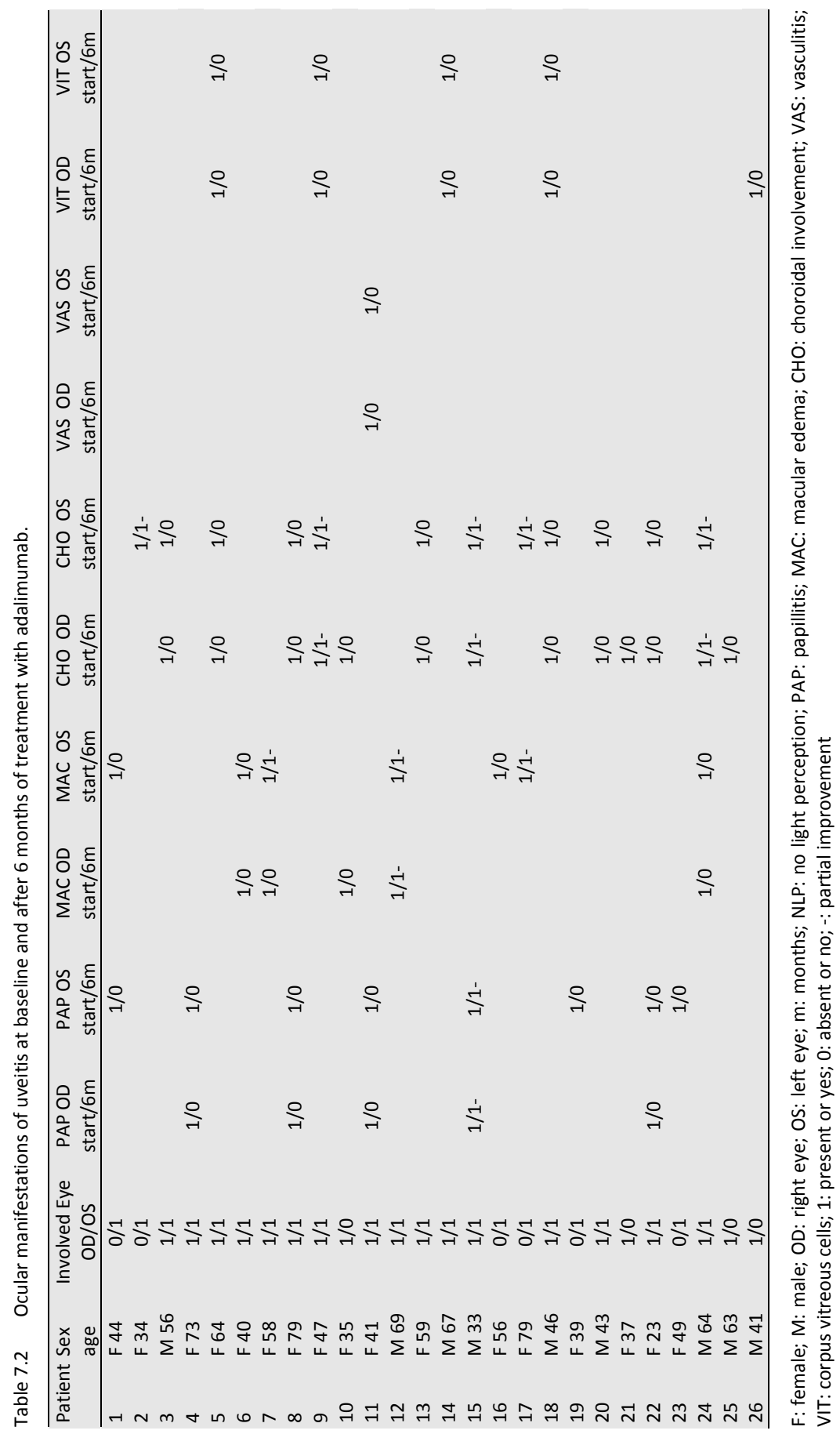


Table 7.2 provides the details on the intraocular inflammatory signs after six months of treatment with adalimumab. The results after 12 months of treatment with adalimumab are not shown in Table 7.2 for viewing purposes, since in none of the patients the results regarding intraocular inflammatory signs changed between six and 12 months. Papillitis (the presence of inflammatory disc swelling) was present in eight patients and resolved in seven patients (no staining on FA), one had partial response (less staining on FA). Eight patients had macular involvement, this resolved in five of them (no leakage on FA or OCT) and a partial response was seen in three patients (less leakage). An example of resolved macular edema after treatment is shown in Figure 7.1. Choroidal involvement was present in 15 patients and resolved in ten (clearance of inflammatory activity on funduscopy) whereas five had a partial response. Vasculitis resolved in the one patient (no leakage on FA as shown in Figure 7.2). All of the five patients with vitreous involvement showed a clearing of the vitreous of at least two steps on fundus examination. The final outcome regarding intraocular inflammatory signs showed improvement in 22 patients (85\%) and stabilization in four patients (15\%).
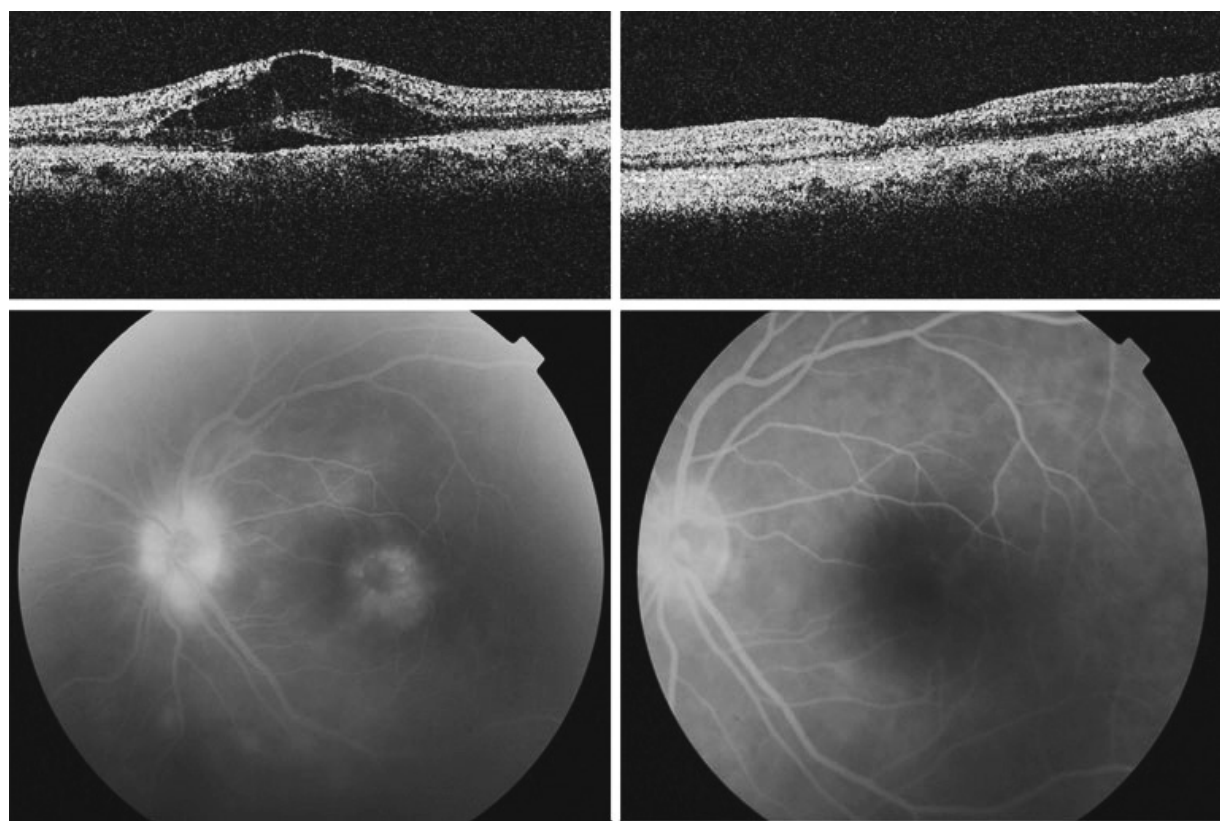

Figure 7.1 Patient 1: Optical coherence tomography (top) and fluorescein angiography (bottom) of OS showing macula edema before (left) and after (right) starting with adalimumab. 

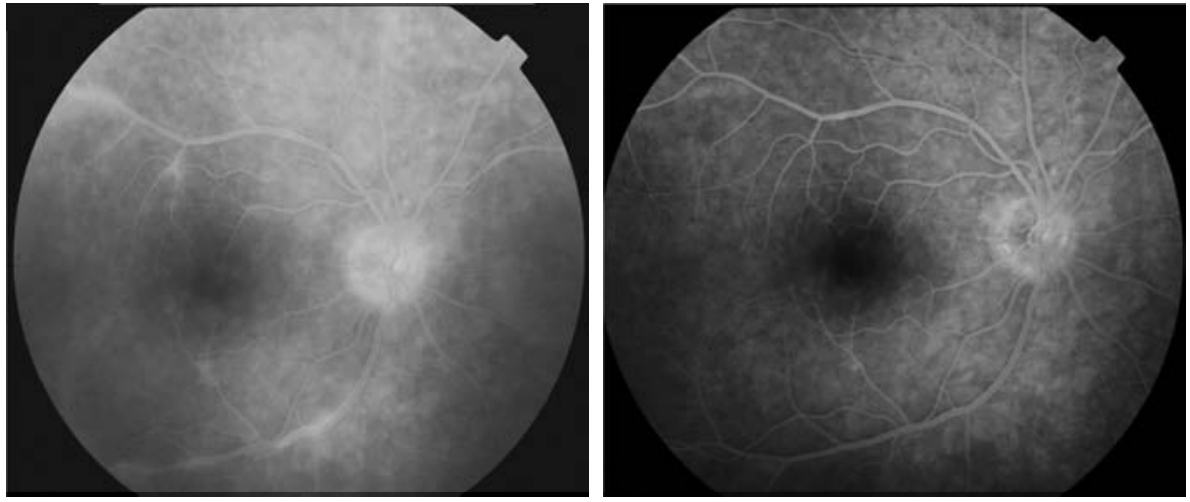

Figure 7.2 Patient 11: Fluorescein angiography showing vasculitis before (left) and after (right) starting with adalimumab.

Patient number 22 developed bilateral glaucoma prior to the start of adalimumab treatment, partly due to prednisone therapy, and was successfully treated with a glaucoma surgery procedure OD (Baerveldt implant) after eight months of adalimumab treatment. This procedure was performed successfully during adalimumab therapy and no activation was seen postoperatively.

Table 7.1 displays the effect on clinical manifestations after six and twelve months of treatment with adalimumab. Inflammatory parameters demonstrated a positive reaction during the anti-TNF- $\alpha$ treatment with adalimumab; the sIL-2R levels increased in three of 26 patients and decreased or stayed within normal limits in 23 patients, whereas the ACE levels increased in two patients and decreased or stayed within normal limits in 24 of the 26 patients. CRP levels at baseline were elevated in seven patients. Only one patient had a slightly elevated CRP level after six months (14 $\mathrm{mg} / \mathrm{ml}$ ), whereas after 12 months in all patients the CRP level was within the normal range. Mean levels of CRP, ACE, and SIL-2R decreased significantly during treatment with adalimumab.

None of the patients had an abnormal FVC ( $<80 \%$ of the predicted value); eight patients appeared to have a decreased diffusing capacity (DLCO $<80 \%$ of the predicted value) at baseline. After six months of treatment, seven of those eight patients demonstrated an improvement in DLCO of at least $10 \%$, whereas one patient remained stable. This increase in DLCO in patients with a decreased DLCO at baseline was significant $(p<0.01)$ and still present after one year of treatment.

Most of the patients ( $n=21 ; 81 \%$ ) suffered from fatigue (FAS score $\geq 22$ ), whereas 11 $(42 \%)$ suffered from very severe fatigue (FAS score $>35$ ). Fourteen of these 21 patients (67\%) became less fatigued, four (19\%) remained stable and three $(14 \%)$ reported a 
minor increase of their fatigue problems, as depicted by the FAS. The FAS score decreased significantly during treatment with adalimumab $(p<0.01 ;$ Table 7.1$)$.

Only one patient showed any signs of serious adverse effects during adalimumab treatment. This patient (number 16) developed a severe side effect at the injection site which led to the formation of a solid subcutaneous mass. However, because of the favourable effect on the uveitis she wanted to continue the treatment. Over time, this effect on the skin decreased, but was still present after 12 months of treatment. Minor adverse effects, such as local skin reactions occurred in four patients. These minor adverse effects tapered off during the treatment period. All but one patient continued treatment with adalimumab during the follow-up period of one year. This one patient decided by herself to discontinue adalimumab after a period of seven months into the treatment, although no side effects had occurred.

\section{Discussion}

In this prospective case series of sarcoidosis patients with refractory chronic noninfectious posterior uveitis, adalimumab treatment appeared successful. For it not only showed an improvement of the intraocular inflammatory signs in the majority of patients (85\%), but also appeared to have a significantly positive effect on other sarcoidosis related features, including inflammatory parameters, diffusing capacity, and fatigue. Until the endpoint of the evaluation (December 2010), no deteriorations were reported in those successfully treated. Serious adverse effects only occurred in one patient.

The presence of posterior uveitis is a predictor of a poor visual prognosis, making treatment with immunosuppressive drugs mandatory. ${ }^{6,8}$ All patients in our case series had uncontrolled inflammation due to prednisone and MTX resistance or intolerance, or to a flare-up during treatment, and therefore ocular inflammation after 12 months of follow-up would have been expected to be worse without attempting a different therapy like with adalimumab. Intraocular inflammatory signs at baseline were modest in some included patients. However, in the past they had posterior uveitis which again showed a flare-up, also with respect to the serological inflammatory signs, despite treatment. Delay in effective treatment could lead to refractory inflammation, potentially leading to further damage in the eye. Given the fact that further therapeutic options were limited in these cases, early adjunctive treatment was indicated. Furthermore, six of the included patients responded to previous therapy with immunosuppressive drugs, but demonstrated severe adverse effects. Therefore, also in these patients, the intraocular inflammatory signs were not pronounced.

If visually disabling cataract formation or glaucoma develops in patients with uveitis, it is essential that no ocular inflammatory activity is present at the time of surgery. ${ }^{32}$ One of our patients was successfully treated with a glaucoma surgery procedure 
(Baerveldt implant) during adalimumab therapy and no activation was seen postoperatively.

Disabling side effects of steroid treatment, including cataract formation, glaucoma, osteoporosis, Cushing's syndrome or diabetes mellitus, and the refractory character of the uveitis in some sarcoidosis patients, stress the need for alternatives. In the patients of this case series, adalimumab appeared to be a well tolerated alternative, and the dosage of both prednisone and MTX could be tapered down significantly during this treatment.

Previously, adalimumab also appeared to be an appropriate alternative for infliximab in patients with Crohn's disease who first responded quite well, but had to stop due to antibody formation and/or the development of an allergic reaction and became intolerant to infliximab. ${ }^{33}$ The decision to switch to another TNF- $\alpha$ inhibitor has not been studied systematically in sarcoidosis. However, switching from infliximab to adalimumab has been successful for some patients in case of allergic reactions. ${ }^{34}$ In our institute, we successfully switched therapy in five patients (including patient 16 of the present study) whom had formed antibodies against infliximab (data not shown). Previously, the combination of anti-TNF- $\alpha$ therapy and a cytotoxic drug has been shown to be superior to anti-TNF- $\alpha$ therapy alone. ${ }^{35}$ However, this was not reported in all situations. ${ }^{36,37}$ In our patients, the immunosuppressive medication as taken at the start of anti-TNF- $\alpha$ therapy was continued unless side effects occurred or contraindications existed. In those cases, the dosage of the MTX and prednisone was tapered off as described in the results section.

It remains unclear how long anti-TNF- $\alpha$ therapy in a responding patient should be continued. In sarcoidosis, longer follow-up data are needed to determine the optimal treatment period to avoid disease relapse or deterioration. In our experience, treatment should be continued for at least a year instead of a shorter period as in rheumatoid arthritis.

A recent randomized controlled trial with infliximab versus placebo in chronic pulmonary sarcoidosis patients showed an improvement in FVC, the primary end point of that study. ${ }^{12}$ Although in our studied population none of the patients had a decreased FVC ( $<80 \%$ of predicted), eight showed a decreased DLCO $(<80 \%$ of predicted) at baseline. These latter patients demonstrated a significant improvement of the DLCO after six months and one year of treatment with adalimumab. Unfortunately, the DLCO was not evaluated in the previously mentioned infliximab study. $^{12}$

Several reports suggest that CRP can predict response to anti-TNF- $\alpha$ therapy in different inflammatory diseases. ${ }^{38-42}$ In line with this, in the present study, a decrease of the CRP levels was demonstrated after six months as well as after one year of treatment with adalimumab. Also, the decrease in ACE and SIL2-R levels, and the improvement of fatigue during treatment with adalimumab is in accordance with the findings of previous studies with anti-TNF- $\alpha$ agents, mainly infliximab, in sarcoidosis patients. $^{11,43}$ Thus, although the primary reason for initiating treatment with 
adalimumab was refractory uveitis, the treatment also resulted in the improvement of systemic (inflammatory) manifestations of sarcoidosis.

This study has several limitations. Since during the follow-up period every sarcoidosis patient with refractory chronic non-infectious uveitis (as defined previously) in our clinic was treated with adalimumab in the absence of contra-indications, no control group could be evaluated. Also, the clinical examiner was not masked in grading response to treatment.

In conclusion, in this case series of sarcoidosis patients with refractory chronic noninfectious posterior uveitis, adalimumab appeared to be successful by showing improvement of intraocular inflammatory signs. Moreover, other relevant clinical indicators of disease activity improved as well. Future randomized studies are needed to determine optimal dosage, dose interval, and duration of therapy in refractory multisystemic sarcoidosis. 


\section{References}

1. Rothova A. Ocular involvement in sarcoidosis. Br J Ophthalmol 2000;84:110-6.

2. Kosmorsky GS, Meisler DM, Rice TW, Meziane MA, Lowder CY. Chest computed tomography and mediastinoscopy in the diagnosis of sarcoidosis-associated uveitis. Am J Ophthalmol 1998;126:132-4.

3. Iannuzzi MC, Rybicki BA, Teirstein AS. Sarcoidosis. N Engl J Med 2007;357:2153-65.

4. Herbort CP, Rao NA, Mochizuki M. International criteria for the diagnosis of ocular sarcoidosis: results of the first International Workshop On Ocular Sarcoidosis (IWOS). Ocul Immunol Inflamm 2009;17:160-9.

5. Martin TM, Doyle TM, Smith JR, Dinulescu D, Rust K, Rosenbaum JT. Uveitis in patients with sarcoidosis is not associated with mutations in NOD2 (CARD15). Am J Ophthalmol 2003;136:933-5.

6. Dana MR, Merayo-Lloves J, Schaumberg DA, Foster CS. Prognosticators for visual outcome in sarcoid uveitis. Ophthalmology 1996;103:1846-53.

7. Ardoin SP, Kredich D, Rabinovich E, Schanberg LE, Jaffe GJ. Infliximab to treat chronic noninfectious uveitis in children: retrospective case series with long-term follow-up. Am J Ophthalmol 2007;144:844-9.

8. Dev S, McCallum RM, Jaffe GJ. Methotrexate treatment for sarcoid-associated panuveitis. Ophthalmology 1999;106:111-8.

9. Baughman RP, Lower EE, Drent M. Inhibitors of tumor necrosis factor (TNF) in sarcoidosis: who, what, and how to use them. Sarcoidosis Vasc Diffuse Lung Dis 2008;25:76-89.

10. Baughman RP, Costabel U, du Bois RM. Treatment of sarcoidosis. Clin Chest Med 2008;29:533-48, ix-x.

11. Elfferich MD, Nelemans PJ, Ponds RW, Vries JD, Wijnen PA, Drent M. Everyday cognitive failure in sarcoidosis: the prevalence and the effect of anti-TNF- $\alpha$ - treatment. Respiration 2010;80:212-9.

12. Baughman RP, Drent M, Kavuru M, Judson MA, Costabel U, du Bois R, Albera C, Brutsche M, Davis G, Donohue JF, Muller-Quernheim J, Schlenker-Herceg R, Flavin S, Lo KH, Oemar B, Barnathan ES. Infliximab therapy in patients with chronic sarcoidosis and pulmonary involvement. Am J Respir Crit Care Med 2006;174:795-802.

13. Baughman RP, Lower EE. Infliximab for refractory sarcoidosis. Sarcoidosis Vasc Diffuse Lung Dis 2001;18:70-4.

14. Galor A, Perez VL, Hammel JP, Lowder CY. Differential effectiveness of etanercept and infliximab in the treatment of ocular inflammation. Ophthalmology 2006;113:2317-23.

15. Hale S, Lightman S. Anti-TNF therapies in the management of acute and chronic uveitis. Cytokine 2006;33:231-7.

16. Sobrin L, Kim EC, Christen W, Papadaki T, Letko E, Foster CS. Infliximab therapy for the treatment of refractory ocular inflammatory disease. Arch Ophthalmol 2007;125:895-900.

17. Petropoulos IK, Vaudaux JD, Guex-Crosier Y. Anti-TNF-alpha therapy in patients with chronic noninfectious uveitis: the experience of Jules Gonin Eye Hospital. Klin Monbl Augenheilkd 2008;225: 457-61.

18. Lindstedt EW, Baarsma GS, Kuijpers RW, van Hagen PM. Anti-TNF-alpha therapy for sight threatening uveitis. Br J Ophthalmol 2005;89:533-6.

19. Takase K, Ohno S, Ideguchi H, Uchio E, Takeno M, Ishigatsubo Y. Successful switching to adalimumab in an infliximab-allergic patient with severe Behcet disease-related uveitis. Rheumatol Int 20211;31:243-5.

20. Seiderer J, Brand S, Dambacher J, Pfennig S, Jurgens M, Goke B, Ochsenkuhn T. Adalimumab in patients with Crohn's disease--safety and efficacy in an open-label single centre study. Aliment Pharmacol Ther 2007;25:787-96.

21. Simonini G, Taddio A, Cattalini M, Caputo R, De Libero C, Naviglio S, Bresci C, Lorusso M, Lepore L, Cimaz R. Prevention of flare recurrences in childhood refractory chronic uveitis: An open-label comparative study of Adalimumab versus Infliximab. Arthritis Care Res (Hoboken). 2011;63:612-8.

22. Kamphuis LS, Lam-Tse WK, Dik WA, van Daele PL, van Biezen $P$, Kwekkeboom DJ, Kuijpers RW, Hooijkaas H, van Laar JA, Bastiaans J, Baarsma GS, van Hagen PM. Efficacy of adalimumab in chronically active and symptomatic sarcoidosis patients. Am J Respir Crit Care Med 2011;184:1214-6.

23. Callejas-Rubio JL, Ortego-Centeno N, Lopez-Perez L, Benticuaga MN. Treatment of therapy-resistant sarcoidosis with adalimumab. Clin Rheumatol 2006;25:596-7. 
24. Field S, Regan AO, Sheahan K, Collins P. Recalcitrant cutaneous sarcoidosis responding to adalimumab but not to etanercept. Clin Exp Dermatol 2010;35:795-6.

25. Philips MA, Lynch J, Azmi FH. Ulcerative cutaneous sarcoidosis responding to adalimumab. J Am Acad Dermatol 2005;53:917.

26. Heffernan MP, Smith DI. Adalimumab for treatment of cutaneous sarcoidosis. Arch Dermatol 2006; 142:17-9.

27. Hunninghake GW, Costabel U, Ando M, Baughman R, Cordier JF, du Bois R, Eklund A, Kitaichi M, Lynch J, Rizzato G, Rose C, Selroos O, Semenzato G, Sharma OP. ATS/ERS/WASOG statement on sarcoidosis. American Thoracic Society/European Respiratory Society/World Association of Sarcoidosis and other Granulomatous Disorders. Sarcoidosis Vasc Diffuse Lung Dis 1999;16:149-73.

28. Bartalesi F, Vicidomini S, Goletti D, Fiorelli C, Fiori G, Melchiorre D, Tortoli E, Mantella A, Benucci M, Girardi E, Cerinic MM, Bartoloni A. QuantiFERON-TB Gold and the TST are both useful for latent tuberculosis infection screening in autoimmune diseases. Eur Respir J 2009;33:586-93.

29. Jabs DA, Nussenblatt RB, Rosenbaum JT. Standardization of uveitis nomenclature for reporting clinical data. Results of the First International Workshop. Am J Ophthalmol 2005;140:509-16.

30. Mostard RL, Voo S, van Kroonenburgh MJ, Verschakelen JA, Wijnen PA, Nelemans PJ, Erckens RJ, Drent M. Inflammatory activity assessment by F18 FDG-PET/CT in persistent symptomatic sarcoidosis. Respir Med 2011;105:1917-24.

31. de Kleijn WP, Elfferich MD, De Vries J, Jonker GJ, Lower EE, Baughman RP, King TE, Jr., Drent M (2009) Fatigue in sarcoidosis: American versus Dutch patients. Sarcoidosis Vasc Diffuse Lung Dis 26:92-7

32. Akova YA, Foster CS. Cataract surgery in patients with sarcoidosis-associated uveitis. Ophthalmology 1994;101:473-9.

33. Sandborn WJ, Hanauer S, Loftus EV, Jr., Tremaine WJ, Kane S, Cohen R, Hanson K, Johnson T, Schmitt D, Jeche R. An open-label study of the human anti-TNF monoclonal antibody adalimumab in subjects with prior loss of response or intolerance to infliximab for Crohn's disease. Am J Gastroenterol 2004;99:1984-9.

34. Baughman RP. Tumor necrosis factor inhibition in treating sarcoidosis: the American experience. Revista Portuguesa de Pneumonologia 2007;13:S47-S50.

35. Breedveld FC, Weisman MH, Kavanaugh AF, Cohen SB, Pavelka K, van Vollenhoven R, Sharp J, Perez JL, Spencer-Green GT. The PREMIER study: A multicenter, randomized, double-blind clinical trial of combination therapy with adalimumab plus methotrexate versus methotrexate alone or adalimumab alone in patients with early, aggressive rheumatoid arthritis who had not had previous methotrexate treatment. Arthritis Rheum 2006;54:26-37.

36. Breban $M$, Ravaud $P$, Claudepierre $P$, Baron $G$, Henry YD, Hudry C, Euller-Ziegler L, Pham T, SolauGervais E, Chary-Valckenaere I, Marcelli C, Perdriger A, Le Loet X, Wendling D, Fautrel B, Fournie B, Combe B, Gaudin P, Jousse S, Mariette X, Baleydier A, Trape G, Dougados M. Maintenance of infliximab treatment in ankylosing spondylitis: results of a one-year randomized controlled trial comparing systematic versus on-demand treatment. Arthritis Rheum 2008;58:88-97.

37. van Riel PL, Taggart AJ, Sany J, Gaubitz M, Nab HW, Pedersen R, Freundlich B, MacPeek D. Efficacy and safety of combination etanercept and methotrexate versus etanercept alone in patients with rheumatoid arthritis with an inadequate response to methotrexate: the ADORE study. Ann Rheum Dis 2006;65:1478-83.

38. Wolbink GJ, Voskuyl AE, Lems WF, de Groot E, Nurmohamed MT, Tak PP, Dijkmans BA, Aarden L. Relationship between serum trough infliximab levels, pretreatment $C$ reactive protein levels, and clinical response to infliximab treatment in patients with rheumatoid arthritis. Ann Rheum Dis 2005;64:704-7.

39. Gratacos J, Casado E, Real J, Torre-Alonso JC. Prediction of major clinical response (ACR50) to infliximab in psoriatic arthritis refractory to methotrexate. Ann Rheum Dis 2007;66:493-7.

40. Stone MA, Payne U, Pacheco-Tena C, Inman RD. Cytokine correlates of clinical response patterns to infliximab treatment of ankylosing spondylitis. Ann Rheum Dis 2004;63:84-7.

41. Louis E, Vermeire $S$, Rutgeerts $P$, De Vos $M$, Van Gossum A, Pescatore P, Fiasse R, Pelckmans P, Reynaert H, D'Haens G, Malaise M, Belaiche J. A positive response to infliximab in Crohn disease: association with a higher systemic inflammation before treatment but not with -308 TNF gene polymorphism. Scand J Gastroenterol 2002;37:818-24. 
42. Sweiss NJ, Barnathan ES, Lo K, Judson MA, Baughman R. C-reactive protein predicts response to infliximab in patients with chronic sarcoidosis. Sarcoidosis Vasc Diffuse Lung Dis 2010;27:49-56.

43. Keijsers RG, Verzijlbergen JF, van Diepen DM, van den Bosch JM, Grutters JC. 18F-FDG PET in sarcoidosis: an observational study in 12 patients treated with infliximab. Sarcoidosis Vasc Diffuse Lung Dis 2008;25:143-9. 



\section{Chapter 8}

Summary, general discussion and

directions for future research 
122 Chapter 8 


\section{Summary}

The clinical course of sarcoidosis is extremely variable. Although the assessment of inflammatory activity is helpful to monitor the course of the disease and guide therapeutic strategies, this assessment remains a challenge for clinicians managing sarcoidosis patients with unexplained persistent disabling symptoms. Each of the currently available markers has its shortcomings regarding sensitivity, specificity, costs and risks or possible side-effects for the patient. Another complicating factor is that specific organ involvement may be beyond the scope of the diagnostic tools used. It is therefore difficult in clinical practice to decide which investigations are required, if the aim is to spare patients invasive testing and limit costs.

The studies presented in this thesis evaluated the relationship between the currently available markers of inflammatory activity, and the relationship between these markers and parameters of disease severity in sarcoidosis. The studies included patients with sarcoidosis who had had unexplained persistent disease-related disabling symptoms for at least one year and were referred to a tertiary care center in the Netherlands. Persistent disabling symptoms were defined as the presence of more than one symptom that had substantial influence on quality of life, and that could not be explained from the results of routine investigations, including the absence of lung functional or chest radiographic deterioration. These symptoms included fatigue (Fatigue Assessment Scale (FAS) $\geq 22)^{1}$, symptoms compatible with small fiber neuropathy (SFN; SFN Screenings List (SFNSL) score $\geq 11)^{2}$, arthralgia and/or muscle pain, dyspnea (MRC dyspnea scale $\geq 3$ ), exercise intolerance or coughing. In addition, we assessed the response of inflammatory signs and clinical characteristics to treatment with adalimumab in sarcoidosis patients with refractory chronic uveitis. The findings are summarized and discussed.

Chapter 1, the general introduction, presents a summary of the clinical features and pathogenesis of sarcoidosis, as well as a brief review of the available markers of inflammatory activity.

Chapter 2 provides an overview of the knowledge about and limitations of the use of metaiodobenzylguanidine (MIBG) scintigraphy in cardiac and pulmonary diseases. ${ }^{123}$ I-radiolabeled MIBG reflects adrenergic neuron integrity. The uptake of MIBG is diminished by injury to adrenergic neurons, for instance induced by inflammation, and increased sympathetic activity is associated with a more rapid rate of MIBG loss. Hence, radiolabeled MIBG is able to reflect neuronal dysfunction in different organs. MIBG neuronal images of the lungs and heart can show heterogeneous distribution patterns involving either diminished or increased MIBG uptake and/or wash-out, reflecting changes in endothelial integrity, neuronal innervations, and clearance of norepinephrine. Interest is growing in the role of neurotransmitter involvement and the relation between endothelial cell integrity and vascularization, and it is of the utmost importance to understand the effect on the pathophysiology of diseases. Currently, however, there is no added clinical value to be gained by routine use of 
MIBG scanning of the lungs and heart. This is partly due to the fact that the exact mechanism of MIBG uptake and wash-out under normal physiological circumstances, and the factors which influence them, have not been fully clarified. Nevertheless, the technique has tremendous potential, as it can unravel previously unknown relationships between innervation, vascularization, and endothelial integrity. Other diagnostic tools like magnetic resonance imaging (MRI) and computed tomography (CT) do not have this ability, so the future looks bright for these new neuronal imaging techniques.

Chapter 3 reports on the assessment of the presence of inflammatory activity using ${ }^{18}$ F-FDG PET in 89 sarcoidosis patients with unexplained persistent disabling symptoms, and evaluates the association between PET findings and serological inflammatory markers. Positive PET findings were classified as thoracic and/or extrathoracic. The serological markers of inflammatory activity we considered were angiotensin-converting enzyme ( $A C E)$, soluble interleukin-2 receptor (sIL-2R), and neopterin. The majority of sarcoidosis patients with persistent disabling symptoms, even those with radiographic stage IV, had positive PET findings. Remarkably, $80 \%$ of the patients had extrathoracic lesions. In $20 \%$ of the patients, PET was positive without signs of serological inflammatory activity. PET appeared to offer added value in assessing inflammatory activity in patients with persistent symptoms in the absence of signs of serological inflammatory activity, as well as in detecting extrathoracic lesions.

Chapter 4 describes the prevalence and distribution pattern of bone and bone marrow involvement as detected by ${ }^{18} \mathrm{~F}$-FDG PET/CT in 94 sarcoidosis patients with positive PET findings. Their PET/CT scans were screened to localize any bone/bone marrow involvement. Additionally, low-dose CT scans were screened for other causes of increased bone uptake. Relevant clinical data were gathered retrospectively.

More than one-third of PET/CT-positive sarcoidosis patients had osseous abnormalities on PET/CT. The majority of these lesions (94\%) could not be detected on low-dose CT. No single preferred location was found. These preliminary results stress the value of $\mathrm{PET} / \mathrm{CT}$ imaging in the assessment of bone/bone marrow involvement in sarcoidosis patients. Its clinical relevance needs to be explored in future studies.

Chapter 5 evaluates the association between severity of pulmonary involvement and ${ }^{18}$ F-FDG PET activity in persistently symptomatic sarcoidosis patients. Over a 5 -year period, relevant clinical data, including laboratory- and lung function test results, were gathered from the medical records of 95 sarcoidosis patients who underwent both PET and high-resolution CT (HRCT) because of unexplained persistent disabling symptoms. The HRCT scans were classified using a semi-quantitative HRCT scoring system. PET findings were classified as positive or negative. The patients with positive pulmonary PET findings $(n=56)$ demonstrated significantly higher total HRCT scores, but lower values of the diffusion capacity for carbon monoxide (DLCO) and forced vital capacity (FVC) compared to the patients with negative pulmonary PET findings ( $n=39)$. 
The severity of the pulmonary involvement in sarcoidosis as assessed by HRCT features and lung function parameters was associated with PET activity. The majority of patients with radiological fibrotic changes on HRCT (85\%) demonstrated pulmonary inflammatory activity. Moreover, a surprisingly high number of these patients also demonstrated extrathoracic PET-positive lesions (82\%) and serological signs of inflammatory activity (73\%).

The question can be raised which patients might benefit from having a PET scan for the assessment of inflammatory activity. Until now, there have been no guidelines for selecting those patients with unexplained persistent disabling symptoms for whom PET might offer added value in the assessment of inflammatory activity.

Chapter 6 makes an attempt to develop a prediction rule that can be used to identify symptomatic sarcoidosis patients for whom there is a high probability that ${ }^{18} \mathrm{~F}$-FDG PET will show the presence of inflammatory activity. A clinical prediction rule, based on SIL-2R levels and HRCT scoring results, was derived and internally validated, and appeared to be useful to identify sarcoidosis patients with a high probability of inflammatory activity. Hence, using this rule may be helpful to identify sarcoidosis patient in whom a PET might be of additional value to assess inflammatory activity. These results may affect patient care by providing supportive evidence for more effective use of PET scan in the assessment of inflammatory activity in sarcoidosis.

Chapter 7 presents the results of a prospective case series that included 26 sarcoidosis patients with refractory chronic uveitis. The included patients were systematically followed for 12 months after the initiation of adalimumab $40 \mathrm{mg}$ sc once a week. The study evaluated the effect of adalimumab on intraocular inflammatory signs and other relevant clinical manifestations (lung function, serological inflammatory parameters, and fatigue) of sarcoidosis. Adalimumab appeared successful in the treatment of sarcoidosis patients with refractory chronic non-infectious uveitis, showing improvement in intraocular inflammatory signs as well as in the other relevant clinical indicators of disease activity that were evaluated. Future randomized studies are needed to determine the optimal dosage, dose interval and duration of therapy in refractory multisystemic sarcoidosis.

In conclusion, this thesis describes the spectrum of techniques to assess inflammatory activity in persistent symptomatic sarcoidosis. It presents an overview of the knowledge about and limitations of the use of MIBG scintigraphy in cardiac and pulmonary diseases, and discusses the relationship between PET findings and serological inflammatory markers, lung function test results and radiologic parameters. PET appeared to offer added value in assessing inflammatory activity in patients with persistent symptoms in the absence of serological inflammatory activity signs. The serological inflammatory parameters that were considered were ACE, neopterin, and sIL-2R. Combining several serological inflammatory markers increased the sensitivity to inflammatory activity as detected by PET. Severity of pulmonary involvement as assessed by HRCT features and lung function parameters was 
associated with PET activity. Based on these findings, a clinical prediction rule that can be used to identify symptomatic sarcoidosis patients for whom there is a high probability that PET will show the presence of inflammatory activity was derived and internally validated, and proved to be able to distinguish between patients with PETpositive and PET-negative findings. The value of PET/CT imaging in the assessment of bone/bone marrow involvement in sarcoidosis patients was demonstrated by the presence of osseous abnormalities on PET/CT in more than one-third of the PETpositive patients, which was much higher than expected according to most previously published studies. Finally, adalimumab appeared successful in the treatment of sarcoidosis patients with refractory chronic non-infectious uveitis, showing improvement in intraocular inflammatory signs as well as in the other relevant clinical indicators of disease activity that were evaluated.

\section{General discussion}

A problem frequently encountered in the clinical setting is illustrated by the following case of a 40-year-old female patient with sarcoidosis. She had been treated with prednisone for two years, mainly because of restrictive lung function loss with a moderate decrease in DLCO. After 6 months, methotrexate was added, due to the lack of amelioration. Despite this therapy, she was still suffering from disabling symptoms, including fatigue, limited exercise capacity, dyspnea at exercise and coughing. No changes were found on the chest X-ray (CXR) (persistently bilateral consolidations) and the pulmonary function impairment remained unchanged. All serological inflammatory markers ( $A C E$, sIL-2R, and neopterin) were negative. The question was raised whether the disease had become quiescent under methotrexate therapy, and the persistent symptoms were a result of previously caused damage, or whether ongoing inflammatory activity was the cause of the persistent symptoms. Several studies have shown that therapy with tumor necrosis factor (TNF)- $\alpha$ inhibitors decreases inflammatory activity, and that this correlates with clinical signs of improvement. $^{3,4}$ However, judging whether this patient might benefit from TNF- $\alpha$ inhibitor treatment was difficult, since in this case the clinician could not rely on the above-mentioned traditional tools. The question is therefore what additional diagnostic tools would be helpful in assessing the presence of inflammatory activity in sarcoidosis?

Assessing inflammatory activity is hampered by the lack of a gold standard. In recent years, PET has been shown to be a very sensitive technique to assess inflammatory activity in sarcoidosis by detecting and quantifying the level of inflammatory and granulomatous reactions that occur in the lungs and elsewhere in the body. ${ }^{5-8}$ This means that a technique has become available that is able to evaluate the presence of inflammatory activity in each organ system. In view of the radiation dose and costs involved in PET, however, it is essential to define appropriate indications for PET. 
Comparative evaluation of the currently used markers for inflammatory activity and the results obtained with PET could be helpful to clarify the value of the latter for the assessment of inflammatory activity and to define a phenotype of patients for whom PET would offer added value. The presence of inflammatory activity can be regarded as highly likely in patients with newly diagnosed acute, symptomatic sarcoidosis. ${ }^{5,9}$ In contrast, it is often rather difficult to answer the question whether inflammatory activity is still present in sarcoidosis patients without deteriorating lung function or radiological deterioration, but with unexplained persistent disabling symptoms. Hence, our aim was to evaluate the value of the various available tools for the assessment of inflammatory activity in a population of sarcoidosis patients with persistent disabling symptoms without a clear clinical explanation.

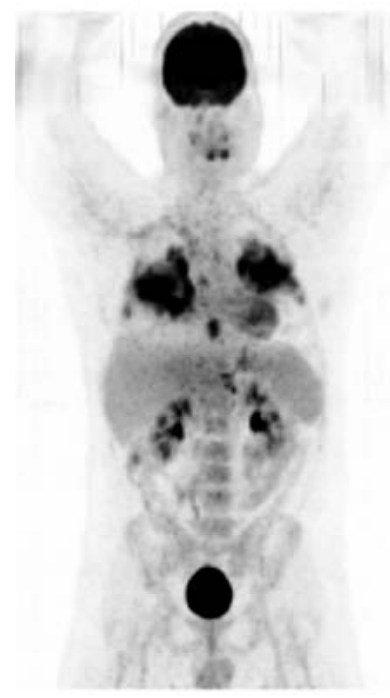

A

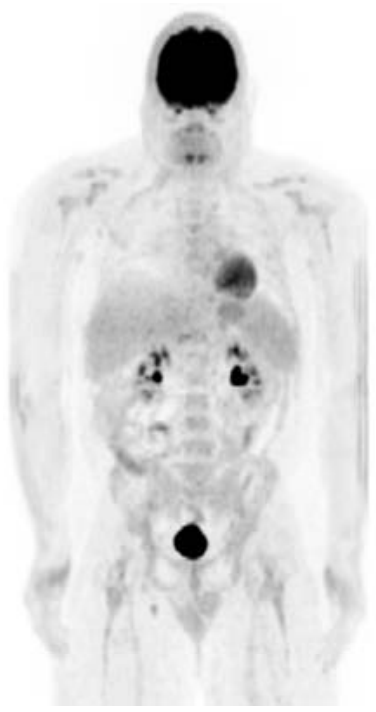

B

Figure 8.1 PET findings of the sarcoidosis patient who is discussed in the text (p126).

a. Coronal PET image showing pathologically increased FDG uptake in the pulmonary parenchyma and para-esophageal lymph nodes.

b. Coronal PET image after therapy with infliximab showing resolution of the pathologically increased FDG uptake in the pulmonary parenchyma and para-esophageal lymph nodes.

\section{Assessment of inflammatory activity}

Inflammatory activity as assessed by positive PET results was present in the majority (75\%) of the sarcoidosis patients with unexplained persistent disabling symptoms in our sample, even those with radiographic stage IV (Chapter 3). As described in the same chapter, five patients with an obstructive sleep apnea syndrome (OSAS) who 
were adequately treated with continuous positive airway pressure (CPAP) still suffered from disabling symptoms, including fatigue. Hypermetabolism detected with PET appeared to be present in these five patients, supporting the assumption that inflammatory activity was still present and probably explained the persistent fatigue. An example of a sarcoidosis patient with pronounced fatigue and multiple PETpositive lesions in the muscles of the lower extremities is shown in Chapter 1, Figure 1.6.

\section{Serological inflammatory markers for the assessment of inflammatory activity}

Previous studies have investigated the value of individual serological inflammatory markers for assessing disease activity. ${ }^{9-14}$ Several studies found that neopterin and sIL$2 R$ levels were significantly elevated in progressive, and thus active, disease. ${ }^{9,12}$ Keijsers et al. ${ }^{5}$ showed that elevated ACE and sIL-2R levels correlated with positive PET findings, though the reported sensitivity of these markers was low. Neopterin levels were not evaluated in their study. Among the serological inflammatory parameters evaluated in the study described in Chapter 3, positive sIL-2R showed the strongest association with PET positivity. Nevertheless, the highest sensitivity as regards the detection of inflammatory activity demonstrated by PET was achieved by combining the three serological inflammatory markers (ACE, SIL-2R, and neopterin). This was a novel finding, as the value of combining serological inflammatory markers had not been studied before. The sensitivity of the combined serological inflammatory markers (80\%) as reported in Chapter 3 is probably an underestimation of the real sensitivity, since neopterin values were only available for $70 \%$ of the patients, and the sensitivity for the subgroup of patients for whom the values of all three serological inflammatory markers were available $(n=62)$ was calculated to be $86 \%$. The positive predictive value of the combined serological inflammatory markers appeared to be excellent, though the negative predictive value was moderate. We concluded that PET appears to offer added value in assessing inflammatory activity in patients with persistent symptoms in the absence of signs of serological inflammatory activity.

Inflammatory activity in sarcoidosis originates from several different mechanisms, viz. ongoing T-cell and macrophage activity and granuloma formation. ${ }^{10,11,14-16}$ In accordance with this, we found that all of the serological inflammatory markers we used offered added value in detecting inflammatory activity. In the subgroup of patients for whom values of all three serological inflammatory markers were available, increased levels of only one serological inflammatory marker were found in 12 of the 36 patients with positive combined serological inflammatory markers. ACE, sIL-2R, and neopterin were the single increased marker in 4 of these patients each. ACE is mainly produced by activated granuloma cells (epitheloid cells), ${ }^{17}$ while sIL-2R is a marker of T-cell activity ${ }^{10,14,18}$ and neopterin represents activation of the monocyte/macrophage system. ${ }^{12}$ Other relevant inflammatory pathways, not 
detected by the serological inflammatory markers we used, probably account for the fact that some of the PET-positive patients had negative serological inflammatory markers. As explained above, missing neopterin values presumably also reduced the sensitivity of the combined serological inflammatory markers in detecting inflammatory activity in our population. This sensitivity will most likely increase if complete results for all serological inflammatory markers are available in future prospective trials.

\section{Evaluating the extent of disease by assessing extrathoracic inflammatory activity}

Remarkably, extrathoracic PET-positive lesions were found in $80 \%$ of the PET-positive patients, which stresses the value of whole-body evaluation. Grutters et al. ${ }^{10}$ found an association between sIL-2R levels and extrathoracic involvement, though this was not confirmed in our population. A possible explanation for this discrepancy might be the higher prevalence of extrathoracic involvement in our study, as discussed in Chapter 3. In turn, this might be the result of our use of PET for the assessment of extrathoracic involvement, Grutters et al. ${ }^{10}$ used clinical, functional, and radiologic data. The prevalence of extrathoracic involvement in the PET-positive patients in our study was comparable to that found in studies using PET in active sarcoidosis. ${ }^{5-7,19}$ The extrathoracic organs we found to be involved included peripheral lymph nodes, bone, spleen, muscle, liver, parotid glands, skin, and the central nervous system. The extrathoracic organ involvement was higher than we had suspected before performing PET. In almost two-thirds of the patients with extrathoracic PET-positive lesions, these lesions had not been suspected beforehand. The high frequency of extrathoracic lesions we established shows that this is another merit of using PET (to assess the extent of the disease). This was underlined by the presence of osseous abnormalities on PET/CT in more than one-third of the PET-positive patients, as described in Chapter 4. In a large cohort study of 137 sarcoidosis patients, Teirstein et al. ${ }^{6}$ found that PET established the presence of increased extracardiac FDG uptake which had not been identified by physical examination, chest radiography or CT scans. Our results were in accordance with these findings. Hence, PET may uncover occult sarcoidosis localizations or multiple organ involvement. Moreover, it can establish the most appropriate location for a biopsy to obtain histological evidence for the diagnosis. And detecting extrathoracic lesions may also provide an explanation for (mainly extrathoracic) symptoms. In addition, the assessment of a PET-positive lesion can be useful in monitoring the treatment effect.

\section{Pulmonary involvement}

The CXR is the most commonly used radiologic imaging technique to evaluate patients with pulmonary sarcoidosis. The Scadding radiographic staging system provides general information regarding the prognosis of the pulmonary disease over time. In 
general, patients with lower CXR stages have a higher chance of resolution of their radiographic findings. ${ }^{20,21}$ However, the CXR stage has been shown to correlate only weakly with the level of dyspnea; no significant correlation was demonstrated between CXR findings and either lung function test results or 6-minute walk distance. ${ }^{15,20-23}$ Moreover, one major issue concerning the radiographic staging system has been interobserver variability, as a result of which it has limited applicability in individual patient assessments, including treatment decisions. ${ }^{21}$ A prospective study of 36 patients compared clinical status and spirometry during flares of pulmonary sarcoidosis with CXR findings as described by the CXR International Labour Organization profusion score. ${ }^{24}$ It found there was too much variation for a cut-off to be identified that would reliably diagnose exacerbations. Approximately one-half of the radiographic readings showed an improvement or no change during a significant exacerbation. In line with this, we found no clear relation between CXR stages and PET findings.

The presence and extent of parenchymal abnormalities on HRCT has been found to correlate with functional impairment in sarcoidosis. ${ }^{25-29}$ Previous follow-up CT studies in patients with pulmonary sarcoidosis have shown that nodular opacities represent potentially reversible findings. ${ }^{30,31}$ As regards parenchymal consolidations, however, it is not possible to differentiate between fibrotic or granulomatous components in the consolidations on the basis of HRCT findings. Due to pre-existing major abnormalities, radiological features are frequently of limited value for the assessment of inflammatory activity in sarcoidosis patients with fibrotic disease. HRCT is a morphological imaging technique that provides only indirect information on the underlying metabolic changes. To the best of our knowledge, no studies on the radiological substrate of parenchymal FDG uptake, as detected by PET, had been performed previously in a population of sarcoidosis patients. Consequently, no comparison between PET findings and HRCT was available. Achieving a reliable comparison of results requires a standardized scoring system of abnormal findings on HRCT and PET. Previous studies found that the intra- and inter-reader reliability of a semiquantitative HRCT scoring system described by Oberstein et al. ${ }^{32}$ was good, and the HRCT features of this scoring system were associated with respiratory functional impairment in sarcoidosis. ${ }^{25}$ The inter-observer agreement of the PET scoring system we used proved to be very good, as reported in Chapter 3. As described in Chapter 5, the severity of pulmonary involvement as assessed by HRCT features and lung function parameters correlated with PET activity in sarcoidosis. The semiquantitative HRCT scoring system we used appeared to offer a better ability to identify patients with positive pulmonary PET findings than the traditionally used radiographic staging system introduced by Scadding. It is also important to emphasize that a proportion of the patients with normal CXR findings (stage 0 ) as well as the majority of patients with signs of fibrosis on CXR (stage IV) or HRCT had positive pulmonary PET findings. An example of positive pulmonary PET findings in a sarcoidosis patient with fibrotic changes on HRCT is shown in Figure 8.2. 


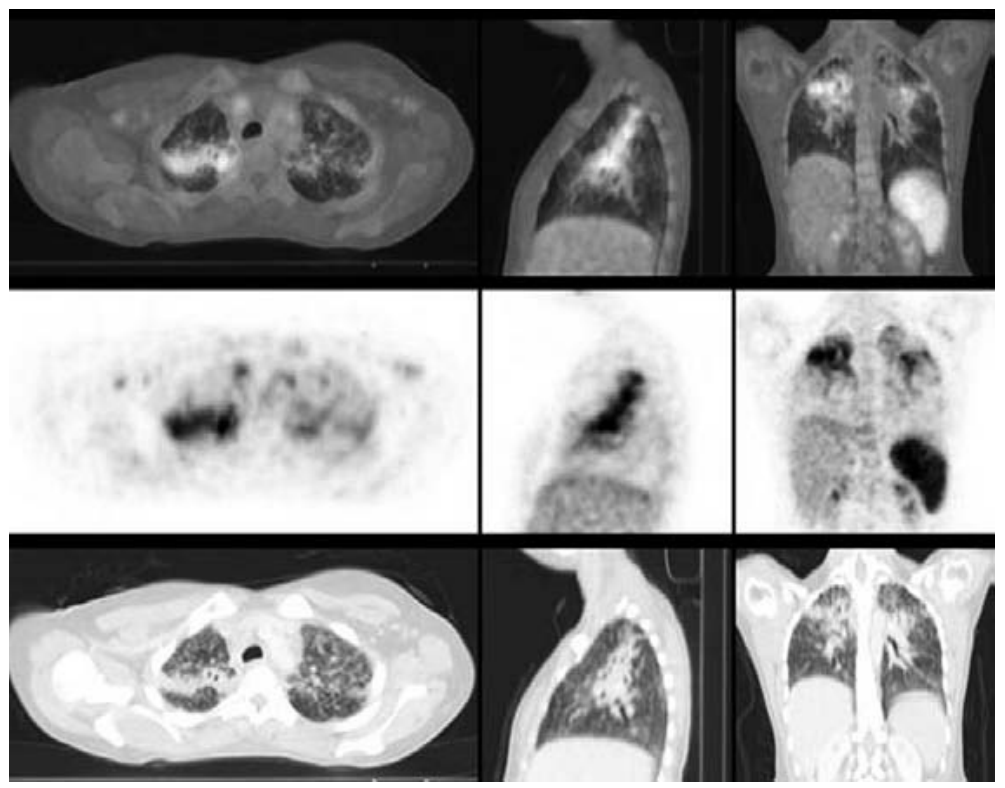

Figure 8.2 Sarcoidosis patient with signs of pulmonary fibrosis and ${ }^{18}$ F-FDG PET activity.

Top: transversal (left), sagittal (middle) and coronal (right) positron emission tomography/computed tomography (PET/CT) fusion images showing that the increased ${ }^{18} \mathrm{~F}$ fluorodeoxyglucose (FDG) uptake in the pulmonary parenchyma corresponds with the parenchymal consolidations. The abdominal increased FDG uptake corresponds with the spleen. Middle: transversal (left), sagittal (middle) and coronal (right) PET images showing increased FDG uptake in the pulmonary parenchyma and in the spleen (coronal image).

Bottom: transversal (left), sagittal (middle) and coronal (right) CT images showing parenchymal consolidations with hilar retraction and architectural distorsion of the pulmonary parenchyma.

Assessment of disease activity through lung function tests requires evidence of progression between two measurements, and so does not reflect the current status. Moreover, lung function testing cannot distinguish between reversible granulomatous lesions and irreversible fibrotic changes, and correlates only modestly with the level of dyspnea reported by patients. ${ }^{15,21}$ The assessment of the global lung burden as traditionally performed by lung function testing in combination with CXR abnormalities therefore seems insufficient for sarcoidosis patients with unexplained persistent disabling symptoms. A more accurate and global measure of both pulmonary and extrapulmonary disease may be achieved by the use of combined $\mathrm{PET} / \mathrm{CT}$ in these patients.

Increased FDG uptake has also been observed in patients with idiopathic pulmonary fibrosis (IPF). ${ }^{33-36}$ All of the models proposed for the pathogenesis of pulmonary fibrosis involve a central role for fibroblasts, which are known to express glucose transporter-1. ${ }^{33,37}$ It could be speculated that the elevated FDG uptake in patients with fibrotic changes, including honeycombing, is a reflection of increased fibroblast 
metabolism and not due to inflammatory activity sensu strictu. ${ }^{33}$ However, the majority of the sarcoidosis patients with fibrotic changes in our population showed extrathoracic PET-positive findings (80\%) and increased serological inflammatory markers (78\%). Furthermore, the mean maximum standardized uptake values (SUVmax; 7.2 \pm 4.1 ) in these patients were higher than the values reported by two studies with IPF patients ${ }^{33,36}(0.99 \pm 0.29$ and $2.9 \pm 1.1$, respectively). These findings strongly suggest that PET-positive findings in sarcoidosis patients with CXR stage IV are related to inflammatory activity. The extrathoracic findings can be helpful to differentiate between sarcoidosis and other interstitial lung diseases like IPF in patients presenting with pulmonary fibrosis.

\section{Predicting the presence of inflammatory activity}

Based on the results reported above, a clinical prediction rule, based on sIL-2R levels and HRCT scoring results, was derived and internally validated, as reported in Chapter 6. This clinical prediction rule was useful to identify patients for whom there is a high probability that PET will show the presence of inflammatory activity. If only patients with scores below a chosen cut-off value of the prediction rule score are referred to PET for further evaluation, the use of this prediction rule can substantially reduce the number of referrals to PET scanning. As discussed in Chapter 6, Table 6.3, for example, PET would be indicated for less than a third of the patients in our study if a positive predictive value for the presence of inflammatory activity (PET positivity) of $\geq 90 \%$ is considered acceptable for clinical decision making without referral to PET. This predictive value was reached with a positive sIL-2R result alone or with a total HRCT score of $\geq 6$ points. The clinical prediction rule we derived is a first attempt to identify patients with a high probability that PET will show the presence of inflammatory activity. It shows that such easily applicable predictive models can be developed for clinical use. This has the potential to increase the cost-effectiveness of diagnostic investigation, as performing PET for the assessment of inflammatory activity is unnecessary in patients with a high predicted probability. An additional advantage is that the assessment of inflammatory activity could become more standardized. Future prospective studies are warranted to develop more sophisticated models, and the search for new inflammatory parameters should continue as well.

Further improvement might be achieved by genotyping the sarcoidosis patients, since different genotypes might account for the variable results of the tools currently available for the assessment of inflammatory activity. The use of genotype-corrected ACE levels, human leukocyte antigens (HLA) genotypes, TNF polymorphisms and butyrophilin-like 2 (BTNL2) variant alleles is of potential value to improve the prediction of the probability of the presence of inflammatory activity and/or to assess the prognosis more accurately. ${ }^{17,38-45}$ This requires further clinical phenotypegenotype studies that could lead to a better classification of sarcoidosis patients. 


\section{Prognostic value of inflammatory activity}

The ability to identify patients at increased risk of progressive disease or complications is crucial, since they require a different management and monitoring approach. Rothkrans et al. ${ }^{14}$ found that sIL-2R was useful for monitoring respiratory disease severity in sarcoidosis. Other studies showed that sIL-2R and neopterin levels were elevated in sarcoidosis patients with progressive disease, requiring steroid treatment. ${ }^{9,12}$ These levels were particularly elevated in patients with acute disease, although patients with persistent disease also showed a moderate but significant increase. ${ }^{12}$ This indicates the potential value of SIL-2R and neopterin as suitable parameters for predicting disease progression and severity in sarcoidosis patients who have no indication for therapy at the time of diagnosis. $9,12,14$

There are several arguments for the prognostic value of PET-positive findings. Keijsers et al. $^{46}$ found that increased FDG uptake in the pulmonary parenchyma correlated with the number of neutrophils and the $\mathrm{CD} 103^{+} \mathrm{CD} 4^{+} / \mathrm{CD} 4^{+}$ratio in bronchoalveolar lavage (BAL) fluid of sarcoidosis patients. In agreement with this, we also found signs of inflammation in the BAL fluid (increased numbers of lymphocytes as well as polymorphonuclear neutrophils, indicating disease severity) of patients with PETpositive findings (Chapter 3). In earlier studies, an increase in the number of neutrophils in BAL fluid was found to be associated with an unfavourable outcome. ${ }^{9,47}$ Another study showed that diffuse parenchymal activity in sarcoidosis patients, as imaged by ${ }^{18}$ F-FDG PET, predicts a future deterioration of DLCO when medical treatment is withheld. ${ }^{48}$ The same study also found that treatment with corticosteroids or immunosuppressive drugs improved lung function significantly. ${ }^{48}$ PET also enables a more accurate clinical assessment of prognostic factors by demonstrating and monitoring organ involvement, like bone involvement, which is associated with a chronic course of the disease. ${ }^{49,50}$ We showed in Chapter 4 that $\mathrm{PET} / \mathrm{CT}$ is an excellent modality to detect bone/bone marrow involvement compared to more conventional modalities, suggesting that physiological changes precede morphological changes, which is a concept known from PET/CT in oncology. ${ }^{51}$ Nevertheless, no clear data exist on the prognostic significance of PET/CT-positive osseous findings in sarcoidosis patients or on whether there is an increased risk of fracture at these sites. ${ }^{49}$ However, since follow-up PET/CT after therapy in our study showed improvement of the osseous involvement, PET/CT may play a role in monitoring osseous involvement in sarcoidosis. Based on the above findings, it is tempting to speculate that increased FDG uptake not only demonstrates inflammatory activity, but also has prognostic value.

The prognostic value of intraocular inflammatory signs is well-established, as ocular manifestations of sarcoidosis have significant impact on visual prognosis. ${ }^{52,53}$ The presence of posterior or panuveitis in particular is a risk factor indicating a poor prognosis. $^{54,55}$

Detection of cardiac sarcoidosis is of the utmost importance with respect to the prognosis, since this is a major cause of serious morbidity and mortality in 
sarcoidosis. ${ }^{17,56,57}$ Fasting cardiac PET seems to be the most sensitive test for detecting active sarcoid lesions and their response to treatment, but there is no thoroughly evaluated diagnostic algorithm to screen for cardiac sarcoidosis. ${ }^{57-59}$ As described in Chapter 2, changes in MIBG uptake due to cardiac autonomic dysfunction can appear in sarcoidosis. ${ }^{60-63}$ Myocardial inflammatory activity may play a role, and autonomic dysregulation might contribute to fatal arrhythmias and unexplained sudden death. ${ }^{64}$ Small fiber neuropathy occurs frequently in sarcoidosis, and it is known from patients with neuropathy that the involvement of small autonomic nerve fibers is a predictor of cardiovascular mortality. ${ }^{65-67}$ Active granulomatous infiltration and the resulting myocardial fibrosis are considered to be the substrate. Cardiac sympathetic dysfunction, assessed by means of myocardial ${ }^{123}$ I-MIBG scanning, appears to be heterogeneous in sarcoidosis patients and depends on the presence or absence of small fiber neuropathy (SFN). ${ }^{68}$ Cardiac sympathetic nervous system abnormalities detected by ${ }^{123}$ I-MIBG have predictive value for ventricular tachyarrhythmia, and can be used to assess the prognosis of patients with chronic heart failure, as well as the risk of sudden death, as shown in recent studies. ${ }^{69-71}$ This indicates the potential of ${ }^{123}$ I-MIBG for the assessment of cardiac involvement and its prognostic value in sarcoidosis. Further studies in this field are warranted.

\section{Implications of inflammatory activity for therapy}

The indications for treatment of individual patients depend on many factors, not just whether the patient is symptomatic but also whether there is evidence of asymptomatic significant disease, especially in vital organs. The majority of patients with signs of fibrosis on CXR (stage IV) or HRCT in our population had positive pulmonary PET findings. The presence of potential partial reversibility in patients with radiological signs of fibrosis may have therapeutic consequences. ${ }^{6}$ Inflammatory activity can indicate persistent evolution of the disease and may therefore be a target for therapy. Deciding which sarcoidosis patients with fibrotic disease may benefit from pharmacological treatment remains a challenge to clinicians, as it is not always clear whether respiratory symptoms in these patients are a result of organ damage or due to ongoing inflammation or both. Careful consideration also needs to be given to the likely benefits of any therapy, set against the risk of adverse events, since adding the burden of medication like corticosteroids to disabled sarcoidosis patients with pulmonary fibrosis might harm them even further. To date, there is no medication with the proven capability of reversing fibrosis, but there is hope that treatment can arrest fibrosis of reversible granulomas that persist among the fibrotic elements. ${ }^{72}$ This is in line with the results of the post-hoc analysis in the Sarcoidosis Investigators study, ${ }^{73}$ which suggested a greater benefit of infliximab therapy in patients with more severe disease, including CXR stage IV. Techniques that are purported to differentiate between fibrotic tissue and granulomatous tissue with inflammatory activity are therefore of importance. There is little evidence to support corticosteroid or 
immunosuppressive treatment of fibrotic lung disease unless the presence of inflammatory activity can be demonstrated. ${ }^{72}$

Several reports have demonstrated a significant reduction of FDG uptake after the initiation or modification of treatment in sarcoidosis patients. ${ }^{3,4,6,7}$ Keijsers et al. ${ }^{3}$ demonstrated that changes in PET imaging in a small cohort of sarcoidosis patients treated with infliximab considerably correlated with clinical signs of improvement, including reduced fatigue. Teirstein et al. ${ }^{6}$ described that the improvement of symptoms, conventional imaging findings, and physiological data paralleled the therapy-related decrease in SUVmax as seen on the PET scans in most patients, including three patients with CXR stage IV. A decrease in FDG uptake after therapy was also found in patients with refractory sarcoidosis treated with adalimumab. ${ }^{4}$ The same study found that the patients' quality of life improved, which is in agreement with a previous study, which found a positive effect of treatment with TNF- $\alpha$ inhibitors on cognition and fatigue. ${ }^{74}$ The adalimumab study found no effect on pulmonary function tests and ACE levels in patients with refractory sarcoidosis. ${ }^{4}$ Possible explanations for this are that the number of included patients was small $(n=10)$, some patients had nearly normal lung function which could thus not be expected to improve, and further deterioration in lung function may have been prevented by the adalimumab therapy. Furthermore, it was unclear how many patients had increased ACE levels at baseline. We studied a larger population ( $n=26$; Chapter 7) and found that treatment with adalimumab decreased intraocular inflammatory signs, laboratory inflammatory parameters (CRP and SIL-2R), and fatigue. In the same study, DLCO improved after therapy with adalimumab in those cases with an impaired DLCO at baseline. PET/CT was repeated after a change in therapy in three of the patients with bone involvement discussed in Chapter 4 , and showed a decrease in the number of bone lesions and the SUVmax, respectively.

Several studies have suggested that infliximab might be more beneficial to patients with multi-organ extrapulmonary involvement, ${ }^{73,75}$ underlining the importance of assessing the extent of disease and the possible role of PET for this purpose. Research into various inflammatory diseases, including pulmonary sarcoidosis, has found that CRP levels can predict the response to anti-TNF- $\alpha$ therapy. ${ }^{76-80}$ In line with this, we reported in Chapter 7 that CRP levels had decreased after six months as well as after one year of treatment with adalimumab. The CRP levels appeared to be higher in the PET-positive patients compared with the PET-negative patients in the studies discussed in this thesis. The exact importance of the presence of inflammatory activity for treatment decisions obviously needs to be established in future studies, although the above-mentioned limited data support the prognostic value of PET-positivity and the implications for therapy.

The value of PET in the follow-up of therapy is another topic of interest. It is still not clear how long therapy, including anti-TNF- $\alpha$ agents, should be continued. Further studies are required to investigate if PET could be helpful in guiding the duration of treatment. If this is the case, PET could also reduce the costs by avoiding unnecessarily 
prolonged treatment with this expensive medication, and avoid long-term sideeffects. Based on the above-mentioned results of studies with follow-up PET during treatment, ${ }^{3,4,6}$ a reduction in inflammatory activity can be presumed to have occurred in patients with clinical signs of improvement during treatment. Follow-up PET scans therefore seem unnecessary in these patients.

Improvement of cardiac sympathetic function, assessed with ${ }^{123}$ I-MIBG single photon emission computed tomography (SPECT) after treatment with carvedilol has been reported in sarcoidosis (Figure 8.3). ${ }^{60}$

This is in accordance with previous findings in patients with idiopathic dilated cardiomyopathy. ${ }^{81}$ Carvedilol has not only adrenergic receptor blocking effects but also antioxidant activity, ${ }^{82}$ and future studies are required to explore the clinical relevance of the relations between oxidative stress, antioxidant therapy and cardiac dysfunction in sarcoidosis. Cardiovascular autonomic function in sarcoidosis has also been reported to improve after therapy with infliximab, but no trial has been conducted until now. ${ }^{83}$

\section{Concluding remarks on a strategy for the assessment of inflammatory activity: which tests for which patients?}

Minimally invasive testing is required to shorten radiation exposure and reduce costs, and to keep the inconvenience for patients to a minimum. As explained above, the presence of inflammatory activity in patients with newly diagnosed acute, symptomatic sarcoidosis is virtually universally accepted. ${ }^{5,9}$ During the follow-up of sarcoidosis patients, the presence of inflammatory activity is indicated by deterioration in terms of lung-function or radiological findings, hypercalcemia, hypercalciuria, progressive cutaneous involvement or uveitis. ${ }^{15,17,84,85}$ The absence of these features allows a wait-and-see policy in asymptomatic patients. In sarcoidosis patients with unexplained persistent disabling symptoms, however, the absence of these features will not be reassuring, and both patients and clinicians will not feel satisfied without further exploration of possible treatable conditions. Initially, depending on the presenting symptoms, comorbidity like obstructive sleep apnea syndrome, depression or hypothyroidism should be excluded. ${ }^{86,87,88}$ If these do not provide an explanation for the symptoms, further assessment of inflammatory activity is warranted, since this seems to have prognostic value and might have implications for therapy, as discussed above. PET is a sensitive method to assess inflammatory activity and the extent of disease in sarcoidosis. ${ }^{5-8}$ PET is not indicated in the standard work-up, but can be of great value to complement more routinely used techniques. 


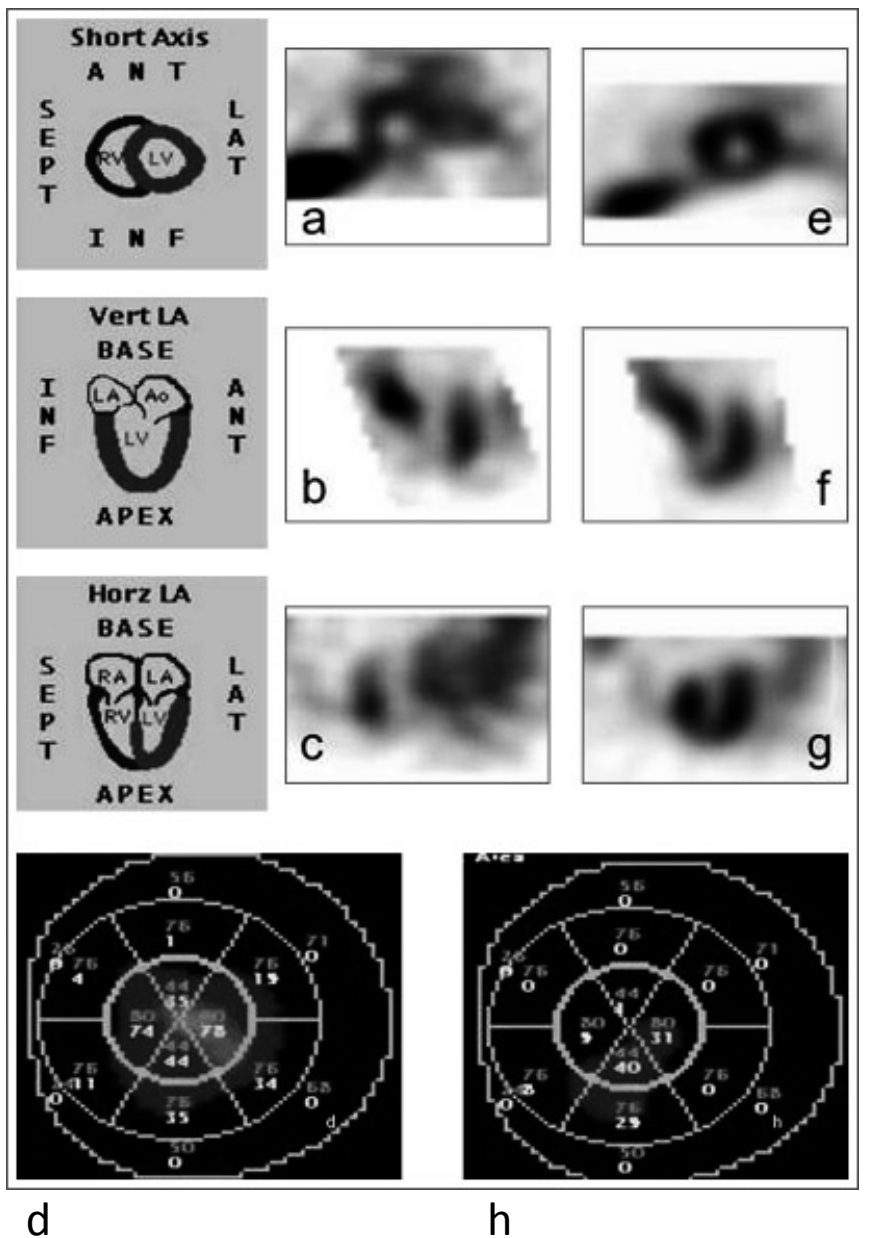

Figure $8.3 \quad{ }^{123}$ I-metaiodobenzylguanidine single photon emission computed tomography $\left({ }^{123}\right.$ I-MIBG SPECT) study of a 48 year-old man known with pulmonary sarcoidosis (disease duration 5 years) and small fiber neuropathy, who presented with cardiac arrhythmia and dizziness that had lasted two weeks. The images demonstrate no uptake of ${ }^{123}$ I-MIBG in the apical inferior wall of the myocardium (a, b, c). Bulls' eye quantification showed a defect size of $16.3 \%$ (d). A myocardial perfusion SPECT scintigraphy with ${ }^{201}$ Thallium showed normal perfusion in the apical inferior wall. Echocardiography and magnetic resonance imaging (MRI) of the heart were also judged normal. He was treated with carvedilol for five months and his clinical condition stabilized and no activity of sarcoidosis could be found. He did not recall having had any further heart rhythm disturbances. The ${ }^{123}$ I-MIBG SPECT study was repeated and showed improvement of the uptake in the apical inferior wall $(\mathbf{e}, \mathbf{f}, \mathbf{g})$, with a defect size of only $3.9 \%$ (h). ${ }^{60}$ This case illustrates that ${ }^{123}$ I-MIBG is useful to monitor treatment effects. 
Based on the current findings, PET seems to offer added value in sarcoidosis patients with unexplained persistent disabling symptoms. PET appears especially helpful in those persistently symptomatic patients without serological signs of inflammatory activity and in patients with radiologic signs of fibrosis. The use of PET to assess the extent of disease can uncover a suitable location for biopsy to obtain histological evidence for the diagnosis or to explain (mainly extrathoracic) symptoms. Furthermore, the detection of extrathoracic involvement can offer prognostic value.

\section{Impact for individual patients}

The detection of inflammatory activity in sarcoidosis patients with unexplained persistent disabling symptoms might justify a trial with additional pharmacological treatment options. Conversely, the absence of inflammatory activity allows a conservative approach in terms of pharmacological treatment. This could avoid sideeffects as well as redundant use of expensive medication, and would support the choice of other treatment options like rehabilitation. However, prospective evaluation of this approach is required. Apart from the value of PET imaging in treatment decisions or follow-up, simply establishing that there is an organic cause for the symptoms can be extremely reassuring to many patients. A standardized approach for the assessment of inflammatory activity is required, and developing a clinical prediction rule for this purpose appeared to be feasible. Such standardization is needed for clinical purposes but also to keep the costs manageable.

\section{Limitations of the studies}

The studies presented in this thesis were performed in a referral centre for sarcoidosis, so the refractory character of the disease may have been more severe than in a general sarcoidosis population. PET was not performed in every referred patient, which may have caused a selection bias in some of the studies discussed in this thesis. The questions asked by the referring physicians and the reasons for referring the patients to our interstitial lung disease service were very diverse, ranging from requests for therapeutic advice about features in refractory sarcoidosis, like hypercalcemia, uveitis or severe respiratory impairment not responding to corticosteroids, to questions about genetic issues or occupational exposures. In these patients, no PET was indicated to answer the questions appropriately. This does not mean the patients had less severe sarcoidosis, however. Though no other diseases that are able to cause PET-positive findings were diagnosed during the follow-up, other causes of PET-positive findings cannot be excluded completely. Since clinical data were gathered retrospectively in some of the studies, complete data were not available in some cases. 


\section{Directions for future research}

Differences in terms of incidence and phenotype complicate comparisons of studies into the prognosis and effect of treatment in sarcoidosis, since patient populations are heterogeneous. Stratification of patients in clinical trials falls short of providing the ideal degree of individualization. The key to further progress in this field is to define disease types, predict progression and assess the need for therapy. Besides their clinical value, the results presented in this thesis could thus be helpful in defining these patient categories by providing a more standardized procedure for establishing the presence of inflammatory activity and organ involvement. Since a better definition of patient categories may now be possible, the need for multicenter studies is greater than ever, to ensure the inclusion of sufficiently large patient populations. Future studies aimed at improving patient management should attempt to standardize the work-up for sarcoidosis patients with persistent disabling symptoms.

Defining clinical phenotypes has become an important goal, as genetic studies have identified distinct genotypes associated with different clinical phenotypes. ${ }^{38-41,44,45,89-91}$ Several classification systems based on clinical outcome have been developed, but none of these have been prospectively validated. ${ }^{12,91,92}$ Also, all of these classification system have disadvantages, like the need for a substantial follow-up period, ${ }^{91}$ the assumption that the long-term outcome can always be predicted from clinical features at the time of presentation, ${ }^{12}$ or interobserver variability. ${ }^{92}$ There is a need to investigate whether such extended scoring systems can be improved by the inclusion of a flowchart (i.e. a clinical prediction rule) for the assessment of inflammatory activity.

So far, no instrument to establish the total burden of granulomatous inflammation is available. This could be achieved by quantification of the total FDG uptake in the body as a whole and for each individual organ system, as measured by the sum of the SUVS per region. This would allow a more precise comparison between different measurements and may enhance the accuracy of the definition of comparable patient populations. So far, the implementation is hampered by technical issues, e.g. the segmentation of the presence of FDG in the blood volume.

The use of several other nuclear techniques and tracers in sarcoidosis deserves further exploration. Prospective studies are needed to evaluate the prognostic value of cardiac sympathetic dysfunction in sarcoidosis, assessed with ${ }^{123}$ I-MIBG scintigraphy, and its response to therapy with e.g. betablocking agents or TNF- $\alpha$ inhibitors. Scintigraphy using ${ }^{99 \mathrm{~m}}$ Technetium labeled anti-TNF- $\alpha\left({ }^{99 \mathrm{~m}} \mathrm{Tc}\right.$ anti-TNF- $\left.\alpha\right)$ monoclonal antibodies (infliximab) offers many research opportunities. ${ }^{93,94}$

${ }^{99 m}$ Tc-infliximab scintigraphy has been studied in patients with rheumatoid arthritis to detect levels of intra-articular TNF- $\alpha$ after local therapy with infliximab. ${ }^{94}$ This technique might be able to visualize levels of TNF- $\alpha$ at specific localizations in sarcoidosis patients. Hypothetically, this could also offer therapeutic options by allowing targeted therapy. 
Standardization of the assessment of inflammatory activity is warranted, as well as further evaluation of relevant prognostic features. It is my hope that the answers to the above-mentioned clinical questions may be helpful in understanding the impact of this often elusive disorder and hence improve the management of sarcoidosis patients. 


\section{References}

1. de Kleijn WP, Elfferich MD, De Vries J, Jonker GJ, Lower EE, Baughman RP, King TE Jr, Drent M. Fatigue in sarcoidosis: American versus Dutch patients. Sarcoidosis Vasc Diffuse Lung Dis. 2009;26:92-7.

2. Hoitsma E, De Vries J, Drent M. The small fiber neuropathy screening list: Construction and crossvalidation in sarcoidosis. Respir Med 2011;105:95-100.

3. Keijsers RG, Verzijlbergen JF, van Diepen DM, van den Bosch JM, Grutters JC. 18F-FDG PET in sarcoidosis: an observational study in 12 patients treated with infliximab. Sarcoidosis Vasc Diffuse Lung Dis 2008;25:143-9.

4. Milman N, Graudal N, Loft A, Mortensen J, Larsen J, Baslund B. Effect of the TNFalpha inhibitor adalimumab in patients with recalcitrant sarcoidosis: a prospective observational study using FDGPET. Clin Respir J. 2011:doi: 10.1111/j.752-699X.2011.00276.x. [Epub ahead of print].

5. Keijsers RG, Verzijlbergen FJ, Oyen WJ, van den Bosch JM, Ruven HJ, van Velzen-Blad H, Grutters JC. 18F-FDG PET, genotype-corrected ACE and sIL-2R in newly diagnosed sarcoidosis. Eur J Nucl Med Mol Imaging 2009;36:1131-7.

6. Teirstein AS, Machac J, Almeida O, Lu P, Padilla ML, lannuzzi MC. Results of 188 whole-body fluorodeoxyglucose positron emission tomography scans in 137 patients with sarcoidosis. Chest 2007;132:1949-53.

7. Braun JJ, Kessler R, Constantinesco A, Imperiale A. 18F-FDG PET/CT in sarcoidosis management: review and report of 20 cases. Eur J Nucl Med Mol Imaging 2008;35:1537-43.

8. Keijsers RG, Grutters JC, Thomeer M, Du Bois RM, Van Buul MM, Lavalaye J, Van Den Bosch JM, Verzijlbergen FJ. Imaging the inflammatory activity of sarcoidosis: sensitivity and inter observer agreement of (67)Ga imaging and (18)F-FDG PET. Q J Nucl Med Mol Imaging 2011;55:66-71.

9. Ziegenhagen MW, Rothe ME, Schlaak M, Muller-Quernheim J. Bronchoalveolar and serological parameters reflecting the severity of sarcoidosis. Eur Respir J 2003;21:407-13.

10. Grutters JC, Fellrath JM, Mulder L, Janssen R, van den Bosch JM, van Velzen-Blad H. Serum soluble interleukin-2 receptor measurement in patients with sarcoidosis: a clinical evaluation. Chest 2003;124:186-95.

11. Ziegenhagen MW, Benner UK, Zissel G, Zabel P, Schlaak M, Muller-Quernheim J. Sarcoidosis: TNFalpha release from alveolar macrophages and serum level of sIL-2R are prognostic markers. Am J Respir Crit Care Med. 1997;156:1586-92.

12. Prasse A, Katic C, Germann M, Buchwald A, Zissel G, Muller-Quernheim J. Phenotyping sarcoidosis from a pulmonary perspective. Am J Respir Crit Care Med 2008;177:330-6.

13. Muller-Quernheim J. Serum markers for the staging of disease activity of sarcoidosis and other interstitial lung diseases of unknown etiology. Sarcoidosis Vasc Diffuse Lung Dis 1998;15:22-37.

14. Rothkrantz-Kos S, van Dieijen-Visser MP, Mulder PG, Drent M. Potential usefulness of inflammatory markers to monitor respiratory functional impairment in sarcoidosis. Clin Chem 2003;49:1510-7.

15. Consensus conference: activity of sarcoidosis. Third WASOG meeting, Los Angeles, USA, September 811, 1993. Eur Respir J 1994;7:624-7.

16. Morgenthau AS, lannuzzi MC. Recent advances in sarcoidosis. Chest 2011;139:174-82.

17. Iannuzzi MC, Rybicki BA, Teirstein AS. Sarcoidosis. New Engl J Med 2007;357:2153-65.

18. Smith KA. Interleukin-2: inception, impact, and implications. Science (New York, NY 1988;240: 1169-76.

19. Nishiyama Y, Yamamoto Y, Fukunaga K, Takinami H, Iwado Y, Satoh K, Ohkawa M. Comparative evaluation of 18F-FDG PET and 67Ga scintigraphy in patients with sarcoidosis. J Nucl Med 2006;47:1571-6.

20. Keir G, Wells AU. Assessing pulmonary disease and response to therapy: which test? Semin Respir Crit Care Med. 2010;31:409-18.

21. Baughman RP, Culver DA, Judson MA. A concise review of pulmonary sarcoidosis. Am J Respir Crit Care Med. 2011;183:573-81.

22. Yeager $H$, Rossman MD, Baughman RP, Teirstein AS, Judson MA, Rabin DL, lannuzzi MC, Rose C, Bresnitz EA, DePalo L, Hunninghakes G, Johns CJ, McLennan G, Moller DR, Newman LS, Rybicki B, Weinberger SE, Wilkins PC, Cherniack R; ACCESS Research Group. Pulmonary and psychosocial findings at enrollment in the ACCESS study. Sarcoidosis Vasc Diffuse Lung Dis 2005;22:147-53. 
23. Baughman RP, Sparkman BK, Lower EE. Six-minute walk test and health status assessment in sarcoidosis. Chest 2007;132:207-13.

24. Judson MA, Gilbert GE, Rodgers JK, Greer CF, Schabel SI. The utility of the chest radiograph in diagnosing exacerbations of pulmonary sarcoidosis. Respirology 2008;13:97-102.

25. Drent M, De Vries J, Lenters M, Lamers RJ, Rothkranz-Kos S, Wouters EF, van Dieijen-Visser MP, Verschakelen JA. Sarcoidosis: assessment of disease severity using HRCT. Eur Radiol 2003;13:2462-71.

26. Remy-Jardin M, Giraud F, Remy J, Wattinne L, Wallaert B, Duhamel A. Pulmonary sarcoidosis: role of $\mathrm{CT}$ in the evaluation of disease activity and functional impairment and in prognosis assessment. Radiology 1994;191:675-80.

27. Bergin CJ, Bell DY, Coblentz CL, Chiles C, Gamsu G, Maclntyre NR, Coleman RE, Putman CE. Sarcoidosis: correlation of pulmonary parenchymal pattern at $\mathrm{CT}$ with results of pulmonary function tests. Radiology 1989;171:619-24.

28. Leung AN, Brauner MW, Caillat-Vigneron N, Valeyre D, Grenier P. Sarcoidosis activity: correlation of HRCT findings with those of $67 \mathrm{Ga}$ scanning, bronchoalveolar lavage, and serum angiotensinconverting enzyme assay. J Comput Assist Tomogr 1998;22:229-34.

29. Abehsera M, Valeyre D, Grenier P, Jaillet H, Battesti JP, Brauner MW. Sarcoidosis with pulmonary fibrosis: CT patterns and correlation with pulmonary function. AJR 2000;174:1751-7.

30. Brauner MW, Lenoir S, Grenier P, Cluzel P, Battesti JP, Valeyre D. Pulmonary sarcoidosis: CT assessment of lesion reversibility. Radiology 1992;182:349-54.

31. Murdoch J, Muller NL. Pulmonary sarcoidosis: changes on follow-up CT examination. AJR 1992; 159:473-7.

32. Oberstein A, von Zitzewitz $H$, Schweden F, Muller-Quernheim J. Non invasive evaluation of the inflammatory activity in sarcoidosis with high-resolution computed tomography. Sarcoidosis Vasc Diffuse Lung Dis 1997;14:65-72.

33. Groves AM, Win T, Screaton NJ, Berovic M, Endozo R, Booth H, Kayani I, Menezes LJ, Dickson JC, Ell PJ. Idiopathic pulmonary fibrosis and diffuse parenchymal lung disease: implications from initial experience with 18F-FDG PET/CT. J Nucl Med 2009;50:538-45.

34. Meissner HH, Soo Hoo GW, Khonsary SA, Mandelkern M, Brown CV, Santiago SM. Idiopathic pulmonary fibrosis: evaluation with positron emission tomography. Respiration 2006;73:197-202.

35. Nusair S, Rubinstein R, Freedman NM, Amir G, Bogot NR, Izhar U, Breuer R. Positron emission tomography in interstitial lung disease. Respirology 2007;12:843-7.

36. Umeda Y, Demura Y, Ishizaki T, Ameshima S, Miyamori I, Saito Y, Tsuchida T, Fujibayashi Y, Okazawa $\mathrm{H}$. Dual-time-point 18F-FDG PET imaging for diagnosis of disease type and disease activity in patients with idiopathic interstitial pneumonia. Eur J Nucl Med Mol Imaging 2009;36:1121-30.

37. Ortiz PA, Haspel HC. Differential control of the functional cell surface expression and content of hexose transporter GLUT-1 by glucose and glucose metabolism in murine fibroblasts. Biochem $\mathrm{J}$ 1993;295:67-72.

38. Sato H, Grutters JC, Pantelidis P, Mizzon AN, Ahmad T, Van Houte AJ, Lammers JW, Van Den Bosch JM, Welsh KI, Du Bois RM. HLA-DQB1*0201: a marker for good prognosis in British and Dutch patients with sarcoidosis. Am J Respir Cell Mol Biol 2002;27:406-12.

39. Berlin M, Fogdell-Hahn A, Olerup O, Eklund A, Grunewald J. HLA-DR predicts the prognosis in Scandinavian patients with pulmonary sarcoidosis. Am J Respir Crit Care Med 1997;156:1601-5.

40. Voorter CE, Drent M, van den Berg-Loonen EM. Severe pulmonary sarcoidosis is strongly associated with the haplotype HLA-DQB1*0602-DRB1*150101. Hum Immunol 2005;66:826-35.

41. Wijnen PA, Nelemans PJ, Verschakelen JA, Bekers O, Voorter CE, Drent M. The role of tumor necrosis factor alpha G-308A polymorphisms in the course of pulmonary sarcoidosis. Tissue Antigens 2010;75:262-8.

42. Biller H, Zissel G, Ruprecht B, Nauck M, Busse Grawitz A, Muller-Quernheim J. Genotype-corrected reference values for serum angiotensin-converting enzyme. Eur Respir J 2006;28:1085-90.

43. Tomita $H$, Ina $Y$, Sugiura $Y$, Sato $S$, Kawaguchi $H$, Morishita $M$, Yamamoto $M$, Ueda R. Polymorphism in the angiotensin-converting enzyme (ACE) gene and sarcoidosis. Am J Respir Crit Care Med 1997;156:255-9.

44. Wijnen PA, Voorter CE, Nelemans PJ, Verschakelen JA, Bekers O, Drent M. Butyrophilin-like 2 in pulmonary sarcoidosis: a factor for susceptibility and progression? Hum Immunol 2011;72:342-7. 
45. Valentonyte R, Hampe J, Huse K, Rosenstiel P, Albrecht M, Stenzel A, Nagy M, Gaede KI, Franke A, Haesler R, Koch A, Lengauer T, Seegert D, Reiling N, Ehlers S, Schwinger E, Platzer M, Krawczak $M$, Müller-Quernheim J, Schürmann M, Schreiber S. Sarcoidosis is associated with a truncating splice site mutation in BTNL2. Nat Genet 2005;37:357-64.

46. Keijsers RG, Grutters JC, van Velzen-Blad H, van den Bosch JM, Oyen WJ, Verzijlbergen FJ. (18)F-FDG PET patterns and BAL cell profiles in pulmonary sarcoidosis. Eur J Nucl Med Mol Imaging 2010; 37:1181-8.

47. Drent M, Jacobs JA, de Vries J, Lamers RJ, Liem IH, Wouters EF. Does the cellular bronchoalveolar lavage fluid profile reflect the severity of sarcoidosis? Eur Respir J 1999;13:1338-44.

48. Keijsers RG, Verzijlbergen EJ, van den Bosch JM, Zanen P, van de Garde EM, Oyen WJ, Grutters JC. 18F-FDG PET as a predictor of pulmonary function in sarcoidosis. Sarcoidosis Vasc Diffuse Lung Dis 2011;28:123-9.

49. Zisman DA, Shorr AF, Lynch JP, 3rd. Sarcoidosis involving the musculoskeletal system. Semin Respir Crit Care Med. 2002;23:555-70.

50. Lazar CA, Culver DA. Treatment of sarcoidosis. Semin Respir Crit Care Med. 2010;31:501-18.

51. Tutt AN, Plunkett TA, Barrington SF, Leslie MD. The role of positron emission tomography in the management of colorectal cancer. Colorectal Dis 2004;6:2-9.

52. Martin TM, Doyle TM, Smith JR, Dinulescu D, Rust K, Rosenbaum JT. Uveitis in patients with sarcoidosis is not associated with mutations in NOD2 (CARD15). Am J Ophthalmol 2003;136:933-5.

53. Dana MR, Merayo-Lloves J, Schaumberg DA, Foster CS. Prognosticators for visual outcome in sarcoid uveitis. Ophthalmology 1996;103:1846-53.

54. Rothova A, Suttorp-van Schulten MS, Frits Treffers W, Kijlstra A. Causes and frequency of blindness in patients with intraocular inflammatory disease. Br J Ophthalmol 1996;80:332-6.

55. Rose AS, Tielker MA, Knox KS. Hepatic, ocular, and cutaneous sarcoidosis. Clin Chest Med 2008; 29:509-24, ix.

56. Baughman RP, Lower EE. Who dies from sarcoidosis and why? Am J Respir Crit Care Med 2011; 183:1446-7.

57. Iannuzzi MC, Fontana JR. Sarcoidosis: clinical presentation, immunopathogenesis, and therapeutics. JAMA 2011;305:391-9.

58. Youssef G, Leung E, Mylonas I, Nery P, Williams K, Wisenberg G, Gulenchyn KY, Dekemp RA, Dasilva J, Birnie D, Wells GA, Beanlands RS. The Use of 18F-FDG PET in the Diagnosis of Cardiac Sarcoidosis: A Systematic Review and Metaanalysis Including the Ontario Experience. J Nucl Med 2012;53:241-8.

59. Ohira H, Tsujino I, Ishimaru S, Oyama N, Takei T, Tsukamoto E, Miura M, Sakaue S, Tamaki N, Nishimura M. Myocardial imaging with 18F-fluoro-2-deoxyglucose positron emission tomography and magnetic resonance imaging in sarcoidosis. Eur J Nucl Med Mol Imaging 2008;35:933-41.

60. Smulders NM, Bast A, van Kroonenburgh MJ, Drent M. Improvement of cardiac sympathetic nerve function in sarcoidosis. Sarcoidosis Vasc Diffuse Lung Dis 2008;25:140-2.

61. Imai E, Kaminaga T, Takada K, Kutomi K, Furui S. Radioactive defect on I-123 MIBG myocardial SPECT imaging in a patient with cardiac sarcoidosis. Clin Nucl Med 2002;27:729-30.

62. Matsuo S, Nakamura Y, Matsui T, Matsumoto T, Kinoshita M. Detection of denervated but viable myocardium in cardiac sarcoidosis with I-123 MIBG and TI-201 SPECT imaging. Ann Nucl Med 2001;15:373-5.

63. Misumi I, Kimura Y, Hokamura Y, Honda Y, Yasunaga T, Nakashima K, Takemura N, Asoshina M, Uranaka N, Takenaka S, Shima K. Scintigraphic detection of regional disruption of the adrenergic nervous system in sarcoid heart disease. Jpn Circ J 1996;60:774-8.

64. Wichter T, Matheja P, Eckardt L, Kies P, Schäfers K, Schulze-Bahr E, Haverkamp W, Borggrefe M, Schober O, Breithardt G, Schäfers M. Cardiac autonomic dysfunction in Brugada syndrome. Circulation 2002;105:702-6.

65. Hoitsma E, Marziniak M, Faber CG, Reulen JP, Sommer C, De Baets M, Drent M. Small fibre neuropathy in sarcoidosis. Lancet 2002;359:2085-6.

66. Tuck RR, McLeod JG. Autonomic dysfunction in Guillain-Barre syndrome. J Neurol Neurosurg Psychiatry 1981;44:983-90.

67. Ewing DJ, Campbell IW, Clarke BF. Assessment of cardiovascular effects in diabetic autonomic neuropathy and prognostic implications. Ann Intern Med 1980;92:308-11. 
68. Hoitsma E, Faber CG, van Kroonenburgh MJ, Gorgels AP, Halders SG, Heidendal GA, Kessels AG, Reulen JP, Drent M. Association of small fiber neuropathy with cardiac sympathetic dysfunction in sarcoidosis. Sarcoidosis Vasc Diffuse Lung Dis 2005;22:43-50.

69. Akutsu Y, Kaneko K, Kodama Y, Li HL, Kawamura M, Asano T, Tanno K, Shinozuka A, Gokan T, Kobayashi $Y$. The significance of cardiac sympathetic nervous system abnormality in the long-term prognosis of patients with a history of ventricular tachyarrhythmia. J Nucl Med 2009;50:61-7.

70. Jacobson AF, Lombard J, Banerjee G, Camici PG. 123I-mIBG scintigraphy to predict risk for adverse cardiac outcomes in heart failure patients: design of two prospective multicenter international trials. $J$ Nucl Cardiol 2009;16:113-21.

71. Tamaki S, Yamada T, Okuyama Y, Morita T, Sanada S, Tsukamoto Y, Masuda M, Okuda K, Iwasaki Y, Yasui T, Hori M, Fukunami M. Cardiac iodine-123 metaiodobenzylguanidine imaging predicts sudden cardiac death independently of left ventricular ejection fraction in patients with chronic heart failure and left ventricular systolic dysfunction: results from a comparative study with signal-averaged electrocardiogram, heart rate variability, and QT dispersion. J Am Coll Cardiol 2009;53:426-35.

72. Teirstein AT, Morgenthau AS. "End-stage" pulmonary fibrosis in sarcoidosis. Mt Sinai J Med 2009;76:30-6.

73. Baughman RP, Drent M, Kavuru M, Judson MA, Costabel U, du Bois R, Albera C, Brutsche M, Davis G, Donohue JF, Müller-Quernheim J, Schlenker-Herceg R, Flavin S, Lo KH, Oemar B, Barnathan ES; Sarcoidosis Investigators. Infliximab therapy in patients with chronic sarcoidosis and pulmonary involvement. Am J Respir Crit Care Med 2006;174:795-802.

74. Elfferich MD, Nelemans PJ, Ponds RW, De Vries J, Wijnen PA, Drent M. Everyday cognitive failure in sarcoidosis: the prevalence and the effect of anti-TNF-alpha treatment. Respiration 2010;80:212-9.

75. Hostettler KE, Studler U, Tamm M, Brutsche MH. Long-term treatment with infliximab in patients with sarcoidosis. Respiration 2012;83:218-24.

76. Wolbink GJ, Voskuyl AE, Lems WF, de Groot E, Nurmohamed MT, Tak PP, Dijkmans BA, Aarden L. Relationship between serum trough infliximab levels, pretreatment $C$ reactive protein levels, and clinical response to infliximab treatment in patients with rheumatoid arthritis. Ann Rheum Dis 2005;64:704-7.

77. Gratacos J, Casado E, Real J, Torre-Alonso JC. Prediction of major clinical response (ACR50) to infliximab in psoriatic arthritis refractory to methotrexate. Ann Rheum Dis 2007;66:493-7.

78. Stone MA, Payne U, Pacheco-Tena C, Inman RD. Cytokine correlates of clinical response patterns to infliximab treatment of ankylosing spondylitis. Ann Rheum Dis 2004;63:84-7.

79. Louis E, Vermeire S, Rutgeerts $P$, De Vos M, Van Gossum A, Pescatore P, Fiasse R, Pelckmans P, Reynaert H, D'Haens G, Malaise M, Belaiche J. A positive response to infliximab in Crohn disease: association with a higher systemic inflammation before treatment but not with -308 TNF gene polymorphism. Scand J Gastroenterol 2002;37:818-24.

80. Sweiss NJ, Barnathan ES, Lo K, Judson MA, Baughman R. C-reactive protein predicts response to infliximab in patients with chronic sarcoidosis. Sarcoidosis Vasc Diffuse Lung Dis 2010;27:49-56.

81. Gerson MC, Craft LL, McGuire N, Suresh DP, Abraham WT, Wagoner LE. Carvedilol improves left ventricular function in heart failure patients with idiopathic dilated cardiomyopathy and a wide range of sympathetic nervous system function as measured by iodine 123 metaiodobenzylguanidine. J Nucl Cardiol 2002;9:608-15.

82. Dandona P, Ghanim H, Brooks DP. Antioxidant activity of carvedilol in cardiovascular disease. J Hypertens 2007;25:731-41.

83. Hoitsma E, Faber CG, van Santen-Hoeufft M, De Vries J, Reulen JP, Drent M. Improvement of small fiber neuropathy in a sarcoidosis patient after treatment with infliximab. Sarcoidosis Vasc Diffuse Lung Dis 2006;23:73-7.

84. Birnbaum AD, Oh FS, Chakrabarti A, Tessler HH, Goldstein DA. Clinical features and diagnostic evaluation of biopsy-proven ocular sarcoidosis. Arch Ophthalmol 2011;129:409-13.

85. Herbort CP, Rao NA, Mochizuki M. International criteria for the diagnosis of ocular sarcoidosis: results of the first International Workshop On Ocular Sarcoidosis (IWOS). Ocul Immunol Inflamm 2009; 17:160-9.

86. Antonelli A, Fazzi P, Fallahi P, Ferrari SM, Ferrannini E. Prevalence of hypothyroidism and Graves disease in sarcoidosis. Chest 2006;130:526-32. 
87. Verbraecken J, Hoitsma E, van der Grinten CP, Cobben NA, Wouters EF, Drent M. Sleep disturbances associated with periodic leg movements in chronic sarcoidosis. Sarcoidosis Vasc Diffuse Lung Dis 2004;21:137-46.

88. Drent M, Lower EE, De Vries J. Sarcoidosis-associated fatigue. Eur Respir J 2012;40:255-263.

89. Pabst S, Fränken T, Schönau J, Stier S, Nickenig G, Meyer R, Skowasch D, Grohé C. Transforming growth factor- $\beta$ gene polymorphisms in different phenotypes of sarcoidosis. Eur Respir J 2011;38: 169-175.

90. Fischer A, Nothnagel M, Franke A, Jacobs G, Saadati HR, Gaede KI, Rosenstiel P, Schürmann M, Müller-Quernheim J, Schreiber S, Hofmann S. Association of inflammatory bowel disease risk loci with sarcoidosis, and its acute and chronic subphenotypes. Eur Respir J 2011;37:610-616.

91. Baughman RP, Nagai S, Balter M, Costabel U, Drent M, du Bois R, Grutters JC, Judson MA, Lambiri I, Lower EE, Muller-Quernheim J, Prasse A, Rizzato G, Rottoli P, Spagnolo P, Teirstein A. Defining the clinical outcome status (COS) in sarcoidosis: results of WASOG Task Force. Sarcoidosis Vasc Diffuse Lung Dis 2011;28:56-64.

92. Wasfi YS, Rose CS, Murphy JR, Silveira LJ, Grutters JC, Inoue Y, Judson MA, Maier LA. A new tool to assess sarcoidosis severity. Chest 2006;129: 1234-45.

93. D'Alessandria C, Malviya G, Viscido A, Aratari A, Maccioni F, Amato A, Scopinaro F, Caprilli R, Signore A. Use of a $99 \mathrm{mTc}$ labeled anti-TNFalpha monoclonal antibody in Crohn's disease: in vitro and in vivo studies. Q J Nucl Med Mol Imaging 2007;51:334-42.

94. Conti F, Priori R, Chimenti MS, Coari G, Annovazzi A, Valesini G, Signore A. Successful treatment with intraarticular infliximab for resistant knee monarthritis in a patient with spondylarthropathy: a role for scintigraphy with 99mTc-infliximab. Arthritis Rheum 2005;52:1224-6. 

Samenvatting

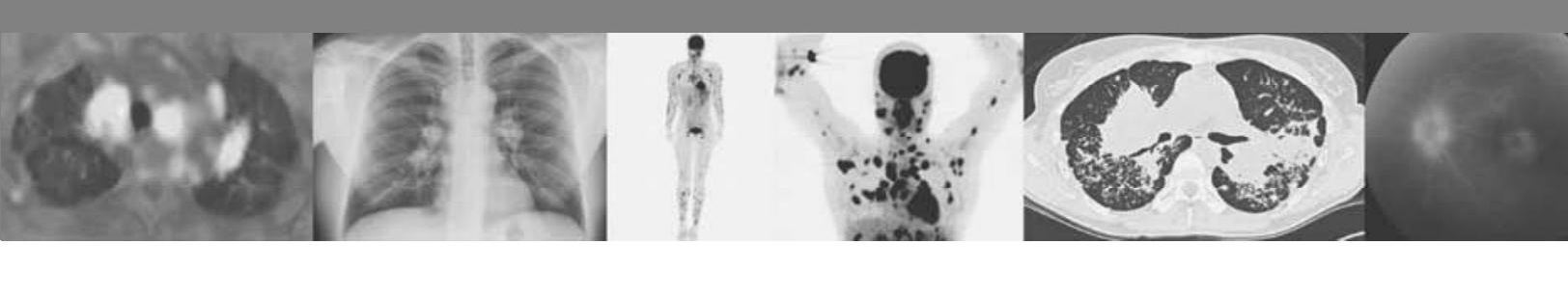




\section{Samenvatting}

Sarcoïdose is een multisysteem aandoening die gekenmerkt wordt door cellulaire activiteit met vorming van niet-verkazende granulomen in verschillende orgaansystemen. Derhalve kunnen patiënten afhankelijk van de initiële presentatie bij verschillende (orgaan)specialisten terecht komen. In de meerderheid van de gevallen zal de longarts de behandeling coördineren, aangezien intrathoracale manifestaties het meeste voorkomen. De ziekte komt voor in alle leeftijdscategorieën, maar de initiële presentatie is meestal tussen het 20e en 40e levensjaar. Sarcoïdose kan per toeval ontdekt worden of gepaard gaan met symptomen. Frequent voorkomende symptomen zijn moeheid, dyspnoe, hoesten, thoracale en/of musculoskeletale pijnklachten en een verminderde inspanningstolerantie.

In het algemeen heeft de ziekte een goede prognose. Bij meer dan de helft van de patiënten treedt binnen drie jaar na de diagnose remissie op. Na tien jaar heeft twee derde van de patiënten geen of slechts beperkte restverschijnselen. Bij het overblijvende deel van de patiënten persisteert de aandoening, hetgeen kan leiden tot significante orgaanschade. Minder dan $5 \%$ van de patiënten overlijdt ten gevolge van sarcoïdose en de oorzaak is dan meestal cardiale of neurologische aantasting danwel respiratoir falen door pulmonale fibrose. Het negroïde ras en bepaalde klinische bevindingen, zoals lupus pernio, botlokalisaties of ernstige pulmonale aantasting zijn geassocieerd met een chronisch ziektebeloop.

Het vaststellen van inflammatoire activiteit is belangrijk voor de beleidsvorming bij sarcoïdose en is met name waardevol bij het volgen van het ziektebeloop en als leidraad voor het therapeutisch beleid. Bij sarcoïdose geeft activiteit niet de uitgebreidheid of ernst van de ziekte weer, noch de noodzaak om therapie te starten. De term geeft aan dat de ziekte nog activiteit vertoont, dat er actieve granulomen met geactiveerde T-cellen en macrofagen aanwezig zijn. Aanhoudende activiteit kan in sommige gevallen tot progressie van de ziekte leiden. In de praktijk wordt voor het vaststellen van inflammatoire activiteit met name gebruik gemaakt van klinische parameters, zoals veranderingen in longfunctiewaarden en radiologische bevindingen. Daarnaast worden vaak serologische inflammatoire markers bepaald, zoals het angiotensin-converting enzyme (ACE), neopterine, C-reactive protein (CRP) en soluble interleukine-2 receptor (sIL-2R). Gestegen ACE en neopterine serumwaarden weerspiegelen de granuloomvorming en een verhoogde sIL-2R waarde is een maat voor de T-cel activiteit. Voor het stellen van de diagnose sarcoïdose zijn deze bepalingen niet bruikbaar, aangezien ze weinig specifiek zijn. Wel kunnen ze waardevol zijn voor de activiteitsbepaling bij sarcoïdose en daardoor nuttig bij het volgen van het ziekteverloop. 


\section{${ }^{18}$ F-FDG PET scan}

De afgelopen jaren wordt in het diagnostisch traject van sarcoïdosepatiënten in toenemende mate gebruik gemaakt van de fluoride18-fluorodeoxyglucose ( ${ }^{18} \mathrm{~F}$-FDG) positron emissie tomografie (PET) scan. Bij de meeste onderzoeken met betrekking tot de PET scan bij sarcoïdose is gebruik gemaakt van ${ }^{18} \mathrm{~F}-\mathrm{FDG}$, hetgeen wereldwijd de meest gebruikte PET radiotracer is vanwege de beschikbaarheid, de relatief lange halfwaardetijd en de goede opname die leidt tot een hoge concentratie in benigne en maligne laesies. De PET scan heeft een zeer hoge sensitiviteit voor het vaststellen van inflammatoire activiteit bij sarcoïdose. Tevens heeft deze techniek verschillende voordelen ten opzichte van andere nucleaire technieken door de vrij korte scantijd en het genereren van beelden met een hoge spatiële- en contrastresolutie, wat leidt tot accurate resultaten met een relatief lage stralingsbelasting. Steeds vaker wordt gebruikt gemaakt van de gecombineerde PET/CT scan, waarmee betere plaatsbepaling en attenuatiecorrectie mogelijk is. Tevens kan hierdoor informatie over morfologische en metabole veranderingen tegelijkertijd bestudeerd worden. Bij de ${ }^{18}$ F-FDG PET scan wordt een verhoogd glucosemetabolisme gedetecteerd. Gestimuleerde ontstekingscellen vertonen toegenomen glycolyse. Dit wordt met name verklaard door een verhoogd aantal glucose transporterproteïnen en gedeeltelijk door de verhoogde affiniteit van deze transporters voor dit substraat. De intracellulaire opname van ${ }^{18}$ F-FDG verloopt via dezelfde weg als glucose, maar na opname in de cel wordt het gefosforyleerd door het hexokinase enzym tot ${ }^{18}$ F-FDG-6 fosfaat. Dit kan niet afgebroken worden via glycolyse en kan slechts moeizaam gedefosforyleerd worden door glucose-6-fosfatase. De verhoogde ${ }^{18}$ F-FDG waarde in inflammatoire celgroepen kan vervolgens met behulp van de PET scan gedetecteerd worden. Het verrichten van een PET scan bij sarcoïdosepatiënten geeft informatie over de onderliggende metabole veranderingen, in tegenstelling tot onderzoeken zoals longfunctietesten, een thoraxfoto of hoge resolutie computertomografie (HRCT), die informatie geven over functionele en morfologische afwijkingen. De metabole veranderingen, zichtbaar gemaakt door de lokaal verhoogde ${ }^{18}$ F-FDG opname, zijn nuttig bij het bepalen van de uitgebreidheid en de inflammatoire activiteit van de ziekte.

Bij nieuw gediagnosticeerde, symptomatische sarcoïdosepatiënten en bij sarcoïdosepatiënten met progressieve radiologische of longfunctionele afwijkingen kan aangenomen worden dat er sprake is van inflammatoire activiteit. Bij sarcoïdosepatiënten met persisterende invaliderende symptomen is het echter vaak moeilijk om vast te stellen of er nog sprake is van activiteit van de ziekte. Bij dergelijke patiënten hebben klinische en radiologische bevindingen slechts beperkte waarde bij het vaststellen van inflammatoire activiteit, aangezien ook niet-onderzochte organen betrokken kunnen zijn bij het ziekteproces. Symptomen zoals moeheid zijn aspecifiek, moeilijk objectiveerbaar en kunnen samenhangen met ziekte-activiteit. Indien moeheidsklachten op de voorgrond staan, is het uitsluiten van andere aandoeningen, zoals een obstructief slaapapnoe syndroom, hypothyreoïdie of een onderliggende 
depressie echter van belang, aangezien deze met moeheid gepaard gaande aandoeningen frequent voorkomen bij sarcoïdosepatiënten. Verder kunnen symptomen zoals hoesten en dyspnoe, naast gerelateerd te zijn aan inflammatoire activiteit, tevens het gevolg zijn van orgaanschade bij een gevorderd stadium van de ziekte, zoals fibrotische longafwijkingen. Bij deze patiënten is het vaststellen van inflammatoire activiteit belangrijk aangezien de fibrotische afwijkingen zelf niet reversibel zijn. In het algemeen wordt verondersteld dat sarcoïdosepatiënten met fibrotische afwijkingen geen baat hebben bij een behandeling met immunosuppressiva indien er geen inflammatoire activiteit meer aanwezig is.

Het doel van het in dit proefschrift beschreven onderzoek was het evalueren van de waarde van de beschikbare testen voor het vaststellen van inflammatoire activiteit en de relatie van deze testen met parameters van de ernst van de ziekte in een populatie van sarcoïdosepatiënten met onverklaarde persisterende symptomen. Tevens werd bij sarcoïdosepatiënten met refractaire chronische uveïtis de respons van inflammatoire parameters en klinische kenmerken op de behandeling met adalimumab onderzocht.

Hoofdstuk 2 geeft een overzicht van de kennis omtrent en de beperkingen van het gebruik van metaiodobenzylguanidine (MIBG) scintigrafie bij cardiale en pulmonale aandoeningen. ${ }^{123}$ I-radiogemerkt MIBG geeft de integriteit van de adrenerge neuronen weer. De opname van MIBG is verminderd bij beschadiging, bijvoorbeeld door inflammatie, van adrenerge neuronen en verhoogde sympathische activiteit is geassocieerd met een versnelde afname van MIBG. Daardoor is radiogemerkt MIBG in staat om neuronale dysfunctie in verschillende organen weer te geven. Neuronale MIBG opname van het hart en de longen kan heterogene distributiepatronen vertonen, zowel door verminderde als door toegenomen MIBG opname en/of klaring, hetgeen veranderingen in endotheliale integriteit, neuronale innervaties en klaring van noradrenaline weergeeft. De belangstelling voor de rol van neurotransmitters en de relatie tussen de integriteit van endotheelcellen en vascularisatie neemt toe en is van groot belang om het effect op de pathofysiologie te begrijpen. Op dit moment heeft het routinematig gebruik van MIBG scan van hart en longen echter geen toegevoegde klinische waarde. Dit is ten dele te wijten aan het feit dat de exacte mechanismen van MIBG opname en -klaring onder normale omstandigheden, en de factoren die dit proces beïnvloeden, nog niet volledig opgehelderd zijn. Desalniettemin heeft deze techniek enorme mogelijkheden, omdat het tot nog toe onbekende relaties tussen innervatie, vascularisatie en integriteit van het endotheel aan het licht kan brengen. Aangezien andere diagnostische technieken, zoals Magnetic Resonance Imaging (MRI) en CT, deze capaciteit niet hebben zullen in de toekomst zeker toepassingen komen voor deze nieuwe neuronale beeldvormende techniek.

In hoofdstuk 3 wordt het vaststellen van inflammatoire activiteit met behulp van een ${ }^{18}$ F-FDG PET scan bij 89 sarcoïdose patiënten met onverklaarde persisterende invaliderende symptomen beschreven en tevens wordt de relatie tussen de PET 
bevindingen en enkele serologische inflammatoire markers onderzocht. PET-positieve bevindingen werden ingedeeld als thoracaal en/of extrathoracaal. De gebruikte serologische inflammatoire markers waren ACE, sIL-2R en neopterine. Het merendeel van de sarcoïdose patiënten, zelfs degenen met radiologisch (eind)stadium IV, hadden PET-positieve bevindingen. Opvallend was dat $80 \%$ van de patiënten extrathoracale laesies bleek te hebben. In $20 \%$ van deze patiënten was de PET positief zonder dat er sprake was van serologische inflammatoire activiteit. Het gebruik van een PET scan bleek toegevoegde waarde te hebben voor het vaststellen van inflammatoire activiteit bij persisterend symptomatische patiënten zonder tekenen van serologische inflammatoire activiteit en voor het detecteren van extrathoracale laesies.

In hoofdstuk 4 wordt het onderzoek naar de prevalentie en het distributiepatroon van bot- en beenmergbetrokkenheid beschreven. Dit werd onderzocht bij 94 sarcoïdosepatiënten met ${ }^{18}$ F-FDG PET/CT-positieve bevindingen. Deze PET/CT scans werden beoordeeld met de vraag of er bot- of beenmergaantastingen aanwezig waren. Tevens werden de lage dosis CT scans geëvalueerd om andere oorzaken van verhoogde ossale ${ }^{18}$ F-FDG opname op te sporen. Relevante klinische data werden retrospectief verzameld.

Bij meer dan een derde van de PET-positieve sarcoïdosepatiënten bleken botafwijkingen zichtbaar te zijn op de PET/CT. Het merendeel van deze laesies (94\%) kon niet gedetecteerd worden met behulp van een lage dosis CT scan. Er bleek geen sprake te zijn van een voorkeurslokalisatie. Deze eerste resultaten ondersteunen de waarde van de PET/CT voor het aantonen van bot- of beenmergbetrokkenheid bij sarcoïdosepatiënten. Verder onderzoek is noodzakelijk om de klinische relevantie hiervan verder uit te werken.

In hoofdstuk 5 wordt het onderzoek naar de relatie tussen de ernst van de longaantasting en de aanwezigheid van ${ }^{18}$ F-FDG PET activiteit bij sarcoïdose beschreven. De resultaten van relevante klinische data, inclusief longfunctie- en laboratoriumuitslagen, van 95 patiënten met sarcoïdose die zowel een PET als een HRCT scan ondergingen in verband met onverklaarde persisterende symptomen, werden verzameld. De HRCT scans werden geclassificeerd volgens een semikwantitatief HRCT scoringssysteem. De PET scans werden ingedeeld als positief of negatief. Patiënten met positieve pulmonale PET bevindingen $(n=56)$ hadden een significant hogere totale HRCT score, maar een lagere geforceerde vitale capaciteit (FVC) en diffusie capaciteit van de long voor koolmonoxide (DLCO), in vergelijking met de patiënten met negatieve pulmonale PET bevindingen $(n=39)$. De ernst van de longaantasting, beoordeeld door middel van HRCT bevindingen en de longfunctie parameters, bleek geassocieerd te zijn met PET activiteit. Het merendeel (85\%) van de patiënten met radiologisch fibrotische veranderingen vertoonde inflammatoire activiteit. Tevens had een verrassend groot deel van deze patiënten ook extrathoracale PET-positieve laesies (82\%) en verhoogde uitslagen van de onderzochte serologische inflammatoire markers (73\%). 
Het is van belang om te bepalen bij welke patiënten een PET scan bijdragend kan zijn voor het vaststellen van inflammatoire activiteit. Tot op heden waren geen richtlijnen hiervoor beschikbaar. In hoofdstuk 6 wordt een klinische predictieregel beschreven die ontworpen is om patiënten te identificeren bij wie de ${ }^{18}$ F-FDG PET met hoge waarschijnlijkheid de aanwezigheid van inflammatoire activiteit zou aantonen. Deze klinische predictieregel is gebaseerd op de resultaten van de SIL-2R bepaling en de HRCT scan scoringsresultaten en werd intern gevalideerd. De predictieregel bleek bruikbaar te zijn voor het identificeren van sarcoïdosepatiënten bij wie de aanwezigheid van inflammatoire activiteit zeer waarschijnlijk was. Het gebruik van deze regel zou dus behulpzaam kunnen zijn bij het identificeren van sarcoïdosepatiënten voor wie het verrichten van een PET scan meerwaarde zou hebben om inflammatoire activiteit vast te stellen. De gevonden resultaten kunnen van klinisch belang zijn door het ondersteunen van een selectiever gebruik van een PET scan voor het vaststellen van inflammatoire activiteit bij sarcoïdose.

In hoofdstuk 7 worden de resultaten beschreven van een prospectieve patiëntenserie bestaande uit 26 sarcoïdosepatiënten met refractaire chronische uveïtis. De geïncludeerde patiënten werden systematisch vervolgd gedurende 12 maanden na start van de behandeling met adalimumab 40 mg subcutaan één keer per week. Het doel van het onderzoek was om het effect van adalimumab op intraoculaire inflammatoire kenmerken en andere relevante klinische manifestaties van sarcoïdose (longfunctie, serologische inflammatoire markers en moeheid) te evalueren. Adalimumab bleek succesvol te zijn bij de behandeling van sarcoïdosepatiënten met refractaire chronische uveïtis aangezien zowel de intraoculaire inflammatoire kenmerken als de andere relevante onderzochte indicatoren van ziekte-activiteit verbeterden. Toekomstige gerandomiseerde onderzoeken zijn noodzakelijk voor het optimaliseren van de dosering, het dosisinterval en de duur van behandeling bij refractaire multisystemische sarcoïdose.

De belangrijkste bevindingen beschreven in dit proefschrift, evenals de hieruit voortvloeiende mogelijkheden voor verder onderzoek, worden besproken in hoofdstuk 8. Deze thesis beschrijft het spectrum aan onderzoekstechnieken voor het vaststellen van inflammatoire activiteit bij sarcoïdosepatiënten met onverklaarde persisterende symptomen. Er wordt een overzicht gegeven van de kennis over en de beperkingen van het gebruik van MIBG scintigrafie bij cardiale en pulmonale aandoeningen. Verder wordt de relatie tussen PET bevindingen en serologische inflammatoire markers, longfunctie en radiologische parameters bediscussieerd. Ten slotte wordt het positieve effect van behandeling met adalimumab op intraoculaire inflammatoire kenmerken en op andere relevante klinische indicatoren van ziekteactiviteit bij sarcoïdosepatiënten met refractaire chronische niet-infectieuze uveitis beschreven. 


\section{Beschouwing}

Het vaststellen van inflammatoire activiteit kan prognostische en therapeutische implicaties hebben en kan tevens nuttig zijn voor het monitoren van het ziektebeloop bij sarcoïdosepatiënten. Een gestandaardiseerde benadering voor het vaststellen van inflammatoire activiteit is dus van groot belang. Het vaststellen van ziekteactiviteit met behulp van longfunctietesten en thoraxfoto's vereist evidentie voor progressie tussen twee metingen en geeft dus niet de actuele status weer. Tevens kan op basis van deze onderzoeken geen duidelijk onderscheid gemaakt worden tussen reversibele granulomateuze laesies en irreversibele fibrotische veranderingen. Ook is er slechts een matige correlatie tussen enerzijds de bevindingen bij longfunctietesten en thoraxfoto's, en anderzijds de dyspnoeklachten die de patiënten uiten. De mogelijkheden voor het vaststellen van de globale pulmonale status, en sowieso van de extrapulmonale betrokkenheid, met behulp van deze traditioneel gebruikte onderzoeken zijn dus beperkt. Een meer accurate meting van de globale pulmonale en extrapulmonale inflammatoire activiteit zou geleverd kunnen worden door middel van een gecombineerde PET/CT scan bij deze patiënten. Het gebruik van de PET scan voor het vaststellen van inflammatoire activiteit lijkt met name nuttig te zijn bij sarcoïdosepatiënten met onverklaarde persisterende symptomen en binnen deze groep in het bijzonder bij patiënten zonder verhoogde serologische inflammatoire markers en bij patiënten met fibrotische afwijkingen. Het gebruik voor het vaststellen van de uitgebreidheid van orgaanaantasting kan zinvol zijn voor het kiezen van de juiste biopsielocatie om de diagnose te onderbouwen of ter verklaring van (met name extrathoracale) symptomen. Tevens kan het aantonen van extrathoracale laesies van prognostisch belang zijn. Afgezien van de waarde van de PET scan voor therapeutische besluitvorming of follow-up, kan alleen al het vaststellen van somatische afwijkingen zeer waardevol zijn voor patiënten met persisterende symptomen die voordien niet verklaard konden worden. Een verdere standaardisatie van het diagnostisch traject voor het vaststellen van inflammatoire activiteit bij sarcoïdosepatiënten met onverklaarde persisterende symptomen is wenselijk voor klinische doeleinden, maar ook om de kosten beheersbaar te houden. 


\section{Dankwoord}
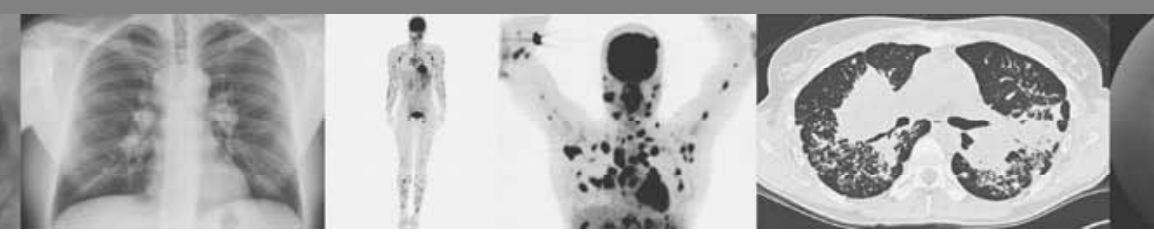
156 


\section{Dankwoord}

Velen hebben op directe of indirecte wijze bijgedragen aan de totstandkoming van dit proefschrift. Een aantal personen die een prominente rol speelden wil ik graag in het bijzonder noemen.

Aan de basis stond mijn promotor, prof. dr. M. Drent. Beste Marjolein, jij was degene die met het idee kwam om dit traject te starten en een betere promotor had ik mij niet kunnen wensen. Jouw enthousiasme en gedrevenheid zijn ongekend en erg motiverend. In de afgelopen jaren heb ik veel van je kunnen leren. Bedankt voor je steun, oprechtheid en vertrouwen.

Dr. M.J.P.G. van Kroonenburgh, beste Marinus, ook bij jou stond de deur steeds open. Het was altijd erg aangenaam om de ontwikkelingen met jou te bespreken en om tijdens de brainstormsessies nieuwe paden uit te zetten. Vele versies van de manuscripten voorzag je van commentaar, dat steeds doorspekt was met de jouw kenmerkende droge humor. Dank voor alles.

Prof. dr. J.A. Verschakelen, beste Johny, de lange sessies waarin de radiologische onderzoeken beoordeeld werden waren zeer leerzaam. De gesprekken die frequent afdwaalden naar de meest uiteenlopende onderwerpen makten deze dagen extra speciaal. Dank voor alle moeite en adviezen.

Verder wil ik de leden van de beoordelingscommissie, prof. dr. M.P. van DieijenVisser, prof. dr. U. Costabel, prof. dr. J.C. Grutters, prof. dr. F.M. Mottaghy en prof. dr. F.J. van Schooten, bedanken voor de kritische beoordeling van het manuscript.

Een speciaal woord van dank voor dr. Petal 'dr. PW' Wijnen. Gelukkig ben jij een nachtmens, daardoor kon je op de meest onmogelijke tijdstippen het ontwerp van figuren aanpassen, de database steeds opnieuw ordenen en dubbelchecken, computerstoringen verhelpen, pestmails versturen, gevraagd en ongevraagd je mening geven etc., etc., etc. Rijst redt computers dus inderdaad van de verdrinkingsdood. De bonnetjes dienen op tijd afgehaald te worden.

Ook de overige leden van de onderzoeksgroep, dr. Roel Erckens en dr. Stefan Vöö wil ik graag bedanken voor hun hulp en betrokkenheid en de vaak hilarische besprekingen. Dr. Léonne Prompers en dr. René Weijers, dank voor jullie onmisbare bijdrage aan het 'botverhaal'. Hopelijk leidt het vervolgonderzoek nog tot vele interessante resultaten. Rik Marcellis, je zult zien: wat soms zo ver lijkt, is ook voor jou al dichtbij. Marjon Elfferich, dank voor al het werk dat jij achter de schermen verzet. Sita Pisana, jij bent een secretaresse van het soort dat een beschermde status zou moeten krijgen. 
Dr. Patty Nelemans en Sander van Kuijk, nooit geweten dat statistiek zo grappig kon zijn. Over jullie kamer kan een nieuwe realityserie uitgezonden worden. 'Patty works for food' zou een pakkende titel zijn. Kijkcijfers verzekerd.

Medewerkers van de afdeling nucleaire geneeskunde in het MUMC. Bedankt voor de administratieve ondersteuning, het verrichten van aanvullende metingen en het enthousiasme om de toepassing van nieuwe technieken te proberen.

Tiny Wouters, de layout was bij jou in goede handen. Als je jouw ervaring met promovendi en promoties zou opschrijven en bundelen, had je gegarandeerd zelf genoeg materiaal voor een proefschrift. Bedankt voor al het werk en de vele tips.

Mijn collega's van de longartsenmaatschap 'Oude Mijnstreek' in het Atrium Medisch Centrum; Eric, Frank, Gerben, Jan, Michiel, Monique en Robrecht. Dank voor jullie belangstelling en ondersteuning. Jullie kunde, collegialiteit en humor maken het een voorrecht om met jullie te mogen samenwerken. Hopelijk kunnen we dat nog lang zo doen.

Alle arts-assistenten longziekten, medewerk(st)ers van de polikliniek, secretariaat, longbehandelkamer, longfunctieafdeling en verpleegafdeling longziekten van het Atrium Medisch Centrum. Dank voor de getoonde interesse.

Mijn paranimfen, Guy en Hilko. Guy, (vak)broeder, ik ben er trots op dat jij bij de verdediging naast me staat. Aangezien goed voorbeeld doet volgen, ben jij wellicht degene geweest die ruim 16 jaar geleden mijn sluimerende interesse in geneeskunde echt heeft laten opbloeien. Hilko, als 'Praktikant' hebben we de eerste klinische stappen gezamenlijk gezet. Vele niet-klinische stappen zijn daaraan voorafgegaan en erna gevolgd. Drie letters: TOP. Duidelijk.

Vrienden maken het vaak mogelijk om zaken in het juiste perspectief te zien. Een aantal van hen wil ik in het bijzonder noemen. Erik, Annemieke, Ruud en Nadine, jullie zijn al jaren een vaste waarde in mijn leven. Vele hoogte- en dieptepunten hebben we samen beleefd. Hopelijk zullen nog vele goede momenten volgen. Nadine, bedankt dat ik alweer gebruik heb kunnen maken van je grote grafische talent. Het is je wederom gelukt om de opborrelende ideeën om te zetten in een concreet en mooi resultaat. De 'Leuvenaars', hoewel ondertussen niemand van ons meer in Leuven woont zien we elkaar gelukkig nog regelmatig. Samenzijn met jullie en de bende kinderen behoort tot de mooie zaken in het leven. Mannen van de band in ruste; Bernd, David en Freek, de drukte leidt ertoe dat we elkaar de laatste tijd te weinig hebben gezien en het rock ' $n$ roll gevoel heeft plaatsgemaakt voor allerlei vaderlijke gevoelens. Tijd om Freek's legendarische hotdogfeestjes nieuw leven in te blazen en weer een stevige pint of bolleke in "t stad" te gaan pakken. 
Julien, nu jouw boekje ook af lijkt te raken en jullie samen een grote stap hebben gezet, kunnen we komend jaar bij jullie nog twee keer een goed feest meemaken!

Mijn petekinderen, Guus en het kleine meisje dat bij het ter perse gaan van deze thesis nog op zich laat wachten: jullie hebben nog geen enkel besef van dit proefschrift, maar ik ben zo vereerd jullie peetoom te zijn, dat dit boekje niet compleet is zonder jullie hierin vermeld te hebben.

Liebe Doris, lieber Ernst, eure unbegrenzte, liebevolle und unermüdbare Hilfsbereitschaft bedeutet sehr viel für uns. Ohne euch wären die 'Baggerausflüge' lange nicht so interessant für die Kinder und unsere Bäuche oft leer.

Lieve pap en mam, jullie hebben me altijd de vrijheid gegeven om mijn eigen keuzes te maken. Deze keuzes waren echter niet mogelijk geweest zonder de kansen die jullie me gegeven hebben. Stilaan begin ik te beseffen hoeveel respect dat verdient. Dank voor jullie liefde.

Op het eind, maar met stip bovenaan: mijn gezin. Lieve Louis en Milla, in vergelijking met jullie is al het andere niet meer belangrijk. ledere dag opnieuw zijn jullie een bron van geluk. Wat is het mooi dat jullie er zijn. Lieve Meera, de afgelopen jaren waren door de vele grote veranderingen zeer intensief, maar ook erg mooi. Jouw creativiteit maakt alles mogelijk. Je bent geweldig, ik hou van je. 

Curriculum vitae

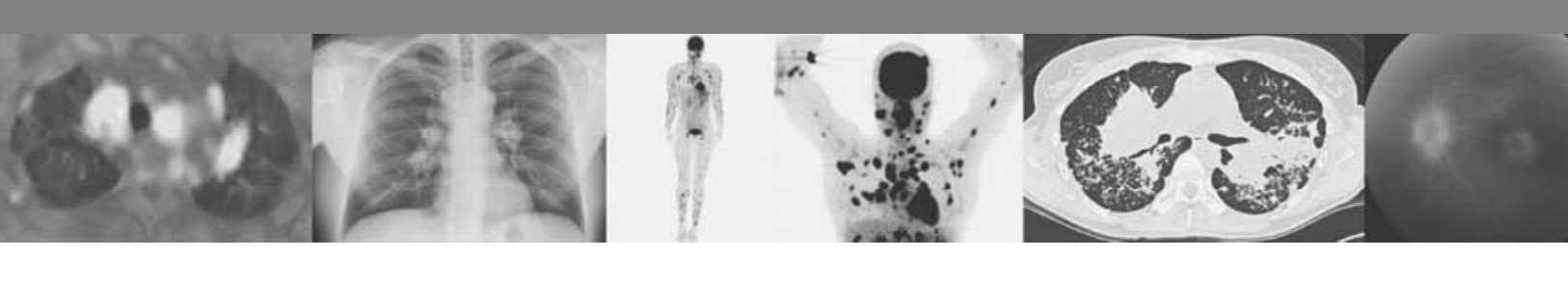




\section{Curriculum vitae}

Rémy Mostard was born on July 31st, 1978 in Susteren, The Netherlands. In 1996, he finished his secondary education at the Gymnasium of the College Sittard. In the same year, he started his medical studies at the Catholic University of Leuven, Belgium. During his studies, he completed an internship in Tropical Medicine at the Centre Hospitalier Universitaire, Kigali, Rwanda. He obtained his MD magna cum laude in 2003. Subsequently, he worked as a resident at the Department of Pulmonary Medicine at the Atrium Medical Center, Heerlen, The Netherlands, where he started his training in Pulmonary Medicine in 2004. In 2008, he completed part of this training at the Maastricht University Medical Center (MUMC), with a focus on interstitial lung diseases. Since his registration as a pulmonologist in March 2010, he has been working at the Atrium Medical Center, Heerlen, with special interest in interstitial lung diseases. The research project as described in this thesis started at the end of 2009 at the Maastricht University, with prof. dr. M. Drent and dr. M.J.P.G. van Kroonenburgh as promoter and co-promotor, respectively. At the WASOG/BAL Conference in June 2011 in Maastricht, The Netherlands, he recieved the Award for Excellence in Sarcoidosis Research in The Netherlands. He is married to Meera and together they have two children: Louis and Milla. 



\section{List of publications}

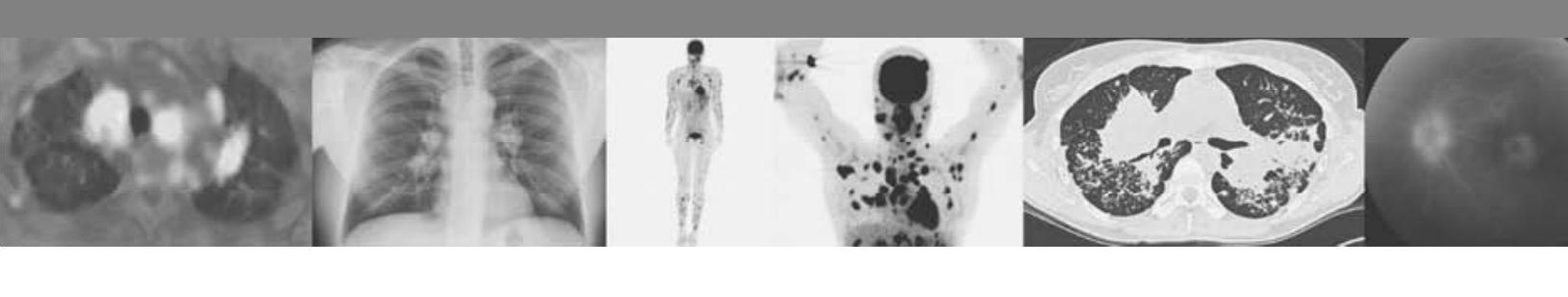




\section{List of publications}

Mostard RLM, Erckens RJ, Wijnen PAHM, Schouten JS, Drent M. Adalimumab therapy successful in sarcoidosis patients with chronic non-infectious uveitis. Graefes Arch Clin Exp Ophtalmonol 2012;250:713-720.

Mostard RLM, Prompers L, Weijers RE, van Kroonenburgh MJPG, Wijnen PAHM, Geusens PPMM, Drent M. ${ }^{18}$ F-FDG PET/CT for detecting bone and bone marrow involvement in sarcoidosis patients. Clin Nucl Med 2012;37:21-25.

Mostard RLM, Verschakelen JA, van Kroonenburgh MJPG, Nelemans PJ, Wijnen PAHM, Vöö S, Drent M. Severity of pulmonary involvement and ${ }^{18}$ F-FDG PET activity in sarcoidosis. Submitted.

Mostard RLM, van Kuijk SMJ, Verschakelen JA, van Kroonenburgh MJPG, Nelemans PJ, Wijnen PAHM, Drent M. A predictive tool for an effective use of ${ }^{18}$ F-FDG PET in assessing activity of sarcoidosis. BMC Pulm Med 2012; in press.

Mostard RLM, Vöö S, van Kroonenburgh MJPG, Wijnen PAHM, Nelemans PJ, Erckens RJ, Drent M. Inflammatory activity assessment by ${ }^{18} \mathrm{~F}-\mathrm{FDG} P E T / C T$ in persistent symptomatic sarcoidosis. Respir Med 2011;105:1917-1924.

Westers-Attema A, Veraart JCJM, de Pont CDJM, Mostard RLM, Vöö S, van Kroonenburgh MJPG, Drent M. PET-scan: findings in a patient with severe cutaneous and systemic sarcoidosis. Clin Nucl Med 2011;36:1049-1050.

van Kroonenburgh MJPG, Mostard RLM, Vöö S. Metaiodobenzylguanidine scintigraphy in pulmonary and cardiac disease. Curr Opin Pulm Med 2010;16:511-515.

Mostard RLM, van Haren EHJ. Pneumonie veroorzaakt door Mycoplasma pneumoniae. Tijdschr voor Geneeskunde 2008;64:818-822. 